SÉRGIO KINYA FUGIMOTO

ESTRUTURA DE TARIFAS DE ENERGIA ELÉTRICA ANÁLISE CRÍTICA E PROPOSIÇÕES METODOLÓGICAS

São Paulo

2010 
SÉRGIO KINYA FUGIMOTO

\title{
ESTRUTURA DE TARIFAS DE ENERGIA ELÉTRICA ANÁLISE CRÍTICA E PROPOSIÇÕES METODOLÓGICAS
}

\author{
Tese apresentada à Escola \\ Politécnica da Universidade de \\ São Paulo para obtenção do \\ Título de Doutor em \\ Engenharia.
}

São Paulo 
SÉRGIO KINYA FUGIMOTO

\section{ESTRUTURA DE TARIFAS DE ENERGIA ELÉTRICA ANÁLISE CRÍTICA E PROPOSIÇÕES METODOLÓGICAS}

Tese apresentada à Escola

Politécnica da Universidade de São

Paulo para obtenção do Título de Doutor em Engenharia.

Área de concentração:

Engenharia Elétrica

Orientador:

Prof. Dr. Carlos Márcio Vieira Tahan

São Paulo

2010 
Este exemplar foi revisado e alterado em relação à versão original, sob responsabilidade única do autor e com a anuência de seu orientador.

São Paulo, de novembro de 2010.

Assinatura do autor

Assinatura do orientador

FICHA CATALOGRÁFICA

Fugimoto, Sérgio Kinya

Estrutura de tarifas de energia elétrica: análise crítica e proposições metodológicas / S.K. Fugimoto. -- ed.rev. -- São Paulo, 2010.

$195 \mathrm{p}$.

Tese (Doutorado) - Escola Politécnica da Universidade de São Paulo. Departamento de Engenharia de Energia e Automação Elétricas.

1. Distribuição de energia elétrica 2. Serviços públicos (Regulação) 3. Tarifas públicas I. Universidade de São Paulo. Escola Politécnica. Departamento de Engenharia de Energia e Automação Elétricas II. t. 
Aos meus pais, Hideo (in memoriam) e Maria, pela minha vida e pela formação dos meus valores com base na observação dos seus incansáveis esforços.

A minha esposa Lílian, com amor e gratidão, por sua compreensão e apoio em todos os momentos da minha vida.

Aos meus filhos, Aline Yukari e Victor Yukio, felicidade maior da minha vida, que me ensinam o valor de prezar cada momento.

Ao meu mestre, Daisaku Ikeda, pelo exemplo de dedicação em prol da felicidade das pessoas.

A dedicação do autor. 


\section{AGRADECIMENTOS}

Ao orientador, professor Carlos Márcio Vieira Tahan, por sua paciência, dedicação e sabedoria, bem como pela oportunidade de realização do curso de doutorado.

Aos professores Dorel Soares Ramos, Francisco Anuatti Neto, pelo aprendizado e pelas sugestões e críticas para o aprimoramento desta tese.

Aos professores Marco Antonio de Paiva Delgado e Paulo Eduardo Steele Santos pelas idéias inovadoras que contribuíram para o enriquecimento deste estudo.

Aos executivos da EDP, Paulo Casate e Michel Itkes, por permitirem e apoiarem o desenvolvimento deste trabalho.

Aos amigos em Portugal, da ERSE e da EDP, Paulo Verdelho, Isabel Apolinário, Paulo Oliveira, Carlos Dourado e Alexandre Pais da Silva, por compartilharem informações imprescindíveis para esta pesquisa.

Aos colegas do projeto de Estrutura Tarifária, em especial, Neusa Antunes, Saulo Castilho, Júlio Sales, Wagner Okada, Fábio Hage, Mauro Machado, Fernando Damonte e Carlos Morosoli, pelas discussões e apoio.

Aos colegas da EDP, em especial Bonifácio Nakamura, Bruno Merlino, Cássia Shira, Cristiane Toma, José Pascon, Kleber Hashimoto, Rafael Moura, Regina Bi e Vanderlei Pereira, aos amigos da academia TSKF, em especial Antonio Theodosio, aos colegas da BSGI, em especial Megumi Shimada, que me suportaram e me incentivaram nos momentos finais deste trabalho.

O agradecimento sincero do autor. 
I went to the woods because I wanted to live deliberately. I wanted to live deep and suck out all the marrow of life. To put to rout all that was not life. And not, when I had come to die, discover that I had not lived.

\section{Henry David Thoreau}




\section{RESUMO}

Atualmente, o setor elétrico se prepara para o terceiro ciclo de revisões tarifárias das distribuidoras. Com o cenário regulatório mais consolidado em termos de definição da receita requerida, os agentes estão voltando suas atenções para a necessária adequação e correção da estrutura de tarifas. De fato, a ANEEL definiu temas para os projetos de pesquisa e desenvolvimento (P\&D) considerados estratégicos para o desenvolvimento do setor elétrico nacional, dentre eles, o de Estrutura Tarifária. Recentemente, a agência também divulgou consultas públicas que tratam da alocação dos custos de referência que formam as tarifas, dos sinais de preço e das tarifas para os consumidores atendidos em BT. Em sintonia com a discussão atual do setor de distribuição de energia elétrica, a tese defendida neste trabalho procura analisar a metodologia de cálculo das tarifas, sistematizando um conhecimento disperso em várias referências bibliografias. Para isso são discutidos os principais aspectos da teoria de precificação de ponta, abrangendo as abordagens americana, britânica e francesa, e pesquisada a conexão entre a lógica embutida na alocação horária dos custos e os critérios de dimensionamento do sistema de distribuição de energia elétrica. Visando refletir os custos decorrentes do atendimento de cada tipo de consumidor, indicando o melhor aproveitamento do sistema elétrico de distribuição, são apresentadas propostas de aprimoramentos e inovação cujos destaques são a mudança de paradigma da alocação dos custos de expansão somente no horário de ponta do sistema, a definição ex-post dos postos tarifários, a agregação média dos custos horários para formar as tarifas de referência dos postos tarifários e um estudo de caso com a aplicação da metodologia sobre as curvas de carga abstraídas do possível efeito do sinal tarifário existente. A tese defendida neste trabalho busca provar, então, que a metodologia atual, embora desenhada na época em que o setor elétrico era verticalizado, pode ser adaptada segundo os aprimoramentos e inovações propostas e, assim, aplicada ao ambiente atual no qual as empresas e as tarifas estão segregadas.

Palavras chaves: Distribuição de energia elétrica. Serviços públicos (Regulação). Tarifas públicas. 


\begin{abstract}
Currently, the electric energy sector is preparing for the third round of the distributors' tariff revisions. Since the regulatory environment is more consolidated in terms of required revenue, the agents are turning their attention to the necessary adjustment and correction of the tariff structure. In fact, ANEEL (regulatory agency) set topics for $R \& D$ projects considered strategic for the development of national energy sector, among them, the Tariff Structure Project. Recently, the regulatory agency also announced public hearings dealing with the costs allocation, price signals and tariffs for low-voltage consumers. In line with this debate, the thesis finds to analyze the methodology for calculating tariffs, systematizing knowledge dispersed in various references. For this, it discusses the major aspects of peak pricing theory, including American, British and French approaches, and researches the connection between the logic built into the costs allocation by hour and the criteria for electricity distribution system planning. Aiming to reflect the costs of each customer type, indicating a better utilization of the distribution system, are proposed improvements and innovation whose highlights are: shifting the idea that expansion costs should be only allocated in peak time of the system, setting the periods after calculating the costs, changing how to derive the reference charges by average aggregation of the costs and applying the methodology on altered load curves. Finally, this thesis seeks to prove that the current methodology, although designed by the time in which the electricity sector was aggregated, can be adapted according to the proposed improvements and innovations, and thus applied to the current environment in which electric energy businesses and tariffs are separated in generation, transmission, and distribution and retail areas.
\end{abstract}

Keywords: Electric energy distribution. Utilities (Regulatory). Public tariffs. 


\section{SUMÁRIO}

CAPÍTULO 1 - INTRODUÇÃO .......................................................................1

1.1. Caracterização do problema e relevância do tema.....................................

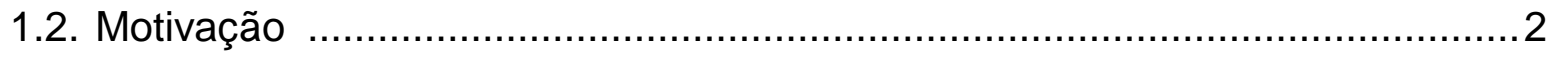

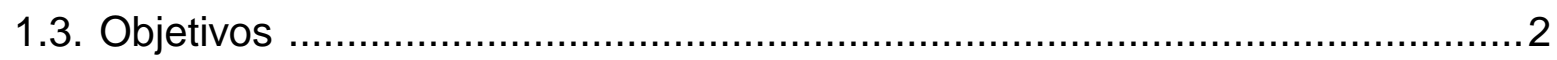

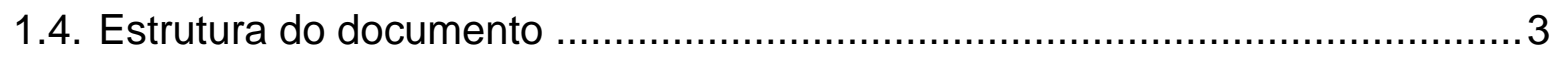

CAPÍTULO 2 - HISTÓRICO DA TARIFAÇÃO DE ENERGIA ELÉTRICA .................5

2.1. O setor de energia elétrica brasileiro .................................................... 5

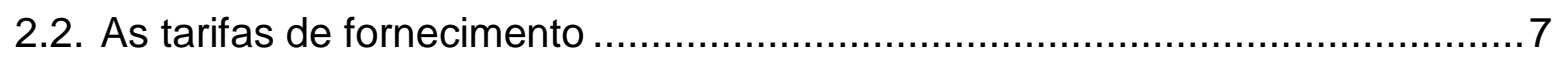

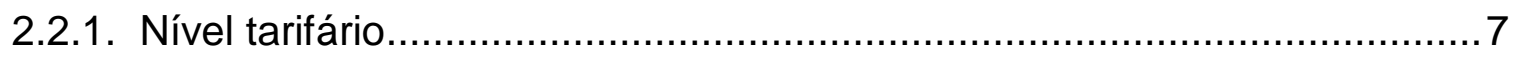

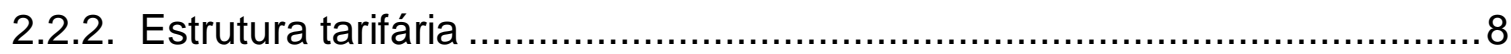

2.3. Alocação de custos na tarifa ............................................................ 11

2.4. A evolução da estrutura tarifária ...................................................... 11

2.5. A tarifa de uso do sistema de distribuição ........................................... 14

2.6. Experiências internacionais recentes................................................ 15

2.6.1. Estrutura de tarifas em Portugal ..................................................... 15

2.6.2. Estrutura de tarifas no Reino Unido ............................................. 18

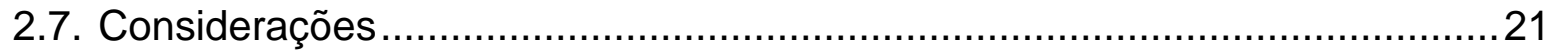

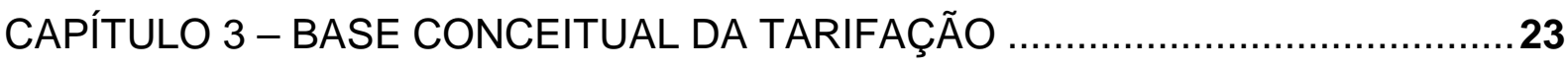

3.1. Princípios de regulação econômica ..................................................... 23

3.2. Precificação de ponta ................................................................... 30

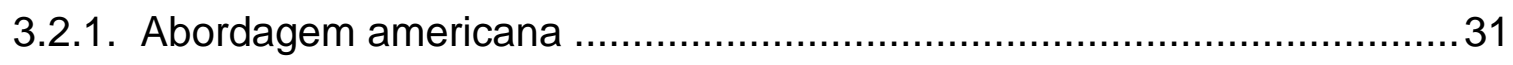

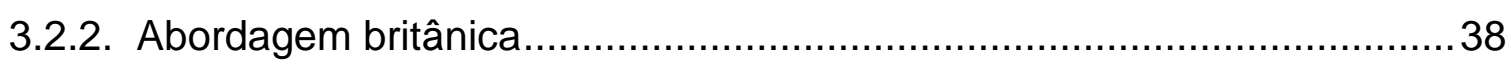

3.2.3. Abordagem francesa ............................................................ 40

3.3. Métodos para cálculo dos custos marginais de expansão no setor elétrico ...42

3.3.1. Lei de Quantidade de Obras (LQO) .................................................... 42

3.3.2. Custo Incremental Médio de Longo Prazo (CIMLP) ............................. 45

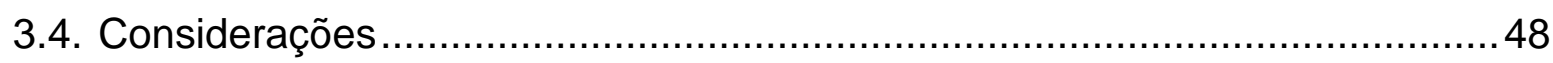


4.1. Custo marginal por nível de tensão na antiga estrutura tarifária.....................55

4.1.1. Custo marginal de geração na antiga estrutura tarifária ..........................56

4.1.2. Custo marginal de transporte na antiga estrutura tarifária.......................58

4.2. Custos por nível na atual estrutura tarifária ..................................................60

4.2.1. Custo de geração na atual estrutura tarifária $\quad$...................................60

4.2.2. Custo de transmissão na atual estrutura tarifária ....................................61

4.2.3. Custo de marginal de distribuição na atual estrutura tarifária...................62

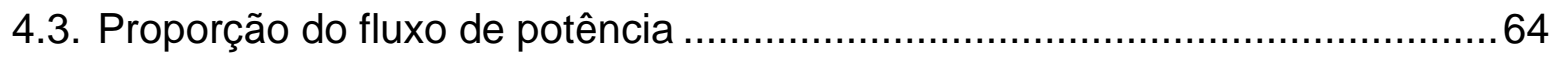

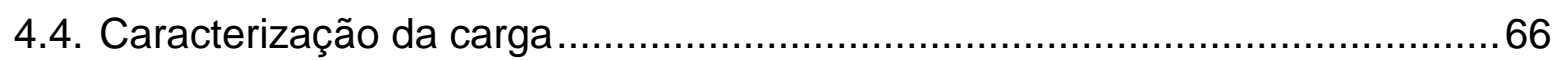

4.5. Componentes da responsabilidade de potência ........................................... 70

4.5.1. Probabilidade de um cliente-tipo se associar a uma rede-tipo.................72

4.5.2. Demanda do cliente-tipo ou fator de coincidência ..................................77

4.5.3. Índice de Perdas de Potência ............................................................... 77

4.6. Cálculo do custo marginal de capacidade do cliente ...................................78

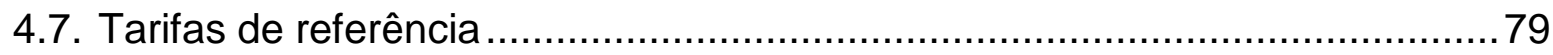

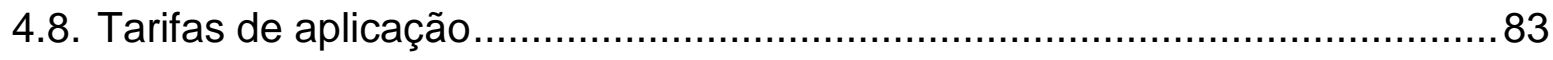

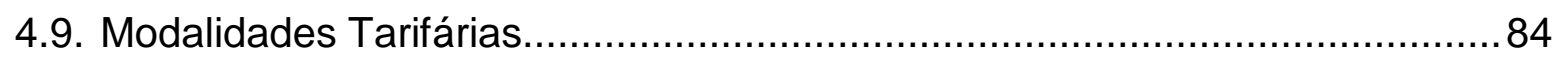

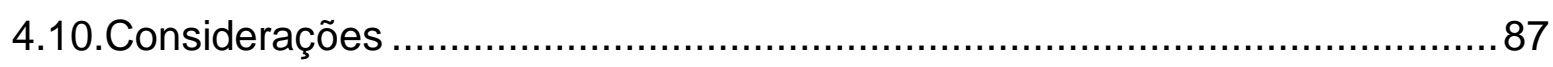

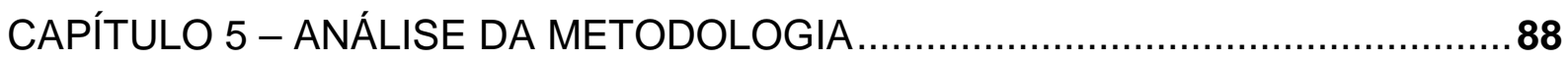

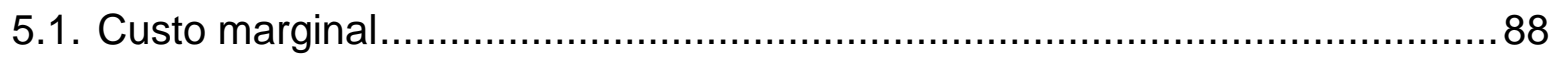

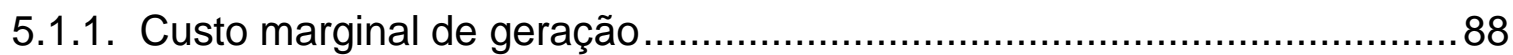

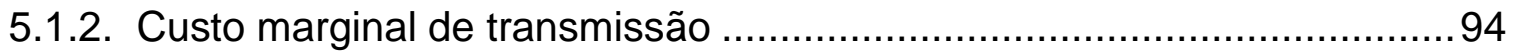

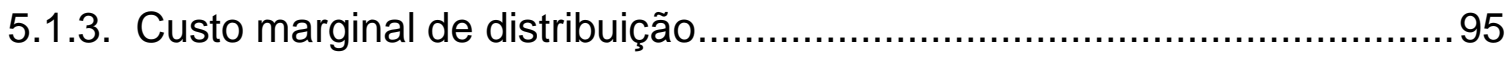

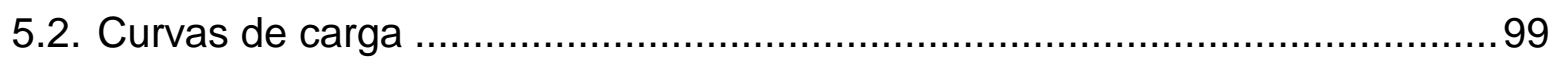

5.3. Responsabilidade de potência .............................................................. 101

5.4. Influência das perdas no dimensionamento do sistema ..............................105

5.5. Custo marginal de capacidade ..........................................................112

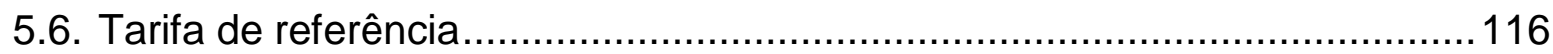

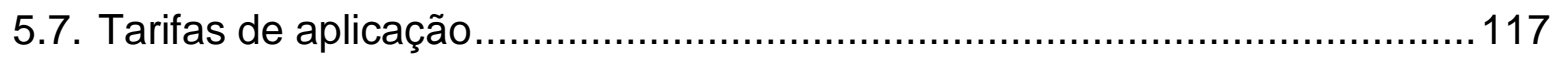

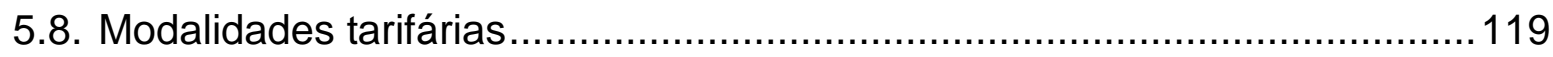

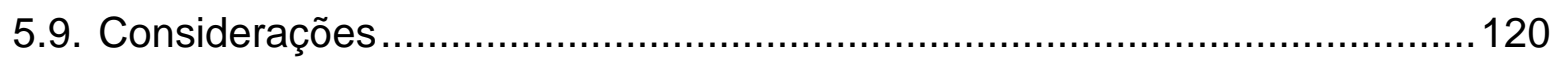


6.1. Alocação das componentes da receita requerida ......................................122

6.2. Sinalização horo-sazonal da tarifa de energia ........................................... 126

6.3. Cálculos dos custos marginais de expansão ........................................... 127

6.4. Cálculo horário dos custos marginais conforme sua origem.........................128

6.5. Metodologia dos custos do cliente: consideração perdas............................. 132

6.6. Comparação entre a alocação horária conforme a origem dos custos e a

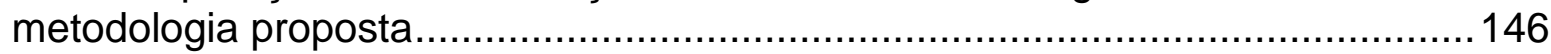

6.7. Agregação dos custos horários e definição de postos tarifários ...................149

6.8. Relações entre as tarifas de ponta e fora de ponta .................................. 150

6.9. Aprimoramentos da construção das modalidades tarifárias ......................... 152

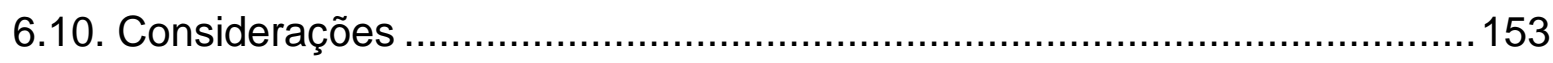

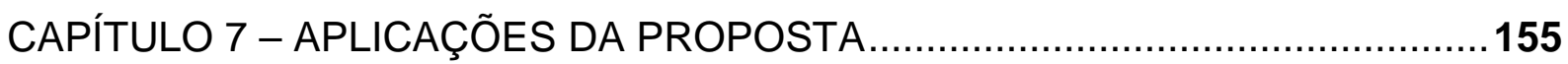

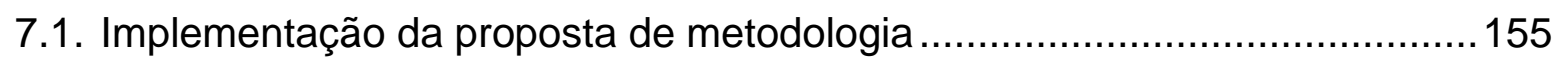

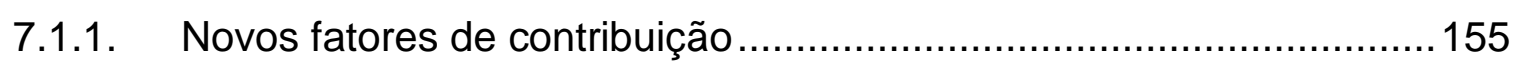

7.1.2. Nova agregação dos custos em postos tarifários ..............................159

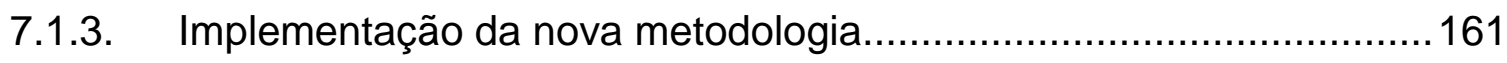

7.2. Estudo de caso da realimentação da metodologia .....................................162

7.2.1. Desmodulação das curvas dos clientes tipo ........................................163

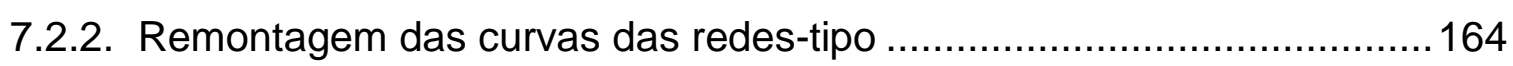

7.2.3. Estudo da aplicação das curvas desmoduladas no método atual .........166

7.3. Implementação da proposta sobre as curvas desmoduladas .......................169

7.3.1. Nova forma de agregação aplicada sobre curvas desmoduladas ..........169

7.3.2. Metodologia proposta sobre curvas desmoduladas..............................171

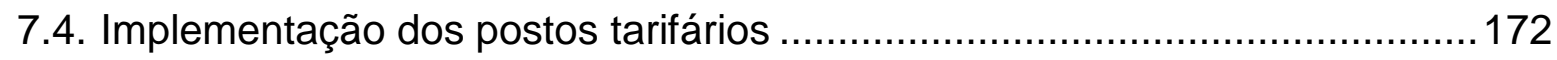

7.5. Implementação das modalidades tarifárias..............................................175

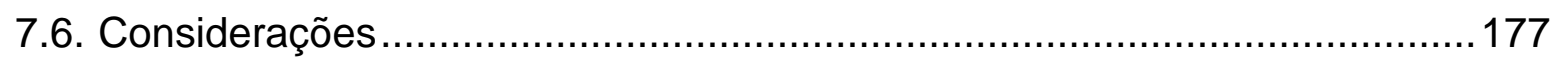

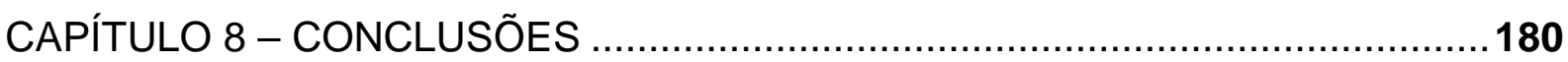

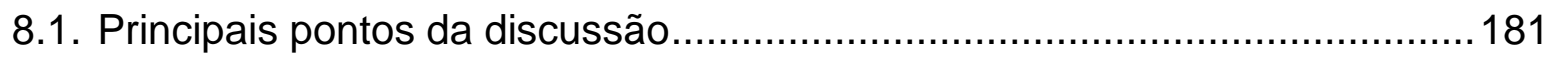

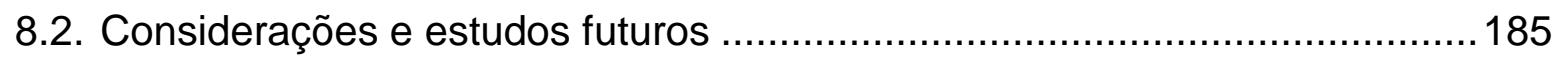

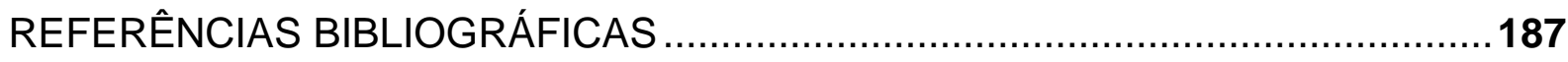

APÊNDICE - REPRESENTAÇÃO MATEMÁTICO- LRIC PRICING .......................193 


\section{CAPÍTULO 1 - INTRODUÇÃO}

\subsection{Caracterização do problema e relevância do tema}

O novo modelo do setor elétrico, adotado a partir da segunda metade da década de 1990, estabeleceu a separação dos segmentos da indústria de energia elétrica (geração, transmissão, distribuição e comercialização), antes reunidos em grandes empresas regionais, predominantemente estatais.

Os setores de geração e comercialização são considerados ambientes competitivos e não requerem uma forte regulamentação econômica, ao contrário da transmissão e da distribuição de energia elétrica que, por terem características de monopólio natural, são regulados tanto técnica como economicamente pela Agência Nacional de Energia Elétrica (ANEEL).

A segregação da indústria de energia elétrica implicou a necessidade de criação de tarifas específicas para cada segmento a partir de uma tarifa única de fornecimento, desenhada em um ambiente no qual as empresas eram, em sua maioria, verticalizadas.

Além disso, um dos pilares desse modelo é o livre acesso ao sistema de transporte (transmissão e distribuição) que deve ser provido por meio de regras de acesso transparentes e tarifas de uso justas. Sendo assim, é importante que tanto a estrutura de tarifas quanto as regras de acesso sejam elaboradas sob a mesma diretriz.

Embora a tarifa de fornecimento seja hoje constituída por "tarifa de uso do sistema de distribuição" e "tarifa de energia", o fato é que a atual estrutura das tarifas ainda está baseada em um modelo que utiliza sinais históricos do sistema elétrico vigente no ambiente setorial anterior, necessitando de aprimoramentos e, até mesmo, da reavaliação da própria metodologia de cálculo. 


\subsection{Motivação}

Atualmente, o setor elétrico se prepara para o início do terceiro ciclo de revisões tarifárias das distribuidoras, após a alteração do modelo do setor iniciada em meados da década de 1990. Com o cenário regulatório mais consolidado em termos de definição das componentes da receita necessária para a operação das empresas, os agentes e o regulador estão voltando suas atenções para a necessária adequação e correção da estrutura de tarifas.

De fato, a ANEEL publicou, em dezembro de 2008, chamadas públicas para os projetos de pesquisa e desenvolvimento (P\&D) considerados estratégicos para o desenvolvimento do setor elétrico nacional. Um destes projetos trata da Estrutura Tarifária e tem como objetivo o aprimoramento da metodologia que contemple a correta repartição dos custos entre os diferentes tipos de consumidores, permitindo a identificação clara dos sinais econômicos e a expansão eficiente do sistema.

Recentemente, a ANEEL divulgou notas técnicas referentes às Consultas Públicas nำ 56/2009, nº 11/2010 e no 11/2010 que precedem a Audiência Pública que irá propor alteração metodológica da estrutura tarifária. Os documentos tratam da alocação dos custos de referência que formam as tarifas, dos sinais de preço nas tarifas horo-sazonais e as tarifas para os consumidores atendidos em BT.

Por isso, o assunto em destaque nos próximos anos, no âmbito da regulação da distribuição, passa a ser a definição de uma metodologia de cálculo da estrutura tarifária que possa conciliar vários fatores, como a alocação adequada do custo por tipo de consumidor, considerando a propensão a pagar e a capacidade de pagamento, bem como a eficiente expansão da rede elétrica atendendo os níveis de qualidade exigidos pela sociedade.

\subsection{Objetivos}

Em sintonia com a discussão atual do setor de distribuição de energia elétrica, são objetivos dessa tese i) alcançar uma visão analítica, discutindo com profundidade a metodologia de cálculo das tarifas de fornecimento, de uso do 
sistema e de energia, bem como ii) propor aprimoramentos que reflitam os custos decorrentes do atendimento de cada tipo de consumidor, indicando o melhor aproveitamento do sistema elétrico da distribuidora.

\subsection{Estrutura do documento}

A tese inicia-se com $\circ$ Capítulo 2, de caráter histórico, que pretende apresentar a organização da indústria de energia elétrica, discutir os conceitos de nível tarifário e de estrutura tarifária e apresentar as recentes experiências internacionais com contribuições relevantes no aspecto de estrutura de tarifas e similaridades com o ambiente institucional brasileiro.

No Capitulo 3 são apresentados os princípios básicos de economia que justificam a necessidade de regulação no setor de distribuição de energia elétrica, incluindo as metodologias aplicadas no setor elétrico para o cálculo dos custos marginais. São discutidos também os principais aspectos da teoria de precificação de ponta, abrangendo as abordagens americana, britânica e francesa, sendo que esta última constitui a base da metodologia aplicada no Brasil.

Os Capitulo 4 discorre sobre a metodologia atual de cálculo das tarifas de fornecimento. Como o método atualmente aplicado pela ANEEL tem como base a metodologia empregada desde meados da década de 1980, o texto apresenta a comparação entre as componentes do processo de cálculo empregados atualmente e os estabelecidos anteriormente.

O Capítulo 5 analisa, com detalhes, a metodologia atualmente empregada pela ANEEL, e procura identificar a conexão entre a lógica embutida na alocação horária de custos e os critérios de dimensionamento do sistema de distribuição de energia elétrica.

O Capítulo 6 apresenta as propostas de aprimoramentos e de inovações cujos destaques são a mudança de paradigma da alocação dos custos de expansão somente no horário de ponta do sistema, a definição ex-post dos postos tarifários, a agregação média dos custos horários para formar as tarifas de referência dos postos 
tarifários, e um estudo de caso com aplicação da metodologia sobre as curvas de carga abstraídas do possível efeito do sinal tarifário existente.

O Capítulo 7 realiza diversas simulações para que seja possível comparar, isoladamente, o efeito de cada proposta. Também a metodologia proposta é aplicada sobre as curvas de carga desmoduladas para que seja demonstrado o impacto desse processo de retirada do sinal tarifário.

Finalizando o trabalho, o Capítulo 8 apresenta as conclusões sobre os aprimoramentos e inovações necessárias para que a aplicação da metodologia de cálculo das tarifas no ambiente regulatório atual e identifica futuros estudos visando aprimorar, sob a ótica do consumidor, a metodologia proposta nesta tese. 


\section{CAPÍTULO 2 - HISTÓRICO DA TARIFAÇÃO DE ENERGIA ELÉTRICA}

\subsection{O setor de energia elétrica brasileiro}

O setor de energia elétrica pode ser subdividido em quatro segmentos de negócio: geração, transmissão, distribuição e comercialização. O sistema de geração de energia elétrica do Brasil apresenta a característica de estar interligado nacionalmente pelo sistema de transmissão, excetuando-se poucas regiões, sendo denominado Sistema Interligado Nacional (SIN). De acordo com o ONS (2010), apenas $3,4 \%$ da capacidade de geração de energia elétrica do país encontra-se fora do SIN, em pequenos sistemas isolados localizados principalmente na região amazônica.

No segmento de distribuição, há 63 concessionárias e 26 permissionárias no Brasil, que foram responsáveis pelo fornecimento de energia elétrica para, aproximadamente, 65 milhões de unidades consumidoras em 2009. As distribuidoras fornecem energia elétrica para os consumidores localizados em sua área geográfica de concessão, denominados clientes cativos. Ademais, determinados consumidores, aqueles com potência instalada acima de $3 \mathrm{MW}$ ou $500 \mathrm{~kW}$ em casos específicos, denominados no setor como "livres" ou "especiais"1, respectivamente, podem escolher a sua fornecedora entre as diversas comercializadoras e geradoras de energia elétrica ${ }^{2}$. A distribuidora, neste caso, continua provendo o serviço de acesso à rede de distribuição, embora não seja responsável pela venda de energia elétrica.

Valores divulgados pela Empresa de Pesquisa Energética (EPE, 2010), mostram que o consumo anual de energia elétrica alcançou, em maio de 2010, um

\footnotetext{
${ }^{1}$ Os consumidores livres são aqueles que atendem aos critérios definidos nos artigos 15 ou 16 da Lei no 9.074/1995: consumidores conectados em tensão igual ou superior a $69 \mathrm{kV}$ e carga acima de 3 MW; ou novos consumidores (conectados após a publicação da referida Lei) com carga acima de $3 \mathrm{MW}$ independentemente da tensão de fornecimento. Já os consumidores especiais, conforme $\S 5^{\circ}$ do art. 26 da Lei o 9.427/96, são aqueles com carga acima de $500 \mathrm{~kW}$ atendidos por fontes de produção incentivadas de que trata o $\S 1^{\circ}$ do referido artigo.

2 Os consumidores que, apesar de aptos a optar, permanecem atendidos pela distribuidora são conhecidos no setor como potencialmente livres.
} 
total de 404,0 TWh, montante este 3,9\% superior ao mesmo período do ano anterior, o que demonstra a recuperação do crescimento do setor e da economia brasileira após a crise financeira mundial que se iniciou no final de 2008.

Conforme definido no modelo do setor elétrico brasileiro, os segmentos de geração e comercialização são considerados competitivos e assim não requerem uma forte regulamentação econômica, ao contrário dos segmentos de transmissão e distribuição de energia elétrica que, por terem características de monopólios naturais, são regulados tanto técnica como economicamente pela Agência Nacional de Energia Elétrica (ANEEL).

Anteriormente ao modelo adotado a partir de 1995, era permitido aos agentes atuarem em toda a cadeia do setor elétrico, controlando as atividades de geração, transmissão, distribuição e comercialização de energia elétrica. Com o novo modelo, e em especial, a Lei no 10.848/04, os agentes de distribuição não podem deter ativos de geração de energia nem exercer atividades não relacionadas com a distribuição de energia elétrica, restrição que inclui a comercialização de energia elétrica para consumidores livres ${ }^{3}$.

Como parte do programa de incentivo às fontes alternativas de energia elétrica, as unidades consumidoras com demanda maior que $500 \mathrm{~kW}$ atendidos em qualquer tensão também podem escolher seu fornecedor desde que a energia seja oriunda de fontes incentivadas como pequenas centrais hidrelétricas $(\mathrm{PCH})$, solar, eólica, biomassa e co-geração qualificada.

É importante destacar essa característica do setor, pois a atual estrutura de tarifas de fornecimento reflete uma composição de custos de um contexto no qual grande parte dos agentes atuava em todos os segmentos do setor elétrico, como será discorrido posteriormente.

\footnotetext{
${ }^{3}$ Art. $4^{\circ} \S 5^{\circ}$ da Lei no $9074 / 95$ com redação dada pela Lei no $10.848 / 04$. As distribuidoras que atuam no Sistema Interligado não podem desenvolver atividades i) de geração de energia elétrica e ii) de transmissão de energia elétrica, iii) de venda de energia a consumidores livres, iv) de participação em outras sociedades, direta ou indiretamente empresa, ou v) estranhas ao objeto de concessão, exceto aquelas permitidas por lei ou constantes do contrato de concessão.
} 


\subsection{As tarifas de fornecimento}

O processo de determinação das tarifas das distribuidoras de energia elétrica ocorre em dois estágios. Na primeira fase calcula-se a receita requerida total que a empresa poderá obter para manter seu equilíbrio econômico-financeiro no período de um ano, definindo então o nível tarifário.

Na segunda, as tarifas a serem cobradas dos diversos tipos de usuários são determinadas de modo a produzir a receita almejada, supondo que os consumidores adquiram as quantidades estimadas do produto. O conjunto desses preços é denominado estrutura tarifária.

\subsubsection{Nível tarifário}

A receita necessária para que a distribuidora de energia elétrica mantenha o equilíbrio econômico-financeiro, conhecida como receita requerida, é composta por duas parcelas correspondentes aos seguintes custos: i) custos exógenos aos da distribuidora (chamado de custos "não gerenciáveis"), ou Parcela A, e ii) custos sob o controle das distribuidoras (denominado de custos "gerenciáveis"), ou Parcela B.

Os custos da Parcela A incluem os custos de energia comprada para revenda, os custos de conexão e transmissão e determinados encargos setoriais (taxas regulatórias). A Parcela B compreende os itens de custo que estão sob o controle das concessionárias: os custos da prestação do serviço de distribuição e a remuneração dos investimentos.

Os custos da Parcela $A$ são geralmente repassados às tarifas de forma integral. Os custos da Parcela B, por sua vez, são anualmente corrigidos, no processo de reajuste tarifário, de acordo com o índice IGP-M, ajustado por um índice que busca induzir as distribuidoras na busca da eficiência operacional, conhecido como Fator X.

Já na revisão tarifária periódica, que ocorre de quatro em quatro anos para a maior parte das distribuidoras, a ANEEL determina uma nova receita requerida. Como as variações reais da Parcela $A$ são reconhecidas integralmente nas tarifas, a função básica da revisão tarifária é definir o novo valor da Parcela B. 
Atualmente os critérios utilizados pelo regulador para a definição dos custos gerenciáveis são os seguintes:

1 Custos da prestação do serviço de distribuição. Utiliza um modelo conhecido como "Empresa de Referência" que simula os custos de uma firma virtual atendendo, de modo eficiente, a mesma área de concessão da distribuidora em termos de ativos físicos e mercado de energia. Engloba, basicamente, os custos da estrutura administrativa, dos serviços comerciais e da operação e manutenção das instalações.

2 Remuneração e depreciação dos ativos vinculados à prestação do serviço de distribuição. As taxas de depreciação e de remuneração do capital são aplicadas sobre as denominadas Base de Remuneração Regulatória (BRR) Bruta e Líquida, respectivamente. Esta base é definida, em linhas gerais, por meio da reavaliação dos ativos pelo valor de reposição (BRR bruta) deduzida da depreciação contábil (BRR líquida).

3 Fator X. Tem como objetivo compartilhar os ganhos de escala com 0 consumidor utilizando o método do fluxo de caixa descontado. Essa sistemática calcula as receitas e custos no período tarifário com base em projeções de crescimento de mercado e de investimentos.

Depois de definida a receita requerida da distribuidora, ou seja, o nível tarifário, é necessário segregar os custos totais por cada tipo de consumidor, calculando-se as várias tarifas de energia elétrica, ou seja, a estrutura tarifária.

\subsubsection{Estrutura tarifária}

Antes de detalhar como é feita a alocação entre as tarifas de energia, é necessário apresentar os diversos tipos de consumidor para os quais são calculadas as tarifas de energia elétrica.

Pode-se dividir os consumidores de energia elétrica de acordo com a finalidade da unidade consumidora, como residência, comércio, indústria, e por nível de tensão no qual é feito o atendimento, como alta tensão (acima de 69 kV), média tensão (de $1 \mathrm{kV}$ até $69 \mathrm{kV}$ ), baixa tensão (abaixo de $1 \mathrm{kV}$ ). 
Dessa forma, a estrutura das tarifas de fornecimento de energia elétrica pode ser desenhada para abranger cada tipo unidade de consumidora classificada pelo nível de tensão de atendimento e pela sua finalidade.

Como visto, para a maioria dos consumidores, os cativos, a distribuidora é responsável fornecimento de energia elétrica como um todo, englobando o transporte e o produto (energia elétrica gerada). Porém, para determinados consumidores, os livres, que podem escolher o fornecedor do produto energia elétrica, a distribuidora local presta apenas o serviço de transporte.

Assim, a tarifa de fornecimento de energia elétrica da distribuidora é segregada em duas: a tarifa de uso do sistema de distribuição (TUSD) e a tarifa de energia (TE).

A TUSD é paga tanto pelos consumidores cativos como pelos livres, pelo uso do sistema de distribuição da empresa de distribuição à qual estão conectados. Enquanto que a TE é cobrada somente dos consumidores cativos, pois os livres compram energia diretamente das comercializadoras de energia elétrica ou dos agentes de geração.

É importante notar que um consumidor que opte pelo mercado livre continuará pagando a TUSD ao distribuidor local e deixará de pagar a tarifa de energia, a TE, tendo em vista a contratação do fornecimento de energia com outro fornecedor.

A TUSD compreende os custos do serviço de distribuição, encargos setoriais, remuneração dos investimentos e suas depreciações. A TE compreende os custos de compra com energia elétrica que inclui também encargos setoriais associados. Para os consumidores cativos atendidos em média e alta tensão, as tarifas de fornecimento de energia elétrica são binômias, ou seja, cobradas pelo consumo de energia e pela máxima potência utilizada no período ${ }^{4}$. Há três tipos possíveis de tarifação para os consumidores: a tarifa convencional, tarifa horo-sazonal verde (THS Verde) e a tarifa horo-sazonal azul (THS Azul).

\footnotetext{
${ }^{4}$ É importante ressaltar a diferença entre a TE (tarifa de energia) e a tarifa cobrada em termos de energia. A primeira é o preço de venda da "mercadoria" energia, enquanto que a segunda é o preço cobrado de determinado serviço, inclusive o relacionado com a capacidade do sistema, utilizando a energia como unidade de medida.
} 
A tarifa convencional possui apenas um preço para a energia e outro para a potência. As tarifas horo-sazonais possuem quatro preços diferentes de energia que dependem do horário (na ponta ou fora de ponta do sistema) e do período do ano (úmido ou seco) de utilização.

A diferença entre as duas tarifas horo-sazonais é o preço da potência utilizada. A THS Verde possui apenas um valor de tarifa enquanto que a THS Azul tem dois preços, um para a ponta e outro para fora de ponta. Isto não significa, porém, que o custo do horário de ponta não é cobrado dos consumidores que optam pela THS Verde. Neste caso, este custo está incorporado na tarifa de energia do horário de ponta que, justamente por isso, é maior do que a tarifa de energia da THS Azul.

Contudo, não são todos os consumidores que podem optar por essas três modalidades tarifárias. Somente os consumidores conectados em média tensão (tensões inferiores a $69 \mathrm{kV}$ ) e com demanda contratada inferior a $300 \mathrm{~kW}$ podem escolher a melhor, dentre as três, o que depende do fator de carga e do fator de modulação do consumidor. Aqueles atendidos em média tensão e com demanda contratada igual ou superior a $300 \mathrm{~kW}$ podem optar por uma das duas tarifas horosazonais, enquanto os demais, obrigatoriamente, devem contratar a THS Azul, como pode ser visto na Tabela 2.1.

Tabela 2.1 - Opções de contratação para consumidores MT e AT

\begin{tabular}{ccccc}
$\begin{array}{c}\text { Tensão } \\
(\mathbf{k V})\end{array}$ & $\begin{array}{c}\text { Demanda } \\
\text { contratada } \\
(\mathbf{k W})\end{array}$ & & Opções tarifárias \\
\hline$<69$ & $<300$ & Azul & Verde & Convencional \\
$<69$ & $>=300$ & Azul & Verde & \\
$>=69$ & & Azul & & \\
\hline
\end{tabular}

Para os consumidores atendidos em baixa tensão, a tarifa é cobrada somente em função do consumo de energia elétrica do período, não existindo o preço para a potência. Isto não significa, porém, que os custos de uso do sistema de distribuição não contribuem para o seu cálculo, pois a metodologia sempre os utiliza nos diversos períodos de uso da rede, independentemente do nível de tensão de conexão. Na prática o que dificulta a implantação da tarifa de binômia para os consumidores conectados em baixa tensão é o custo da medição. 


\subsection{Alocação de custos na tarifa}

No caso da tarifa de energia (TE), a alocação dos custos, basicamente compra de energia e encargos associados, nos diversos tipos de consumidores é feita proporcionalmente ao consumo de energia elétrica; ou seja, o direcionador de custos às diferentes tarifas é a própria energia consumida.

Este tipo de alocação é conhecido no setor elétrico, como "selo", alusão ao selo postal, que consiste de um preço único independente do destino da correspondência. No caso da tarifa de energia elétrica, o termo "selo" corresponde ao valor igual do produto energia elétrica que pagam os diferentes tipos de consumidores.

Similarmente, determinados componentes da tarifa de uso do sistema de distribuição (TUSD) são alocados na forma de "selo", como o custo de transmissão e encargos setoriais associados. Neste caso, os custos de acesso e uso de transmissão são divididos em função da potência contratada, independentemente do tipo do consumidor ou do nível de tensão em que estiver conectado.

Assim, basicamente os componentes da Parcela $A$ (custos de aquisição de energia, custo de transporte e encargos setoriais) são cobradas na forma de "selo" nas tarifas de energia (TE) e de uso do sistema (TUSD).

Por outro lado, a Parcela $B$ da receita requerida, constituída pelos custos de prestação do serviço e remuneração dos investimentos, que correspondem a aproximadamente um terço dos custos da distribuidora, é alocada para os diferentes consumidores de forma proporcional aos custos marginais de expansão calculados para cada tipo de consumidor, conforme detalhado no Capítulo 4.

\subsection{A evolução da estrutura tarifária}

A metodologia de cálculo de uma tarifa deve buscar os princípios de eficiência, eqüidade, justiça, equilíbrio financeiro, simplicidade e estabilidade, sinalizando aos consumidores a direção do mínimo custo e promovendo o uso racional da energia elétrica (BORN; BITU, 1993). Ao mesmo tempo é necessário 
garantir o equilíbrio econômico-financeiro da concessão para a prestação do serviço, de acordo com a qualidade exigida, assim como uma tarifa justa que possibilite a correta alocação dos custos ao consumidor.

Contudo, como o foco deste trabalho é analisar a relatividade de tarifas entre as diversas categorias de consumidores (estrutura tarifária), não será detalhada a formação da receita necessária para cobrir os custos da distribuidora (nível tarifário). Assim, a estrutura tarifária adequada visa "dar a cada categoria de consumidores a convicção de estar pagando um preço justo pelos serviços que recebe e a sensação de não estar sendo injustiçada pelo preço que as outras categorias estão pagando" (DNAEE, 1985).

Embora o Decreto n 41.019/57 tenha criado as classes de consumidores para a aplicação de tarifas, a atual estrutura, com tarifa binômia para clientes do Grupo $A^{5}$, foi definida posteriormente pelo Decreto $n^{0}$ 62.724/68. De acordo com esse regulamento, havia a "necessidade de repartir os custos de maneira que a cada grupo de consumidores seja atribuída a fração equivalente ao custo do serviço que lhe for prestado".

Porém, a alocação dos custos determinada por esse regulamento resultava tarifas de demanda acima dos custos necessários ao seu fornecimento, incentivando as distribuidoras que atuavam na geração de energia elétrica a aumentar a potência instalada de suas usinas para obter um benefício financeiro adicional propiciado pela legislação, de acordo com o MME (1981).

Em 1974, o Decreto-Lei nำ 1.383 estabeleceu a progressiva equalização tarifária tornando assim desnecessária a apresentação dos custos por nível de tensão das concessionárias. Como as tarifas sofreram afastamentos em relação aos reais custos, as empresas passaram a ter remuneração real fora dos limites legais estabelecidos. Para mitigar essa situação, as despesas com a compra de energia eram ajustadas por meio do aumento ou diminuição da tarifa de suprimento. $\mathrm{Na}$ prática, esse mecanismo em conjunto com outros, como a Reserva Global de Garantia, foram utilizados para a distribuição de recursos financeiros entre as concessionárias (MME, 1981).

\footnotetext{
${ }^{5}$ Grupo A: unidades consumidoras com fornecimento em tensão igual ou superior a $2,3 \mathrm{kV}$, caracterizado pela estruturação tarifária binômia.
} 
Nessas condições, em 1977, um acordo de cooperação entre o DNAEE/Eletrobrás e a Electricité de France (EDF) possibilitou o início de estudos para a aplicação da teoria de custos marginais na estrutura tarifária do setor elétrico brasileiro. Essa metodologia considera os custos provocados ao sistema pelo aumento da demanda em cada categoria de consumidores e período de consumo.

O enfoque marginalista, para cálculo das tarifas, implica a necessidade do conhecimento do comportamento da carga e dos custos nos diversos níveis do sistema elétrico (DNAEE, 1985). A caracterização da carga é elaborada com base nos dados de medições amostrais e por isso considera o aspecto probabilístico desses custos no sistema de oferta e demanda. É importante notar que a obtenção dos custos considerava toda a cadeia da indústria de energia elétrica, desde a produção de energia até a comercialização para o consumidor final, pois grande parte do setor elétrico era verticalmente integrada, diferentemente do cenário atual.

Assim, a estrutura das tarifas de fornecimento horo-sazonais, em postos tarifários de ponta e fora de ponta, período seco e úmido, considera os custos da geração, transmissão e distribuição de energia de meados da década de 1980.

A partir de 1993, alterações na legislação determinaram o fim da equalização tarifária e a utilização do price-cap, e não mais o custo do serviço, como base para o estabelecimento das tarifas de fornecimento. Embora o nível das tarifas fosse ajustado para cada área de concessão, as relações entre os postos tarifários continuaram iguais às da época da implantação das tarifas horo-sazonais.

O Comitê de Revitalização do Modelo do Setor Elétrico, criado em 2001 para diagnosticar as causas do racionamento de energia elétrica e propor aprimoramentos para o setor, reconheceu, dentre outros temas, a necessidade de realinhamento das tarifas de fornecimento devido ao subsidio cruzado existente entre grupos de consumidores.

A premissa adotada foi considerar como correto o cálculo das tarifas de uso do sistema de distribuição (TUSD). A soma dessa tarifa com o preço da energia comprada pela distribuidora acrescido de encargos correspondentes, que compõem basicamente a TE, deveria corresponder às tarifas de fornecimento aplicadas aos consumidores finais. Porém, essa somatória (TUSD + TE) era superior às tarifas de 
fornecimento para determinados grupos de consumidores e inferior para outros, comprovando a presença de um subsídio cruzado entre classes.

Para retificar a tarifa de fornecimento de maneira a não impactar significativamente o consumidor, foi criado o realinhamento tarifário que previa a correção gradativa da tarifa de energia elétrica que tenderia, ao final do processo, ao mesmo preço de energia para todos os tipos de consumidor.

\subsection{A tarifa de uso do sistema de distribuição}

Inicialmente a TUSD era calculada a partir do valor da tarifa de fornecimento, que incluía todos os custos da cadeia produtiva, subtraída dos custos não relacionados com a atividade de distribuição de energia elétrica (despesas com compra de energia e encargos e custo de comercialização) como definido pela Resolução ANEEL no 286/1999. O custo para atender os consumidores cativos foi estimado pela agência reguladora em $30 \%$ da receita líquida total, pois não havia separação contábil das atividades de distribuição e comercialização.

Essa receita específica de distribuição foi alocada entre os diversos níveis de tensão com base em custos marginais padrão calculados pela ANEEL como médias dos custos fornecidos pelas distribuidoras, expurgados os valores extremos. De acordo com Antunes apud Noda $(2001)^{6}$, as tarifas de uso do sistema de distribuição foram, em geral, subestimadas se comparadas com o custo real para atender os clientes do serviço de distribuição.

Esse modelo, denominado de top-down, foi mantido pela Resolução no 594/2001 que aperfeiçoou alguns dos componentes que deveriam ser expurgados da tarifa de fornecimento.

Com o ciclo de revisão tarifária de 2003, os custos de distribuição puderam ser estimados pela ANEEL, permitindo que a metodologia de cálculo da TUSD fosse modificada pela Resolução ANEEL no 152/2003. A principal alteração foi sobre a receita da distribuidora, anteriormente calculada por diferença, passando a ser

\footnotetext{
${ }^{6}$ ANTUNES, N. P. Tarifas de distribuição - metodologia e aplicação. Apresentado no Curso de Tarifas no Novo Modelo do Setor Elétrico - VI CTSE - Estágio I, 2001, 178 p.
} 
estimada com base nos custos operacionais eficientes e na remuneração de investimentos prudentes obtidos no processo de revisão tarifária. Esse modelo, ao contrário do critério definido em 1999, é denominado de bottom- up.

Em relação à estrutura tarifária foram mantidos os procedimentos anteriores para a proporcionalização da receita do serviço de distribuição com base nos custos marginais de capacidade dos consumidores. Esses custos, por sua vez, são calculados a partir dos custos padrão por faixas de tensão, das curvas de carga e do diagrama unifilar simplificado do fluxo de potência.

A Resolução no 166/2005 manteve, em linhas gerais, essa metodologia para o cálculo da estrutura tarifária, inovando, porém, com a manutenção e publicação das relações entre postos tarifários utilizadas à época em que foram criadas as tarifas horo-sazonais, meados da década de 1980.

A ANEEL divulgou, no ano passado, a Consulta Pública nº 56/2009 que trata da "primeira parte da proposta de alteração metodológica da estrutura tarifária aplicada ao setor de distribuição". Neste processo, disponibilizou uma nota técnica, a primeira de uma série de cinco documentos, na qual são discutidos critérios para alocação de cada item que compõem a receita requerida da distribuidora.

Recentemente, a ANEEL apresentou documento, no âmbito das Consultas Públicas nำ11/2010, que trata dos sinais de preço nas tarifas horo-sazonais e das tarifas para os consumidores atendidos em BT, e no 12/2010, que discute a metodologia para estimação dos custos marginais de expansão das redes de distribuição. Essas consultas precedem a Audiência Pública prevista para o segundo semestre de 2010 que irá propor a alteração da metodológica de cálculo da estrutura tarifária.

\subsection{Experiências internacionais recentes}

\subsubsection{Estrutura de tarifas em Portugal}

Em Portugal, desde julho de 2007, todos os consumidores podem optar pela compra de energia elétrica de diversos fornecedores. Dessa forma, a distribuidora 
não é mais a responsável pelo fornecimento regulado de energia elétrica, mesmo para aqueles consumidores que não exerceram a opção. Neste caso, o consumidor é atendido pelo denominado comercializador de último recurso.

O comercializador de último recurso é responsável, então, por adquirir, para cada hora de cada dia, a energia correspondente à melhor expectativa dos consumos dos seus clientes.

No caso de consumidores que optam pelo mercado livre, as tarifas de acesso à rede, aplicadas pelas concessionárias de distribuição e de transmissão, são resultantes das adições das Tarifas de Uso da Rede de Transporte, de Uso Global do Sistema ${ }^{7}$ e Uso da Rede de Distribuição, como pode ser observado na Figura 2.1.

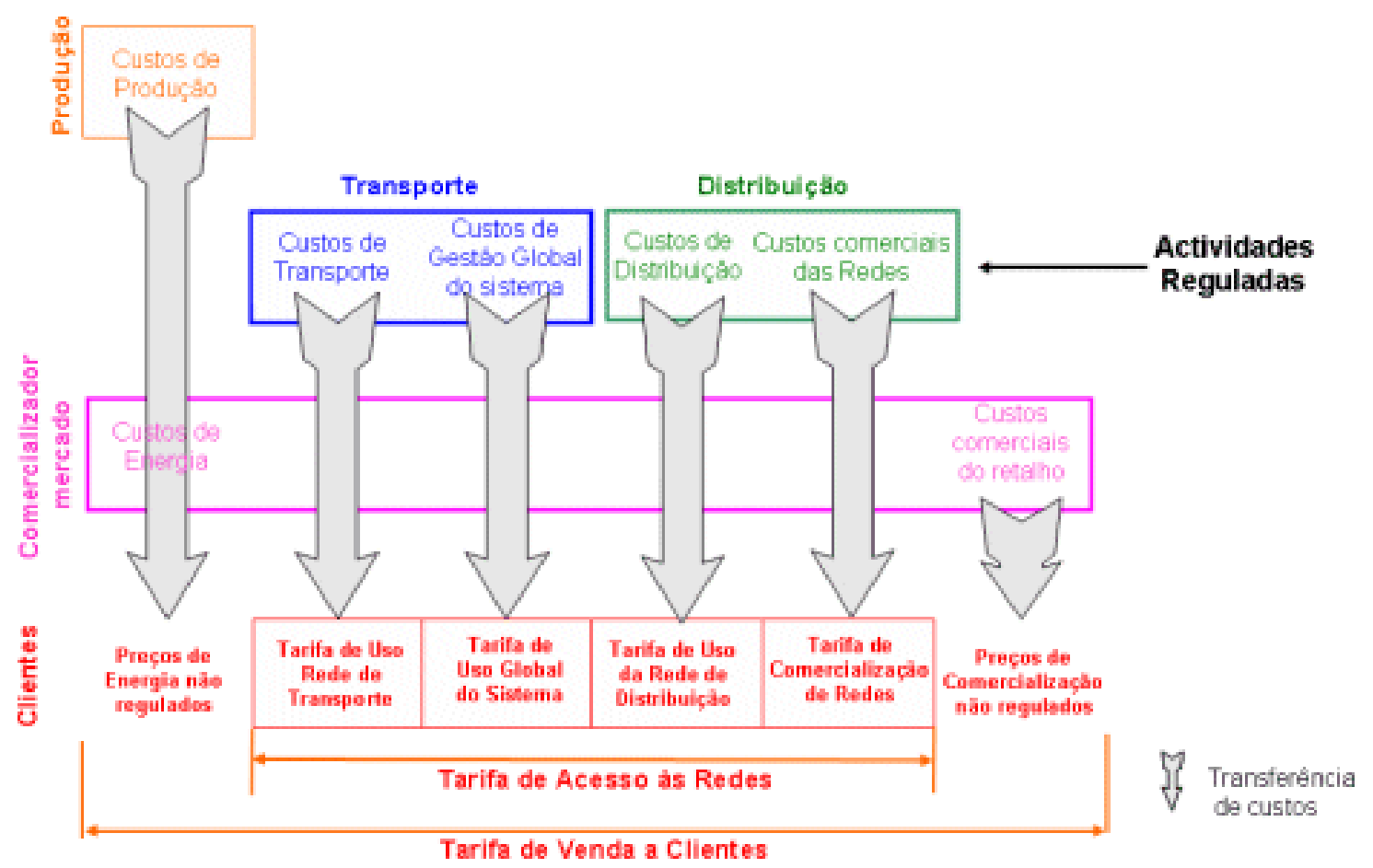

Figura 2.1 - Atividades e tarifas que integram as Tarifas de Acesso às Redes Fonte: ERSE (2010)

\footnotetext{
${ }^{7}$ A tarifa de Uso Global do Sistema é composta, essencialmente, por custos associados a medidas de política energética, ambiental e de interesse econômico geral, por exemplo: remuneração dos terrenos afetos ao domínio público hídrico, convergência tarifária, tarifa social, custos agência reguladoras, eficiência energética.
} 
As tarifas de uso das redes de transporte (transmissão) e de distribuição são compostas por preços de energia, preços de potência contratada, de potência em horas de ponta e preços de energia reativa.

Os preços de energia na tarifa de uso de redes não têm, evidentemente, como objetivo recuperar os custos de energia, uma vez a distribuidora não é responsável pela sua comercialização, mas sim refletir o sinal econômico do custo das perdas de energia nas redes.

Assim, de acordo com a ERSE (2010), a relação existente entre o nível de perdas numa rede e dos investimentos efetuados, justificado pela redução dessas perdas atuais e futuras, é transmitida para os consumidores através da estrutura de preços, por meio da componente energia da tarifa de uso das redes.

Os preços de potência contratada visam transmitir os custos associados aos trechos de rede próximos ao consumidor, uma vez que o dimensionamento desses trechos periféricos ao sistema de distribuição é condicionado pelo comportamento de um pequeno número de clientes, por vezes até mesmo de um único consumidor.

Já os preços de potência média, em horas de ponta, procuram transmitir os custos dos trechos mais centrais do sistema, compostos pelas instalações em níveis de tensão mais elevados, que são utilizados por um grande número de clientes. Devido à diversidade das ocorrências dos picos de cada cliente, o regulador de Portugal entende que o comportamento individual de um cliente condicionaria o dimensionamento desses trechos mais distantes do consumidor apenas proporcionalmente à sua potência média.

Os preços de potência das tarifas de redes são determinados pela aplicação de um fator multiplicativo aos custos incrementais de potência das redes de transporte e de distribuição, preservando a estrutura dos custos incrementais conforme as Tabelas 2.2 e 2.3. Os fatores multiplicativos são determinados de forma a que as tarifas de redes aplicadas ao mercado previsto proporcionem as receitas permitidas. 
Tabela 2.2 - Estrutura dos custos incrementais de potência das Tarifas de Uso da Rede de Transporte em 2010

\begin{tabular}{ccc}
\hline $\begin{array}{c}\text { Nível de } \\
\text { tensão }\end{array}$ & $\begin{array}{c}\text { Potência contratada } \\
(€ / \text { kW.mês })\end{array}$ & $\begin{array}{c}\text { Potência } \\
\text { horas de ponta } \\
(€ / \text { kW.mês })\end{array}$ \\
\hline MAT & 0,0750 & 0,6749 \\
\hline AT & 0,1437 & 1,2932 \\
\hline
\end{tabular}

Fonte: ERSE (2010)

Tabela 2.3 - Estrutura dos custos incrementais de potência das Tarifas de Uso da Rede de Distribuição em 2010

\begin{tabular}{ccc}
\hline $\begin{array}{c}\text { Nível de } \\
\text { tensão }\end{array}$ & $\begin{array}{c}\text { Potência contratada } \\
(\boldsymbol{\epsilon} / \mathbf{k W} \text {.mês) }\end{array}$ & $\begin{array}{c}\text { Potência } \\
\text { horas de ponta } \\
(\boldsymbol{\epsilon} / \mathbf{k W} \text {.mês })\end{array}$ \\
\hline AT & 0,0987 & 0,9774 \\
\hline MT & 0,8183 & 4,6509 \\
\hline BT & 0,4946 & 5,4998 \\
\hline
\end{tabular}

Fonte: ERSE (2010)

Ainda no âmbito da prestação do serviço de distribuição, a tarifação da energia reativa fornecida (indutiva) é considerada uma variável a ser utilizada na cobrança pelo uso das redes, na medida em que a sua compensação possibilita a diminuição dos custos globais do sistema elétrico, quer ao nível da minimização das perdas de energia nos ramos periféricos das redes, quer ao nível do seu sobredimensionamento.

\subsubsection{Estrutura de tarifas no Reino Unido}

O estudo desenvolvido pela Universidade de Bath foi encomendado pelo regulador britânico, Office of Gas and Electricity Markets (Ofgem), para examinar se outras metodologias de tarifação seriam mais eficientes na promoção do desenvolvimento econômico do sistema de distribuição (LI ET AL., 2005).

Os pontos fracos identificados incluem incapacidade de refletir os investimentos futuros, falta de distinção do custo de implantação em diferentes locais, pouco reconhecimento do custo dos fluxos de potência reativa, e a inconsistência no tratamento entre a geração e o consumo. 
Em linhas gerais, o estudo da Universidade de Bath aborda três metodologias para o cálculo das tarifas de uso do sistema de distribuição: Distribution Reinforcement Model (DRM); Investment Cost Related Pricing (ICRP) e Long Run Incremental Cost (LRIC).

O modelo tarifário DRM é utilizado na Inglaterra para o cálculo das tarifas de distribuição há mais de 25 anos. Fundamentalmente é uma metodologia de repartição que atribui os custos da rede já existente para os usuários, dependendo do uso que fazem de cada nível de tensão do sistema de distribuição, estimado a partir de sua máxima demanda e das características da classe do consumidor.

As outras duas modelagens tarifárias, ICRP e LRIC, podem ser consideradas como aproximações com base nos custos marginais. Na primeira abordagem, assume-se que o acréscimo da demanda é assegurado pela expansão da rede de maneira uniforme. Na segunda, o custo marginal é estimado a partir da mudança no valor presente dos custos previstos de reforço da rede em conseqüência da adição do incremento de carga. Ambas as abordagens metodológicas podem ser calculadas considerando os fluxos de potência DC e AC criando assim simulações que incorporam também o impacto dos reativos no sistema de distribuição, no último caso.

A metodologia ICRP segue o mesmo critério empregado pelo National Grid para as tarifas de transmissão. A metodologia reflete o custo para atender um incremento de demanda em cada nó na rede de referência, sendo considerado um custo padrão para a rede, conhecido como a "constante expansão", expressa em $£ / \mathrm{kW} / \mathrm{km}$.

$\mathrm{Na}$ abordagem atualmente utilizada para a transmissão, a constante de expansão não varia com a tensão. Contudo, ao aplicar esta metodologia para a distribuição, o estudo da Universidade de Bath tem utilizado diferentes constantes de expansão para cada circuito na rede de referência e não uma média da expansão da rede.

Os custos marginais derivados desta metodologia são expressos em relação a uma barra de referência, na qual o custo marginal de conexão de carga ou geração é zero, como no modelo de transmissão utilizado no Brasil. Na aplicação 
desta metodologia ao sistema de distribuição, o modelo reconhece todos os denominados pontos de fronteira ou Grid Supply Points (GSP) como "barra de referência", uma vez que não existe custo de rede de distribuição decorrente da adição de carga ou geração nestes locais. Assim as tarifas ICRP serão sempre relativas ao GSP, sendo então coerente com a abordagem DRM, de acordo com Universidade de Bath.

No caso do sistema de transmissão, os custos são alocados entre os segmentos carga e geração, na proporção de $73 \%$ e $27 \%$, respectivamente, diferentemente do sistema brasileiro cujo rateio é igual para ambos os segmentos. Para o sistema de distribuição, contudo, com a pequena quantidade de geração, tal regra não seria adequada, conforme avaliação do referido estudo. Nesta situação, a diferença necessária para recuperar todo o custo do sistema é alocada ao segmento carga.

É uma característica da metodologia ICRP não reconhecer o grau em que os ativos existentes estão carregados, assumindo que a rede possa ser expandida linearmente para acomodar a demanda sem gerar excesso de capacidade. Esta é uma desvantagem da metodologia quando aplicada aos sistemas de distribuição cujos investimentos são pontuais e não contínuos e cuja carga varia consideravelmente.

O método LRIC, por outro lado, consegue tratar a existência de ociosidade na rede de distribuição, avaliando o custo adicional que surge da necessidade de antecipação de investimento resultante do aumento da demanda em qualquer barramento do sistema ou, alternativamente, a redução de custo decorrente do adiamento de investimentos.

Este novo modelo de tarifação considera, então, que os custos para atender a carga estão baseados na natureza e no momento do impacto do investimento futuro na rede. Usando a mesma matriz de sensibilidade do método nodal, ICRP, a metodologia analisa o valor presente dos investimentos futuros, com e sem o incremento de carga, e exprime o custo como a diferença entre os dois valores presentes. Assim, reflete os custos dos ativos para atender o incremento de demanda, que, para redes de distribuição será uma função da distância, como no 
modelo ICRP, e também do horizonte de tempo no qual os novos investimentos serão necessários.

No modelo ICRP, os custos em cada nó são, originalmente, simétricos para a carga e para a geração, ou seja, para um determinado ponto as tarifas são iguais, porém de sinais contrários dependendo do tipo do agente. Isto não ocorre no modelo LRIC, uma vez que a natureza do reforço, ou mesmo a sua necessidade, pode ser significativamente diferente no caso da conexão, no mesmo ponto, de uma carga ou de uma geração.

A antecipação de investimentos decorrentes da adição de demanda no futuro pode ter um pequeno custo associado. Assim, considerando que grande parte da rede é relativamente pouco utilizada, as receitas geradas a partir das tarifas derivadas do método LRIC irão recuperar uma pequena proporção da receita autorizada, menor do que na metodologia ICRP.

Como resultado, após o ajuste para reconciliar esses custos com a receita autorizada, a variação das tarifas em cada nó é substancialmente menor em comparação com a abordagem nodal (ICRP), segundo o estudo.

A reconciliação da receita normalmente é feita por meio de um selo, aditivo ou multiplicativo, ou ainda por meio da Regra de Ramsey que, embora seja defendida pelo Ofgem, tem restrições no mundo acadêmico. Isto porque a adoção dos preços de Ramsey exigiria o conhecimento das elasticidades preço da demanda que são difíceis de serem estimadas, dada a escassez de dados nesta área.

\subsection{Considerações}

Neste capítulo foi discutida a evolução da estrutura de tarifas, desde os primeiros estudos que culminaram com as tarifas horo-sazonais até as iniciativas recentes da ANEEL, o que demonstra a importância atual desse assunto.

Embora, no passado, as tarifas de fornecimento de energia elétrica fossem constituídas por duas componentes, não necessariamente a tarifa cobrada em termos de energia estava relacionada somente os custos de geração. Da mesma forma, na componente cobrada em termos de demanda de potência, existiam os 
custos dos investimentos na capacidade de geração, além dos custos dos sistemas de distribuição e de transmissão.

Por outro lado, atualmente, as tarifas de fornecimento de energia elétrica estão segregadas em duas parcelas: a tarifa de energia (TE) e a tarifa de uso do sistema de distribuição (TUSD). Embora a TE seja cobrada em termos de energia, a TUSD possui componentes que podem ser cobradas tanto em termos de energia, como em termos de potência, dependendo da lógica utilizada para a formação dos custos repassados para a tarifa.

As experiências internacionais recentes apresentadas neste capítulo demonstram que a implantação do mercado competitivo e do livre acesso ao sistema de distribuição exigiu a segregação das tarifas e a preocupação com a cobrança mais justa possível nos diversos pontos de conexão.

Assim, em Portugal, as tarifas são consideradas aditivas, pois cada parcela é responsável pela recuperação dos custos da geração de energia elétrica e da prestação dos serviços de transmissão, de distribuição, de comercialização. Já no caso do Reino Unido, a proposta de um sinal locacional está no centro das discussões do aprimoramento da metodologia de cálculo da tarifa de distribuição. As tarifas em cada ponto de conexão poderão incorporar o impacto de eventuais investimentos, dentro do horizonte de estudo, decorrentes do nível de carregamento do sistema de distribuição. 


\section{CAPÍTULO 3 - BASE CONCEITUAL DA TARIFAÇÃO}

Este capítulo apresenta os princípios de Micro-economia que fundamentam a regulação no transporte de energia elétrica, incluindo um histórico sobre as abordagens teóricas da precificação de ponta, bem como discute as metodologias utilizadas para o cálculo dos custos marginais no setor elétrico brasileiro.

\subsection{Princípios de regulação econômica}

Segundo a teoria econômica, os mercados podem ser classificados, simplificadamente, com base em dois critérios: i) a possibilidade de substituição dos produtos; e ii) a interdependência dos competidores. Este último critério é relacionado com o número de firmas na indústria e o com o grau de diferenciação do produto. Se há muitas empresas, cada uma delas tenderá a ignorar as demais, enquanto que se há poucas empresas, cada uma terá consciência da sua interdependência e levará em consideração as ações das demais.

Há autores que visualizam um terceiro critério que é iii) a facilidade de entrada de outras firmas no mercado. Com base nesses critérios, é possível classificar os mercados nas seguintes estruturas: competição perfeita; monopólio; competição monopolista; e oligopólio.

Na competição perfeita há um grande número de vendedores, de modo que uma empresa isoladamente, por não ter porte, não afeta os níveis de mercado e, conseqüentemente, o preço de equilíbrio. Nesse mercado prevalecem as seguintes premissas: não há diferenciação entre produtos ofertados, não existem barreiras de entrada e todas as informações são conhecidas pelos agentes.

No mercado monopolista, ao contrário, há apenas uma única empresa que domina inteiramente a oferta. Não havendo concorrência nem produto substituto, os consumidores se submetem às condições impostas pelo vendedor, ou simplesmente deixam de consumir o produto.

A concorrência monopolista é uma estrutura de mercado intermediária entre a concorrência perfeita e o monopólio e possui as seguintes características: número 
relativamente grande de empresas com certo poder concorrencial; segmentos de mercados e produtos diferenciados; margem de manobra para fixação dos preços não muito ampla.

Finalmente, o oligopólio é uma estrutura caracterizada por um pequeno número de empresas que dominam a oferta de mercado. Normalmente as empresas discutem suas estruturas de custos, embora o mesmo não ocorra com relação a sua estratégia de produção e de marketing.

No caso da indústria de energia elétrica, o setor de transporte de energia, transmissão e distribuição, possuem características de monopólio natural. Isto porque se mais de uma empresa atendesse determinada região, o custo total médio das empresas seria maior que o custo médio de um único agente, para o mesmo nível de atendimento. Além disso, é indesejável a duplicação das instalações de transporte em razão do alto investimento inicial necessário para prover o serviço.

Do ponto de vista de uma empresa no mercado competitivo, a curva de demanda corresponde ao preço estabelecido pelas forças de mercado (oferta de mercado versus demanda de mercado), sendo constante independentemente da quantidade. Como há "infinitas" empresas nessa estrutura de mercado, nenhuma delas tem condições de alterar o preço ou praticar preço superior ao estabelecido no mercado por não dispor de quantidade suficiente. Contudo, a esse preço dado pelo mercado, a empresa poderá vender até o limite da sua estrutura de custos que corresponde a quantidade em que o custo marginal do produto iguala ao preço de mercado.

Por outro lado, no monopólio, a curva de demanda da empresa é a própria curva da demanda do mercado como um todo. A empresa monopolista, ao ser exclusiva no mercado, não está sujeita aos preços competitivos. O monopolista não utiliza a igualdade entre a oferta e a demanda para determinar preço e quantidade de equilíbrio, como no mercado competitivo. A maximização dos lucros é obtida igualando-se o custo marginal à receita marginal. Nesse ponto, determina-se a quantidade $\left(Q_{m}\right)$ que levará ao mercado e que substituída na curva da demanda determina o preço $\left(P_{m}\right)$ do produto, como pode ser observado na Figura 3.1.

Comparando essa condição com um mercado em concorrência perfeita, no 
qual o preço de equilíbrio é a intersecção da curva de demanda com a curva de custos marginais, observa-se que a condição de maximização de lucro em monopólio não otimiza a condição de bem-estar social, pois o preço é superior ao custo marginal no ponto em que este equivale à receita marginal.

Assim, no caso do serviço de distribuição de energia elétrica, cujas características são de monopólio natural, é necessária a atuação da agência reguladora do setor elétrico (ANEEL) que define a tarifa de energia elétrica para maximizar o bem-estar social ao mesmo tempo em que procura garantir o equilíbrio econômico da concessão do serviço público.

De acordo com Pires e Piccinini (1998), a "regulação tarifária é um dos aspectos mais importantes da regulamentação dos serviços públicos, tendo em vista a necessidade, em um regime de monopólio natural, de se garantir tanto a rentabilidade do investidor quanto a preservação dos interesses dos consumidores".

Desta forma, considerando a teoria econômica, o preço do serviço de distribuição de energia elétrica deveria ser definido no ponto $\mathrm{P}^{*}$ (vide Figura 3.1) em que a curva de custos marginais corta a curva de demanda do mercado, solução essa conhecida como first best.

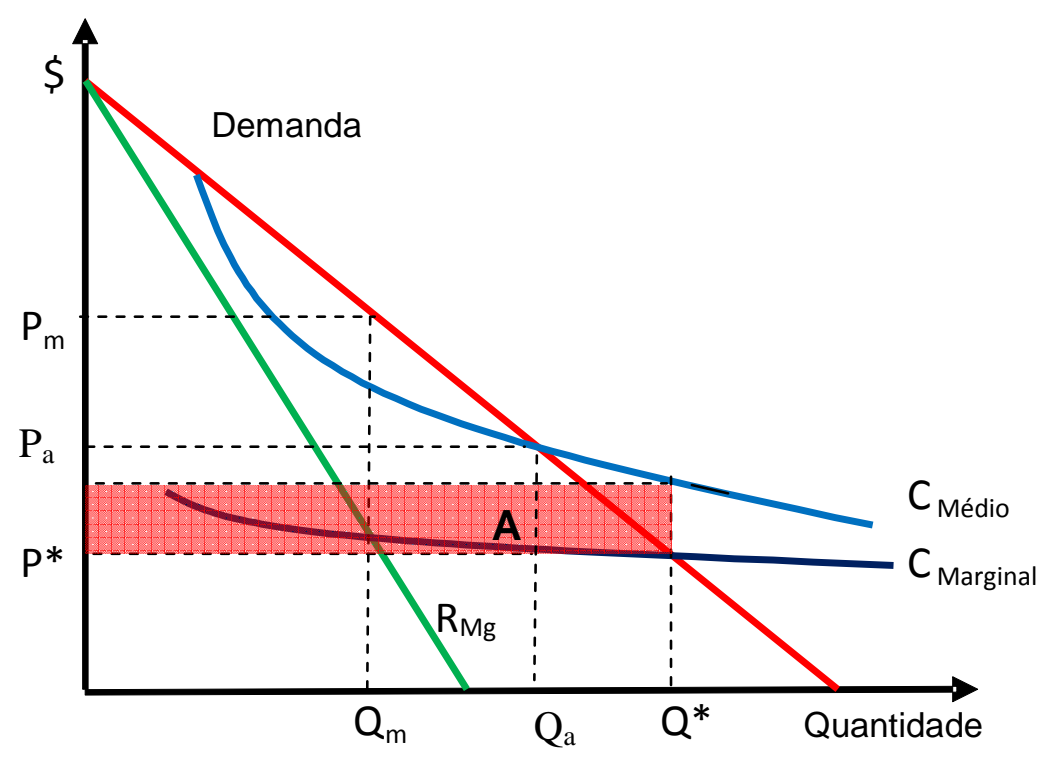

Figura 3.1 - Tarifa à custo marginal em monopólio natural 
Onde:

$Q_{m}$ - quantidade no ponto em que o custo marginal é igual à receita marginal;

$\mathrm{P}_{\mathrm{m}}$ - preço no ponto em que o custo marginal é igual à receita marginal;

$Q^{*}$ - quantidade no ponto em que a curva de custo marginal corta a curva de demanda;

$\mathrm{P}^{*}$ - preço no ponto em que a curva de custo marginal corta a curva de demanda;

$\mathrm{Q}_{\mathrm{a}}$ - quantidade no ponto em que a curva de custo médio corta a curva de demanda;

$\mathrm{P}_{\mathrm{a}}$ - preço no ponto em que a curva de custo médio corta a curva de demanda.

Em tese, como no monopólio natural os custos médios superam os custos marginais $^{1}$, a agência reguladora não pode emular o mercado competitivo simplesmente definindo a tarifa com base nos custos marginais (first best), pois nessa situação, a distribuidora não conseguirá recuperar todos os seus custos.

Ou seja, neste caso de indústria de aplicação intensiva de capital, o preço "ótimo", definido sob o ponto de vista da eficiência alocativa (preços iguais aos custos marginais), pode trazer prejuízos à distribuidora, comprometendo a eficiência produtiva, pois o custo marginal é inferior ao custo médio. As perdas de receita para a distribuidora de energia elétrica, neste caso, seria o retângulo A da Figura 3.1.

Dessa forma a alternativa seria definir o preço do serviço como igual ao custo médio. Essa solução resulta, porém, em perda de bem estar, identificada na Figura 3.2 pelo triângulo $B$.

\footnotetext{
${ }^{1}$ Conforme Santos et al. (2008), em um monopólio forte, em função da economia de escala, a curva de custo marginal se mantém sempre abaixo da curva de custos totais médios ao longo de praticamente toda a curva de demanda. Isto ocorre em empresas que exigem infra-estrutura pesada e altos custos de capital (gerando custos médios altos). e custos baixos de produção de uma unidade adicional. Como exemplo exposto por Moreira (1998), o custo de transporte de um passageiro adicional (custo marginal) é próximo de zero para um vôo prestes a decolar, porém o custo médio desse passageiro (soma dos custos de capital, combustível e pessoal dividido pelo número de passageiros) pode ser alto.
} 


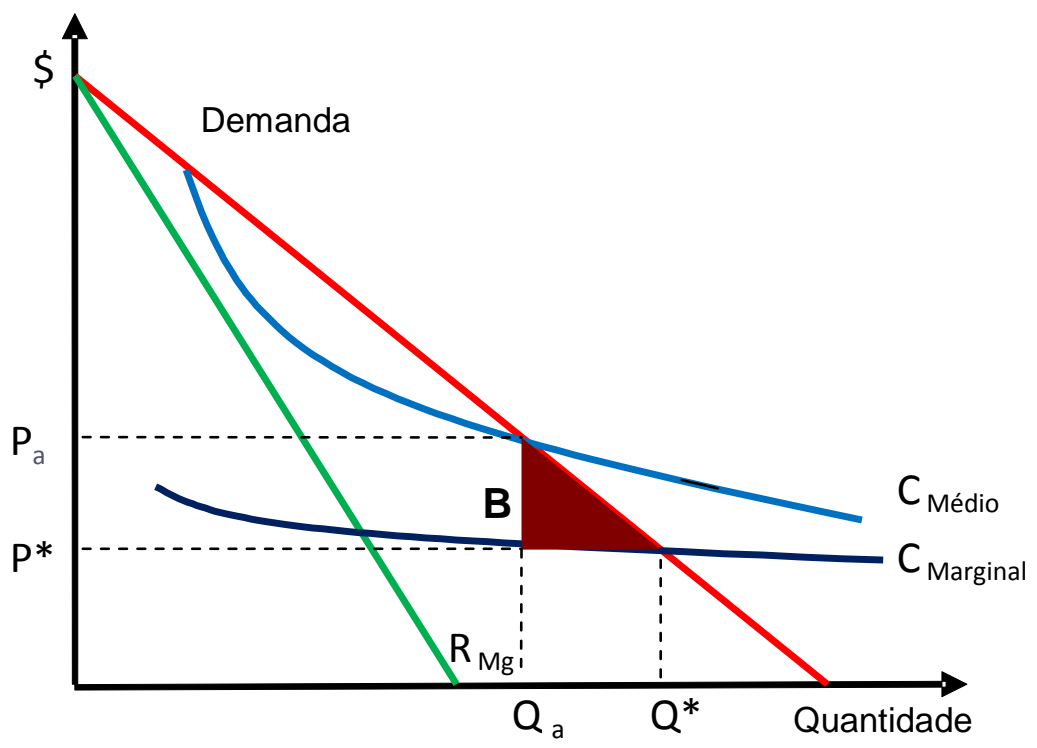

Figura 3.2 - Tarifa ao custo médio em monopólio natural

Uma solução para se obter a alocação ótima e, ao mesmo tempo, manter o equilíbrio econômico da concessionária, seria cobrar um preço igual ao custo marginal e cobrir as perdas de receita da distribuidora por meio de um subsídio ou de outra tarifa que independa da quantidade vendida.

De acordo com Viscusi, Vernon e Herrington (1992), há vários argumentos contrários ao subsídio, como, o não incentivo à redução de custos, a cobertura dos custos pelas pessoas que não utilizam o serviço, o total de benefício do consumidor podendo ser menor que o total de custos.

Outro desafio comumente associado à indústria de rede surge do fato de vários produtos serem produzidos utilizando um mesmo conjunto de ativos. A determinação do preço mais adequado para cada produto pode ser complexa devido à dificuldade de isolar os custos incorridos na produção de cada determinado produto.

No Brasil, como será relatado a seguir, parte da tarifa é calculada proporcionalmente ao custo marginal de cada tipo de consumidor, tendo como restrição a necessidade de recuperar a receita requerida da distribuidora. Esse método é conhecido na literatura equal percentage of marginal cost (EPMC), como apresentado por Gilbert (1991). 
Geralmente o ajuste entre a receita decorrente de tarifas baseadas nos custos marginais e a receita requerida da distribuidora pode ser feito por meio dos seguintes critérios:

- Proporcional aos custos marginais diretamente atribuíveis a cada classe de consumo e seus consumidores;

- Proporcional à demanda do consumidor;

- Ajuste absoluto no preço unitário (aditivo ou multiplicativo $\mathrm{R} \$ / \mathrm{kW}$ ); ou

- Ajuste fixo para cada consumidor (aditivo ou multiplicativo $\mathrm{R} \$$ ).

De todo modo, qualquer critério de ajuste envolve certo grau de arbitrariedade na divisão dos custos e, portanto, distorce a sinalização original de preços que, por sua vez, distorce o padrão de consumo.

Uma alternativa seria a Regra de Ramsey, aplicável no caso da existência de mais de um produto. Esse método aloca, inversamente proporcional à elasticidadepreço da demanda de cada produto, o adicional da receita necessária para a operação da empresa não coberta pelos custos marginais.

Uma segunda opção seria aplicar o preço não linear, ou tarifas em duas partes, que consiste de um valor fixo independente do consumo e um valor por unidade. Se este preço por unidade for igual ao custo marginal, é possível ter uma tarifação eficiente na qual o valor fixo seja estabelecido de forma que a receita total recupere integralmente os custos da empresa. Para isso, por exemplo, o preço fixo das tarifas em duas partes poderia ser calculado de modo que a soma deste valor pago por todos os consumidores corresponda à diferença entre o preço a custo marginal e o preço a custo médio identificada pelo retângulo A da Figura 3.1.

Há várias formas de se calcular esse preço fixo, uma delas é simplesmente dividir as perdas pelo número de consumidores. Contudo, como os consumidores variam consideravelmente em termos de demanda pelo serviço, esse taxa adicional pode exceder a propensão a pagar de parte dos consumidores excluindo-os do mercado (VISCUSI; VERNON; HERRINGTON, 1992).

A solução ideal seria determinar diferentes taxas fixas para diferentes classes de consumidores, alterando também os preços por unidade de modo a manter o 
valor total pago pelo consumidor no limite da sua propensão a pagar para uma determinada quantidade de produto, formando um sistema de tarifação denominado de multitarifas.

A tarifação adequada é aquela que consegue balancear a perda de eficiência devido à exclusão de consumidores causada pela taxa fixa e a perda de consumo adicional decorrente do preço por unidade acima do custo marginal. A Tabela 3.1 apresenta um exemplo dessa tarifação para o serviço de telefonia.

\section{Tabela 3.1 - Tarifas multipartes para serviço de telefonia}

\begin{tabular}{ccc}
\hline & $\begin{array}{c}\text { Tarifa fixa mensal } \\
(\$)\end{array}$ & $\begin{array}{c}\text { Tarifa por ligação } \\
\text { (\$/minuto) }\end{array}$ \\
\hline Tarifa 1 & 5 & 0,1 \\
Tarifa 2 & 10 & 0,05 \\
Tarifa 3 & 20 & 0 \\
\hline
\end{tabular}

Fonte:Viscusi; Vernon; Herrington (1992)

A Figura 3.3 mostra o custo total do consumidor em função do número de minutos utilizados nas ligações mensais. O gráfico indica que para um consumidor que utiliza até 100 minutos por mês, a indicada é a Tarifa 1; entre 100 e 200 minutos, a Tarifa 2; e acima de 200 minutos, a Tarifa 3.

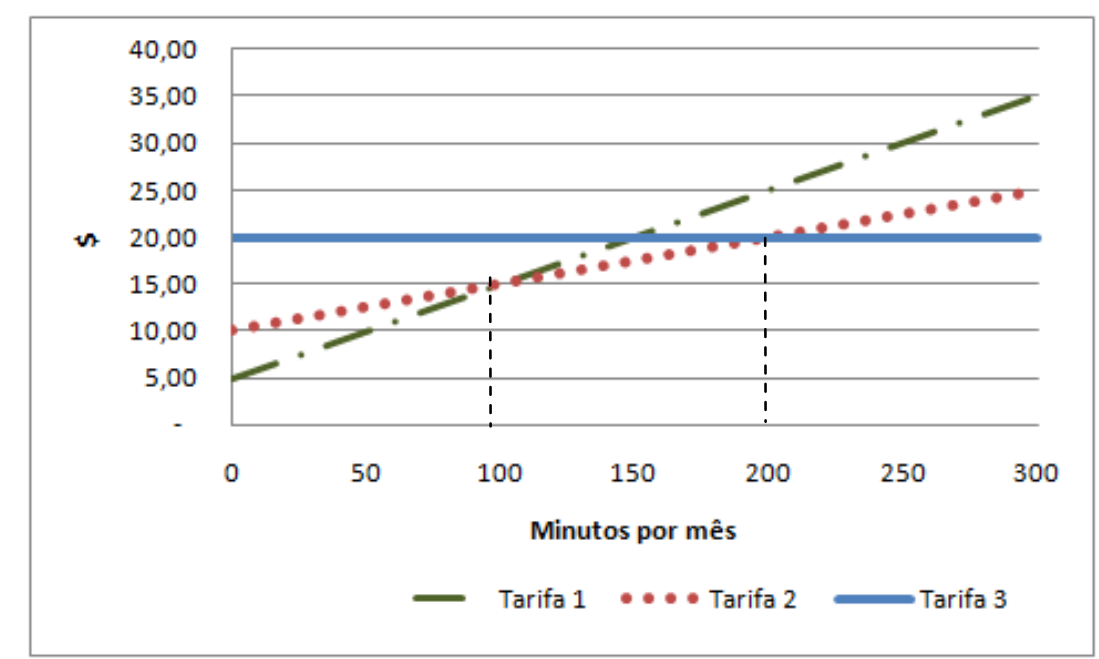

Figura 3.3 - Aplicação das Tarifas Multipartes 


\subsection{Precificação de ponta}

O mercado de energia elétrica tem duas características básicas que 0 diferencia dos mercados comuns e que devem ser consideradas no estudo dos custos marginais e da precificação de ponta. A primeira está relacionada à incapacidade, em termos econômicos, de armazenar eletricidade em quantidades significativas. A segunda é a alteração rápida da demanda ao longo do tempo, o que implica que a capacidade dos equipamentos (subestações, redes de transporte, transformadores) seja determinada pela maior demanda que deva ser atendida naquele momento.

Conforme Houthakker (1951), também podem ser classificados quatro tipos de custos relacionados com o fornecimento de energia elétrica:

- Custos de energia, função da quantidade de energia (MWh) produzida e relacionados com os custos de operação, de combustíveis e perdas na transmissão;

- Custos de capacidade, dependentes da demanda máxima sobre os equipamentos, incluindo custo de capital, manutenção e conexão no sistema de transporte;

- Custos dos consumidores, relacionados com o número e tipo de consumidores como os custos de medição, de emissão de contas, das conexões de uso exclusivo do consumidor; e

- Custos residuais, não pertencentes a nenhuma das categorias, podendo ser discricionariamente alocados a determinadas quantidades.

Para Drèze (1964), a precificação de custos marginais para os produtos, cujas demandas são periódicas e não armazenáveis, é um caso especial de preços para multiprodutos. Além disso, é uma importante aplicação para o gerenciamento das empresas prestadoras de serviço publico por conta das interações entre os preços praticados e a política de investimento a ser adotada.

De acordo com a classificação apresentada por Joskow (1976), a literatura sobre precificação na ponta pode ser dividida em três abordagens: a americana, a 
britânica e a francesa. A primeira tem como característica principal o enfoque nas curvas de demanda dos períodos de ponta e fora de ponta para a definição dos preços. A segunda se preocupa um pouco mais com o lado da oferta levando em conta que a energia elétrica não é, necessariamente, suprida somente por fontes uniformes e homogêneas, mas que os custos podem variar conforme as características da planta que atende os diferentes períodos. Já a terceira abordagem busca contemplar as duas outras vertentes observando também as restrições elétricas de todo o sistema de produção, transmissão e distribuição de energia elétrica.

\subsubsection{Abordagem americana}

A metodologia americana, cujos maiores expoentes são Houthakker (1951), Steiner (1957), Hirshleifer (1958) e Willianson (1966), analisa as implicações dos preços de ponta no contexto de i) plantas com capacidade de produção homogênea, ii) retornos constantes de escala e iii) custos marginais de curto prazo constantes independentemente do tamanho das plantas.

Conforme Drèze (1964), esta abordagem também foi desenvolvida independentemente por Boiteux (1960). Com base naquela referência são descritos, a seguir, os pontos principais da definição de custos marginais. É possível verificar, com base nas três suposições acima apresentadas, que a função de custo para a planta de capacidade $q_{c}$, pode ser descrita da seguinte forma:

$$
f\left(q_{c}, q\right)=\left\{\begin{array}{cr}
\beta q_{c}+b q & 0 \leq q \leq q_{c} \\
\infty & q>q_{c}
\end{array}\right.
$$

Onde:

q é a quantidade por unidade de tempo;

$\beta$ é o custo marginal de capacidade;

b é o custo marginal de curto prazo.

Do ponto de vista do planejamento, o custo marginal de uma unidade de produção é b, custo marginal de curto prazo, se houver excesso de capacidade; ou $\beta$ $+b=\delta$, custo marginal de longo prazo, se exigir novas instalações. Assim $\beta$ 
corresponde ao custo de prover uma unidade de capacidade, e é assumido como independente da quantidade de capacidade exigida, conforme Drèze (1964).

Assim, a função de custo total de longo prazo pode ser escrita da seguinte forma:

$$
F(q)=f(q, q)=\delta q, \quad q \geq 0
$$

A Figura 3.4 representa graficamente as considerações anteriores.

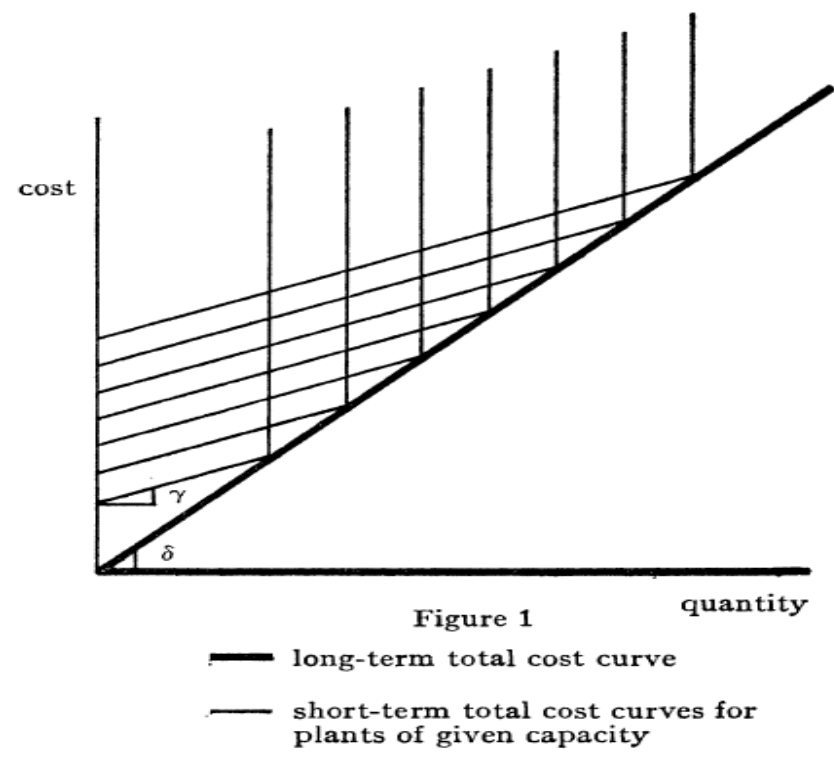

Figura 3.4 - Curvas de custos marginais de curto e longo prazo

Fonte: Drèze (1964)

Neste caso, o objetivo da precificação de ponta é determinar o nível ótimo de produção em cada período e os preços pelos quais os compradores irão adquirir essas quantidades. A quantidade de capacidade que se exige é a potência máxima em qualquer período - ou seja, a máxima demanda no sistema (ou ponta).

Para a solução apresentada por Steiner (1957), por suposição, o produto é disponibilizado em dois períodos de igual duração (dia e noite) e são conhecidas as duas curvas de demanda cada período. Essas curvas são funções decrescentes em função da quantidade de produto e são independentes uma da outra. Além disso, a curva de demanda para o primeiro período (ponta) está acima da curva do segundo período (fora de ponta) para todas as quantidades, como demonstrado na Figura 3.5. 


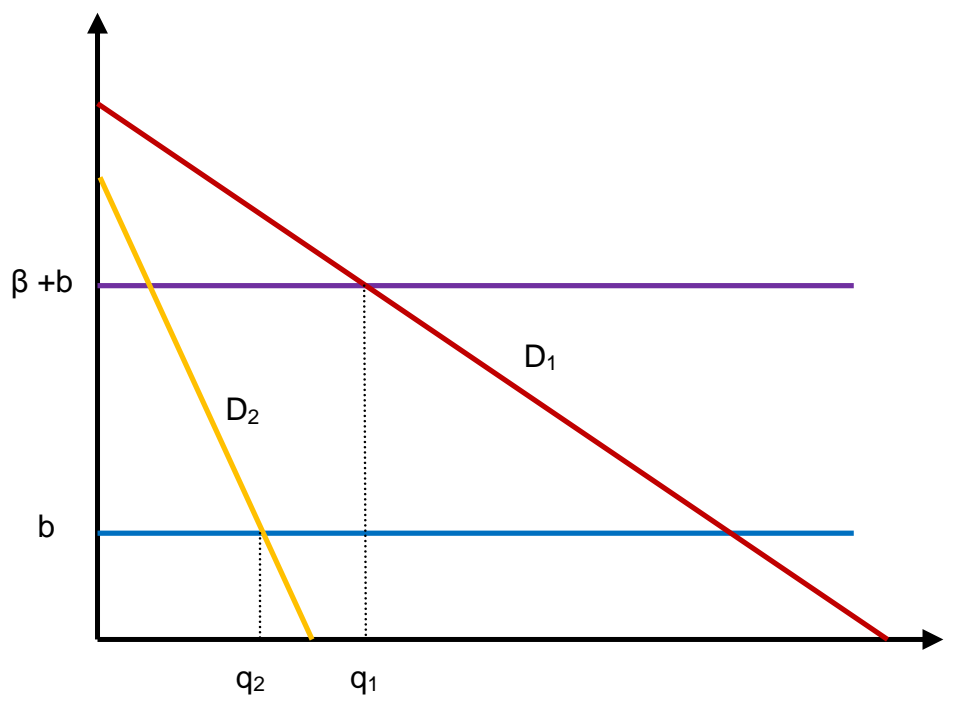

Figura 3.5 - Firm Peak Case

Na Figura 3.5 as curvas de $D_{1}$ e $D_{2}$ representam a demanda em períodos distintos. A solução clássica demonstra que a precificação ótima ocorreria se fossem cobrados os custos marginais de longo prazo $(\delta=\beta+b)$ no horário de ponta e os custos marginais de curto prazo (b) no horário fora de ponta.

O custo total da capacidade é recuperado para a quantidade $q_{1}$, e uma vez que a procura marginal por capacidade é decorrente somente dos usuários do Período 1 , o preço adequado para este período é $P_{1}=b+\beta$.

O custo de capacidade é recuperado pelos usuários do Período 1 mesmo se não houvesse demanda no Período 2. Assim, deve ser permitida a compra do produto aos usuários do Período 2, desde que eles paguem os custos operacionais de produção. A quantidade adequada é, então, $q_{2}$ com preço $P_{2}=b$ (Steiner, 1957).

Este exemplo corresponde ao peak firm case no qual a demanda máxima não se move de um período para outro quando os preços aumentam no período de ponta e diminuem no período fora de ponta. Contudo, em determinadas condições, poderá ocorrer a inversão das demandas entre os períodos, dependendo do formato das curvas de demanda, como demonstrado na Figura 3.6. A este fenômeno dá-se o nome de shifting peak case. 


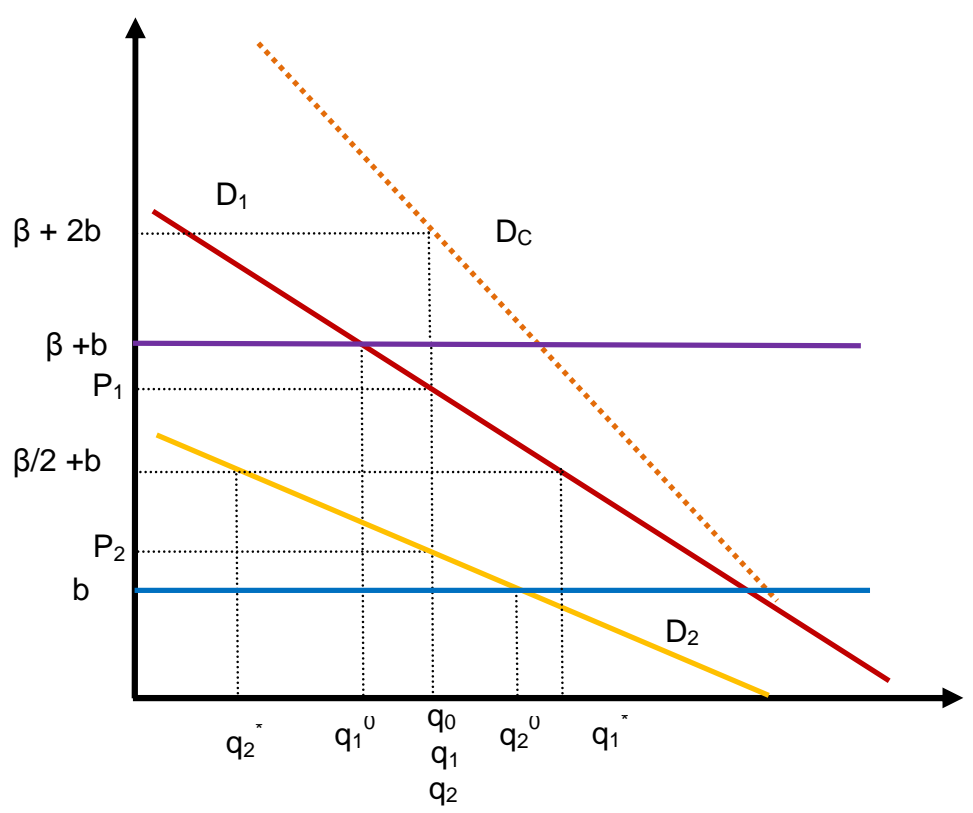

Figura 3.6 - Shifting Peak Case

Fonte: Adaptado de Steiner (1957).

A existência de inversão de ponta complica o cálculo de preços eficientes, requerendo informações relevantes sobre os custos de produção e as posições das funções de demanda.

Se fosse aplicado o critério anterior, as quantidades $q_{1}{ }^{0}$ e $q_{2}{ }^{0}$ seriam menos satisfatórias, pois $\mathrm{q}_{1}{ }^{0}$ seria inferior $\mathrm{a}_{2}{ }^{0}$. O custo marginal de curto prazo (preço fora de ponta) seria cobrado somente para as quantidades que, de fato, representam o pico de demanda sobre a capacidade. Ao contrário, o custo da capacidade aplicado a apenas à quantidade $q_{1}{ }^{0}$ iria remunerar uma capacidade menor do que as $q_{2}{ }^{0}$ unidades de capacidade necessárias.

Também um "preço médio" $P^{*}=\beta / 2+b$ não seria adequado, pois para os níveis de produção resultantes seria exigida uma capacidade de $\mathrm{q}_{1}{ }^{*}$ unidades cobrando apenas $\left(\mathrm{q}_{1}{ }^{*}\right.$ e $\left.\mathrm{q}_{2}{ }^{*}\right) / 2$ unidades.

A solução proposta por Steiner é a construção da curva DC, correspondente à soma vertical das parcelas positivas $D_{1}$ e $D_{2}$, que pode ser interpretada como a efetiva demanda total por capacidade. 
A quantidade total de capacidade igual a $q_{0}$ é justificada pelas curvas de demanda combinadas. Dada esta capacidade, as quantidades em cada período podem ser estendidas até este valor desde que os preços excedam os custos de operação, b, em cada caso período. A quantidade ideal é, então, $q_{0}=q_{1}=q_{2}$ com os preços $\mathrm{P}_{1}$ e $\mathrm{P}_{2}$ mostrados na Figura 3.6.

Para generalizar o argumento é essencial reconhecer que uma unidade de capacidade é justificada se, e somente se, i) é coberta pela demanda em qualquer período sozinho, ou ii) é coberta pelas demandas combinados em dois ou mais períodos.

Uma vez que a capacidade adequada é determinada, a quantidade produzida em cada período deve ser estendida até o limite da capacidade, a menos que as unidades adicionais de produção não recuperem os custos de operação.

A característica da solução o caso de dois períodos e shifting peak, é que as quantidades ideais são iguais e os preços diferentes. Para facilitar o entendimento, Steiner escreve os preços em termos de um desvio em relação aos preços médios:

$$
\begin{gathered}
\mathrm{P}_{1}=\mathrm{b}+\frac{\beta}{2}+\mathrm{k}_{1} \\
\mathrm{P}_{12}=\mathrm{b}+\frac{\beta}{2}+\mathrm{k}_{2}
\end{gathered}
$$

Onde $\mathrm{k}_{1}+\mathrm{k}_{2}=0$, pois a soma dos preços deve resultar $2 b+\beta$.

Houthakker (1951) propôs uma solução semelhante para casos com mais de dois períodos de carga. Davidson ${ }^{2}$ (1955) apud Steiner (1957) discutiu o shifting peak case e apresentou uma solução, semelhante à de Houthakker, porém com a inserção de um elemento dinâmico. Se a quantidade no período fora de ponta tende atingir a demanda de ponta, o respectivo preço deve ser acrescido de uma componente "a" de modo a manter a quantidade abaixo do nível de pico. O excesso resultante das receitas sobre o período de fora de ponta deve ser refletido em uma redução do preço no período de ponta. Isto é:

$$
\mathrm{P}_{2}=\mathrm{b}+\mathrm{a}
$$

\footnotetext{
${ }^{2}$ DAVIDSON, R.K. Price Discrimination in Selling Gas and Electricity. Baltimore: Johns Hopkins Press, 1955.
} 


$$
P_{1}=\beta+b-\frac{a_{2}}{q_{1}}
$$

O nível do ajuste "a" é incerto, podendo atingir o limite quando $P_{1}=P_{2}$. $A$ proposta de Davidson era um processo iterativo em que o ajuste "a" seria feito gradualmente considerando a resposta da demanda até que um equilíbrio fosse encontrado. Não estaria claro no método se o equilíbrio seria nas quantidades demandadas ou nos preços a serem cobrados.

Com uma abordagem diferente, Hirshleifer (1958) critica alguns aspectos da solução de Steiner, como a não separação dos custos de curto e longo prazo e a suposição de que as curvas de demanda $D_{1}$ e $D_{2}$ sejam independentes uma da outra. Entendia que seria mais coerente com a teoria tradicional e com a natureza das alternativas de produção que fosse definida uma função custo marginal de curto prazo. Neste caso, no ponto em que se atinge a capacidade máxima da planta, os custos tornam-se indefinidos, como se pode observar nas curvas SRMCA e SRMCB da Figura 3.7.

Segundo Hirshleifer (1958), Steiner não discutiu explicitamente o problema de curto prazo, pois concentrou sua atenção sobre a aquisição e cobrança de capacidade. A solução correta seria cobrar então os valores $Q_{A} S$ e $Q_{A} P$ que correspondem aos custos de curto prazo em vez dos preços $Q_{B} V$ e $Q_{B} T$ propostos por Steiner.

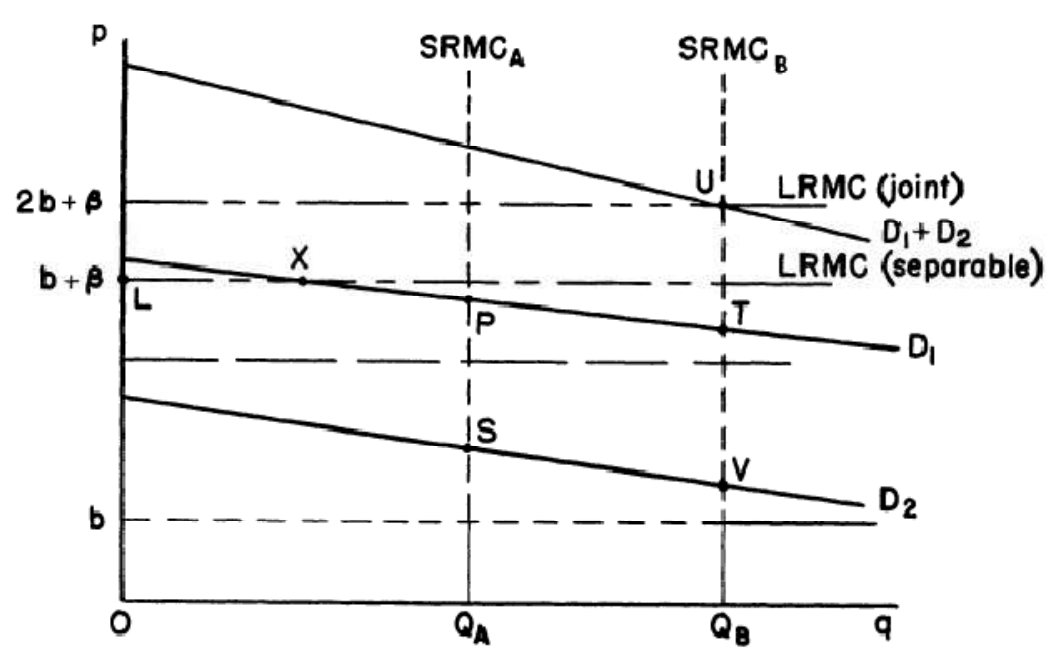

Figura 3.7 - Soluções de curto e longo prazo

Fonte: Hirshleifer (1958) 
Williamson (1966) critica Steiner argumentando que o estudo da precificação das cargas periódicas requer que os custos e as demandas sejam especificados cuidadosamente. Considera que as soluções anteriores tratam de caso específico de dois períodos com igual duração e que a generalização da proposta pode levar a erros.

A proposta de Williamson é considerar todo o ciclo de demanda como a unidade natural para expressar os custos. Para que essa especificação dos custos seja "apropriada", é necessário também que as exigências sejam especificadas em uma maneira consistente.

Em particular, é necessário ponderar a demanda de cada período pela fração do ciclo sobre o qual é responsável. Assim, a demanda é expressa como $D_{i}^{*} w_{i}$, onde i refere-se ao período em questão e $w_{i}$ a fração do ciclo. Cada curva de demanda representa a quantidade de produção por ciclo que seria exigida a cada preço, se a demanda em questão prevalecesse sobre todo o ciclo.

Esse critério permite lidar com períodos de duração diferentes, enquanto nos outros estudos a existência de períodos iguais era explicitamente exigida, sendo a formulação proposta por Williamson mais geral do que aquelas desenvolvidas anteriormente.

A técnica desenvolvida por Williamson combina as curvas de demanda dos diversos períodos de carga para obter uma "demanda efetiva por capacidade". Considerando cada período individualmente e assumindo que a planta opera somente neste período, permanecendo desligada durante o restante do ciclo, o preço cobrado deve ser $b+\beta / w_{i}$. Assim, a receita total será $P_{i}{ }^{*} Q_{i}{ }^{*} w_{i}$, os custos totais serão $b^{*} Q_{i}^{*} w_{i}+\beta^{*} Q_{i}$, e somente se $P_{i}=b+\beta / w_{i}$ o total de receitas será igual ao total de custo.

Com base nestas hipóteses, pode-se construir uma nova curva seguindo os seguintes passos: i) calcula-se diferença entre a curva de demanda e os custos marginais de curto prazo; ii) multiplica-se cada ponto pela fração $w_{i}$; e iii) adiciona-se verticalmente esta curva ponderada de capacidade à curva de custo marginal de curto prazo. Para se obter a curva total de demanda por capacidade é preciso combinar as contribuições das curvas ponderadas de cada período, calculadas de 
acordo com o procedimento descrito anteriormente. A Figura 3.8 demonstra a formação da curva de demanda efetiva $\left(D_{E}\right)$ a partir das curvas de demanda $\left(D_{1}\right.$ e $D_{2}$ ) de dois diferentes os períodos cujas durações correspondem a 1/3 e 2/3 do ciclo, respectivamente.

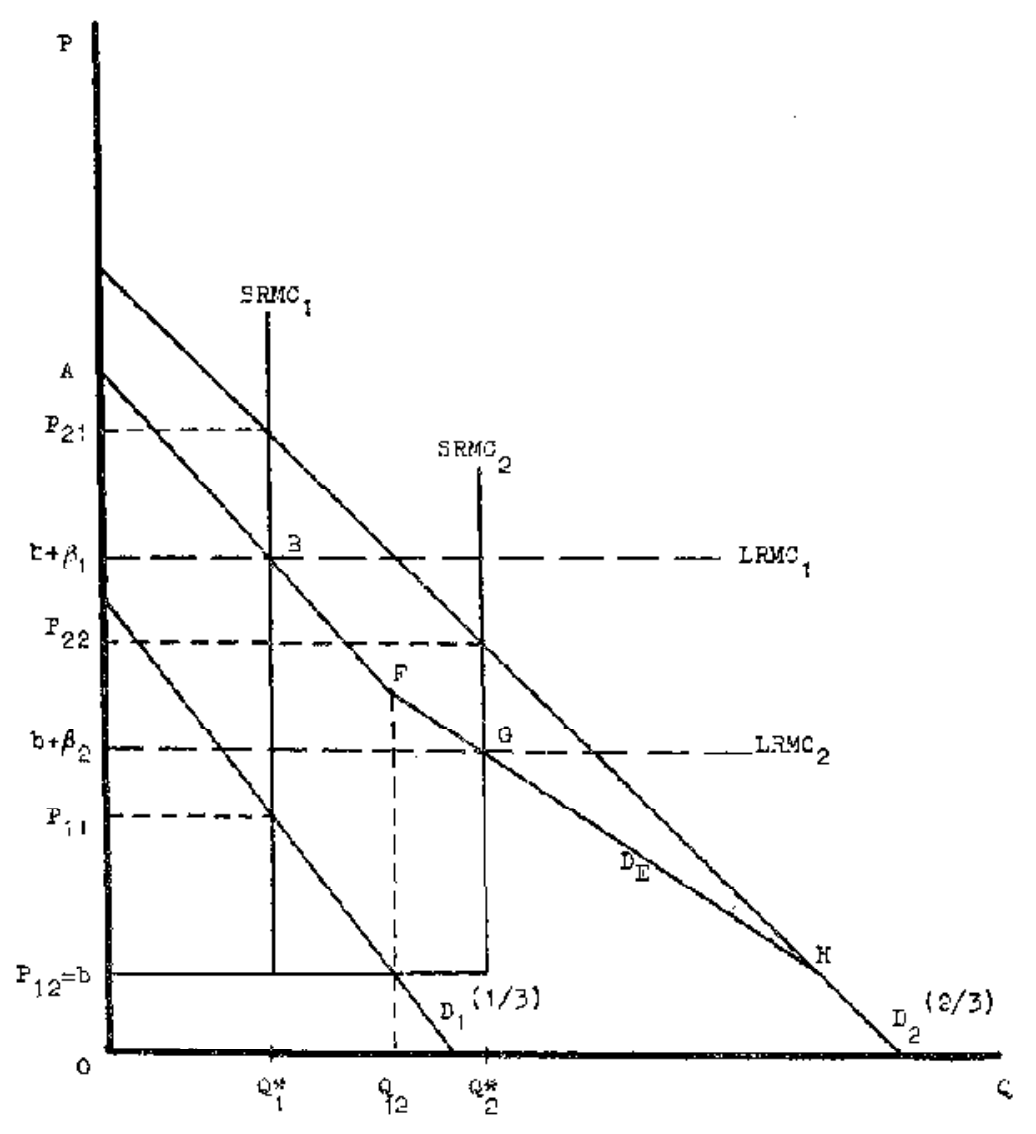

Figura 3.8 - Formação da curva de demanda efetiva $\left(D_{E}\right)$

Fonte: Williamson (1966)

Em resumo, para obter a curva de demanda efetiva por capacidade, Steiner soma verticalmente as demandas em cada período ao invés de utilizar uma média ponderada das demandas como apresentado por Williamson.

\subsubsection{Abordagem britânica}

A abordagem britânica para $\circ$ problema da precificação de ponta, representada pelos estudos de teóricos como Turvey (1968), Crew e Kleindorfer (1971), e Wenders (1976), enfoca a especificação das plantas que estão atendendo 
os diferentes períodos de carga, no contexto de uma tecnologia de produção heterogênea e a utilização ótima das possibilidades técnicas.

Essa vertente também reconhece a necessidade de desligamentos periódicos para manutenção com a conseqüente flutuação na capacidade disponível e impactos na identificação dos custos dos períodos de ponta e fora de ponta, conforme estudo de Joskow (1976).

Turvey (1968) descarta a suposição de capacidade de produção homogênea reconhecendo que a provisão eficiente de uma demanda periódica geralmente implicará um mix de plantas de diversas capacidades com diferentes custos de investimentos e de operação.

Também critica a suposição de que os valores são constantes para os custos marginais de operação e de capacidade como sendo "uma noção muito simples para ser significativa". Observa também que, a curva de custo marginal seria positivamente inclinada para um sistema elétrico constituído de plantas com diferenças em idade, localização e de tecnologia.

Crew e Kleindorfer (1971) também demonstraram que somente o custo marginal de operação não seria suficiente para as decisões de preços quando se pode empregar mais de um tipo de planta para atender à demanda.

Como apresentado por Wenders (1976), o sistema seria atendido pela combinação ótima das diferentes plantas disponíveis, no exemplo da Figura 3.9, para os períodos denominados base, intermediário e ponta. A planta com custo menor de operação e maior de capacidade, como uma hidrelétrica, atenderia a base do sistema enquanto uma planta com características inversas (custos maior de operação e menor de capacidade) iria suprir o período de ponta. 


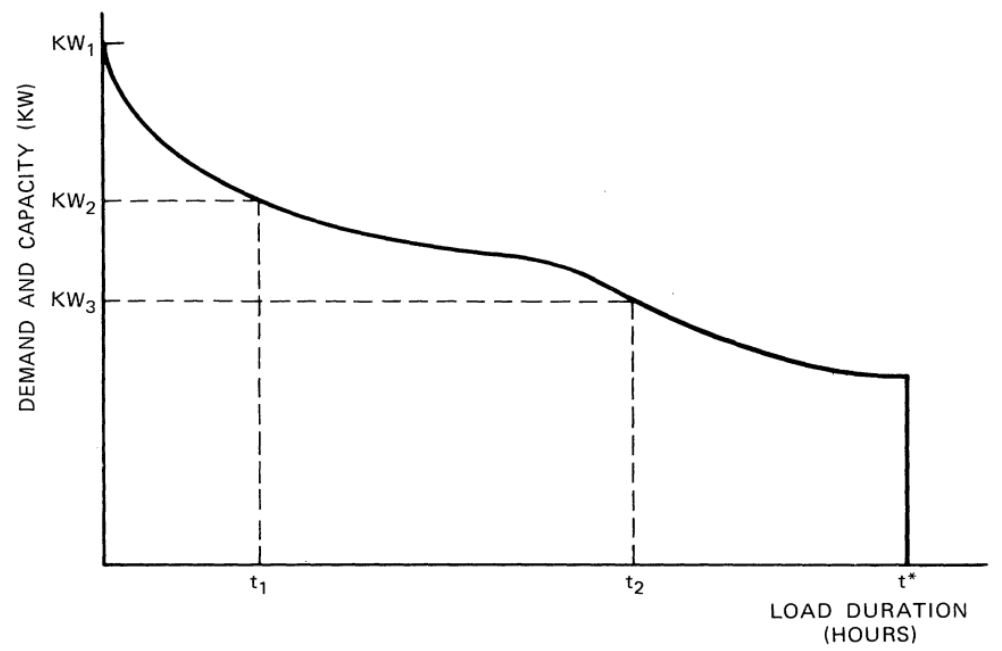

\section{Figura 3.9 - Curva de duração de carga}

Fonte: Wenders (1976)

Dessa forma, para essa vertente teórica, os preços que deveriam ser cobrados nos diversos períodos estão diretamente relacionados com os custos marginais das respectivas plantas que fornecem energia elétrica em cada momento. Wenders (1976) demonstra também que, diferentemente dos resultados tradicionais, os custos de capacidade irão aparecer não somente para o período de ponta como também, sob certas circunstâncias, para os períodos fora de ponta.

Os estudos destes teóricos estão mais relacionados com o lado da oferta do que os trabalhos dos teóricos americanos. De fato, a ênfase é bem menor para os efeitos da elasticidade da demanda e da possibilidade de shifting peak.

\subsubsection{Abordagem francesa}

A França desenvolveu uma metodologia teórica que abrange ambas as vertentes para a precificação de ponta: a americana, que reconhece a elasticidade da demanda e a possibilidade de shifting peaks, e a britânica, que enfatiza explicitamente as possibilidades técnicas da geração de eletricidade, segundo Joskow (1976).

A análise dos problemas das variáveis de preço de ponta foi primeiramente assumida pelos economistas e engenheiros da EDF. O desenvolvimento da teoria está intimamente relacionado com o planejamento de investimentos e com os estudos para definição das tarifas, pois os franceses estavam cientes da relação 
entre a política de preços e a política de investimentos no contexto de uma operação eficiente de uma empresa publica.

A abordagem francesa apresentou alguns avanços que são importantes para a teoria de precificação. O primeiro aspecto é que eles reconheceram e incorporaram o fato de que a demanda por eletricidade não somente é periódica, mas altamente incerta. Isso significa que, às vezes, a demanda excederá a capacidade disponível podendo ocasionar corte de cargas. Essa incerteza associada à demanda e ao suprimento é o que impõe a existência de margem de reserva para sistemas de geração elétrica.

O segundo avanço está relacionado com o anterior: o reconhecimento dos custos de cortes ou de racionamento incorridos devido à incerteza no suprimento. A introdução desses custos tem implicação tanto para 0 planejamento de investimentos como para a definição dos preços.

A terceira proposição, diferentemente das vertentes teóricas anteriores que tratam primariamente da geração de energia elétrica, é a importância direcionada para os sistemas de distribuição e de transmissão cujos investimentos podem atingir $50 \%$ do total dos custos de fornecimento.

Em particular, reconhecem que os custos marginais refletiriam características da carga do sistema. Diferentemente dos sistemas de geração e de transmissão que possuem uma natureza de compartilhamento, no caso da distribuição à medida que se move pela rede até o consumidor final, o sistema se torna cada vez mais individual.

Isto implica que os custos do sistema de distribuição dependem mais de características individuais ou das características da demanda de determinados grupos de clientes que não necessariamente podem ser coincidentes com os padrões de demanda do sistema. Esta situação é diferente da causalidade de custo para os componentes do sistema "comum", constituído pelas usinas e sistema de transporte de grandes blocos de carga, e implica preços de ponta com base mais nítida nas características individuais das cargas do sistema. 
Em resumo, as contribuições indicam que a aplicação dos princípios de precificação a custos marginais para o cálculo real de preços é consideravelmente mais complicada do que as prescrições baseadas em modelos simples possam indicar, de acordo com Joskow (1976).

Aspectos relacionados como a elasticidade da demanda, incertezas, custos de racionamento, tecnologia heterogênea e outras complicações de um sistema real de suprimento podem ajudar a estender os princípios básicos de precificação para refletir mais adequadamente a realidade.

\subsection{Métodos para cálculo dos custos marginais de expansão no setor elétrico}

No setor elétrico são utilizados, basicamente, dois métodos para cálculo dos custos marginais de expansão: a Lei de Quantidade de Obras (LQO) e o Custo Incremental Médio de Longo Prazo (CIMLP). O primeiro está baseado em investimentos realizados para atender o crescimento de mercado e pressupõe que a tendência do passado se repetirá no futuro. O segundo, utiliza a previsão de uma série de investimentos relacionados com a expectativa de crescimento de mercado dentro de um horizonte de planejamento.

\subsubsection{Lei de Quantidade de Obras (LQO)}

A Lei de Quantidade de Obras (LQO) está baseada em funções que correlacionam os valores históricos de investimentos com o crescimento de mercado. Os investimentos podem ser agregados como extensão de rede, quantidade de postos de transformação, potência dos transformadores; e o mercado, por sua vez, pode ser mensurado em termos de potência (MVA) ou em energia (MWh).

Originalmente, contudo, as equações deduzidas por Juricic $^{3}$ (1971, apud DNAEE, 1985) estimavam o volume mínimo de condutores de uma rede de distribuição radial para o atendimento de uma área circular por meio de circuitos com

\footnotetext{
3 JURICI, R. Lois Theoriques des Quantités DÓuvrages Dans Le Réseaux Électriques. Revue generale de l'electricité, tomo 80, no 4, Abril de 1971.
} 
densidade de carga homogênea e com transformador instalado no seu centro, dada uma restrição de queda de tensão máxima (ANTUNES, A.U., 2004). Este método é denominado de "cross-section" ou de "cortes instantâneos" sobre as redes, constituindo então a aplicação direta das Leis de Juricic, conforme DNAEE (1985).

A metodologia empregada no Brasil, proposta pela Eletrobrás/DNAEE, substituiu a abordagem de evolução das obras desagregadas em áreas elementares por outra que contempla o desenvolvimento das obras, no tempo, de modo agregado considerando, em geral, toda a área da concessionária. De acordo com Antunes, A.U. (2004), esta sistemática é conhecida por "Modelo das Séries Temporais".

Assim, a partir do modelo original de Juricic, é possível deduzir as novas LQO's segundo o método das séries temporais, que podem ser descritas da seguinte forma, conforme DNAEE (1985):

$$
X(t)=K^{*}[P(t)]^{\alpha}
$$

Onde:

$\mathrm{X}(\mathrm{t})$ é a quantidade física das obras;

Ké o coeficiente angular dimensional;

$P(t)$ é o consumo do nível de tensão em estudo;

a é o coeficiente de rendimento de escala.

No processo de definição dos coeficientes da LQO pode ser utilizado um artifício matemático, transformando as equações exponenciais em retas por meio da propriedade dos logaritmos. Aplicando-se o método dos mínimos quadrados aos históricos das obras e dos consumos no nível de tensão em estudo, é possível identificar os estimadores das variáveis $\mathrm{K}$ e a, se o número de anos da série for suficiente, conforme DNAEE (1985).

$$
\log X(t)=\log K+\alpha \log P(t)
$$

Determinada a função LQO para cada tipo de agregado de obra, pode-se, então, calcular o custo médio de desenvolvimento anual, também denominado de custo marginal de expansão, que é o produto da derivada da LQO pelo custo unitário 
anualizado do referido agregado, conforme ANEEL (2001).

A derivada da LQO de um determinado agregado, que corresponde à quantidade de obras marginais, pode ser assim calculada:

$$
\frac{\partial X(t)}{\partial P(t)}=\alpha^{*} K^{*}[P(t)]^{(\alpha-1)}=\frac{\alpha^{*} K^{*}[P(t)]^{\alpha}}{P(t)}
$$

Substituindo 3.7 em 3.9, obtém-se:

$$
\frac{\partial X(t)}{\partial P(t)}=\frac{\alpha^{*} X(t)}{P(t)}
$$

O custo anualizado pode ser calculado, segundo DNAEE (1985), pela aplicação de um Fator $A$, que corresponde à soma das taxas de remuneração, da depreciação econômica e de operação e manutenção sobre o custo unitário médio do agregado $\left(I_{j}\right)$. Isto porque todos os gastos futuros com substituições e custos de operação e manutenção, bem como remuneração do investimento devem ser recuperados, uma vez que o benefício que se presta à comunidade deve ser perene (DNAEE, 1985).

$$
A=t m a+t d+t o p
$$

Onde,

A é a despesa anual em determinado tipo de investimento;

tma é a taxa mínima de atratividade (remuneração);

td é a taxa de depreciação econômica;

top é o custo de operação e manutenção (em percentual do investimento).

Segundo Antunes, A.U. (2004), outra maneira de se transformar o investimento total em base anual é o Método Sinking Fund ${ }^{4}$ que calcula, por meio do

\footnotetext{
${ }^{4}$ Diferentemente do sistema de amortização constante (SAC), o devedor pode constituir um fundo de amortização do empréstimo (sinking fund), no qual deposita periodicamente as quotas de amortização. Essas quotas devem render juros de tal modo que, na data de pagamento do principal, o saldo desse fundo de amortização seja igual ao capital a pagar, liquidando, dessa maneira, o empréstimo. No método SAC a amortização constante e a remuneração aplicada sobre o saldo descontado da depreciação resultam uma parcela total decrescente ao longo do período; já no
} 
Fator de Recuperação de Capital (FRC), o valor de uma série de custos anuais a partir do valor presente do total do investimento, dados o período de vida útil das instalações e a taxa de remuneração.

$$
F R C=\frac{t m a *(1+t m a)^{n}}{(1+t m a)^{n}-1}
$$

Onde:

n é a vida útil das obras, dada em anos.

Neste valor anual estão incluídas tanto a remuneração do investimento como a sua depreciação econômica no período aplicada a mesma taxa de remuneração. Para completar a formulação do Fator A é necessário incluir os custos de operação e manutenção, como visto a seguir.

$$
A=F R C+t o p
$$

O custo marginal de um agregado de obra é obtido então multiplicando a derivada da LQO de um determinado agregado pelo seu custo unitário anualizado:

$$
C m g X(t)=\frac{\partial C[X(t)]}{\partial P(t)}=A * I_{j} * \frac{\partial X(t)}{\partial P(t)}=A^{*} I_{j} * \alpha \frac{X(t)}{P(t)}
$$

Por meio dessas formulações é possível, então, calcular o custo marginal de cada agregado de obra. O custo marginal de expansão dos sistemas de distribuição corresponde, então, ao somatório dos custos marginais de cada agregado de obra necessário para o atendimento ao acréscimo de carga do nível de tensão em estudo (ANTUNES, A.U., 2004). Por exemplo, o custo marginal na baixa tensão é o somatório dos custos marginas dos agregados: linhas de baixa tensão, quantidade de postos de transformação e potência dos transformadores.

\subsubsection{Custo Incremental Médio de Longo Prazo (CIMLP)}

No setor elétrico, principalmente nos setores de transmissão e geração, as obras de expansão, em geral, não são divisíveis na proporção necessária para 
atender exatamente ao crescimento da demanda em determinado período.

Nesta situação, nos períodos em que a capacidade do sistema é superior à demanda, o custo marginal é menor em comparação ao instante em que surge um déficit de energia, no qual os custos aumentam rapidamente, podendo atingir um pico por causa do acréscimo "instantâneo" de investimento (DNAEE, 1985).

A metodologia do Custo Incremental Médio de Longo Prazo (CIMLP) foi concebida para lidar com as descontinuidades presentes no processo de expansão, "permitindo a determinação de um valor estável para o custo marginal de longo prazo durante o período de planejamento" (ANTUNES, A.U., 2004).

O CIMLP é uma média dos custos incrementais anuais, ponderada pelo incremento de potência ao longo do tempo, de maneira que as variações dos custos anuais sejam atenuadas.

O custo incremental em determinado ano $\mathrm{i}\left(\Delta \mathrm{C}_{\mathrm{i}}\right)$ pode ser calculado pela relação entre o incremento de investimento $\left(\Delta \mathrm{l}_{\mathrm{i}}\right)$ e a variação da demanda $\left(\Delta \mathrm{D}_{\mathrm{i}}\right)$.

$$
\Delta C_{i}=\frac{\Delta I_{i}}{\Delta D_{i}}
$$

Em outras palavras, o incremento de investimento é igual ao custo incremental multiplicado pela demanda incremental.

$$
\Delta I_{i}=\Delta C_{i} * \Delta D_{i}
$$

Sendo $\mathrm{P}$ o preço praticado pela distribuidora, tem-se que a receita incremental $\left(\mathrm{R}_{\mathrm{i}}\right)$ em determinado ano é:

$$
\Delta R_{i}=P_{i}^{*} \Delta D_{i}
$$

Por sua vez, a soma das receitas incrementais deve ser capaz de cobrir os custos totais dos investimentos durante o período de estudo, considerando uma taxa de retorno a e um período de vida útil das instalações (ANTUNES, A.U., 2004). 


$$
\begin{array}{r}
V P\left(R_{i}\right)=V P\left(I_{i}\right)=V P(C i) \\
\sum_{i=1}^{n} \frac{P_{i}^{*} D_{i}}{(1+a)^{(i-1)}}=\sum_{i=1}^{n} \frac{I_{i}}{(1+a)^{(i-1)}}=\sum_{i=1}^{n} \frac{C_{i} * D_{i}}{(1+a)^{(i-1)}}
\end{array}
$$

Para manter a estabilidade tarifária, o preço $\mathrm{P}$ deve ser constante durante todo o horizonte do estudo, podendo-se concluir que:

$$
P * \sum_{i=1}^{n} \frac{D_{i}}{(1+a)^{(i-1)}}=\sum_{i=1}^{n} \frac{I_{i}}{(1+a)^{(i-1)}}
$$

Sendo calculado a partir dos investimentos e demandas incrementais, este custo pode ser interpretado, então, como Custo Incremental Médio de Longo Prazo:

$$
C I M L P=P=\frac{\sum_{i=1}^{n} \frac{I_{i}}{(1+a)^{i-1}}}{\sum_{i=1}^{n} \frac{D_{i}}{(1+a)^{i-1}}}
$$

De acordo com Antunes, A.U. (2004), a partir deste custo incremental médio, é calculado o custo marginal de expansão aplicando o mesmo fator $A$, discutido no item anterior, referente às Leis de Quantidade de Obras. Para atender o princípio da economia de eficiência alocativa, o preço $\mathrm{P}$ pode ser considerado uma proxy para 0 custo marginal. Como visto, o processo de anualização dos investimentos pode ser feito pelo Método Sinking Fund, que consiste na aplicação do Fator de Recuperação do Capital, ou pelo Método de Amortização Linear, que se fundamenta na aplicação de uma somatória de taxas de remuneração, depreciação econômica e operação e manutenção.

$$
C m g=A * C I M L P=A * \frac{\sum_{i=1}^{n} \frac{I_{i}}{(1+a)^{i-1}}}{\sum_{i=1}^{n} \frac{D_{i}}{(1+a)^{i-1}}}
$$

Outras fontes, no caso do DNAEE (1985) e da ANEEL (2001), denominam como CIMLP, os investimentos já anualizados pelo método de amortização linear como será discutido no capitulo que analisa a metodologia empregada atualmente. 


\subsection{Considerações}

Neste capítulo foram apresentados os princípios da regulação econômica, em especial as teorias de precificação de ponta e a aplicação dos custos marginais no setor elétrico.

Constatou-se que a abordagem francesa dessa teoria, base da metodologia atual, procura englobar as perspectivas das vertentes americana e britânica, que estão mais relacionadas com as óticas da demanda e da oferta, respectivamente, além de inserir o tratamento dos custos de transporte que podem representar quase a metade dos custos de fornecimento de energia elétrica.

A grande diferença entre a abordagem americana e a britânica era a suposição de que, no primeiro caso, plantas homogêneas atenderiam a demanda, enquanto que, no segundo caso, usinas com custos variáveis menores atenderiam em todo o período (na base) e as usinas com custo maiores iriam gerar somente no horário de ponta.

É importante lembrar que essas teorias tratavam do fornecimento de energia elétrica como um todo, principalmente o aspecto relacionado à geração de energia. Atualmente, a discussão da aplicação desse conceito de homogeneidade das plantas e, em conseqüência, dos seus custos, permeia o setor de distribuição de energia elétrica. 


\section{CAPÍTULO 4 - METODOLOGIA ATUAL DE CÁLCULO}

Atualmente, conforme a Resolução Normativa no 166/2005, a tarifa de uso do sistema de distribuição é composta pelas seguintes componentes: TUSD - Fio A, TUSD - Fio B, TUSD - Encargos do Serviço de Distribuição, TUSD - Perdas Técnicas, TUSD - Perdas Não Técnicas; TUSD - CCC, TUSD - CDE e TUSD Proinfa.

Como visto anteriormente, a receita requerida da distribuidora é constituída pelas denominadas Parcela $A$, que engloba os custos de compra de energia, transporte, encargos e tributos, e Parcela $B$, que envolve todos os custos necessários para a entrega da energia pela empresa, inclusive a remuneração dos seus ativos.

Embora as denominações das componentes da tarifa de distribuição, TUSD Parcela A e TUSD - Parcela $B$, estejam relacionadas com os itens que constituem a receita da distribuidora, a primeira, TUSD - Fio A, está associada somente aos custos decorrentes da utilização do sistema de transmissão pela distribuidora ${ }^{1}$ e não a totalidade da Parcela A. Os demais custos desta parcela da receita são recuperados pelos outros elementos da TUSD (perdas, encargos do serviço de distribuição, CCC, CDE e Proinfa) e pela Tarifa de Energia (TE).

Por outro lado, a TUSD - Parcela B é formada integralmente pelos custos gerenciáveis da empresa, calculados no processo de revisão tarifária: remuneração dos ativos, quota de reintegração regulatória decorrente da depreciação e custos da empresa de referência.

Em termos de participação, somente $30 \%$ do valor da fatura de energia elétrica, correspondente a Parcela $\mathrm{B}$, permanece com a distribuidora para a cobertura dos seus custos de operação e remuneração dos investimentos, como demonstrado na Figura 4.1. As demais componentes da Parcela A (compra de

\footnotetext{
${ }^{1}$ A TUSD - Fio A é composta pelos seguintes itens:

i) custo relativo ao pagamento da TUSTRB;

ii) custo relativo ao pagamento da TUSTFR;

iii) custo com a conexão às instalações da Rede Básica;

iv) custo com o uso da rede de distribuição de outras concessionárias; e

v) perdas elétricas na Rede Básica, referentes ao montante de perdas técnicas e não técnicas.
} 
energia, transporte, encargos) são recolhidas pela distribuidora e repassados para demais agentes, de geração e de transmissão, para os fundos setoriais e para os governos estaduais e federal.

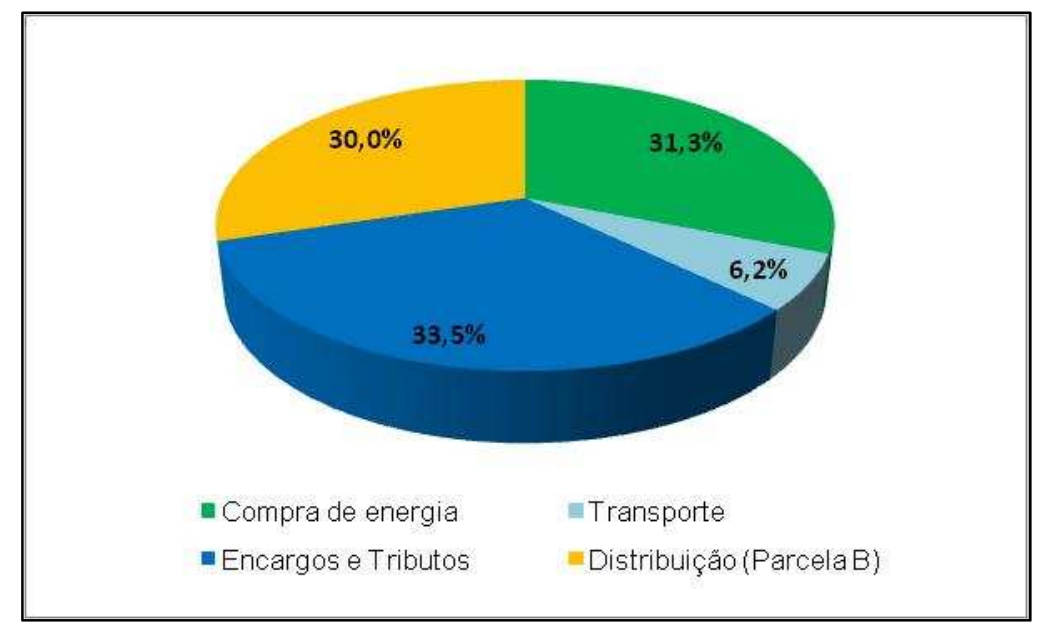

Figura 4.1 - Componentes da fatura de energia elétrica (média Brasil/2007)

Fonte: ANEEL (2008).

Do ponto de vista do critério de alocação, a TUSD - Fio A possui valores idênticos (em $R \$ / k W$ ) para todas as faixas de tensão, aplicáveis às demandas máximas de potência ativa nos postos tarifários de ponta e fora de ponta ${ }^{2}$. Como visto, esse método é conhecido como "selo" uma vez que a tarifa aplicada é a mesma independentemente do tipo e localização do consumidor.

De forma similar, as TUSD - CCC, TUSD - CDE e TUSD - Proinfa possuem valores idênticos ("selo" em $R \$ / M W h$ ) aplicadas ao consumo de energia elétrica dos consumidores, sejam eles classificados como cativos ou livres ${ }^{3}$. Já a TUSD - Perdas não técnicas é cobrada do consumidor em duas parcelas "selo", uma aplicada às demandas máximas de potência ativa nos horários de ponta e fora de ponta e outra aplicada ao consumo de energia elétrica.

\footnotetext{
${ }^{2}$ Os custos referentes aos pagamentos da TUST Rede Básica e TUST Fronteira contribuem somente para a formação da tarifa do horário de ponta, pois a distribuidora paga pelo custo do sistema de transmissão neste posto tarifário.

${ }^{3}$ Essas componentes são aplicadas sobre a parcela de consumo que excede o eventual atendimento feito por empreendimento próprio. Adicionalmente, a TUSD - Proinfa não é aplicável ao consumidor classificado como baixa renda com consumo mensal igual ou inferior a $80 \mathrm{kWh}$.
} 
Por outro lado, as componentes TUSD - Fio B, TUSD - Encargos do sistema de distribuição (exceto os custos do ONS) ${ }^{4}$ e TUSD - Perdas Técnicas são determinadas por faixa de tensão, com base na metodologia que calcula os custos marginais de capacidade dos consumidores. Esse critério de alocação de custos utiliza a metodologia criada em meados da década de 1980, base das tarifas de fornecimento existentes antes da sua segregação em tarifas de uso do sistema de distribuição e em tarifas de energia.

A Figura 4.2 apresenta as componentes da TUSD e os respectivos critérios de rateio de custos. Na primeira coluna são apresentadas as componentes da receita requerida agregadas inicialmente em dois grandes blocos: Parcela $\mathrm{A}$ e Parcela B. Na segunda coluna, as componentes são apresentadas segundo a composição das tarifa de energia (TE) ou tarifa de uso (TUSD). Finalmente, a terceira coluna relaciona as componentes das tarifas com os respectivos critérios de alocação: selo em energia, selo em potência, proporcional à receita e proporcional ao custo marginal de capacidade dos consumidores.

\footnotetext{
${ }^{4}$ Os custos da distribuidora com o ONS são alocados na tarifa na forma de selo em $\mathrm{R} \$ / \mathrm{kW}$.
} 


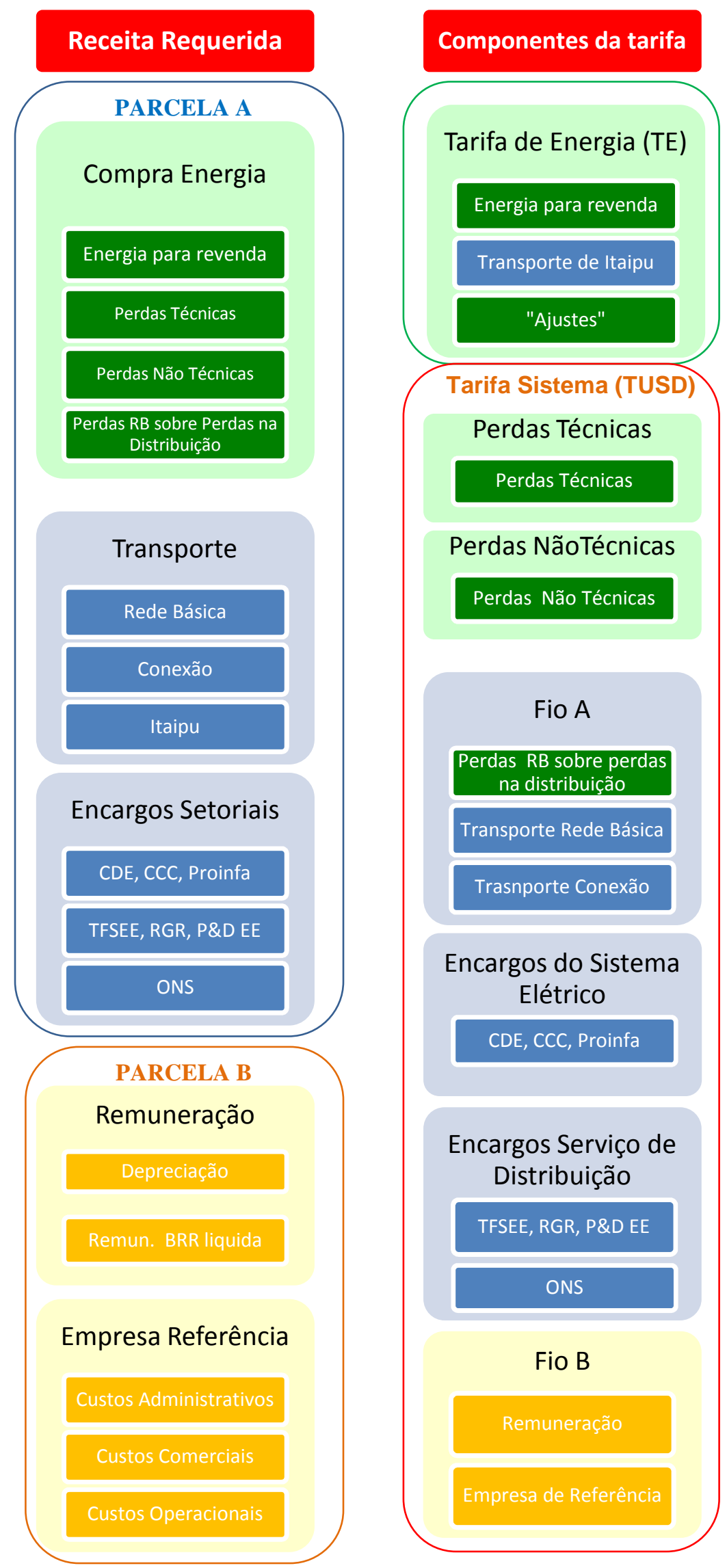

Critério de alocação

Tarifa de Energia (TE)

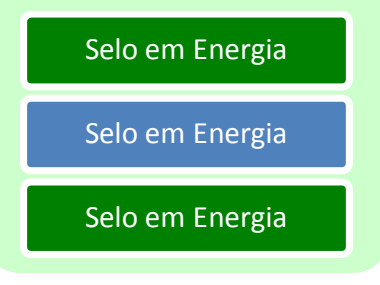

Perdas Técnicas

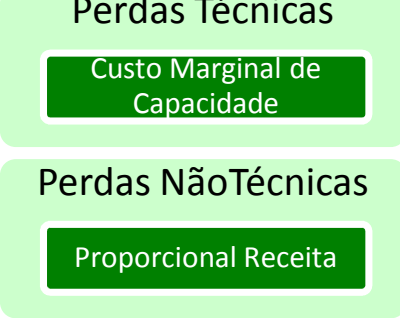

Fio A

Selo em Potência

Selo em Potência (ponta)

Selo em Potência
Encargos do Sistema Elétrico

Selo em Energia

\section{Encargos Serviço de Distribuição

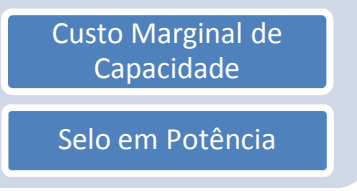

Fio B

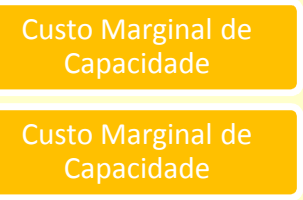


Em resumo, uma parte da TUSD é alocada igualmente entre os consumidores conectados em diferentes níveis de tensão e, outra, proporcionalmente aos custos para atender cada nível tarifário. A metodologia empregada no segundo caso, objeto de estudo deste capítulo, utiliza, como dados de entrada: i) os custos marginais de expansão de cada nível de tensão; ii) o diagrama simplificado do fluxo de potência na condição de carga máxima; e iii) as curvas de carga dos consumidores e das redes que caracterizam o sistema de distribuição de energia elétrica da empresa.

A Figura 4.3 representa esquematicamente a metodologia original empregada no cálculo das tarifas de fornecimento, anteriores ao novo modelo, que considerava todo o custo da cadeia da indústria de energia elétrica, desde a geração até a comercialização.

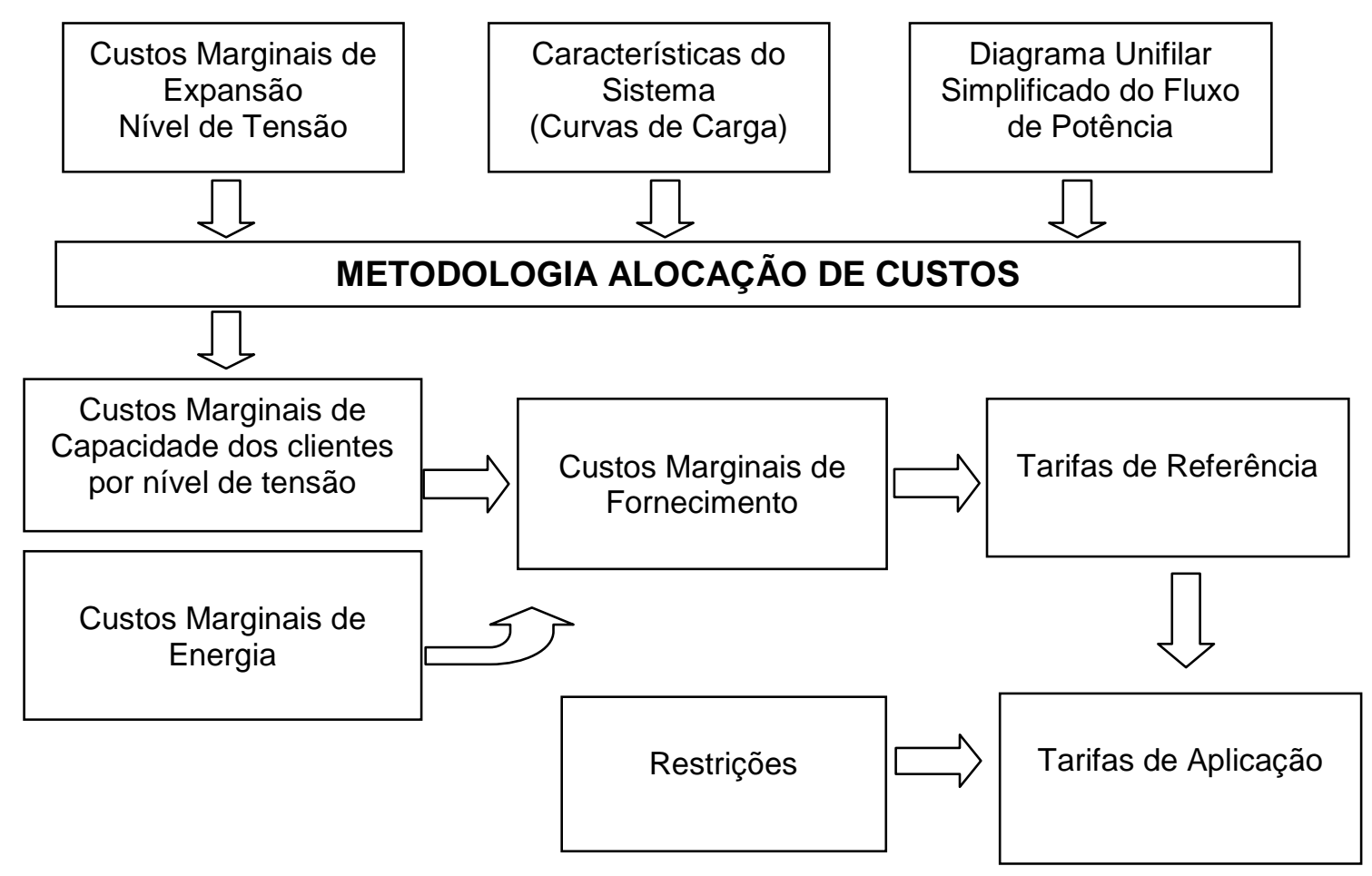

Figura 4.3 - Metodologia de cálculo das tarifas de fornecimento

Fonte: Adaptado de DNAEE (1985).

Os custos marginais de geração de energia elétrica, bem como os associados ao sistema de transmissão integravam a metodologia contribuindo com a sinalização de custos nos horários de ponta e fora de do sistema. 
$\mathrm{Na}$ atual metodologia, esses custos marginais de produção de energia não são utilizados diretamente. Porém, como será discutido posteriormente, os sinais "exógenos" de relação entre tarifas de ponta e fora de ponta e de relação entre períodos seco e úmido, utilizados pela ANEEL, mantém uma relatividade existente na condição anterior na qual as tarifas eram calculadas com base em toda a cadeia de custos.

O método idealizado pela EDF busca identificar o custo marginal para atendimento de determinado consumidor, ou seja, mensurar o impacto de fornecer 1 kW a mais. A conseqüência desse atendimento tem dois aspectos que são considerados na metodologia: o físico e o horário.

No primeiro, a disponibilidade de $1 \mathrm{~kW}$ no sistema, em determinado nível de tensão, tem reflexos no sistema elétrico a montante desse ponto de conexão. Estes reflexos dependem do fluxo de potência e das perdas elétricas.

No segundo aspecto, o custo desse atendimento depende dos horários de maior carregamento das redes que atendem o consumidor. É intuitiva a noção de que um incremento de demanda de potência em horário em que a rede está com menor carregamento poderia ser atendido sem a necessidade de expansão desse sistema. Ao contrário, o atendimento no horário em que a rede está com o maior carregamento é o que determinaria a necessidade de investimentos no sistema de distribuição de energia elétrica, em tese.

Nessa metodologia, então, os custos de expansão são alocados nos horários de maior carregamento das redes nas quais o consumidor está conectado. Em síntese, o custo de capacidade de um determinado consumidor tem como núcleo a responsabilidade desse cliente na formação da máxima demanda de potência ativa do sistema de distribuição que o atende.

A fórmula a seguir, adaptada de Bitu e Born (2000) e Pessanha et al. (2001), apresenta matematicamente o critério utilizado atualmente nos cálculos dos custos de capacidade utilizados para a proporcionalização de parte dos custos das tarifas de uso do sistema de distribuição. 


$$
C M C_{j u}=\sum_{l=l_{0}}^{138 k V} C M L P^{l} * \varnothing\left(l, l_{0}\right) * R_{j u}^{l}
$$

Onde:

$C M C_{j u}$ - custo marginal de capacidade no posto tarifário $u$ de um cliente-tipo $j$ conectado no nível $l$;

$C M L P^{l}$ - custo marginal de longo prazo (custo de expansão) do nível de tensão $l$;

$\emptyset\left(l, l_{0}\right)$ - fator de proporção de fluxo que indica a parcela de utilização do nível de tensão e no atendimento do cliente-tipo $j$ conectado no nível $l_{0}$;

$R_{j u}^{l}$ - responsabilidade de potência do cliente $j$ no posto tarifário $u$ na formação das demandas máximas das redes-tipo que formam o nível de tensão $I$.

As seções seguintes detalham as parcelas que compõem a atual metodologia de cálculo da tarifa de energia: custos marginais, fluxo de potência, caracterização da carga e responsabilidade do consumidor.

Para isso, é importante estudar também, em paralelo, a sistemática de cálculo das tarifas de fornecimento definida por DNAEE (1985), conhecido no setor como "Livro Verde", pois, embora ambas as metodologias utilizem as mesmas componentes, determinados custos não são mais alocados da mesma forma em decorrência da desverticalização da indústria de energia elétrica, como já comentado.

\subsection{Custo marginal por nível de tensão na antiga estrutura tarifária}

Embora o custo marginal de produção não seja utilizado na atual metodologia, é interessante apresentar brevemente a sistemática utilizada no passado, pois os fatores exógenos utilizados atualmente pela ANEEL, que foram calculados sob uma estrutura verticalizada de custos, resultam a sinalização de horários de ponta e fora de ponta, de períodos úmido e seco. 


\subsubsection{Custo marginal de geração na antiga estrutura tarifária}

Como visto, no setor elétrico são utilizados dois métodos como aproximações para o cálculo do custo marginal: a Lei de Quantidade de Obras - LQO e o Custo Incremental Médio de Longo Prazo (CIMLP). No caso dos custos marginais da geração era utilizado, basicamente, o método do CIMLP, sendo os custos obtidos a partir do programa de expansão e de avaliações energéticas ${ }^{5}$.

Conforme MME (1994), em razão da forte predominância de usinas hidrelétricas no sistema brasileiro, caracterizadas por fatores de capacidade baixos comparativamente com unidades termelétricas, as necessidades de expansão resultam "do crescimento do requisito de energia, ao contrário do que ocorre em termos mundiais, onde os requisitos de potência condicionam a expansão".

Esta situação conduziu a uma metodologia de cálculo de custos marginais centrada no atendimento ao requisito de energia. No cálculo eram, então, considerados: i) custos dos investimentos; ii) variação do custo anual de operação e manutenção; iii) variação do custo anual de combustível; iv) variação do custo anual das perdas elétricas e iv) variação anual do custo de déficit. $\mathrm{Na}$ estimativa da variação do mercado, ao invés do seu incremento anual, era utilizada a capacidade de atendimento do sistema expandido, o que mitigava a característica de indivisibilidade dos investimentos (DNAEE, 1985, p. 139).

Após a obtenção do CIMLP, era necessária a sua segregação em custos associados à potência e à energia, pois os custos do plano de expansão não estavam identificados por esse critério. A separação era estimada por meio da identificação da melhor alternativa de geração de energia elétrica no horário de ponta do sistema. Essa escolha poderia ser uma usina termelétrica a gás, uma usina reversível ou a motorização de aproveitamentos já existentes, segundo DNAEE (1985).

\footnotetext{
${ }^{5}$ Modelos matemáticos que simulam as condições de evolução e uso vigentes em um sistema de potência de energia elétrica real (DNAEE, 1985, p.130).
} 
Por meio de avaliações energéticas também eram identificados os preços horários para a produção de energia, pois o custo para atender a carga ao longo do dia se altera em função de uma série de razões: "variações no consumo específico das unidades marginais, modificação das próprias unidades marginais, variação da queda líquida das usinas, devido à elevação do canal de fuga e/ou redução do nível dos reservatórios de regularização do consumo..." (DNAEE, 1985, p. 134).

O cálculo dos custos horários considerava, no caso de energia, a relação entre o custo marginal de operação em cada posto horo-sazonal e o custo marginal de operação do período. Para a potência, a desagregação era feita de acordo com a relação entre a probabilidade déficit de potência no posto horo-sazonal e a probabilidade de déficit de potência em todo o período (MME, 1994).

Além disso, era estimada a sazonalidade dos custos marginais de produção, pois, sendo o sistema de geração predominantemente hidráulico, esses custos variam de acordo com as variações da oferta e dos estoques de água.

A Tabela 4.1 apresenta os custos marginais de produção calculados pelo DNAEE (1985) e atualizados pelo índice de preços ao consumidor americano (Consumer Price Index - CPI-U) ${ }^{6}$ e pela taxa de câmbio de abril de $2010^{7}$.

Tabela 4.1 - Resumo dos Custos Marginais de Produção

\begin{tabular}{crrr}
\hline CUSTOS (R\$/MWh) & \multicolumn{1}{c}{ S-SE-CO } & \multicolumn{1}{c}{ N-NE } \\
\hline \multicolumn{2}{c}{ CIMLP (total) } & 119,94 & 87,70 \\
\hline \multicolumn{2}{c}{ Componente Potência (R\$/kW.mês) } & 12,79 & 13,37 \\
Componente Energia & 75,83 & 63,63 \\
\hline Energia & Ponta & 78,29 & 62,10 \\
Período Úmido & Fora de Ponta & 70,87 & 52,27 \\
\hline Energia & Ponta & 86,36 & 83,06 \\
Período Seco & Fora de Ponta & 78,15 & 69,94 \\
\hline
\end{tabular}

Fonte: DNAEE (1985).

Observa-se nos dados apresentados na tabela anterior que a relatividade entre custos de ponta e fora de ponta, era de $110,5 \%$ e $118,8 \%$ para os sistemas S-

\footnotetext{
${ }^{6} \mathrm{http}: / /$ inflationdata.com/Inflation/Inflation_Calculators/Inflation_Rate_Calculator.asp\#calcresults

${ }^{7}$ http://www4.bcb.gov.br/pec/conversao/Resultado.asp?idpai=convmoeda
} 
SE-CO e N-NE, respectivamente. Da mesma forma, as relatividades encontradas para os períodos seco e úmido, foram de $110,3 \%$ e $133,8 \%$ para os sistemas S-SE$\mathrm{CO}$ e N-NE, respectivamente.

\subsubsection{Custo marginal de transporte na antiga estrutura tarifária}

O sistema de transporte de energia elétrica, na antiga estrutura, era segregado em três partes: i) Interconexão e Transporte Pesado; ii) Repartição; e iii) Distribuição. Na Interconexão, eram classificadas as instalações que operavam em tensão igual ou superior a $345 \mathrm{kV}$. No caso de subestação rebaixadora, era considerada a tensão do secundário do transformador como critério de classificação. As instalações que operavam em tensão entre $230 \mathrm{kV}$ e $44 \mathrm{kV}$ integravam a Repartição e aquelas em tensão inferior ou igual a $34,5 \mathrm{kV}$, a Distribuição, respeitando o critério de tensão do secundário das subestações (DNAEE, 1985, p. 163). O Quadro 4.1 resume essas informações relacionando-as com os grupamentos tarifários.

\begin{tabular}{c|c|c|c}
\hline $\begin{array}{c}\text { Nível } \\
\text { Funcional }\end{array}$ & $\begin{array}{c}\text { Grupamentos } \\
\text { Tarifários }\end{array}$ & $\begin{array}{c}\text { Níveis de tensão } \\
\text { Normalizados (kV) }\end{array}$ & $\begin{array}{c}\text { Níveis de Tensão } \\
\text { Existentes (kV) }\end{array}$ \\
\hline $\begin{array}{c}\text { Inteconexão } \\
\text { e }\end{array}$ & A0 & 750 & 750 \\
$\begin{array}{c}\text { Transporte } \\
\text { Pesado }\end{array}$ & & 500 & 500 \\
& A1 & 230 & 440 \\
\cline { 2 - 4 } Repartição & A2 & 138 & 345 \\
\cline { 2 - 4 } & A3 & 69 & 230 \\
\hline & A4 & 34,5 & 88 \\
\hline \multirow{4}{*}{ Distribuição } & B1 & & 69 \\
& B2 & $220 / 380 \mathrm{~V}$ & $44,513,82,3$ \\
& B3 & $127 / 220 \mathrm{~V}$ & 2511,7 \\
\hline & B4 & & $127 / 220 \mathrm{~V}$ \\
& & & $115 / 230 \mathrm{~V}$ \\
\hline
\end{tabular}

\section{Quadro 4.1 - Classificação das instalações de transporte na antiga estrutura}

Fonte: Adaptado de DNAEE (1985).

No segmento Interconexão e Transporte Pesado, o custo marginal era estimado pelo método do CIMLP devido à disponibilidade de dados planejamento a médio e longo prazo (DNAEE, 1985), uma vez que a falta de informações do 
histórico de obras e as descontinuidades de investimentos inviabilizavam o método LQO.

O CIMLP desse nível de tensão era calculado em termos de custo de potência e de energia pois, ao interligar as usinas aos grandes centros regionais de consumo, essa malha teria "característica de escoar não somente demanda mas também energia" (DNAEE, 1985, p. 171).

Essa divisão considerava uma curva anual de duração e a máxima capacidade do sistema. O custo de potência correspondia a um fator que considerava a demanda máxima de 3 horas $\left(P_{p}\right)$ e o dimensionamento do sistema $\left(P_{\text {máx }}\right)$. Significava, então, que o custo de potência era responsável pela diferença entre a capacidade do sistema e a demanda máxima de 3 horas. O restante do CIMLP era alocado ao custo de energia: no horário de ponta, o custo para atender a demanda máxima de 3 horas; e no horário fora de ponta, a demanda média $\left(P_{m}\right)$.

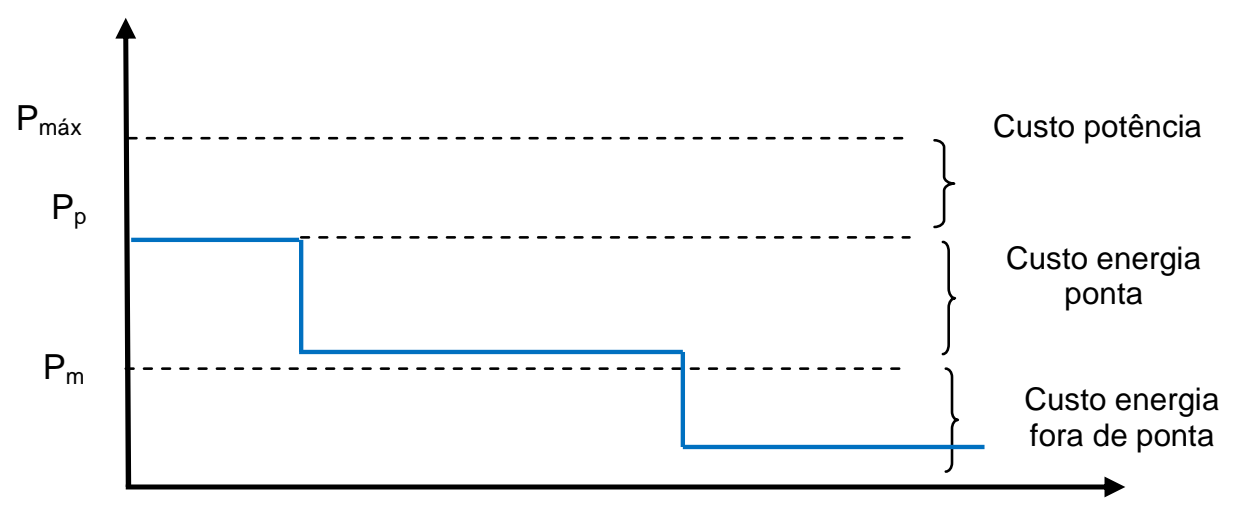

Figura 4.4 - Alocação dos custos de Interconexão e Transporte Pesado

Fonte: Adaptado de DNAEE (1985).

No caso do segmento Repartição, os custos marginais eram alocados somente à potência e, em geral, também eram estimados por meio do critério de CIMLP.

$\mathrm{Na}$ antiga estrutura tarifária, as instalações que operavam em tensão igual ou inferior a $34,5 \mathrm{kV}$ eram classificadas como de Distribuição, diferentemente do atual modelo no qual as instalações que operam em tensão igual ou inferior a 138 kV são consideradas de distribuição. 
De acordo com DNAEE (1985) e DNAEE (1981), o método adequado para estimar o custo marginal desses níveis de tensão era a LQO ao invés do CIMLP. Segundo Antunes, A. U. (2004), na época a principal limitação da aplicação do CIMLP era a inexistência de ferramenta que possibilitasse análises consistentes da evolução do sistema de distribuição no longo prazo.

A Tabela 4.2 apresenta os custos marginais de expansão das instalações de transporte como calculado pelo DNAEE (1985) e atualizados pelo índice de preços ao consumidor americano (Consumer Price Index - CPI-U) e pela taxa de câmbio de abril de 2010.

Tabela 4.2 - Custo de expansão das instalações de transporte (R\$/kW.mês)

\begin{tabular}{cccc}
\hline Nível & N/NE & SE/CO & S \\
\hline A0 & 7,57 & 11,55 & 9,35 \\
A1 & 9,03 & 2,94 & 3,44 \\
A2 & 0,00 & 5,10 & 10,69 \\
A3 & 11,23 & 12,20 & 7,57 \\
A4 & 15,31 & 14,84 & 12,17 \\
BT & 21,09 & 18,20 & 18,59 \\
\hline
\end{tabular}

Fonte: Adaptado de DNAEE (1985).

\subsection{Custos por nível na atual estrutura tarifária}

\subsubsection{Custo de geração na atual estrutura tarifária}

O custo da geração de energia elétrica reconhecido hoje nas tarifas é, basicamente, a média ponderada dos preços dos contratos de longo prazo da distribuidora, que englobam a compra compulsória da energia da usina de Itaipu e dos empreendimentos do Proinfa ${ }^{8}$, os contratos bilaterais assinados antes da Lei ํㅜ $10.848 / 2003$ e os contratos no ambiente regulado (CCEAR) estabelecidos pelo novo modelo setorial.

Há duas restrições impostas pelo regulador: i) o preço dos eventuais contratos bilaterais firmados antes do novo modelo do setor, que determina a

\footnotetext{
${ }^{8}$ Programa de Incentivo às Fontes Alternativas de Energia Elétrica instituído pela Lei no 10.48/2002 para diversificar a matriz energética brasileira com o aumento de geração a partir de fontes eólica, biomassa e pequenas centrais hidrelétricas.
} 
compra de energia em leilões regulados ${ }^{9}$, deve ser aprovado pela ANEEL e; ii) a soma dos montantes dos contratos está limitada ao atendimento ao mercado regulatório da distribuidora que compreende o mercado de fornecimento de energia para os consumidores cativos e as perdas elétricas regulatórias ${ }^{10}$.

Os custos da compra de energia são recuperados, na atual estrutura, pelas tarifas de energia (TE) e de uso (TUSD). Na primeira estão os custos da compra para fornecimento de energia, inclusive perdas elétricas na Rede Básica associadas ao mercado cativo ${ }^{11}$, e na segunda, os custos associados às perdas elétricas, tanto técnicas como as não técnicas.

É preciso ressaltar que, como determinado pela Resolução no 127/04, a compra de energia das usinas do Proinfa é recuperada nas tarifas de uso, pois se trata de um incentivo a ser pago por todos os consumidores, seja cativo ou livre.

Em termos de alocação, o custo de geração contido na TE para os diferentes tipos de consumidores é um único valor (selo) calculado pela divisão desse custo pelo mercado de fornecimento da distribuidora. No caso da TUSD, como visto, as perdas técnicas são proporcionalizadas em função do custo marginal de capacidade (em $\mathrm{R} \$ / \mathrm{kW}$ ) e as perdas não técnicas, proporcionais às demais parcelas da TUSD (em $\mathrm{R} \$ / \mathrm{kW}$ e em $\mathrm{R} \$ / \mathrm{MWh}$ ).

\subsubsection{Custo de transmissão na atual estrutura tarifária}

No atual modelo do setor, as instalações que operam em tensão igual ou superior a 230 kV são integrantes do sistema de transmissão conhecido como Rede Básica. No caso de subestações, o transformador com secundário em tensão inferior a esse nível é considerado, atualmente, como instalações da Rede Básica de Fronteira. No primeiro caso, todos os usuários do sistema de transmissão contribuem, por meio da TUST, para o pagamento do seu custo. No segundo,

\footnotetext{
${ }^{9}$ Segundo a Lei $n^{\circ}$ 10.848/2003, artigo $2^{\circ}$, as distribuidoras devem garantir o atendimento à totalidade do seu mercado mediante contratação regulada, por meio de licitação

${ }^{10}$ É permitido o repasse às tarifas de até $3 \%$ da energia requerida para o atendimento ao mercado, incluindo o montante de perdas elétricas regulatórias definidas pela ANEEL.

${ }_{11}$ No montante de energia comprado pelo consumidor livre diretamente dos geradores ou comercializadores já está incluído a parcela de perdas na Rede Básica.
} 
somente os agentes que utilizam cada instalação da Rede Básica de Fronteira arcam com os respectivos custos pagando a TUST Fronteira.

Já as linhas de propriedade das empresas de transmissão em tensão inferior a 230 kV são classificadas como Demais Instalações de Transmissão (DIT) ${ }^{12}$ cujo custo é pago somente pela distribuidora usuária por meio do encargo de conexão.

O custo de transmissão, correspondente ao pagamento das tarifas de transmissão e do encargo de conexão, é repassado nas tarifas de uso do sistema de distribuição por meio da componente TUSD - Fio A que é calculada pela divisão desse custo pelo mercado de demanda de potência. No caso do cálculo da parte referente ao pagamento da TUST, somente é utilizado o mercado de demanda no horário de ponta, pois é dessa maneira que a tarifa de transmissão é aplicada para a distribuidora atualmente.

Contudo, a Resolução no $399 / 2010$ estabelece a obrigatoriedade de contratação do uso do sistema de transmissão para os dois horários. A partir da definição das novas tarifas de transmissão em 30/06/2011 ${ }^{13}$, o custo nesse horário deverá ser repassado às tarifas de distribuição.

\subsubsection{Custo de marginal de distribuição na atual estrutura tarifária}

Com a reformulação do setor elétrico, a LQO, utilizada no passado para estimar o custo marginal, foi substituída pelo CIMLP em razão das limitações intrínsecas à aplicação daquela metodologia. Ou seja, mudanças do ambiente regulatório tais como o modelo tarifário e a exigência de níveis de qualidade diferenciados, bem como alterações no controle de grande parte das distribuidoras, que podem ter gerado descontinuidades de investimento, contribuem para 0 rompimento com o histórico de investimentos, base da metodologia da LQO (Antunes, A. U., 2004).

\footnotetext{
${ }^{12} \mathrm{Em}$ tese, as instalações em tensão inferior a $230 \mathrm{kV}$ são integrantes do sistema de distribuição. Por razões históricas, determinadas instalações que deveriam pertencer às empresas de distribuição são de propriedade das empresas de transmissão. Neste caso, são tratadas como Demais Instalações de Transmissão.

${ }^{13}$ Até 30/06/2011, a TUST fora de ponta permanecerá igual a zero.
} 
Assim, na atual estrutura tarifária, o custo marginal de distribuição é estimado a partir das projeções de investimentos informadas pela distribuidora no âmbito da revisão tarifária por meio do banco de dados denominado Plano de Desenvolvimento da Distribuição (PDD) ${ }^{14}$.

As informações sobre o planejamento da expansão das redes das distribuidoras são utilizadas para análise da projeção de investimentos associados ao componente $\mathrm{Xe}$ do Fator $\mathrm{X}$ e também para o cálculo e análise do Custo Incremental Médio de Longo Prazo - CIMLP. Para isso, de acordo com a ANEEL (2009c), tanto o Plano de Obras quanto as projeções de crescimento de carga devem ser discretizados anualmente, no horizonte de planejamento considerado.

Essa abordagem da ANEEL está, em linhas gerais, coerente com a proposta do Projeto Reseb ${ }^{15}$ que recomendava a utilização do CIMLP para estimativa do custo de expansão da distribuição. Contudo, aquela metodologia se fundamentava na utilização de planos de investimentos com base em redes-modelo eficientes, diferentemente da atual que considera as obras informadas pelas distribuidoras.

Embora as distribuidoras que passaram pelo $2^{\circ}$ ciclo de revisão tarifária tenham encaminhado o PDD possibilitando então o cálculo do CIMLP, a agência reguladora não está utilizando os valores informados pelas empresas, mantendo os valores determinados no $1^{\circ}$ ciclo de revisão tarifária.

Naquela ocasião, a ANEEL considerou valores médios das concessionárias brasileiras, pois os dados enviados pelas empresas apresentavam distorções e inconsistências. Esses valores foram obtidos pelo tratamento estatístico dos custos com base no planejamento de expansão e crescimento da carga. A tabela a seguir apresenta os dados utilizados pela ANEEL nos dois primeiros ciclos de revisão tarifária.

\footnotetext{
${ }^{14}$ O Plano de Desenvolvimento da Distribuição (PDD) apresenta os resultados dos estudos de planejamento do sistema de distribuição, incluindo plano de obras, relação de obras realizadas e comparação entre o planejado e o realizado.

${ }^{15}$ Projeto de Reestruturação do Setor Elétrico Brasileiro desenvolvido de agosto de 1996 a novembro de 1998 pela consultoria internacional Coopers \& Lybrand.
} 
Tabela 4.3 - Custo de marginal de expansão médios ANEEL - $2002{ }^{16}$

\begin{tabular}{cc}
\hline Grupo & $\mathbf{R} \$ \mathbf{k W . a n o}$ \\
\hline A2 & 29,13 \\
A3 & 35,56 \\
A3a & 36,63 \\
A4 & 41,15 \\
BT & 57,10 \\
\hline
\end{tabular}

\subsection{Proporção do fluxo de potência}

O crescimento de demanda de potência de determinado consumidor também ocasiona aumento de fluxo nos níveis de tensão a montante, porém não necessariamente no mesmo valor, uma vez que o trânsito da energia depende da configuração do sistema.

Assim, o critério de cálculo considera, na alocação do custo de expansão por nível de tensão, o Fator de Proporção de Fluxo - $\phi\left(l, l_{0}\right)$, que representa a parcela de utilização do nível de tensão I no atendimento da carga do nível de tensão Io. Esse fator é calculado com base no diagrama simplificado do sistema de distribuição da empresa no momento de máxima carga.

O fator de proporção, também conhecido como Coeficiente Técnico de Atendimento (CTA) conforme MME (1994), é constituído não somente pelo fluxo direto que passa pela transformação $I, I_{0}$ mas também pelo fluxo indireto que percorre outro nível de tensão a montante da tensão de atendimento.

Por exemplo, na figura a seguir, a carga que circula no nível $13,8 \mathrm{kV}$ é de 25 $\mathrm{MW}$ que corresponde às somas das demandas das transformações $138 \mathrm{kV} / 13,8 \mathrm{kV} \mathrm{e}$ $69 \mathrm{kV} / 13,8 \mathrm{kV}$, respectivamente $10 \mathrm{MW}$ e $15 \mathrm{MW}$. Além das transformações, deveria ser somada a injeção de potência (geração) diretamente no nível de 13,8 kV, se fosse o caso.

\footnotetext{
${ }^{16}$ Conforme Nota Técnica no 271/2009-SRE-SRD/ANEEL, os custos marginais de expansão médios por nível de tensão foram apurados em 2002 com base nos dados fornecidos pelas distribuidoras.
} 
Da mesma forma, a carga que circula no nível 69 kV é 20 MW que corresponde à transformação $138 \mathrm{kV} / 69 \mathrm{kV}$ e à injeção no nível; e, no 138 kV, somente a injeção de $30 \mathrm{MW}$.

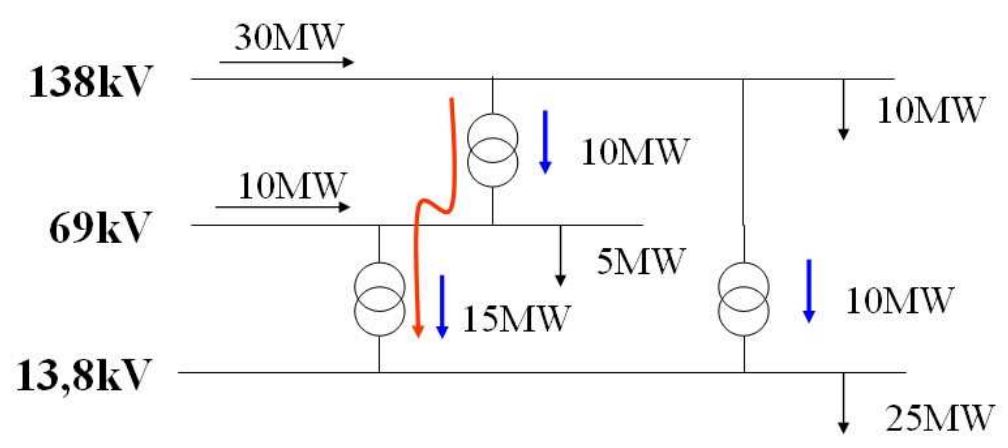

Figura 4.5 - Diagrama Unifilar Simplificado

No exemplo, o fluxo direto do nível de $138 \mathrm{kV}$ para $69 \mathrm{kV}$ corresponde ao valor de $10 \mathrm{MW}$ da transformação e não há fluxo indireto. Calculado em termos de proporção, o fator seria de $10 \mathrm{MW} / 20 \mathrm{MW}$, ou seja, metade do fluxo que circula no nível de $69 \mathrm{kV}$ é proveniente do nível de 138kV uma vez que a outra parte corresponde à injeção de $10 \mathrm{MW}$.

No caso do caminho do nível de $69 \mathrm{kV}$ para $13,8 \mathrm{kV}$, o fluxo direto corresponde ao valor de $15 \mathrm{MW}$ da transformação e sua proporção corresponde a 15MW/25MW.

No caso do nível de $138 \mathrm{kV}$ para $13,8 \mathrm{kV}$, o fluxo direto do nível também corresponde ao valor de $10 \mathrm{MW}$ da transformação e sua proporção corresponde a $10 \mathrm{MW} / 25 \mathrm{MW}$; já o fluxo indireto (em vermelho na Figura 4.5) passa pela transformação $138 \mathrm{kV} / 69 \mathrm{kV}$ e é calculado pela ponderação do fator do fluxo do nível 138kV/69kV e do CTA do fluxo do 69kV/13,8kV (10MW/20MW * 15MW/25MW).

\begin{tabular}{c|c|c|c}
\hline $\begin{array}{c}\text { Níveis de } \\
\text { tensão }\end{array}$ & $\mathbf{1 3 , 8 k V}$ & $\mathbf{6 9 k V}$ & $\mathbf{1 3 8 k V}$ \\
\hline $13,8 \mathrm{kV}$ & 1 & $15 / 25$ & $\begin{array}{c}10 / 25+ \\
15 / 25^{\star} 10 / 20\end{array}$ \\
\hline $69 \mathrm{kV}$ & - & 1 & $10 / 20$ \\
\hline $138 \mathrm{kV}$ & - & - & 1 \\
\hline
\end{tabular}

Quadro 4.2 - Proporção de Fluxo de Potência 
Evidentemente, o Fator de Proporção de Fluxo de um determinado nível de tensão em relação ao mesmo nível corresponde à unidade. Assim a matriz com os valores da proporção de fluxo é quadrada com os elementos da diagonal iguais a $100 \%$.

\subsection{Caracterização da carga}

Em tese, se todas as curvas de carga de cada consumidor e de cada transformação fossem conhecidas, seria possível identificar, de forma determinística, a responsabilidade de potência de cada cliente verificando o comportamento da sua carga no momento de maior carregamento da rede na qual está conectado.

Como não há medição em todos esses pontos, é necessária a utilização da teoria estatística, para estimar a responsabilidade com base em medições amostrais de consumidores e de transformações ou redes.

Assim, o conhecimento do comportamento das cargas e do sistema elétrico da distribuidora é insumo fundamental no cálculo dos custos marginais de capacidade. O conjunto de estudos para analisar esse comportamento, que resulta em curvas representativas dos clientes e das redes, é denominado caracterização da carga (Daimon, 2007).

A caracterização da carga é dividida em três etapas: i. identificação de curvas características; ii. agregação de curvas de carga; iii. ajuste das tipologias ao mercado.

A caracterização da carga compreende um conjunto de técnicas estatísticas que, através de amostras, permite extrapolar os resultados para todo o universo definido previamente (Amendola, 2007). A ANEEL, por meio dos Procedimentos de Distribuição (ANEEL, 2009c), estabeleceu que, nesse processo, fossem utilizadas todas as medições das unidades consumidoras atendidos no nível de tensão igual ou acima de $69 \mathrm{kV}$ e, para as demais, medições por amostragem.

No primeiro caso, a ANEEL determina que as unidades sejam agrupadas por atividades econômicas. Nos demais casos, a estratificação definida pela ANEEL segrega os consumidores por nível de tensão de conexão e por faixa de consumo ou 
de demanda de potência. No caso das unidades ligadas em baixa tensão, porém, a classificação em segundo plano é por finalidade do uso de energia. O Quadro 4.3 apresenta os estratos de medição determinados pela ANEEL.

\begin{tabular}{|c|c|c|}
\hline Nível de tensão & \multicolumn{2}{|c|}{ Estratos de medição } \\
\hline A2-A3-A3a & \multicolumn{2}{|c|}{ Todos os clientes } \\
\hline A4 & \multicolumn{2}{|c|}{$\begin{array}{c}\text { Menor ou igual a } 50 \mathrm{~kW} \\
51 \mathrm{~kW} \text { a } 100 \mathrm{~kW} \\
101 \mathrm{~kW} \text { a } 200 \mathrm{~kW} \\
201 \mathrm{~kW} \text { a } 300 \mathrm{~kW} \\
301 \mathrm{~kW} \text { a } 500 \mathrm{~kW} \\
501 \mathrm{~kW} \text { a } 1.000 \mathrm{~kW} \\
\text { Maior que } 1.000 \mathrm{~kW}\end{array}$} \\
\hline \multirow{4}{*}{ BT } & Residencial & $\begin{array}{c}\text { Até } 79 \mathrm{kWh} \\
80 \mathrm{kWh} \text { a LBR } \\
\text { LBR a } 500 \mathrm{kWh} \\
501 \mathrm{kWh} \text { a } 1.000 \mathrm{kWh} \\
\text { Acima de } 1.000 \mathrm{kWh}\end{array}$ \\
\hline & Rural & $\begin{array}{c}\text { até } 200 \mathrm{kWh} \\
201 \mathrm{kWh} \text { a } 500 \mathrm{kWh} \\
501 \mathrm{kWh} \text { a } 1.000 \mathrm{kWh} \\
1.001 \mathrm{kWh} \text { a } 5.000 \mathrm{kWh} \\
\text { acima de } 5.000 \mathrm{kWh}\end{array}$ \\
\hline & $\begin{array}{c}\text { Comercial, Industrial, } \\
\text { AS }\end{array}$ & $\begin{array}{c}\text { até } 500 \mathrm{kWh} \\
501 \mathrm{kWh} \text { a } 1.000 \mathrm{kWh} \\
1.001 \mathrm{kWh} \text { a } 5.000 \mathrm{kWh} \\
5.001 \mathrm{kWh} \text { a } 10.000 \\
\mathrm{kWh} \\
\text { acima de } 10.000 \mathrm{kWh}\end{array}$ \\
\hline & \multicolumn{2}{|c|}{ Iluminação Pública } \\
\hline
\end{tabular}

\section{Quadro 4.3 - Estratos de medição}

Com os estratos definidos pela ANEEL, a distribuidora calcula o tamanho da amostra das medições que dependerá do total de consumidores existentes e do coeficiente de variação. Aplicando a teoria estatística e considerando que o nível de erro aceitável da amostra de cada estratificação deverá ser no máximo $20 \%$, com nível de confiança de 95\%, determina-se o tamanho da amostra, calculado pela seguinte fórmula, conforme ANEEL (2008c):

$$
n=\frac{1,96^{2}\left(\frac{C V}{R}\right)^{2}}{1+1,96^{2}\left(\frac{C V}{R}\right)^{2}}
$$


Onde:

$\mathrm{n}$ - tamanho da amostra;

$\mathrm{N}$ - tamanho da população;

CV - coeficiente de variação da grandeza explicativa (potência);

$\mathrm{R}$ - erro relativo (20\%) definido pela ANEEL.

Definido o tamanho das amostras, a distribuidora sorteia os consumidores que serão medidos por um período suficiente para obter dados que possibilitem a escolha de curvas que representem um dia útil, um sábado e um domingo, como demonstrado na Figura 4.6 a seguir.

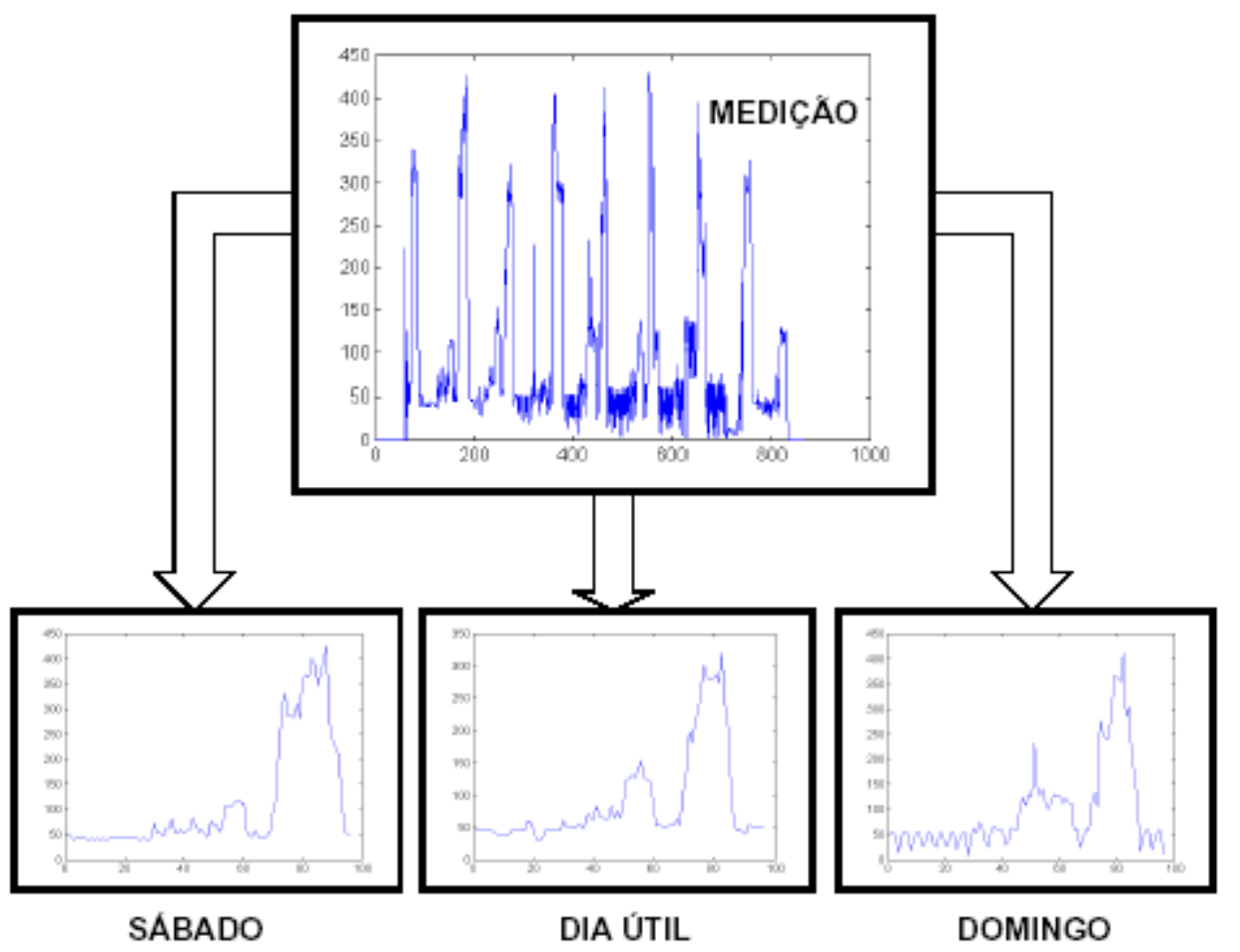

Figura 4.6 - Identificação das curvas características

Fonte: ANEEL (2000)

Sendo o comportamento da curva importante para o cálculo do custo marginal de capacidade, para simplificar as análises das curvas é necessário agregá-las em formas típicas ou homogêneas por meio de técnicas de agrupamento estatístico como clusters analysis. O conjunto de "curvas típicas" de determinado mercado define a "tipologia" dos clientes e transformações (Daimon, 2007). Nesses estudos 
são utilizados o Método das Nuvens Dinâmicas ${ }^{17}$ e em seguida o Método de Descrição e Classificação Ascendente Hierárquico ${ }^{18}$.

No primeiro modelo, formam-se inicialmente $k$ grupos escolhendo aleatoriamente um elemento inicial; em seguida, alocam-se os demais elementos por um critério como a menor distância euclidiana. Para cada grupo redefine-se um novo núcleo e alocam-se os demais elementos. Se esses grupos convergirem, encerra-se a primeira etapa do processo. Essa experiência é repetida por um determinado número de vezes sendo que os elementos que se mantiveram unidos em algum grupo em todas as experiências são caracterizados como forma forte (Daimon, 2007).

Após este agrupamento inicial, é aplicado o Método de Descrição e Classificação Ascendente Hierárquico que procura reduzir o número de curvas por meio da soma das formas fortes mais próximas. Esse método é conhecido como hierárquico, pois, a cada interação do processo, um cluster é agregado ao anterior formando uma seqüência na qual as primeiras agregações são mais próximas matematicamente que as demais. Inicialmente são formados k clusters contendo apenas uma curva das $n$ existentes, ou seja, $k=n$, e em cada iteração agrupa-se dois clusters segundo determinado critério resultando k-1 clusters. Repetindo sucessivamente este critério, ao final de n-1 iteração, todos os elementos estarão agrupados. Com o armazenamento de cada iteração, é possível escolher a quantidade de cluster que representarão o universo de n curvas.

O método hierárquico possui a vantagem de produzir partições sucessivas, porém não é conveniente quando a quantidade de objetos a serem classificados é significativa. Isto porque este critério precisa calcular a distância relativa de cada elemento em relação aos demais. Ao contrário, o método não hierárquico não depende de todas essas informações, embora a partição dependa dos centros dos clusters escolhidos inicialmente.

\footnotetext{
17 O Método de Nuvens Dinâmicas (NUDYC) separa a população em grupos de indivíduos semelhantes, definindo as chamadas "formas fortes".

${ }^{18}$ Método de Descrição e Classificação Ascendente Hierárquico (DESC-R2) que descreve os tipos de uma determinada tipologia e faz reagrupamentos sucessivos dos tipos através de fusões sucessivas de formas fortes parecidas.
} 
Aplicando-se os dois critérios sucessivamente, determina-se a curva característica de um cluster a partir das curvas que o compõem, como demonstrado na Figura 4.7.

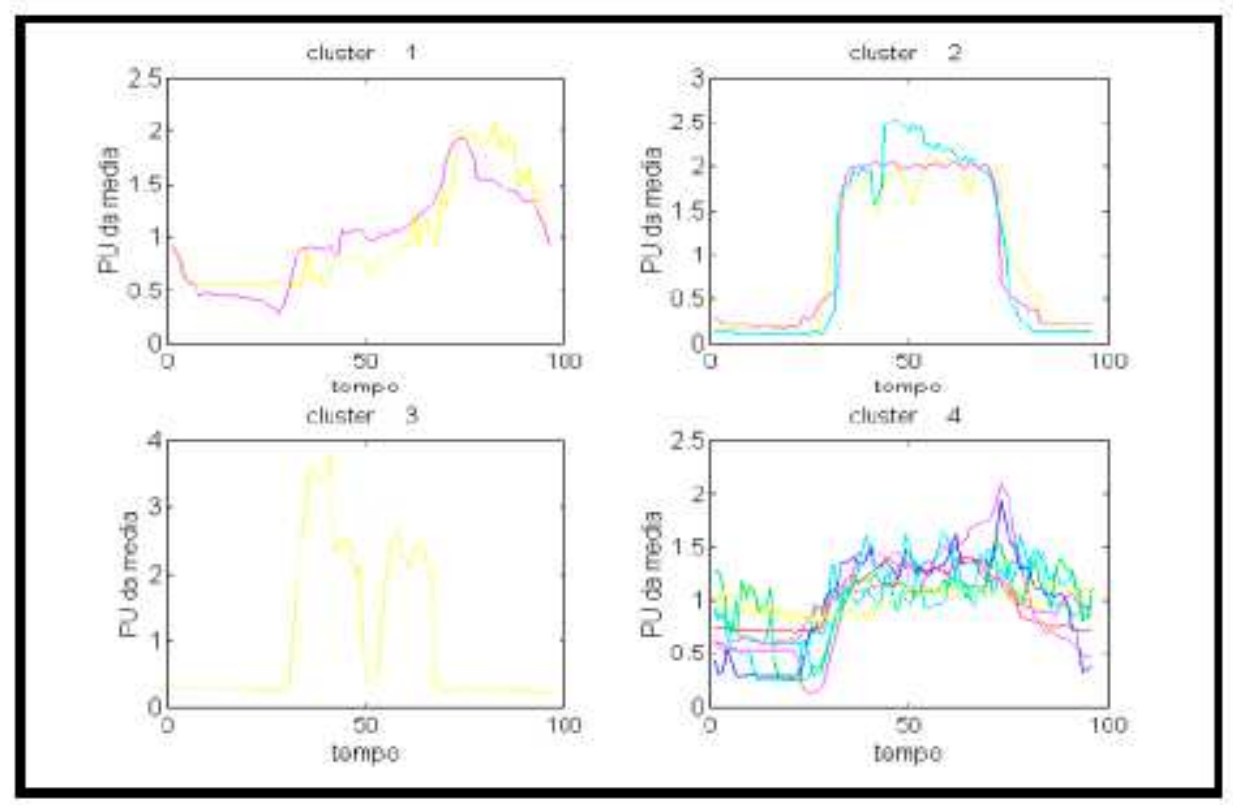

Figura 4.7 - Curvas de carga que compõem os clusters

Fonte: ANEEL (2000)

A etapa final do processo de caracterização da carga é constituída pelo ajuste das curvas típicas ao mercado anual do estrato que representam e pelo cálculo dos parâmetros complementares.

Para efetuar o ajuste é necessário conhecer os fatores conhecidos como ponderação de sábado e ponderação de domingo que provém das relações entre energia consumida nos dias úteis e nos finais de semana estimadas pelas medições da campanha.

\subsection{Componentes da responsabilidade de potência}

Como visto na equação 4.1, por meio da responsabilidade de potência $(R)$, os custos de expansão são alocados nos horários de maior carregamento das redes nas quais o consumidor está conectado. Na responsabilidade de potência está, então, o cerne da metodologia do custo marginal de capacidade proposta pela EDF em meados da década de 1980 e mantida no novo modelo do setor elétrico. 
Como visto, a responsabilidade de potência de determinado consumidor depende do comportamento da sua carga nos horários de maior carregamento das redes percorridas pela energia no sistema de distribuição até sua entrega.

Como essa associação é aleatória, em virtude das medições amostrais, cada curva de rede tipo tem coeficientes de participação esperada em cada curva de cliente tipo, que são as respectivas probabilidades de associação das curvas de rede com as curvas de carga.

Esta esperança matemática é denominada responsabilidade de potência do cliente-tipo e pode ser expressa, para cada período tarifário e para cada nível de tensão da seguinte forma:

$$
R_{j u}^{l}=\left(1+\tau_{j u}^{l}\right) \cdot \sum_{h \in u} \pi_{j i(h)}^{l} \cdot P_{j(h i)}^{l}
$$

Onde:

$R_{j u}^{l}$ - responsabilidade de potência do cliente-tipo $j$ no posto tarifário $u$ na formação das demandas máximas das redes-tipo que formam o nível de tensão I situado a montante do seu ponto de conexão.

$\tau_{j u}^{l}$ - taxa de perdas de potência provocadas pelo cliente-tipo $j$ no período $u$, acumuladas desde o seu ponto de conexão até a origem do nível / considerado.

$\pi_{j i(h)}^{l}$ - probabilidade que o cliente-tipo $j$ se associe a uma rede-tipo $i$, situada no nível de tensão $l$, com ponta no horário $h$.

$P_{j(h i)}^{l}$ - é o fator de demanda em p.u. do cliente-tipo $j$ na hora $h$ da ocorrência da ponta das redes-tipo que alimentam o nível de tensão $I$.

Ou seja, para cada hora de demanda máxima das redes-tipos às quais o cliente-tipo está associado, é calculada uma parcela que corresponde à multiplicação dessa probabilidade de associação pelo fator de coincidência do cliente-tipo $j$ na hora de demanda máxima. A responsabilidade de potência para determinado posto tarifário $u$ é o somatório dessas parcelas calculadas para as horas que compõem o referido posto. 


\subsubsection{Probabilidade de um cliente-tipo se associar a uma rede-tipo}

Para ilustrar o conceito da probabilidade de associação, $\pi$, entre clientes-tipo e redes-tipo, apresenta-se um exemplo hipotético, adaptado de ANEEL (2000), de uma distribuição de energia em apenas um nível de tensão constituída de duas curvas de transformações (redes-tipo) que alimentam três curvas de carga (clientestipo).

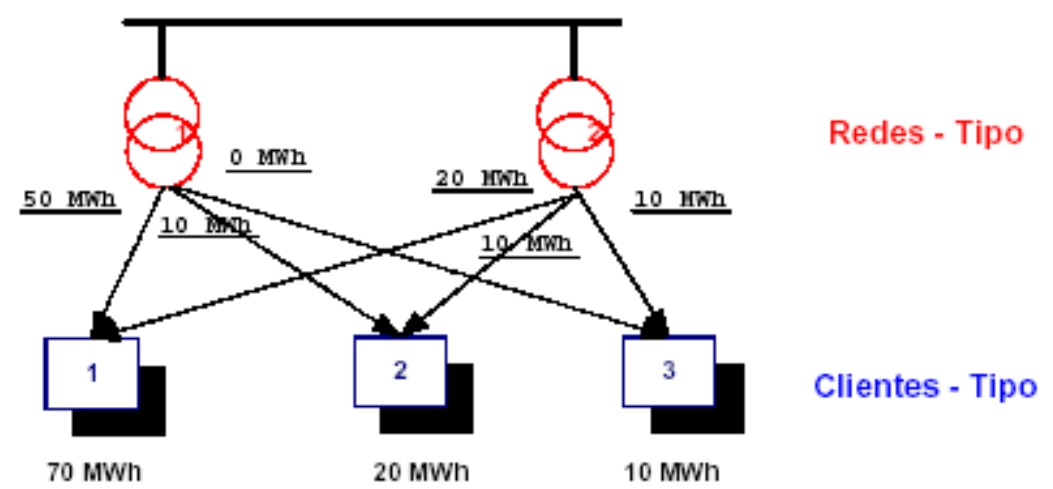

Figura 4.8 - Fluxo de energia das redes-tipo para os clientes-tipo Fonte: ANEEL (2000).

Considerando que as duas redes-tipo do exemplo representam a totalidade do mercado, pode-se definir $\alpha$ como sendo a participação de cada rede-tipo na energia que transita no nível de tensão $l$, sendo então $\alpha$ correspondente à probabilidade de determinada rede ser de um tipo $i$.

Da mesma forma, y pode ser definida como a participação de cada clientetipo na energia que transita no nível de tensão $I$, sendo então y correspondente à probabilidade de determinado cliente ser do tipo $j$.

Tabela 4.4 - Fatores $y$ do exemplo

\begin{tabular}{c|c}
\hline Clientes & Fator $\mathbf{Y}$ \\
\hline Cliente-tipo 1 & $\mathrm{Y}_{1}=70 / 100$ \\
\hline Cliente-tipo 2 & $\mathrm{Y}_{2}=20 / 100$ \\
\hline Cliente-tipo 3 & $\mathrm{Y}_{3}=10 / 100$ \\
\hline
\end{tabular}

Fonte: Adaptado de ANEEL (2000). 
No exemplo, admitindo-se que os fluxos entre redes-tipo e clientes-tipo sejam os apresentados na Figura 4.8, é possível determinar a parcela da energia de cada rede-tipo $i$ que é destinada a cada cliente-tipo $j\left(\beta_{\mathrm{ij}}\right)$.

$$
\gamma_{j}=\sum_{i=1}^{n} \alpha_{i} * \beta_{i j}
$$

Tabela 4.5 - Fatores $\alpha$ e $\beta$ do exemplo

\begin{tabular}{cccc}
\hline & Rede-tipo 1 & Rede-tipo 2 \\
\hline \multirow{2}{*}{ Fator $\alpha$ das redes-tipo } & $\alpha_{1}=60 / 100$ & $\alpha_{2}=40 / 100$ \\
\hline \multirow{3}{*}{ Fator $\boldsymbol{\beta}$} & Cliente-tipo 1 & $\beta_{11}=50 / 60$ & $\beta_{21}=20 / 40$ \\
\cline { 2 - 4 } & Cliente-tipo 2 & $\beta_{12}=10 / 60$ & $\beta_{22}=10 / 40$ \\
\cline { 2 - 4 } & Cliente-tipo 3 & $\beta_{13}=0 / 60$ & $\beta_{23}=10 / 40$ \\
\cline { 2 - 4 } & Total & $60 / 60$ & $40 / 40$ \\
\hline
\end{tabular}

Fonte: Adaptado de ANEEL (2000).

Na prática, como essa associação é aleatória e os fluxos não são conhecidos, os fatores $\beta_{\mathrm{ij}}$ são estimados por um sistema de otimização. O método forma, então, em determinado nível de tensão, um sistema matricial no qual o somatório das curvas de carga dos clientes-tipo, multiplicadas pelos respectivos fatores $\beta_{\mathrm{ij}}$, se aproxima da curva de carga da rede-tipo, para cada hora $h$.

O sistema linear, em geral, é inviável, não sendo possível encontrar um único valor de $\beta_{\mathrm{ij}}$ que relacione o cliente-tipo $j$ com a rede-tipo $i$ nas 24 horas. Uma alternativa para a resolução é a inserção de um erro $\varepsilon_{\mathrm{ij}}$ para cada linha do sistema.

$$
R_{i(t)}=\sum_{j=1}^{n} C_{j(t)} * \beta_{i j(t)}+\varepsilon_{i j(t)}
$$

As coordenadas $\mathrm{R}_{\mathrm{i}}(\mathrm{t})$ e $\mathrm{C}_{\mathrm{j}}(\mathrm{t})$ são as potências (em p.u. da média) de cada hora $h$ das redes-tipo $i$ e dos clientes-tipo $j$ respectivamente. Ou seja, para cada hora existe um sistema de equações desse tipo.

O método assume que a forma da curva de carga que representa a parcela do cliente-tipo $j$ atendida pela rede-tipo $i$ tem exatamente o mesmo formato para as outras parcelas atendidas por outras redes-tipo. Desse modo, todos têm a forma da 
curva de carga do cliente-tipo $j$ e pode-se escrever que $C_{j i}=C_{j}$ para qualquer que seja a rede-tipo $i(M M E, 1994)$.

Os coeficientes $\beta_{\mathrm{ij}}$ são, então, determinados por meio da resolução de um problema de otimização quadrática, onde o objetivo consiste em minimizar a soma do quadrado dos desvios entre as curvas das redes-tipo e a combinação linear das curvas dos clientes-tipo. Considerando $\mathrm{m}$ redes-tipo e $\mathrm{n}$ clientes-tipo, o sistema de equações a ser considerado é o seguinte:

$$
\begin{aligned}
& \operatorname{Min} \mathrm{f}=\sum_{i=1}^{m} \sum_{t=1}^{24}\left(R_{i(t)}-\sum_{j=1}^{n} C_{j(t)} * \beta_{i j(t)}\right)^{2} \\
& \text { sujeito a } \\
& \sum_{i=1}^{m} \alpha_{i} * \beta_{i j}=\gamma_{j}, \forall j \\
& \beta_{i j} \geq 0, \forall i \quad \forall j
\end{aligned}
$$

A restrição acima é decorrente da premissa de que sendo $\alpha_{i}{ }^{*} \beta_{i j}$ a parcela de energia do nível de tensão que passa pela rede-tipo $i$ e destinada a atender 0 cliente-tipo $j$, o somatório de todas as parcelas para um mesmo consumidor deve ser igual a sua participação no mercado $\gamma_{j}$.

Inicialmente, os $\beta_{\mathrm{ij}}$ são calculados para as redes-tipo em baixa tensão (transformações MT/BT) e respectivos clientes-tipo, iniciando-se a seqüência de cálculo do sistema elétrico a partir desses consumidores BT até atingir o nível 138 kV. Assim, são estimados os $\beta_{\mathrm{ij}}$ para as transformações AT/MT cujos clientes-tipo são os consumidores de média tensão e as redes-tipo MT/BT. Em seguida, calculase os $\beta_{\mathrm{ij}}$ das redes AT/MT para os clientes de baixa tensão que correspondem a multiplicação dos $\beta_{\mathrm{ij}}$ calculados nas duas seqüências. O cálculo dos fatores das redes a montante segue a mesma lógica, conforme Antunes, N. P., 2007.

O $\beta_{\mathrm{ij}}$ é, então, a probabilidade da rede-tipo i estar associada ao cliente $j$. Já o fator $\Pi_{\mathrm{ji}}$, utilizado no cálculo da responsabilidade de potência, é a probabilidade do cliente-tipo $j$ estar associado à rede-tipo $i$, em outras palavras, a probabilidade da 
energia ser suprida pela rede-tipo $\mathrm{i}\left(\mathrm{R}_{\mathrm{i}}\right)$ dado que ela é consumida pelo cliente-tipo $j$, ou seja, $\Pi_{j i}=P\left(R_{i} \mid C_{j}\right)$.

Conhecendo $\alpha_{\mathrm{i}}$ e $\beta_{\mathrm{ij}}$ é possível então calcular o fator $\Pi_{\mathrm{ji}}$, aplicando-se 0 conceito de probabilidade condicional e o Teorema de Bayes. De acordo com a teoria estatística, a probabilidade de ocorrer o evento $\mathrm{R}$ dado que ocorreu o evento C é dado pela seguinte fórmula,

$$
\mathrm{P}\left(R_{i} \mid C_{j}\right)=\frac{P\left(R_{i} \cap C_{j}\right)}{P\left(C_{j}\right)}=\frac{P\left(R_{i}\right) \cdot \mathrm{P}\left(C_{j} \mid R_{i}\right)}{P\left(C_{j}\right)}
$$

Pelo teorema da probabilidade total, sabe-se que,

$$
\mathrm{P}\left(C_{j}\right)=\sum_{i} P\left(R_{i}\right) \cdot \mathrm{P}\left(C_{j} \mid R_{i}\right)
$$

Mas, $P\left(R_{i}\right)$ é a probabilidade de a rede ser do tipo $i$, ou seja, $\alpha_{i}$; e $P\left(C_{j} \mid R_{i}\right)$ é a probabilidade do cliente $j$ estar associado à rede $i$, dado que já ocorreu este último evento, ou seja, $\beta_{\mathrm{ij}}$. Assim,

$$
\pi_{\mathrm{ji}}=\frac{P\left(R_{i}\right) \cdot \mathrm{P}\left(C_{j} \mid R_{i}\right)}{\sum_{i} P\left(R_{i}\right) \cdot \mathrm{P}\left(C_{j} \mid R_{i}\right)}=\frac{\alpha_{i} \cdot \beta_{i j}}{\sum_{\mathrm{i}} \alpha_{i} \cdot \beta_{i j}}(410)
$$

Aplicando a Equação 4.10 para o exemplo, temos os seguintes valores para a probabilidade da rede-tipo i estar associada ao cliente-tipo $j$

Tabela 4.6 - Probabilidade condicionada

\begin{tabular}{llccc}
\hline & & Rede-tipo 1 & Rede-tipo 2 & $\Sigma\left(\boldsymbol{\alpha}_{\mathrm{i}}{ }^{*} \boldsymbol{\beta}_{\mathrm{ij}}\right)$ \\
\hline \multirow{2}{*}{$\boldsymbol{\alpha}_{\mathrm{i}} * \boldsymbol{\beta}_{\mathrm{ij}}$} & Cliente-tipo 1 & $50 / 100$ & $20 / 100$ & $70 / 100$ \\
\cline { 2 - 5 } & Cliente-tipo 2 & $10 / 100$ & $10 / 100$ & $20 / 100$ \\
\cline { 2 - 5 } & Cliente-tipo 3 & $0 / 100$ & $10 / 100$ & $10 / 100$ \\
\hline
\end{tabular}

É importante notar que $\sum_{\mathrm{i}} \alpha_{i} \cdot \beta_{i j}$ corresponde ao valor de $\mathrm{y}_{\mathrm{j}}$ que é a participação do cliente-tipo j no mercado do nível tarifário. 
Tabela 4.7 - Fator $\pi$

\begin{tabular}{lllll}
\hline & & Rede-tipo 1 & Rede-tipo 2 & Total \\
\hline \multirow{3}{*}{$\pi_{\mathrm{ji}}=\left(\boldsymbol{\alpha}_{\mathrm{i}} * \boldsymbol{\beta}_{\mathrm{ij}}\right) / \Sigma\left(\boldsymbol{\alpha}_{\mathrm{i}} * \boldsymbol{\beta}_{\mathrm{ij}}\right)$} & Cliente-tipo 1 & $\pi_{11}=50 / 70$ & $\pi_{12}=20 / 70$ & $70 / 70$ \\
\cline { 2 - 5 } & Cliente-tipo 2 & $\pi_{21}=10 / 20$ & $\pi_{22}=10 / 20$ & $20 / 20$ \\
\cline { 2 - 6 } & Cliente-tipo 3 & $\pi_{31}=0 / 10$ & $\pi_{32}=10 / 10$ & $10 / 10$ \\
\hline
\end{tabular}

Essa probabilidade é válida para qualquer momento, pois a associação das curvas de rede e de cliente é independente da hora considerada. É também evidente que o somatório de $\pi_{\mathrm{ji}}$ para um cliente-tipo $j$ corresponde a $100 \%$.

Contudo, o objetivo do cálculo é associar os custos ao horário de máximo carregamento das redes, pois a expansão do sistema é, em geral, decorrente do aumento de carga nesses instantes. Assim, no momento em que o sistema não está plenamente carregado não haveria custo para a entrada de uma nova carga, em tese.

A probabilidade do cliente-tipo $j$ associar-se a rede-tipo $i$ na hora de ponta $h$ da rede-tipo, em outras palavras, a parcela do cliente-tipo $j$ que é atendida pela redetipo $i$ na hora de ponta $h$, é, por definição, calculada somente para as horas de ponta $^{19}$. O atual critério da ANEEL considera como ponta as demandas acima de $90 \%$ da máxima.

Para refletir essa situação, típica de sistemas de transporte dimensionados pela máxima capacidade, a probabilidade $\pi_{\mathrm{ji}}$ é considerada somente nas horas de maior demanda, conhecida no setor, como ponta de rede. Se houver mais do que uma ponta na rede-tipo $i$, considera-se esses eventos como equiprováveis. Assim, para uma determinada hora $h$ de ponta, com $T_{i}$ horas de ponta, a probabilidade $\pi_{j i}(h)$ é dado pela seguinte fórmula:

$$
\pi_{\mathrm{ji}}(h)=\frac{\frac{\alpha_{i} \cdot \beta_{i j}}{T_{i}}}{\sum_{\mathrm{i}} \alpha_{i} \cdot \beta_{i j}}
$$

\footnotetext{
${ }^{19}$ É importante destacar que as pontas das redes-tipo podem ocorrer em horários diferentes da ponta do sistema de distribuição. Da mesma forma, a ponta do sistema pode não coincidir com o horário do posto tarifário ponta. Ao estudar a metodologia é necessário levar em conta o contexto em que o termo ponta está sendo aplicado: às curvas de redes-tipo, ao sistema de distribuição, ao posto tarifário.
} 


\subsubsection{Demanda do cliente-tipo $-P_{j(h i)}^{l}$ ou fator de coincidência}

No cálculo da responsabilidade de potência, como visto na Equação 4.1, é considerado a somatória, nas horas $h$ que pertencem ao posto tarifário $u$, do fator $\pi_{j i(h)}^{l}$ multiplicado pelo fator coincidência do cliente tipo $j$ na hora $h$ de ponta da rede tipo $i\left(P_{j(h i)}^{l}\right)$.

A metodologia considera que a expansão das redes de distribuição é decorrente das demandas máximas da rede. Por isso, é importante calcular qual é a contribuição do cliente na formação desta ponta da rede, ou seja, qual a demanda percentual da carga neste momento. $O$ fator de coincidência define, então, como 0 cliente-tipo influi na formação das horas de ponta (carga máxima) das redes-tipo $j$ que compõem um subgrupo tarifário $k$. Já as horas de ponta de uma rede tipo são aquelas em que a demanda horária excede um percentual, por exemplo, 90\% da sua demanda máxima (ANEEL, 2000).

O fator é um valor em pu, como visto na equação a seguir.

$$
P_{j}(h)=\frac{\text { demanda cliente }- \text { tipoj na hora } h}{\text { demanda máxima }}
$$

\subsection{3. Índice de Perdas de Potência}

Segundo DNAEE (1985), os custos marginais calculados na época não agregavam o custo das perdas. Por isso, no cálculo da responsabilidade de potência, as perdas técnicas no sistema de transporte são inseridas por meio do fator de perdas de potência acumuladas, que é multiplicado pelas demais componentes. Como a responsabilidade de potência é calculada para os postos tarifários, o índice de perdas de potência deve ser estimado para os mesmos períodos.

$\mathrm{Na}$ época, as perdas foram obtidas inicialmente a partir das simulações do fluxo de potência por nível de tensão para cada região constantes do Plano Decenal, representando a média dos valores encontrados no período 1985 a 1994. 
Interessante notar que, a partir desses índices percentuais de perda de potência e dos fatores de carga médio, foram calculados os fatores de perda de energia utilizados no cálculo do custo da energia.

O índice corresponde, então, às perdas de potência acumuladas desde o ponto de conexão do cliente até o nível de tensão à montante para o qual está sendo calculada a responsabilidade de potência, passando pelos níveis de tensão intermediários. As perdas dependem também da proporção do fluxo da carga que circula pelos diversos níveis.

\subsection{Cálculo do custo marginal de capacidade do cliente}

Como visto, o custo marginal de capacidade do cliente-tipo é o somatório dos custos desde o $138 \mathrm{kV}$ até a tensão de atendimento deste consumidor para determinado posto tarifário.

Este custo marginal de capacidade é, inicialmente, calculado para cada cliente-tipo e a seguir agregado por estrato e por subgrupos tarifários, formando um único custo de capacidade para cada subgrupo tarifário. O agrupamento é feito por uma média ponderada na qual são consideradas os custos marginais de capacidade dos clientes-tipo e as respectivas demandas máximas.

Assim, no modelo vigente, o custo marginal de capacidade de cada clientetipo forma o custo marginal do nível tarifário $k$ calculado proporcionalmente à participação do cliente no mercado.

A Tabela 4.8 apresenta os custos dos clientes e as respectivas participações das receitas por nível de tensão, no âmbito da revisão tarifária de 2007 da Escelsa (ANEEL, 2007). Essas relatividades definirão a estrutura da parcela das tarifas que são alocadas proporcionalmente aos custos marginais de capacidade. 
Tabela 4.8 - Custos Marginais de Capacidade dos Clientes

\begin{tabular}{|c|c|c|c|c|c|c|c|c|}
\hline \multirow{2}{*}{$\begin{array}{c}\text { Grupo } \\
\text { tarifário }\end{array}$} & \multicolumn{2}{|c|}{$\begin{array}{c}\text { Custo capacidade } \\
(\mathrm{R} \$ / \mathbf{k W})\end{array}$} & \multicolumn{2}{|c|}{ Demanda (MW) } & \multicolumn{3}{|c|}{ Receita mensal (R\$ mil) } & \multirow{2}{*}{$\%$} \\
\hline & $\mathbf{P}$ & FP & $\mathbf{P}$ & FP & $\mathbf{P}$ & FP & Total & \\
\hline A2 & 7,05 & 20,97 & 295,69 & 335,84 & 2.085 & 7.043 & 9.127 & $9 \%$ \\
\hline A3 & 15,90 & 40,53 & 39,04 & 39,39 & 621 & 1.596 & 2.217 & $2 \%$ \\
\hline A3a & 8,33 & 54,46 & 17,58 & 26,51 & 146 & 1.444 & 1.590 & $1 \%$ \\
\hline $\mathrm{A} 4$ & 30,19 & 57,94 & 151,62 & 231,27 & 4.577 & 13.400 & 17.977 & $17 \%$ \\
\hline \multirow[t]{2}{*}{ BT } & 84,08 & 59,80 & 583,52 & 437,28 & 49.062 & 26.149 & 75.212 & $71 \%$ \\
\hline & & & & & 56.492 & 49.632 & 106.123 & $100 \%$ \\
\hline
\end{tabular}

\subsection{Tarifas de referência}

De acordo com o DNAEE (1985, p. 295), as tarifas de referência devem refletir o melhor possível os custos dos clientes e as faturas devem ser funções lineares dos parâmetros de serviço: consumos e demandas máximas em cada posto tarifário.

No método atual, empregado pela ANEEL, a fronteira entre as tarifas de referência e de aplicação não está claramente identificada. No modelo anterior, por exemplo, no cálculo das tarifas de referência para os consumidores MT, havia a transferência de custos de potência para os preços de energia, em razão do menor fator de carga desses consumidores.

Em termos didáticos, tal processo de cálculo, característico da Tarifa Horosazonal Verde, será considerado como integrante das tarifas de aplicação para que não haja confusão com os preços da "mercadoria" energia propriamente dita.

A passagem dos custos marginais de capacidade para a tarifa de referência é executada pela agência reguladora em etapas. Primeiramente, é feito um ajuste da receita "marginal", calculada conforme Tabela 4.9, à parcela da receita de distribuição que é alocada pelo critério de custos marginais. 


\section{Tabela 4.9 - Receita Anual do Serviço de Distribuição}

\begin{tabular}{lr}
\hline \multicolumn{2}{c}{ Componentes da Receita (R\$ mil) } \\
\hline Atividade de distribuição & 448.024 \\
\hline Perdas técnicas & 58.622 \\
\hline RGR & 14.726 \\
\hline P\&D EE & 7.095 \\
\hline Taxa de fiscalização & 3.665 \\
\hline TOTAL & $\mathbf{5 3 2 . 1 3 2}$ \\
\hline
\end{tabular}

O percentual de ajuste é a relação entre a receita total da Tabela 4.8 e a Receita de Distribuição (Tabela 4.9), em base mensal. Este fator, que no exemplo, corresponde a 0,148 , será aplicado aos custos marginais de capacidade, resultando nas tarifas ajustadas à Receita de Distribuição. Como demonstrado na Tabela 4.10 essas tarifas mantém a relatividade inicial encontrada na aplicação dos custos marginais de capacidade.

Tabela 4.10 - Custos Marginais de Capacidade Ajustados à Receita

\begin{tabular}{|c|c|c|c|c|c|c|c|c|}
\hline \multirow{2}{*}{$\begin{array}{l}\text { Grupo } \\
\text { tarifário }\end{array}$} & \multicolumn{2}{|c|}{$\begin{array}{c}\text { Custo capacidade } \\
(\mathrm{R} \$ / \mathbf{k W})\end{array}$} & \multicolumn{2}{|c|}{ Demanda (MW) } & \multicolumn{3}{|c|}{ Receita mensal (R\$ mil) } & \multirow{2}{*}{$\%$} \\
\hline & $\mathbf{P}$ & FP & $\mathbf{P}$ & FP & $\mathbf{P}$ & FP & Total & \\
\hline $\mathrm{A} 2$ & 2,95 & 8,76 & 295,69 & 335,84 & 871 & 2.943 & 3.814 & $9 \%$ \\
\hline A3 & 6,64 & 16,94 & 39,04 & 39,39 & 259 & 667 & 926 & $2 \%$ \\
\hline A3a & 3,48 & 22,76 & 17,58 & 26,51 & 61 & 603 & 664 & $1 \%$ \\
\hline A4 & 12,62 & 24,21 & 151,62 & 231,27 & 1.913 & 5.599 & 7.512 & $17 \%$ \\
\hline \multirow[t]{2}{*}{ BT } & 35,13 & 24,99 & 583,52 & 437,28 & 20.501 & 10.927 & 31.428 & $71 \%$ \\
\hline & & & & & 23.605 & 20.739 & 44.344 & $100 \%$ \\
\hline
\end{tabular}

A seguir, os sinais de ponta e fora de ponta, determinados pelo regulador, são aplicados aos custos de capacidade, mantendo a mesma receita a ser arrecadada por nível de tensão.

Tabela 4.11 - Sinalização ponta

\begin{tabular}{cc}
\hline \multicolumn{2}{c}{ Relação Ponta/Fora Ponta } \\
\hline A2 & 4,35 \\
\hline A3 & 3,65 \\
\hline A3a & 2,99 \\
\hline A4 & 3,00 \\
\hline BT & 5,00 \\
\hline
\end{tabular}


Tabela 4.12 - Custos Marginais de Capacidade ajustados ao sinal de ponta

\begin{tabular}{|c|c|c|c|c|c|c|c|c|}
\hline \multirow{2}{*}{$\begin{array}{c}\text { Grupo } \\
\text { tarifário }\end{array}$} & \multicolumn{2}{|c|}{$\begin{array}{c}\text { Custo capacidade } \\
(\mathrm{R} \$ \mathbf{k W})\end{array}$} & \multicolumn{2}{|c|}{ Demanda (MW) } & \multicolumn{3}{|c|}{ Receita mensal (R\$ mil) } & \multirow[t]{2}{*}{$\%$} \\
\hline & $\mathbf{P}$ & FP & $\mathbf{P}$ & FP & $\mathbf{P}$ & FP & Total & \\
\hline A2 & 10,23 & 2,35 & 295,69 & 335,84 & 3.024 & 790 & 3.814 & $9 \%$ \\
\hline A3 & 18,59 & 5,09 & 39,04 & 39,39 & 726 & 201 & 926 & $2 \%$ \\
\hline A3a & 25,13 & 8,40 & 17,58 & 26,51 & 442 & 223 & 664 & $1 \%$ \\
\hline $\mathrm{A} 4$ & 32,84 & 10,95 & 151,62 & 231,27 & 4.980 & 2.532 & 7.512 & $17 \%$ \\
\hline \multirow[t]{2}{*}{ BT } & 46,84 & 9,37 & 583,52 & 437,28 & 27.331 & 4.096 & 31.428 & $71 \%$ \\
\hline & & & & & 36.503 & 7.841 & 44.344 & $100 \%$ \\
\hline
\end{tabular}

Finalmente, o último procedimento é feito para ajustar os custos de capacidade ao mercado de faturamento, o que resulta nas tarifas de referência assim reconhecidas didaticamente nesta tese.

\section{Tabela 4.13 - Tarifas de Referência por Nível de Tensão}

\begin{tabular}{|c|c|c|c|c|c|c|c|c|}
\hline \multirow{2}{*}{$\begin{array}{c}\text { Grupo } \\
\text { tarifário }\end{array}$} & \multicolumn{2}{|c|}{$\begin{array}{c}\text { Tarifas de Referência } \\
(\mathrm{R} \$ / \mathbf{k W})\end{array}$} & \multicolumn{2}{|c|}{ Demanda (MW) } & \multicolumn{3}{|c|}{ Receita anual (R\$ mil) } & \multirow{2}{*}{$\%$} \\
\hline & $\mathbf{P}$ & FP & $\mathbf{P}$ & FP & $\mathbf{P}$ & FP & Total & \\
\hline $\mathrm{A} 2$ & 8,11 & 1,86 & $5.889,01$ & $6.915,46$ & 47.762 & 12.893 & 60.655 & $11 \%$ \\
\hline A3 & 14,74 & 4,04 & 342,16 & 343,36 & 5.044 & 1.387 & 6.431 & $1 \%$ \\
\hline A3a & 19,92 & 6,66 & 189,65 & 246,58 & 3.779 & 1.643 & 5.422 & $1 \%$ \\
\hline $\mathrm{A} 4$ & 26,04 & 8,68 & $2.709,62$ & $5.802,62$ & 70.572 & 50.376 & 120.948 & $23 \%$ \\
\hline \multirow[t]{2}{*}{ BT } & 37,14 & 7,43 & $7.862,82$ & $6.277,82$ & 292.041 & 46.634 & 338.676 & $64 \%$ \\
\hline & & & & & 419.198 & 112.934 & 532.132 & $100 \%$ \\
\hline
\end{tabular}

A figura a seguir apresenta os valores absolutos dos custos ilustrando os ajustes promovidos pela ANEEL, desde o custo de capacidade até a tarifa de referência. 


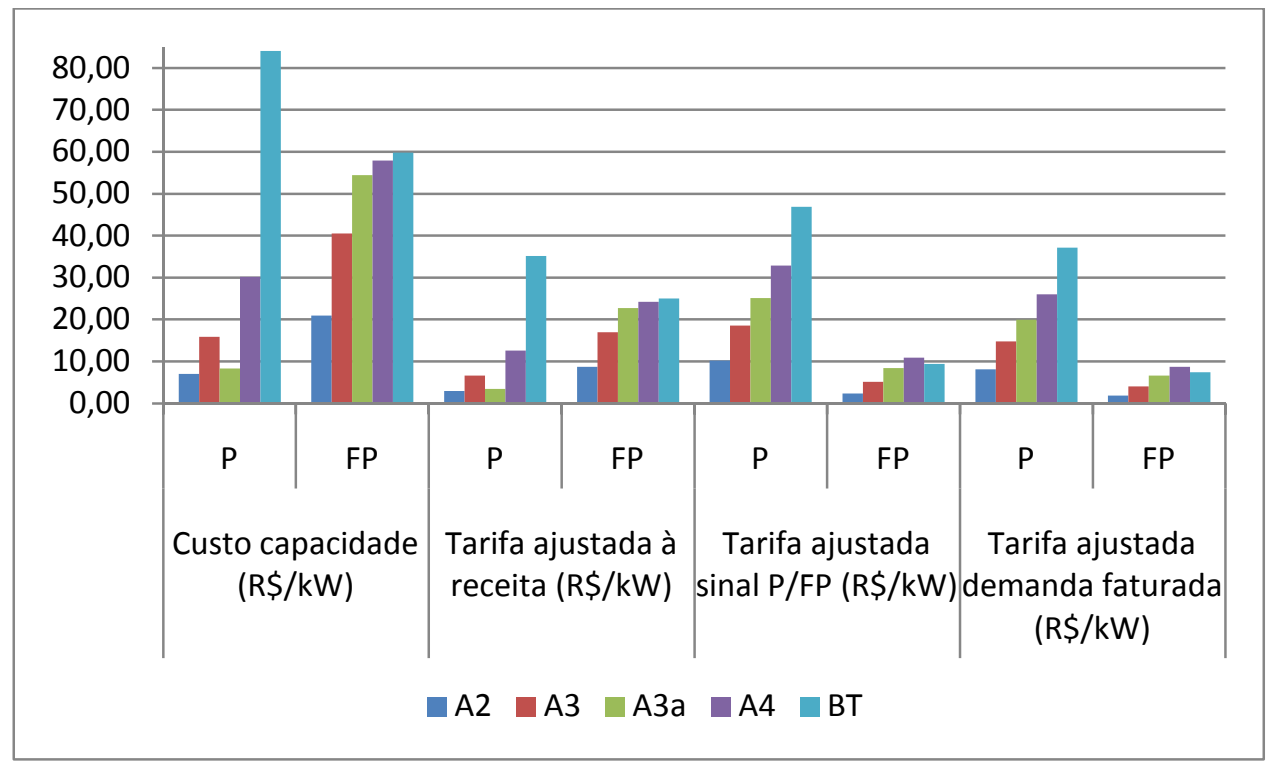

Figura 4.9 - Valores dos custos para a tarifa de referência

É interessante notar que o ajuste ao mercado de faturamento mantém a relatividade entre as tarifas por nível tensão, mas altera a relatividade entre as receitas que seriam arrecadadas, como demonstrado na Figura 4.10.

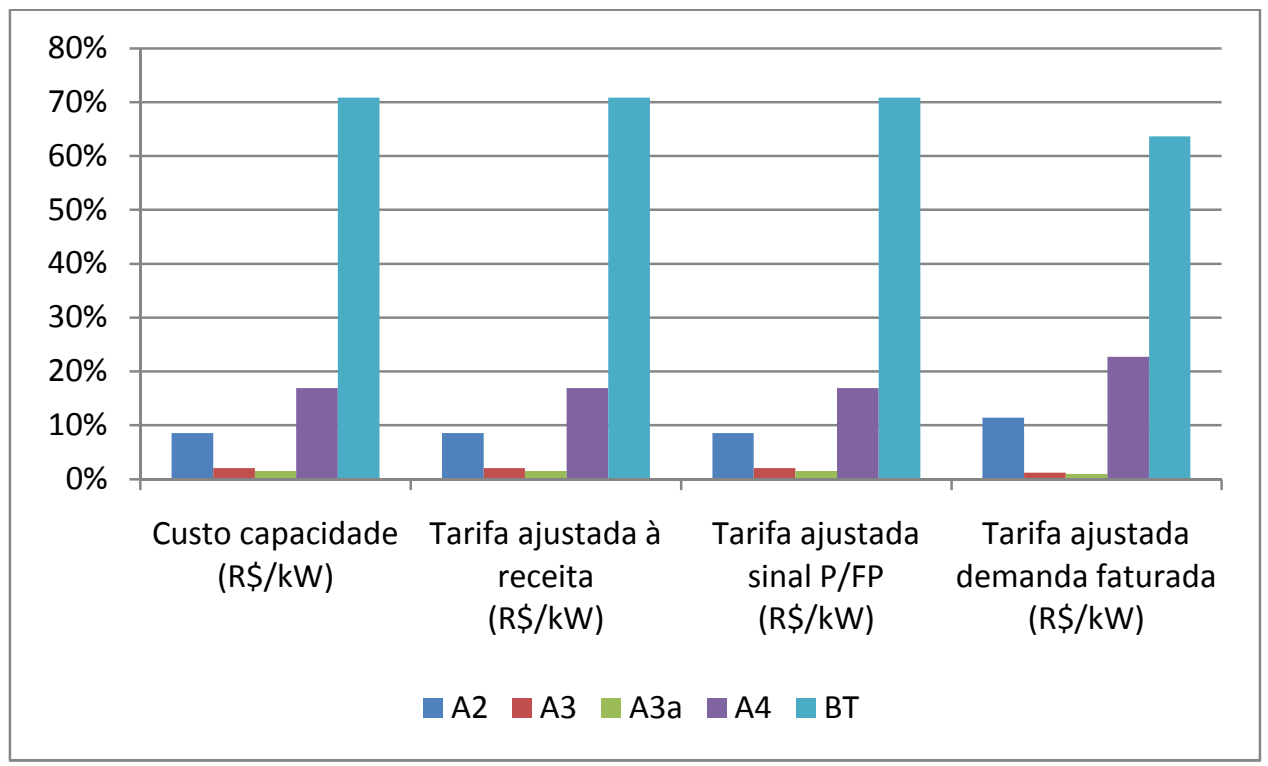

Figura 4.10 - Relatividade das receitas por nível de tensão

Como são instalados nos consumidores BT, em geral, medidores eletromecânicos que registram apenas a energia consumida, é necessário transformar a tarifa do serviço de distribuição desses consumidores de preços por demanda de potência para preços por energia consumida. Esta passagem é 
efetuada pela ANEEL utilizando os dados de fator de carga obtidos das curvas dos clientes-tipo da campanha de medidas.

No exemplo, as tarifas do consumidor BT da Tabela 4.13 são transformados em preço de energia correspondente a $\mathrm{R} \$ 106,28 / \mathrm{MWh}$.

\subsection{Tarifas de aplicação}

As tarifas de aplicação são constituídas pela Tarifa de Energia, aplicável somente aos consumidores cativos, e pela Tarifa de Uso do Sistema de Distribuição, cobradas de todos os usuários conectados no sistema da distribuidora, como já visto.

No caso dos preços de energia, como discutido anteriormente, não há explicitamente a sinalização de custo marginal. O preço da energia é um valor único ("selo") para todos os consumidores independentemente do nível de tensão e da classe de consumo. Contudo, a ANEEL utiliza parâmetros históricos para definir a relatividade dos preços horo-sazonais de energia, como apresentado discussão sobre os custos marginais de produção de energia elétrica.

\section{Tabela 4.14 - Relatividade dos Preços de Referência de Energia}

\begin{tabular}{lc}
\hline \multicolumn{1}{c}{ Tarifas } & Referência \\
\hline Ponta - Período Úmido & 1,72 \\
\hline Fora Ponta - Período Úmido & 1,00 \\
\hline Ponta - Período Seco & 1,93 \\
\hline Fora Ponta - Período Seco & 1,12 \\
\hline Convencional & 1,14 \\
\hline
\end{tabular}

A relatividade da tarifa convencional é aplicada também para os consumidores BT e foi calculada pela ponderação dos preços de referência dos períodos horo-sazonais.

Todas essas relatividades são aplicadas nas componentes da Tarifa de Energia: compra de energia para atendimento ao mercado (não inclui as perdas no sistema de distribuição); custos do transporte da energia proveniente da Usina de Itaipu; Encargos de Serviços do Sistema (ESS); parcela dos custos de P\&D e EE. 
Como mencionado inicialmente, na TUSD, determinadas componentes são alocadas aos consumidores conectados em diferentes níveis de tensão em função do custo marginal de capacidade e as demais em forma de "selo". No caso da tarifa para os consumidores BT, esses custos, calculados originalmente em termos de potência $(R \$ / k W)$, são transformados para a cobrança em termos de energia ( $\mathrm{R} \$ / \mathrm{MWh}$ ) utilizando as demandas máximas (ponta e fora de ponta) obtidas do processo de caracterização da carga e o mercado de energia.

Finalmente, essa tarifa única, calculada inicialmente para todos os clientes BT, é utilizada como base para definir as tarifas das classes B1 - Residencial; B1 Residencial Baixa Renda; B2 - Rural; B2 - Cooperativa de Eletrificação Rural; B3 Demais Classes; B4 - lluminação Pública. Essas tarifas são calculadas mantendo as relatividades existentes desde o modelo tarifário anterior.

\subsection{Modalidades Tarifárias}

O processamento dos dados da campanha de medidas, curvas dos clientestipo e redes-tipo que caracterizam a carga e o sistema de distribuição, identifica a responsabilidade e os custos de expansão de cada grupo de consumidores, conhecidos como clientes-tipo. Seria possível, então, construir as modalidades tarifárias, em cada posto tarifário, a partir do gráfico com os custos marginais de capacidade dos clientes-tipo em função do fator de carga ou horas de utilização, como demonstrado na figura a seguir. 


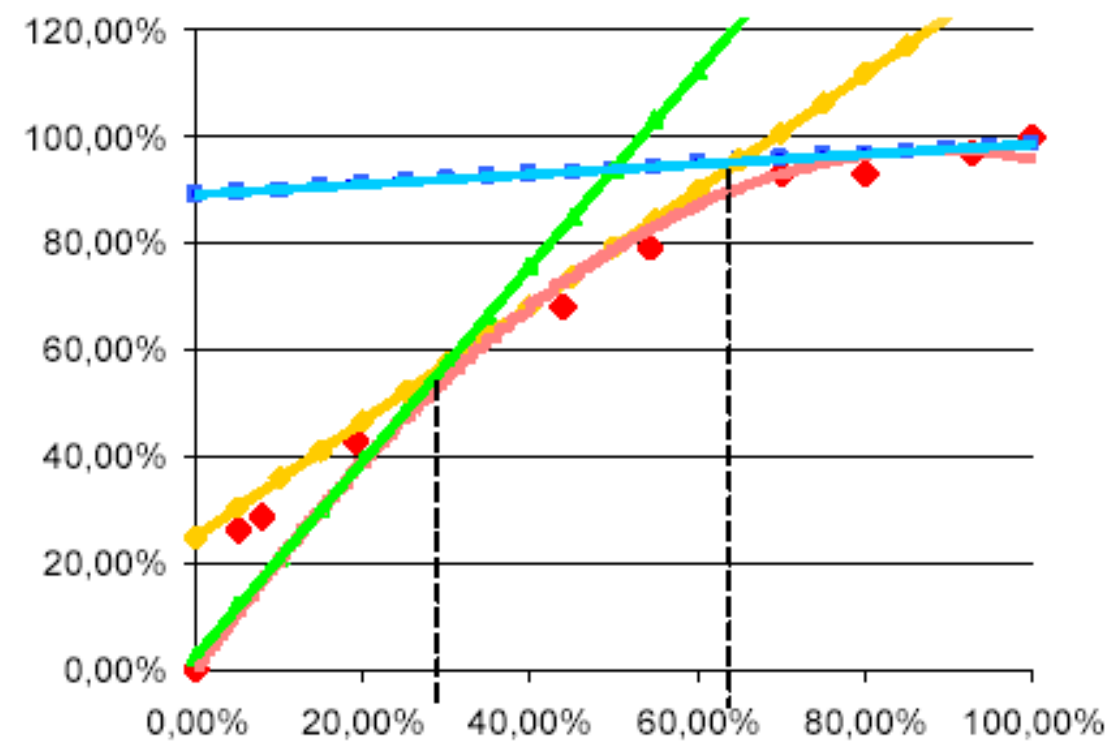

Figura 4. 11 - Modalidades tarifárias

Fonte: Santos (2008)

Observa-se na figura que uma tarifa média única resultaria em pagamentos inferiores em relação aos custos para alguns dos clientes-tipo e superiores para os demais, o que não seria uma maneira adequada de repartição de custos, considerando-se o objetivo de aproximar a tarifa dos custos reais de cada agregado de consumidores.

Do ponto de vista tarifário, é de interesse que as tarifas sejam funções lineares dos parâmetros de serviços fornecidos (consumos e demandas máximas dos clientes), de acordo com Santos et al. (2001). Assim, seria possível definir retas tangentes em vários pontos dessa curva, criando tarifas que buscam aproximar os consumidores de curta utilização, média utilização e longa utilização aos seus respectivos custos, como demonstrado na figura anterior.

No Brasil as modalidades tarifárias horo-sazonais azul e verde, calculadas em meados da década de 1980, correspondem às tarifas de longa utilização e de curta utilização, respectivamente (MME, 1994). Essa estrutura de tarifas foi mantida até os dias atuais, embora a sua construção, a partir da Resolução no 152/2003, tenha causado algumas distorções. 
A tarifa horo-sazonal azul, em tese aplicada aos consumidores com maior fator de carga, possui dois valores de tarifa para demanda (ponta e fora de ponta) e quatro para energia (ponta e fora de ponta nos períodos úmido e seco). Já a tarifa horo-sazonal verde possui apenas um valor de tarifa de demanda que independe do posto tarifário e quatro valores de tarifa de energia. Essa modalidade é aplicável somente para os consumidores do Grupo A até $69 \mathrm{kV}$.

O valor da tarifa de demanda da modalidade Verde é igual ao da tarifa de demanda fora de ponta da Azul. Por outro lado, no valor da tarifa de energia na ponta da modalidade Verde estão incorporados também os custos do serviço de distribuição, cobrados em termos de potência na tarifa horo-sazonal Azul, como demonstrado na Figura 4.12 a seguir.

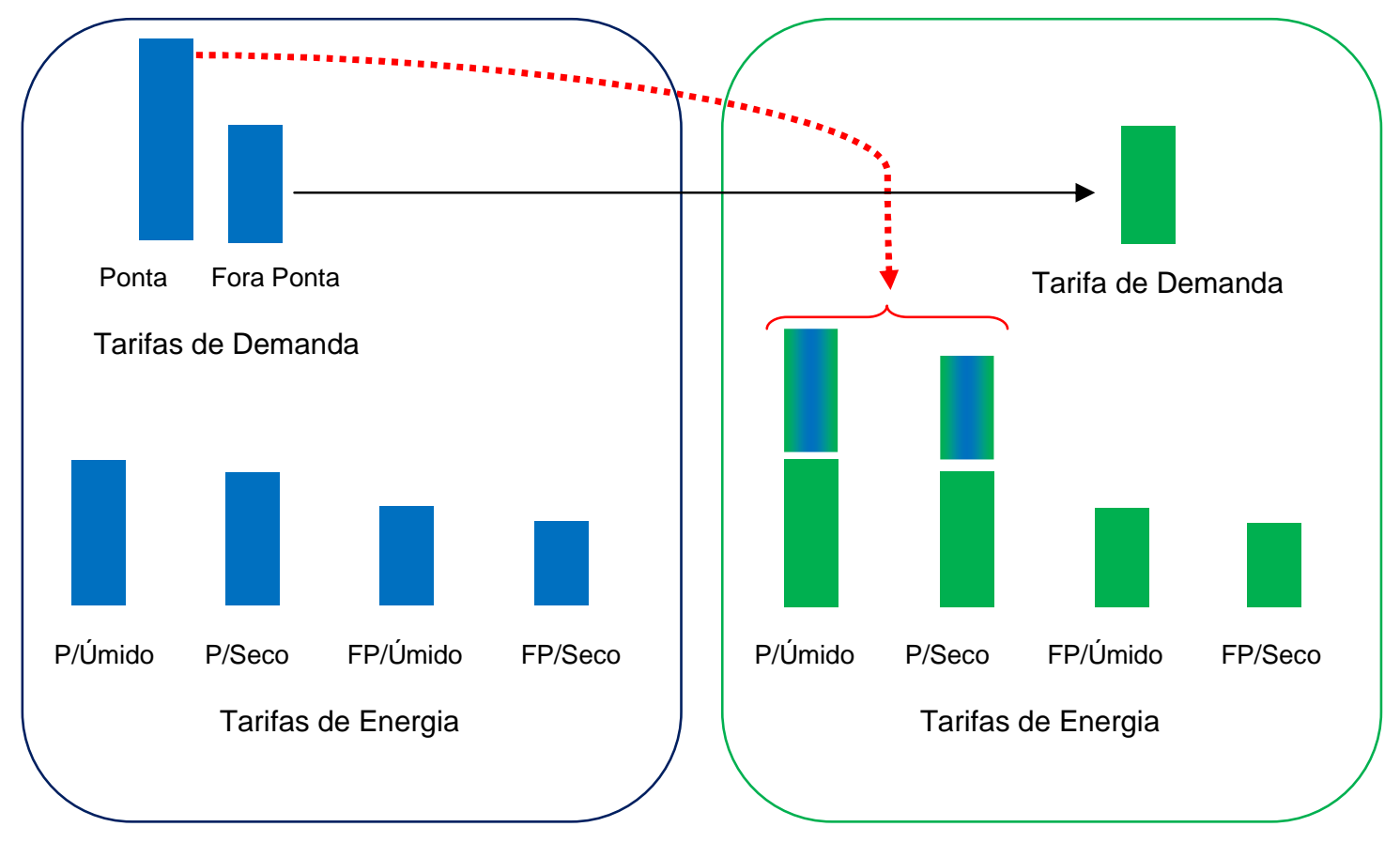

Figura 4.12 - Comparação das THS Azul e Verde

A ANEEL utiliza, na prática, o fator de carga igual 0,66 para transferir os custos de ponta da THS Azul para a tarifa de energia de ponta THS Verde, uma vez que não há tarifa de demanda de ponta nesta modalidade. 
No caso da tarifa convencional, a ANEEL manteve o procedimento que aloca, na tarifa de demanda, $72 \%$ dos custos de ponta e $100 \%$ dos custos fora de ponta ${ }^{20}$.

\subsection{Considerações}

Neste capítulo foi discutida a metodologia atualmente aplicada pela ANEEL para o cálculo das tarifas de fornecimento de energia elétrica, em especial os custos marginais de capacidade do cliente que são direcionadores para a alocação dos principais custos do serviço de distribuição.

Os métodos de cálculo dos custos marginais de expansão da geração, da transmissão e da distribuição foram comparados, destacando que, diferentemente da época em que o método foi implantado, somente os custos marginais de expansão do sistema de distribuição é aplicado atualmente nas tarifas.

Foi também detalhado um dos aspectos mais importantes da metodologia que é a possibilidade de alocação horária dos custos marginais de expansão, considerando os momentos de maior carregamento das redes e as respectivas responsabilidades dos consumidores nesses horários. Contudo, atualmente, a metodologia utiliza os custos horários somente para a formação das tarifas por posto tarifário que, posteriormente, são ajustadas para manter a relatividade entre ponta e fora de ponta.

\footnotetext{
${ }^{20}$ Nessa modalidade há uma única tarifa de demanda que é aplicada sobre o maior valor registrado independentemente do horário.
} 


\section{CAPÍTULO 5 - ANÁLISE DA METODOLOGIA}

O Capítulo 4 apresentou uma visão geral da atual metodologia de cálculo das tarifas de distribuição baseado na alocação horária dos custos marginais de expansão de cada nível de tensão. Contudo, como o ambiente institucional atual difere daquele existente na época em que a metodologia foi desenhada, há algumas inconsistências que podem ser identificadas por meio da análise da metodologia, objeto deste capítulo.

\subsection{Custo marginal}

\subsubsection{Custo marginal de geração}

Atualmente a tarifa de fornecimento de energia elétrica não utiliza o sinal dos custos marginais de geração. Ao contrário, como visto, a tarifa corresponde ao custo médio dos contratos de longo prazo da distribuidora.

Contudo, embora os preços dos contratos sejam iguais independentemente do período e do horário, há uma sinalização horo-sazonal na tarifa de energia paga pelo consumidor cativo. A ANEEL aplica hoje valores diferentes para o preço da energia elétrica segundo os períodos de produção, úmido ou seco, e horários de maior ou menor carregamento do sistema de transporte, ponta ou fora de ponta, como visto anteriormente.

Analisando as planilhas de cálculo da ANEEL, observa-se que essas relatividades das tarifas de energia são provenientes da Resolução no 176/2002 que homologou as tarifas da Cemig. Tal fato confirma que as relatividades foram definidas com base em relações históricas decorrentes da metodologia aplicada em 1985.

Os custos marginais de expansão da geração podem ser estimados, atualmente, com base nos resultados dos leilões de energia, provenientes de novos empreendimentos, estabelecidos pelo novo modelo do setor elétrico.

O preço teto do leilão de determinada usina está relacionado com a curva de custos de expansão estimada pela EPE. O custo marginal de expansão corresponde 
ao preço da usina, obtido no ponto da curva de custos de expansão no qual seja "indiferente entre construir o projeto ou operar o sistema a fim de atender à demanda adicional", ou seja, no ponto em que o custo marginal de expansão é igual ao custo de marginal de operação (MME, 2008).

Dessa forma, os resultados dos leilões poderiam ser utilizados como uma representação da curva de custo de expansão, sendo, então, o preço do empreendimento mais caro aceito no leilão, uma aproximação do custo marginal de expansão. Teoricamente, o "preço do leilão representa um valor atual da expansão, ao passo que o custo marginal de expansão varia com o tempo, refletindo o aproveitamento prioritário dos empreendimentos mais competitivos" (MME, 2008).

No Plano Decenal de Expansão de Energia 2008/2017 é adotado o critério de igualdade entre os custos marginais de operação e de expansão para cada ano do período, além do nível máximo de $5 \%$ de déficit. De acordo com o MME (2008), o custo marginal de expansão utilizado nos estudos corresponde ao valor de $R \$$ $146,00 / \mathrm{MWh}$ que é o preço da usina mais cara contratada nos leilões de novos empreendimentos realizados em 2008.

Contudo, esse custo marginal definido com base nos leilões de novos empreendimentos não tem diferenciação sazonal ou horária de preços. Para obter esses valores poderia ser aplicada a metodologia anterior que utilizava as avaliações energéticas para estimar os custos horários e sazonais.

Em outras palavras, poderiam ser estimadas as diferenciações de preços com base nas simulações dos custos marginas de operação, por patamar, calculados pelos aplicativos regularmente utilizados pelo ONS e pela CCEE.

Ayala et al. (2010), apresenta uma metodologia de cálculo cujas simulações, considerando as informações disponibilizadas no Programa Mensal de Operação (PMO) e acrescida das usinas contratadas nos leilões, demonstra que a razão entre as tarifas nos horários de ponta e fora da ponta é, significativamente, inferior ao estabelecido pela ANEEL, conforme apresentado na Tabela 5.1. 
Tabela 5.1 - Tarifas finais por submercados $(\mathbf{R} \$ / \mathrm{MWh})$

\begin{tabular}{llll}
\hline \multirow{2}{*}{ Submercado } & Horário & Úmido & Seco \\
\hline \multirow{2}{*}{ Sudeste } & Ponta & 169 & 198 \\
& Fora da Ponta & 151 & 168 \\
\hline \multirow{2}{*}{ Sul } & Ponta & 172 & 200 \\
& Fora da Ponta & 158 & 171 \\
\hline \multirow{2}{*}{ Nordeste } & Ponta & 165 & 183 \\
& For a da Ponta & 147 & 163 \\
\hline \multirow{2}{*}{ Norte } & Ponta & 147 & 193 \\
& For a da Ponta & 138 & 172 \\
\hline
\end{tabular}

Fonte: Ayala et al.(2010)

A maior relação entre os preços dos horários de ponta e fora de ponta foi de 1,18 para o período seco da região Sudeste enquanto que a relação utilizada pela agência reguladora é de 1,72. Segundo Ayala et al. (2010), tal resultado reflete o caráter predominante hidráulico do setor elétrico brasileiro que inerentemente tem uma sobre-capacidade destinada a acomodar a grande variabilidade de afluências hidrológicas. Em outras palavras, segundo os autores, os investimentos são direcionados para aumentar a energia firme do sistema e não para o atendimento da ponta. Dessa forma, "as térmicas operam na base e toda a modulação da carga é feita com as hidrelétricas a um custo zero"”.

Outra forma de estimar esses sinais, porém focando o passado e não o futuro, seria por meio da análise dos preços de liquidação de diferenças (PLD) de determinado período.

Nesta situação, considerando o período de 30/06/2001 a 30/04/2010, observa-se que a variação percentual entre os PLD dos patamares pesado e leve em relação ao médio não ultrapassou 1,9\% e -2,9\%, respectivamente. Mesmo considerando o maior desvio padrão, obtido para o patamar pesado no submercado Norte, não haveria uma diferença superior a $40 \%$ entre os preços dos patamares para $99 \%$ das semanas com base em uma distribuição normal. Porém, o PLD tem uma volatilidade grande, como pode ser observada na Tabela 5.2, atingindo $136,1 \%$

\footnotetext{
${ }^{1}$ Sendo a geração elétrica no Brasil predominantemente hidráulica, as usinas termelétricas têm a função de complementação do sistema, sendo acionadas para manter nível de risco aceitável considerando a probabilidade da ocorrência de um regime hidrológico desfavorável.
} 
no submercado Sudeste e $169,8 \%$ no Norte, o que pode ser considerada normal em razão da metodologia atualmente utilizada.

Tabela 5.2 - Diferenças entre os PLDs por patamar nos submercados

\begin{tabular}{|c|c|c|c|}
\hline \multirow{2}{*}{ Submercado } & & \multicolumn{2}{|c|}{ Patamares } \\
\hline & & Pesado/Médio & Leve/Médio \\
\hline \multirow{3}{*}{ SE } & Média & $1,1 \%$ & $-1,9 \%$ \\
\hline & Desvio padrão & $3,0 \%$ & $6,0 \%$ \\
\hline & Máximo & $56,2 \%$ & $-64,8 \%$ \\
\hline \multirow{3}{*}{$\mathbf{S}$} & Média & $1,1 \%$ & $-3,3 \%$ \\
\hline & Desvio padrão & $7,0 \%$ & $6,0 \%$ \\
\hline & Máximo & $136,1 \%$ & $-75,2 \%$ \\
\hline \multirow{3}{*}{ NE } & Média & $0,3 \%$ & $-0,3 \%$ \\
\hline & Desvio padrão & $0,8 \%$ & $1,0 \%$ \\
\hline & Máximo & $4,3 \%$ & $-13,5 \%$ \\
\hline \multirow{3}{*}{$\mathbf{N}$} & Média & $1,9 \%$ & $-2,9 \%$ \\
\hline & Desvio padrão & $13,2 \%$ & $11,1 \%$ \\
\hline & Máximo & $169,8 \%$ & $-86,3 \%$ \\
\hline
\end{tabular}

As próximas duas figuras demonstram graficamente que não há diferenças significativas do PLD por patamar numa mesma semana. Observa-se na Figura 5.1 que, no submercado Sudeste, praticamente não se consegue identificar os custos nos patamares pesado e médio, pois ambos estão sob a curva do PLD do patamar leve. Mesmo no caso do submercado Norte onde as variações são maiores, o patamar pesado quase não se distingue do patamar leve, conforme Figura 5.2. 


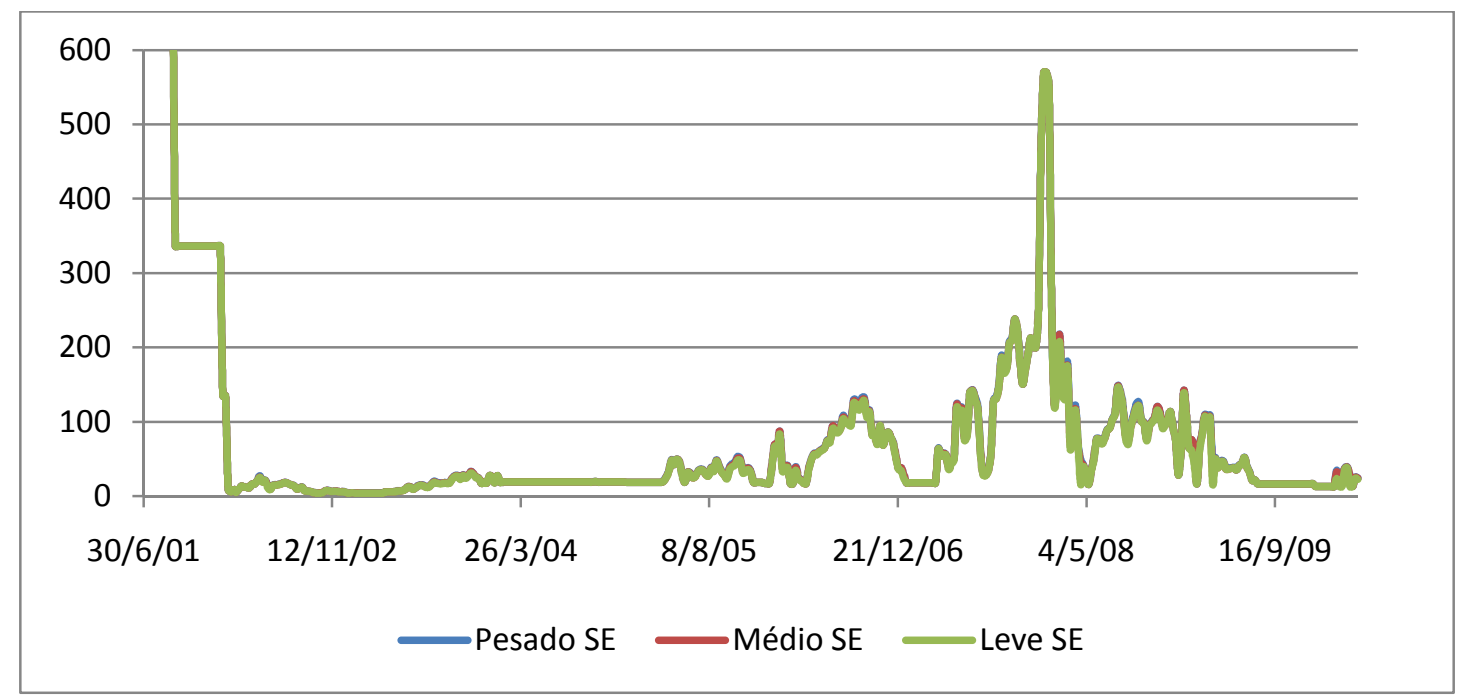

Figura 5.1 - PLD por patamar no Submercado Sudeste

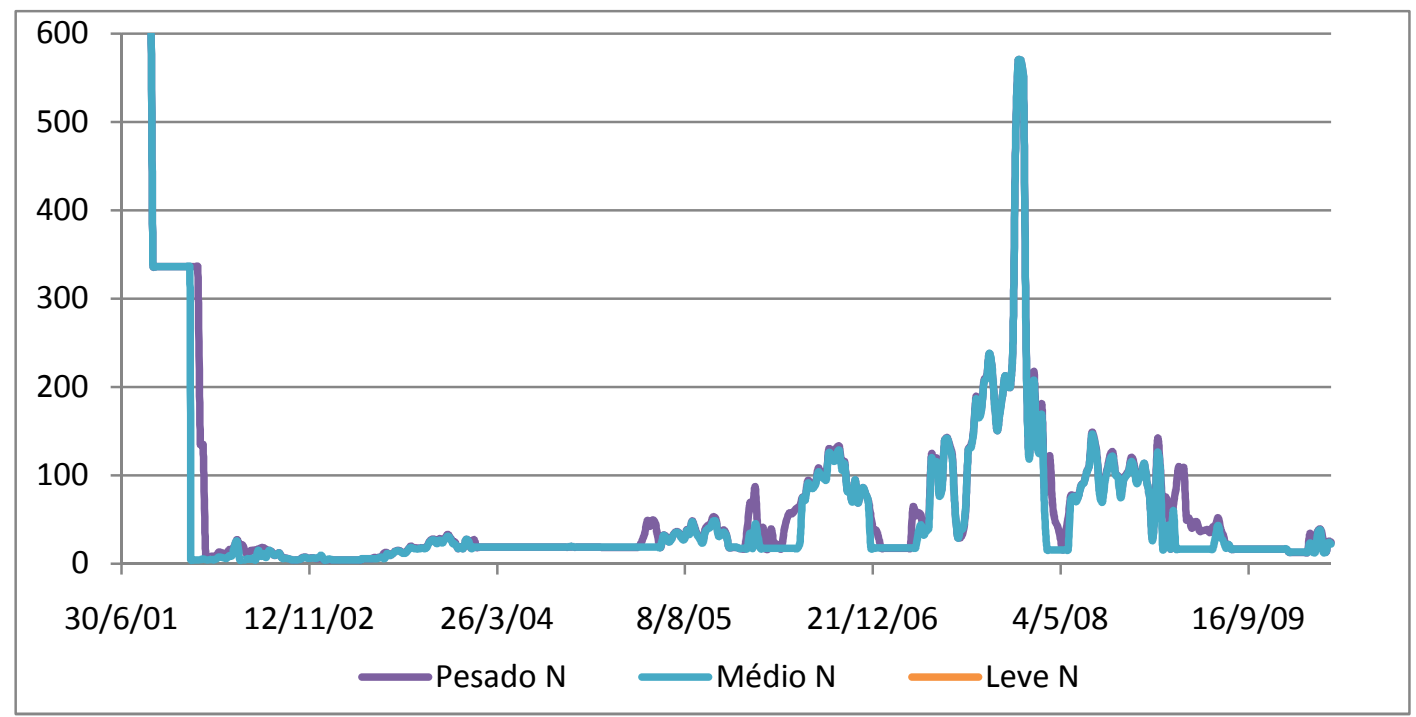

Figura 5.2 - PLD por patamar no Submercado Norte

Sendo a energia produzida, predominantemente, por meio de hidrelétricas, é natural que a sazonalidade na produção esteja refletida nas tarifas dos consumidores desde meados da década de 1980. Os períodos tarifários são denominados seco e úmido, e correspondem, respectivamente, aos períodos de maio a novembro e de dezembro a abril.

Considerando esses meses que definem os períodos e utilizando a mesma base de dados da estimativa anterior, observa-se que há uma clara diferenciação de preços entre os períodos seco e úmido, ao contrário do caso do sinal horário. 
Os anos de 2002 e 2004 são pontos fora da curva e não devem ser considerados na análise, pois, em 2002, ocorreu o racionamento de energia elétrica em, 2004, os preços de curto prazo ficaram estáveis durante todo o ano em razão, principalmente, das sobras de energia decorrentes da retração de mercado. Da mesma forma, os anos de $2008^{2}$ e $2009^{3}$ devem ser descartados da análise uma vez que fenômenos climáticos alteraram a lógica de que o PLD no período úmido é menor do que no período seco. Por outro lado, essas ocorrências comprovam que o PLD está relacionado, em grande parte, com a energia natural afluente ${ }^{4}$, mesmo que as intensidades estejam ocorrendo de maneira não regular.

\section{Tabela 5.3 - Relatividades entre os PLDs seco e úmido}

\begin{tabular}{lrrr}
\hline Ano & $\begin{array}{c}\text { Média } \\
\text { Seco/Úmido }\end{array}$ & $\begin{array}{c}\text { Máximo } \\
\text { Seco/Úmido }\end{array}$ & $\begin{array}{c}\text { Mínima } \\
\text { Seco/Úmido }\end{array}$ \\
\hline 2001 & $152 \%$ & $184 \%$ & $112 \%$ \\
2002 & $30 \%$ & $60 \%$ & $4 \%$ \\
2003 & $192 \%$ & $234 \%$ & $111 \%$ \\
2004 & $78 \%$ & $98 \%$ & $25 \%$ \\
2005 & $139 \%$ & $181 \%$ & $90 \%$ \\
2006 & $222 \%$ & $309 \%$ & $147 \%$ \\
2007 & $208 \%$ & $228 \%$ & $181 \%$ \\
2008 & $42 \%$ & $43 \%$ & $41 \%$ \\
2009 & $47 \%$ & $56 \%$ & $40 \%$ \\
\hline
\end{tabular}

Em resumo, das análises da variação do PLD, conclui-se que não haveria razão para diferenciação horária das tarifas de energia (na ponta e fora de ponta) para os consumidores cativos, pois não houve, na média, variações significativas entre os preços dos patamares de carga leve, médio e pesado. Além disso, a alta volatilidade do PLD justifica que esse sinal de curto prazo não seja repassado para o consumidor cativo, uma vez que não contribui para orientar o seu comportamento.

\footnotetext{
${ }^{2}$ Conforme apresentações de previsão de vazão do PMO -ONS da época, no período úmido de 2007/2008, os preços de curto prazo ficaram altos por causa das baixas afluências decorrentes do fenômeno La Niña. Exemplo: Subsistema Sudeste - 61ํㅡㄹ Dezembro do Histórico - Ranking Decrescente de um total de 77 anos.

${ }^{3}$ Conforme apresentações de previsão de vazão do PMO -ONS da época, no período seco de 2009 , os preços ficaram baixos devido à boa hidrologia no Sul e no Sudeste/Centro-Oeste, decorrente do fenômeno El Niño. Exemplo: Subsistema Sudeste - 3ํㅗ Setembro do Histórico - Ranking Decrescente de um total de 79 anos.

${ }^{4}$ Além da energia natural afluente (ENA), outros fatores como o nível de armazenamento e o balanço estrutural do sistema influenciam o PLD.
} 
Por outro lado, seria adequada a manutenção da diferenciação sazonal na tarifa de energia para os consumidores cativos uma vez que o estudo indica que, em geral, o PLD do período seco é maior do que o preço do período úmido. Mesmo que os preços dos contratos de longo prazo não variem com o período de produção, seria interessante que existisse este sinal para o consumidor final uma vez que a distribuidora está sujeita ao PLD na liquidação de curto prazo. Sob o ponto de vista da expansão do sistema elétrico, a diferenciação de preços para o consumidor final também forneceria um sinal econômico adequado.

\subsubsection{Custo marginal de transmissão}

A distribuidora deve contratar o acesso à Rede Básica para assegurar o atendimento da demanda do seu mercado, dos consumidores livres e das unidades geradoras conectadas em suas instalações. Para cada ponto de conexão com o sistema de transmissão deve ser contratado o montante de uso do sistema de transmissão (MUST) que corresponde à máxima potência demandada pela distribuidora.

Em cada ponto de conexão a TUST possui um valor diferente, pois é calculada com base na metodologia locacional, sendo, então, o custo da conexão à Rede Básica correspondente à somatória do produto da TUST pelo MUST em cada ponto de conexão. Além disso, os custos das instalações de transmissão denominadas de Rede Básica Fronteira e Demais Instalações de Transmissão e instalações de conexão são arcados somente pelos agentes que os utilizam, por meio do pagamento da TUST-FR e do encargo de conexão.

No caso de alocação dos custos de uso da Rede Básica, o valor é, por enquanto, dividido somente pelo mercado de demanda de potência no horário de ponta ${ }^{5}$, enquanto os demais custos, como conexão, DIT e RB Fronteira, são rateados entre os períodos tarifários de ponta e fora de ponta. Este procedimento resulta em um valor igual (selo) que é cobrado na tarifa independentemente do tipo de consumidor atendido pela empresa.

\footnotetext{
${ }^{5}$ Resolução Normativa no 399/2010 definiu, contudo, que o uso do sistema de transmissão será contratado para ambos os horários, sendo que as tarifas fora do horário de ponta permanecerão iguais a zero até 30 de junho de 2011.
} 
Em resumo, nesta componente não há sinal de custo marginal da transmissão e tampouco há sinal locacional que, embora pago pela distribuidora, não é alocado aos consumidores seguindo essa lógica.

\subsubsection{Custo marginal de distribuição}

A Resolução $n^{\circ}$ 234/06 estabelece que a metodologia para análise dos investimentos, para fins tarifários, pode ser baseada em três fontes de informações: i) histórico dos investimentos, ii) plano de obras proposto pela distribuidora com as informações necessárias para sua análise; e iii) simulação através da metodologia de planejamento agregado. Como já discutido no Capítulo 2, o primeiro conjunto de informações possibilita a aplicação da metodologia conhecida como Lei de Quantidade de Obras (LQO) e os demais, do Custo Incremental Médio de Longo Prazo (CIMLP).

Dentre as metodologias possíveis para se calcular o custo de expansão do sistema de distribuição, a ANEEL poderia utilizar, então, os dados do Plano de Desenvolvimento da Distribuição (PDD) para calcular o custo incremental médio de longo prazo.

O PDD foi concebido para coletar informações sobre o planejamento da expansão das redes das distribuidoras, conforme regulamentado pelos Procedimentos de Distribuição (Prodist). Tanto o plano de obras quanto as projeções de crescimento de carga devem ser discretizados anualmente, no horizonte de planejamento considerado, que corresponde a dez anos para o Sistema de Distribuição de Alta Tensão (SDAT) e para as Subestações de Distribuição (SED); e a cinco anos para o Sistema de Distribuição de Média Tensão (SDMT) e para o Sistema de Distribuição de Baixa Tensão (SDBT).

Os investimentos no sistema de distribuição são classificados no PDD como obras relacionadas com i) a expansão das redes elétricas ${ }^{6}$, ii) a renovação dos

\footnotetext{
${ }^{6}$ A obra de expansão está associada exclusivamente ao incremento de carga, motivada pelo aumento de demanda de consumidores existentes ou pela ligação de novos consumidores.
} 
ativos de distribuição ${ }^{7}$, iii) a melhoria da qualidade do sistema ${ }^{8}$, iv) o Programa Luz Para Todos e iv) a participação financeira de terceiros, conforme ANEEL (2009b).

O cálculo dos custos marginais, por nível de tensão, realizados no PDD utiliza o método de CIMLP e considera todas as obras planejadas pela distribuidora, bem como percentuais sobre os investimentos como custos de operação e manutenção, conforme pode ser verificado na planilha disponibilizada no sítio eletrônico da ANEEL.

Em tese, para o cálculo do custo marginal, não poderiam ser utilizadas obras de melhoria uma vez que estas não estão relacionadas com a expansão do sistema. Por outro lado, há agentes que defendem a inserção deste tipo de obra no método de cálculo, pois a adequação do nível de tensão e a redução de perdas elétricas possibilitariam aumentar a capacidade de atendimento de determinado sistema, por exemplo. Em outras palavras, sob esta ótica, os custos de expansão deveriam considerar também as restrições de qualidade.

Esta discussão traz à tona outro aspecto da metodologia que deve ser estudado. Novamente, segundo a teoria econômica, os custos marginais de curto prazo e de longo prazo tendem a se igualar quando o sistema está totalmente ajustado ao mercado. Por esse motivo, há autores que defendem que o custo marginal deva ser estimado levando em consideração um sistema otimizado e não o sistema existente que pode estar tanto sobre ou sub-dimensionado.

O sistema de distribuição de energia elétrica, por vezes não está diretamente ajustado ao mercado, uma vez que a sua expansão pode não ser proporcional à carga a ser atendida: determinadas obras, como a construção de uma subestação e alimentadores, não são divisíveis sob o ponto de vista econômico e de execução.

A aplicação do CIMLP com base no plano de obras da distribuidora definido em um horizonte de planejamento adequado pode mitigar a influência da possível folga no carregamento sistema. A metodologia calcula os valores médios de investimento e de acréscimo de mercado que são valorados a determinada taxa de

\footnotetext{
${ }^{7}$ A obra de renovação é aquela necessária para substituição de ativos elétricos que tenham chegado ao final da vida útil.

${ }_{8}$ A obra de melhoria está relacionada exclusivamente com a melhoria da qualidade e da confiabilidade do sistema de distribuição.
} 
retorno. Este procedimento tem o mérito de tratar as possíveis descontinuidades de investimentos. Por outro lado, o ano de implementação dos investimentos influencia o valor calculado do custo marginal: obras realizadas no final do período têm impacto menor do que as realizadas no início do estudo.

De acordo com Antunes, N. P. (2007) os investimentos, tanto nas redes como nas transformações, deveriam ser segregados para diferenciar os custos de expansão na área urbana e rural. Uma vez que o fluxo que transita nas subestações, neste caso, alimenta tanto as redes urbanas e como as redes rurais, os investimentos nas transformações não poderiam ser alocados somente nos consumidores urbanos.

As metodologias para cálculo de custo marginal necessitam que cada investimento seja anualizado a uma taxa mínima de atratividade. O critério proposto pelo DNAEE (1985) tem duas componentes: a remuneração, calculada pela aplicação da referida taxa sobre o investimento, e a depreciação, correspondente ao valor do investimento dividido pela quantidade de anos previstos de vida útil dos equipamentos. Todavia, esse critério conhecido como Amortização Linear tem a desvantagem de que as parcelas anuais (somatória da remuneração e depreciação) são decrescentes ao longo do período.

A alternativa mais adequada para o cálculo do valor anual do investimento é a aplicação do Fator de Recuperação de Capital que resulta em fluxo uniforme durante todo o período de estudo, o que facilita o tratamento dos custos no período. A aplicação desse método para a anualização dos investimentos, conhecido como Sinking Fund, é defendida por vários autores, como Antunes, A. U. (2004), Antunes, N. P. (2007) e ANEEL (2001).

A Tabela 5.5 apresenta um exemplo de cálculo efetuado pela ANEEL com base nos custos anuais de expansão de determinado sistema. Observa-se, contudo, que a taxa adotada para a anualização dos investimentos (18,96\% no exemplo a seguir) não está correta ao somar as três parcelas (taxas mínima de atratividade, taxa de depreciação e taxa de operação e manutenção do sistema) e aplicá-las para calcular o Fator de Recuperação do Capital. 
Tabela 5.5 - Cálculo ANEEL do CIMLP

\section{Faixa de Tensão: $88 \mathrm{kV}$ a $138 \mathrm{kV}$}

\begin{tabular}{|c|c|c|c|c|c|}
\hline & $\begin{array}{l}\text { Vida Útil (anos) } \\
\text { TMA } \\
\text { Depreciação } \\
\text { O\&M } \\
\text { i }\end{array}$ & $\begin{array}{r}34 \\
12,00 \% \\
2,96 \% \\
4,00 \% \\
18,96 \% \\
\end{array}$ & & & \\
\hline Ano & $\begin{array}{l}\text { Investimento } \\
\text { (R\$) }\end{array}$ & $\begin{array}{c}\text { Valor } \\
\text { anualizado } \\
(\mathbf{R} \$)\end{array}$ & $\begin{array}{c}\text { Valor presente } \\
\text { (R\$) }\end{array}$ & $\begin{array}{c}\text { Demanda } \\
\text { adicional (MW) }\end{array}$ & $\begin{array}{c}\text { Valor } \\
\text { Presente } \\
\text { (kW) }\end{array}$ \\
\hline 2000 & 4.133.800,00 & $785.972,92$ & $785.972,92$ & 53 & 53.000 \\
\hline 2001 & $5.720 .800,00$ & $1.087 .714,42$ & $971.173,59$ & 68 & 60.714 \\
\hline 2002 & $7.654 .500,00$ & $1.455 .375,13$ & $1.160 .216,14$ & 64 & 51.020 \\
\hline 2003 & $3.866 .600,00$ & $735.169,31$ & $523.278,99$ & 60 & 42.707 \\
\hline 2004 & 0,00 & 0,00 & 0,00 & 61 & 38.767 \\
\hline 2005 & 0,00 & 0,00 & 0,00 & 69 & 39.152 \\
\hline 2006 & $5.690 .100,00$ & $1.081 .877,33$ & $548.112,73$ & 71 & 35.971 \\
\hline 2007 & $10.161 .900,00$ & $1.932 .115,30$ & $873.990,84$ & 74 & 33.474 \\
\hline \multirow[t]{3}{*}{2008} & $2.090 .500,00$ & $397.473,61$ & $160.532,92$ & 77 & 31.099 \\
\hline & & Total & $5.023 .278,14$ & & 385.904 \\
\hline & & & & CIMLP $(R \$ / k W)$ & 13,02 \\
\hline
\end{tabular}

Fonte: ANEEL (2000)

Com certeza, o uso da taxa de depreciação é indevido, pois o próprio Fator de Recuperação de Capital, do método Sinking Fund, ao considerar, como parâmetros, a vida útil e a taxa de remuneração, já incorpora a depreciação dos equipamentos.

Além disso, a taxa de operação e manutenção não deveria ser incluída no cálculo do fator de recuperação de capital. Na visão do autor, esta taxa foi estimada, originalmente, como um percentual do investimento. Dessa forma, deve-se aplicar a taxa de operação e manutenção diretamente ao custo do investimento anualizado, ao invés de somar à taxa de remuneração para compor a taxa de atualização do investimento pela aplicação do método de Sinking Fund.

A Tabela 5.6 a seguir apresenta, em detalhes, o que seria a aplicação adequada da metodologia. 
Tabela 5.6 - Cálculo dos custos marginais

\section{Faixa de Tensão: $88 \mathrm{kV}$ a $138 \mathrm{kV}$}

\begin{tabular}{|c|c|c|c|c|}
\hline & $\begin{array}{l}\text { Vida Útil (anos) } \\
\text { TMA } \\
\text { Depreciação } \\
\text { O\&M } \\
\text { i }\end{array}$ & $\begin{array}{r}34 \\
12,00 \% \\
2,96 \% \\
4,00 \% \\
18,96 \% \\
\end{array}$ & \multicolumn{2}{|l|}{33,78} \\
\hline Ano & $\begin{array}{c}\text { Investimento } \\
(\mathbf{R} \$)\end{array}$ & $\begin{array}{c}\text { Valor presente } \\
(\mathbf{R} \$)\end{array}$ & $\begin{array}{l}\text { Demanda adicional } \\
\text { (MW) }\end{array}$ & $\begin{array}{c}\text { Valor Presente } \\
\text { (kW) }\end{array}$ \\
\hline 2000 & $4.133 .800,00$ & $4.133 .800,00$ & 53 & 53.000 \\
\hline 2001 & $5.720 .800,00$ & $5.107 .857,14$ & 68 & 60.714 \\
\hline 2002 & $7.654 .500,00$ & $6.102 .120,54$ & 64 & 51.020 \\
\hline 2003 & $3.866 .600,00$ & 2.752.169,51 & 60 & 42.707 \\
\hline 2004 & 0,00 & 0,00 & 61 & 38.767 \\
\hline 2005 & 0,00 & 0,00 & 69 & 39.152 \\
\hline 2006 & $5.690 .100,00$ & 2.882.781,74 & 71 & 35.971 \\
\hline 2007 & $10.161 .900,00$ & 4.596.727,49 & 74 & 33.474 \\
\hline \multirow[t]{6}{*}{2008} & $2.090 .500,00$ & $844.317,89$ & 77 & 31.099 \\
\hline & Total & 26.419.774,31 & & 385.904 \\
\hline & & & CIMLP $(\mathrm{R} \$ / \mathrm{kW})$ & 68,46 \\
\hline & & & Custo marginal $(\mathrm{R} \$ / \mathrm{kW})$ & 8,39 \\
\hline & & & $\mathrm{O} \& \mathrm{M}(\mathrm{R} \$ / \mathrm{kW})$ & 2,74 \\
\hline & & & $\begin{array}{l}\text { Custo expansão } \\
\text { (R\$/kW) }\end{array}$ & 11,13 \\
\hline
\end{tabular}

\subsection{Curvas de carga}

De acordo com a regulamentação, a estratificação definida pela ANEEL segrega os consumidores por nível de tensão de conexão e por faixa de consumo, para fins de caracterização da carga.

Normalmente, as distribuidoras agrupam as unidades consumidoras exatamente nos estratos previstos pela agência reguladora, como apresentado no Capitulo 4, não se preocupando com as modalidades tarifárias.

O Módulo 2 do Prodist já indica essa necessidade ao instruir que, para fins de caracterização da curva de carga, as distribuidoras considerem "os diversos 
segmentos de unidades consumidoras, conforme modalidades tarifárias, classes de faturamento e faixas de consumo".

Essa classificação é importante para que possam ser identificados os comportamentos causados pelos diferentes tipos de tarifas aplicadas aos consumidores atendidos na média tensão (A4 e A3a), como a THS Azul, THS Verde e Tarifa Convencional. Mesmo porque, a correta aplicação das novas tarifas depende das reações desses tipos de consumidores. O conhecimento da propensão a pagar, da elasticidade preço da demanda e das respectivas curvas de carga características ajudam a mensurar essas reações.

O regulamento também prevê que as estratificações das redes com tensão inferior ou igual a $44 \mathrm{kV}$ sejam feitas considerando a divisão entre redes aéreas e subterrâneas e entre área urbana e rural. Embora não seja utilizado atualmente no cálculo da responsabilidade de potência, esta obrigação possibilita o aprimoramento futuro da metodologia.

Da mesma forma, a necessidade de realizar medições em todo o universo de injeções de potência, inclusive em centrais geradoras atendidas pelo sistema de distribuição, possibilita a sua utilização futura, caso o aplicativo utilizado pela ANEEL tenha esta opção.

O impacto da não utilização das curvas de injeção deve ser analisado com mais profundidade. Teoricamente, caso seja significativo o percentual de injeção em determinado nível, podem ocorrer i) o cálculo inadequado dos fatores п e $\beta$; e ii) a alocação adicional de custos nos sistemas a montante. Isto porque a metodologia procura ajustar as curvas de carga às curvas de rede; faltando uma curva típica com peso significativo no atendimento da carga, os fatores $\beta$ e $\pi$ não serão calculados adequadamente. Além disso, se a injeção de potência no nível estiver atendendo a ponta do sistema que estiver conectada, o fato de não ser considerada na metodologia implicará a alocação de custos, indevidamente, nos níveis a montante. 


\subsection{Responsabilidade de potência}

A metodologia atual aloca os custos para o consumidor nos horários em que a rede está mais carregada, como já visto. Porém, embora a expansão da rede seja conseqüência da necessidade de atender uma carga adicional neste horário de ponta, não necessariamente a ampliação do sistema decorre apenas desta situação.

Em geral, para a escolha da melhor alternativa dentre as várias obras possíveis para atendimento da demanda, a área de planejamento de uma distribuidora leva em consideração critérios econômicos e técnicos, como a taxa de crescimento do mercado, o custo das perdas, o custo de operação e manutenção, além do próprio valor dos investimentos.

O método atual não incorpora a influência das perdas causadas pelas diferentes curvas de carga no dimensionamento adequado do sistema de distribuição, embora considere as perdas de potência acumuladas nos diversos níveis de tensão.

Por exemplo, seja um sistema constituído por duas curvas de rede típicas (R1 e R2) que alimentam três curvas de carga com utilização bem distinta: curva plana (C1), curva com 2 horários de picos (C2) e curva com horário de pico ao final da tarde (C3), como apresentado a seguir.

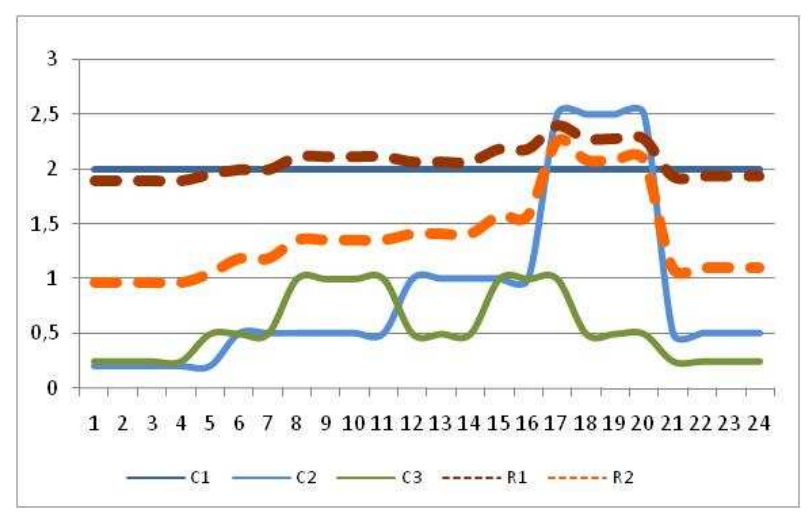

Figura 5.3 - Curvas de redes e de clientes do sistema em estudo 
A rede típica $\mathrm{R} 1$ atende $60 \%$ do mercado enquanto que a $\mathrm{R} 2$ o restante $40 \%$ do mercado. Para simular o cálculo, assumiu-se que as probabilidades das redes estarem associadas aos clientes típicos $\left(\beta_{\mathrm{ij}}\right)$ são aquelas apresentadas na Tabela 5.8 .

Tabela 5.8 - Fatores $\beta$ do sistema

\begin{tabular}{|c|c|c|c|}
\hline & & Rede-tipo 1 & Rede-tipo 2 \\
\hline \multicolumn{2}{|c|}{ Fator $\alpha$ das redes-tipo } & 0,60 & 0,40 \\
\hline \multirow{3}{*}{$\beta$} & Cliente-tipo 1 & 0,75 & 0,35 \\
\hline & Cliente-tipo 2 & 0,15 & 0,50 \\
\hline & Cliente-tipo 3 & 0,10 & 0,15 \\
\hline
\end{tabular}

Conhecendo $\alpha_{i}$ e $\beta_{\mathrm{ij}}$ é possível então calcular o fator $\pi_{\mathrm{ji}}$, que é a probabilidade do cliente-tipo i estar associado à rede-tipo j, conforme Tabela 5.9 a seguir.

Tabela 5.9 - Fatores $\pi$ do sistema

\begin{tabular}{llcc}
\hline & & Rede-tipo 1 & Rede-tipo 2 \\
\hline \multirow{3}{*}{ Cliente-tipo 1 } & 0,76 & 0,24 \\
& Cliente-tipo 2 & 0,31 & 0,69 \\
& Cliente-tipo 3 & 0,50 & 0,50 \\
\hline
\end{tabular}

De acordo com a metodologia, a alocação de custos será feita somente nos horários de maior carregamento das redes $\mathrm{R} 1$ e R2 que, neste caso, ocorrem nos períodos de 15 a 20 na R1, e de 17 a 20 na R2, como pode ser visto na Figura 5.4 a seguir. Assim, para os três clientes, a responsabilidade de potência será calculada somente nesses horários, considerando os respectivos fatores $\mathrm{P}_{\mathrm{h}}$ e a probabilidade de ser atendido pelas redes típicas (fator $\Pi_{\mathrm{jij}}$ ).

A Figura 5.4 demonstra que no restante das curvas, não coincidente com o horário de maior carregamento das redes, não são alocados os custos pela metodologia atual. Observa-se também a influência do fator $P_{h}$ que é menor que a unidade somente para os horários 18, 19 e 20 do cliente tipo 3, resultando em custo menor para esse consumidor. 


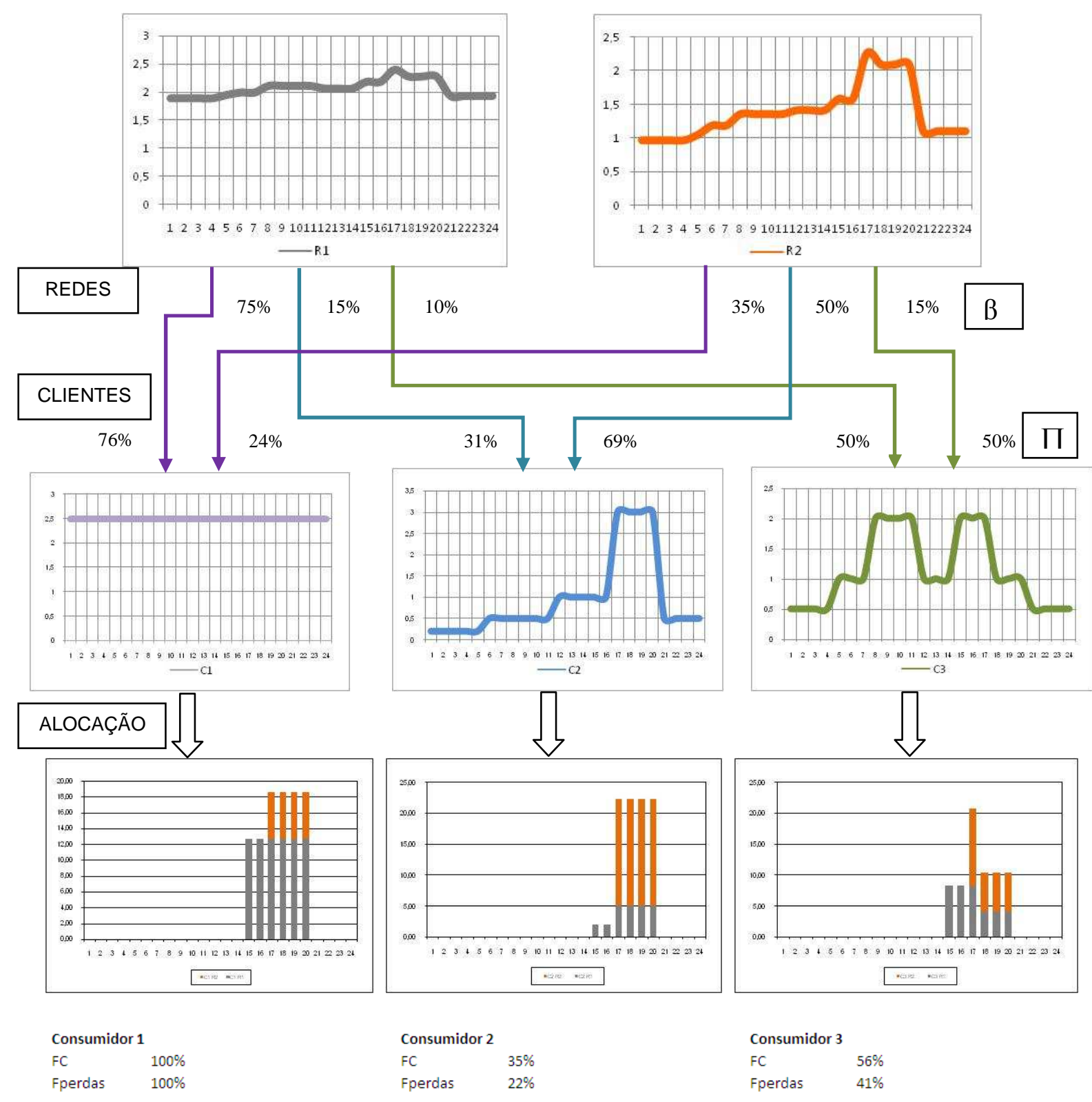

Figura 5.4 - Alocação horário dos custos marginais

Na Figura 5.4 observa-se também a participação do fator $\pi$ no cálculo. Como a probabilidade de o cliente $\mathrm{C} 1$ ser atendido pela rede $\mathrm{R} 1$ é de $76 \%$, a maior parte dos custos é oriunda desta rede (barras em cinza na figura). A mesma situação ocorre para o consumidor C2 que tem a probabilidade de $69 \%$ de ser atendido pela rede R2. Por isso, $\mathrm{C} 2$ tem a maior parte dos seus custos formada pelo custo desta rede (barras em laranja na figura).

Os custos alocados aos clientes correspondem à multiplicação da responsabilidade de potência em cada horário pelo custo de expansão do sistema, estimado em $\mathrm{R} \$ 100,00 / \mathrm{kW}$.ano para este caso. 
Para o cliente $\mathrm{C} 1$, por exemplo, o fator $\Pi_{11}$ é dividido por seis e $0 \Pi_{21}$ por quatro, pois correspondem ao número de horas de maior carregamento das redes $\mathrm{R}_{1}$ e $\mathrm{R}_{2}$; conseqüentemente, os custos são divididos proporcionalmente nesse período. Ainda, como os fatores $\mathrm{P}_{\mathrm{h}}$ da curva de carga deste cliente são unitários para todos os horários, o total de custo alocado será de $\mathrm{R} \$ 100,00$, como pode ser visto na Tabela 5.10. Apenas para manter a sistemática da metodologia atual, definiu-se as horas 17, 18 e 19, em termos de tarifação como posto tarifário ponta. As demais horas são então consideradas integrantes do posto tarifário fora de ponta.

Tabela 5.10 - Custos marginais de capacidade do cliente C1

\begin{tabular}{cccc}
\hline C1 & Total & Ponta & Fora Ponta \\
\hline Custo R1 & 76,27 & 38,14 & 38,14 \\
Custo R2 & 23,73 & 17,80 & 5,93 \\
\hline Custo total & 100,00 & 55,93 & 44,07 \\
\hline
\end{tabular}

Para o cliente $\mathrm{C2}$, o resultado do cálculo é quase o mesmo que o do caso anterior, pois embora os fatores $\mathrm{P}_{\mathrm{h}}$ da curva de carga deste cliente para os períodos de 18 a 20 também sejam 1, isto não ocorre para o período de 16 a 17. Por isso, como visto na Tabela 5.11 , o custo total não alcança o valor de $R \$ 100,00$.

Tabela 5.11 - Custos marginais de capacidade do cliente C2

\begin{tabular}{cccc}
\hline C2 & Total & Ponta & Fora Ponta \\
\hline Custo R1 & 24,83 & 15,52 & 9,31 \\
Custo R2 & 68,97 & 51,72 & 17,24 \\
\hline Custo total & 93,79 & 67,24 & 26,55 \\
\hline
\end{tabular}

Para o cliente C3, o custo é menor porque os fatores $P_{h}$ da curva de carga são menores do que 1 para o período referente às horas 18, 19 e 20, como pode ser observado na Figura 5.4.

Tabela 5.12 - Custos marginais de capacidade do cliente C3

\begin{tabular}{cccc}
\hline C3 & Total & Ponta & Fora Ponta \\
\hline Custo R1 & 37,50 & 16,67 & 20,83 \\
Custo R2 & 31,25 & 25,00 & 6,25 \\
\hline Custo total & 68,75 & 41,67 & 27,08 \\
\hline
\end{tabular}


Embora o cliente C3 tenha um fator de perdas de 41\%, portanto maior do que o do cliente C2 cujo fator é $22 \%$, os custos alocados são menores pelo fato de que a alocação é feita somente nos horários de pico.

Conclui-se que a alocação horária dos custos para os clientes não leva em consideração as perdas decorrentes da curva de carga do cliente na necessidade de expansão do sistema de distribuição de energia elétrica. Embora o cliente C2 tenha um fator de perdas de $22 \%$ enquanto que um consumidor $\mathrm{C} 1$ possuí um fator de perdas igual a $100 \%$, os custos são alocados da mesma maneira para esses clientes.

\subsection{Influência das perdas no dimensionamento do sistema}

É possível demonstrar a importância das perdas no dimensionamento do sistema de distribuição de energia elétrica. Por exemplo, considerando os dados da Tabela 5.13, que apresenta os custos por km de instalação das redes primárias de distribuição em $13,8 \mathrm{kV}$, pode-se estimar uma função que correlacione os custos unitários e a seção do cabo condutor.

Tabela 5.13 - Custos unitários de redes primárias de distribuição

\begin{tabular}{ccc}
\hline Cabo & $\mathbf{S}\left(\mathbf{m m}^{2}\right)$ & Custo $(\mathbf{R} \mathbf{\$} / \mathbf{k m})$ \\
\hline $1 / 0$ & 54 & 49.374 \\
$4 / 0$ & 107 & 57.852 \\
336 & 170 & 68.371 \\
\hline
\end{tabular}

Supondo que a função de custos seja linear, do tipo $a+b * S$, pode-se, por meio de regressão, calcular os parâmetros da equação, conforme demonstrado na Figura 5.5. 


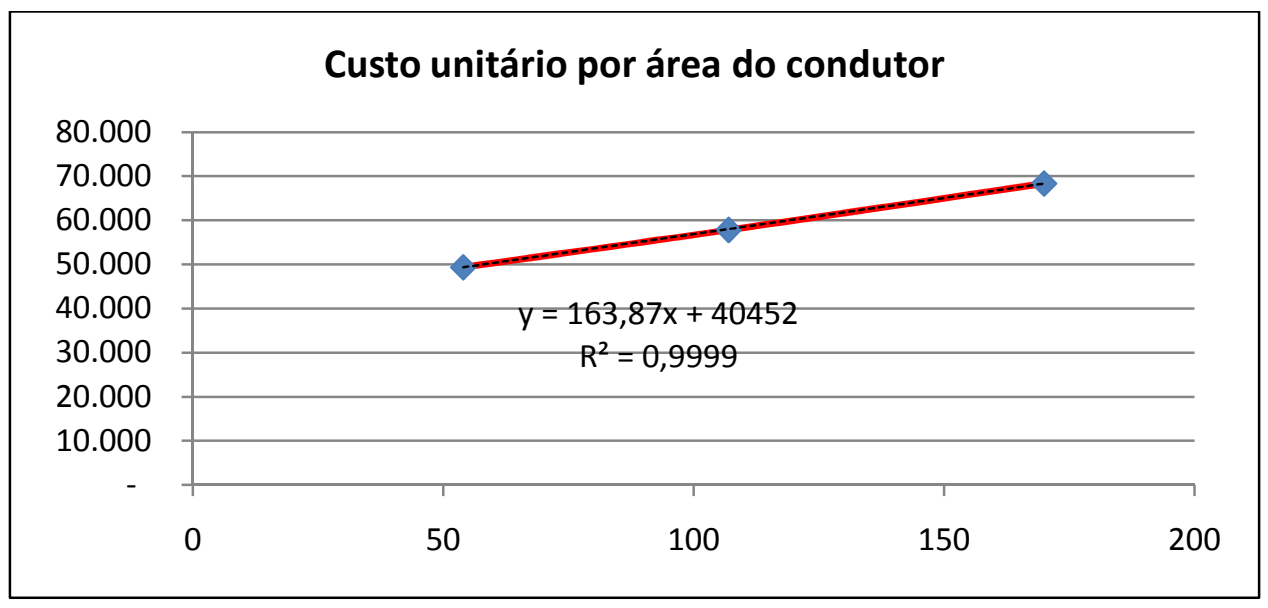

Figura 5.5 - Custos de redes primárias de distribuição

Obtêm-se, então, os parâmetros da função, $a=40.452$ e $b=163,87$, resultando na seguinte expressão que representa os custos unitários de investimento:

$$
\operatorname{Cinv}=\mathrm{a}+\mathrm{b} * \mathrm{~S}=40.452+163,87 * \mathrm{~S}
$$

Os investimentos devem ser convertidos para base anual, por meio da aplicação de um Fator de Recuperação de Capital $^{9}$, o que implica o ajuste da equação anterior:

$$
\operatorname{Cinv}=\mathrm{a}^{\prime}+\mathrm{b}^{\prime} * \mathrm{~S} \quad(5.2)
$$

Por outro lado, além do custo de expansão, as perdas elétricas também devem ser consideradas para se definir a melhor alternativa econômica para 0 atendimento da demanda.

As perdas por km podem ser calculados pela seguinte fórmula:

$$
\mathrm{p}=3 * \mathrm{r} * \mathrm{i}^{2}
$$

Onde,

$\mathrm{p}=$ perdas por $\mathrm{km}$;

$r$ = resistência ôhmica do cabo por km;

$\mathrm{i}=$ corrente elétrica.

\footnotetext{
${ }^{9}$ Fator de recuperação de capital de 0,11 que considera taxa de $10 \%$ a.a. e período de 25 anos.
} 
Estimando-se um custo para a energia e um fator de perdas inerente deste sistema, pode-se calcular o custo anual unitário de perdas (por km) para determinada configuração de rede:

$$
\mathrm{Cp}=3 * \mathrm{r} * \mathrm{i}^{2} * \mathrm{fp} * 8760 * \mathrm{Ce} \quad(5.4)
$$

Onde,

$\mathrm{Cp}=$ custo anual por $\mathrm{km}$ de perdas;

fp = fator de perdas;

Ce = custo da energia.

Considerando-se uma relação fixa entre a resistência ôhmica e a seção em $\mathrm{mm}^{2}$ do cabo $^{10}, r=33 / \mathrm{S}$, a seguinte equação pode ser definida:

$$
\mathrm{Cp}=3 * \frac{33}{\mathrm{~s}} * \mathrm{i}^{2} * \mathrm{fp} * 8760 * \mathrm{Ce}
$$

É possível ajustar esta função para encontrar uma relação entre os custos de perdas e a bitola do cabo (S). Para isso, isolando-se os termos constantes da equação anterior, a corrente i e o custo da energia $\mathrm{Ce}$, determina-se k conforme a seguinte expressão:

$$
\mathrm{k}=3 * 33 * \mathrm{i}^{2} * 8760 * \mathrm{Ce}
$$

Tem-se, então, que o custo anual unitário (por km) de perdas em função da seção do cabo e do fator de perdas pode ser calculado pela seguinte equação:

$$
\mathrm{Cp}=\frac{\mathrm{k} * \mathrm{fp}}{\mathrm{S}}
$$

Como comentado, o custo total para a escolha técnico-econômica das obras deve ser, pelo menos, a soma entre o custo do investimento e o custo de perdas. Assim, somando-se as Equações 5.2 e 5.7, tem-se que:

$$
\begin{gathered}
\text { Ctot }=\operatorname{Cinv}+\mathrm{Cp} \\
\text { Ctot }=\mathrm{a}^{\prime}+\mathrm{b}^{\prime} * \mathrm{~S}+\frac{\mathrm{k} * \mathrm{fp}}{\mathrm{S}}
\end{gathered}
$$

\footnotetext{
${ }^{10} \mathrm{r}(\Omega / \mathrm{km})=\rho / \mathrm{S}^{*} 1000$
} 
A melhor alternativa, que representa o mínimo custo, pode se encontrada igualando a zero a derivada da função custo total em relação a $\mathrm{S}$, como descrito a seguir:

$$
\begin{gathered}
\frac{d C \text { tot }}{d S}=b^{\prime}-\frac{k * f p}{S^{2}}=0 \\
S^{2}=\frac{k * f p}{b^{\prime}}=0 \\
S=\sqrt{\frac{k * f p}{b^{\prime}}} \\
S=\sqrt{\frac{k}{b^{\prime}}} * \sqrt{f p}
\end{gathered}
$$

Assim, o mínimo custo total será dado para uma seção "econômica" de cabo que depende da raiz quadrada do fator de perdas.

Utilizando a equação anterior, pode-se fazer algumas simulações, supondo o custo de energia $\mathrm{Ce}=\mathrm{R} \$ 100 / \mathrm{MWh}$ e o atendimento de uma carga máxima de 100 A. Variando-se o fator de carga e fator de perdas (estimado como $\mathrm{fp}=0,3^{*} \mathrm{fc}+$ $\left.0,7^{*} \mathrm{fc}^{2}\right)$, pode-se calcular o condutor econômico, que minimiza os custos totais, para

\begin{tabular}{|c|c|c|c|c|c|}
\hline fc & fp & $\begin{array}{c}\text { Cp anual } \\
(\mathrm{R} \$ / \mathbf{k m})\end{array}$ & $\begin{array}{c}\text { Cinv anual } \\
(\mathrm{R} \$ / \mathbf{k m})\end{array}$ & $\begin{array}{l}\text { Custo total } \\
(\mathrm{R} \$ \mathbf{k m})\end{array}$ & $\mathrm{S}\left(\mathrm{mm}^{2}\right)$ \\
\hline 0,10 & 0,04 & 761 & 5.217 & 5.978 & 42 \\
\hline 0,20 & 0,09 & 1.174 & 5.630 & 6.804 & 65 \\
\hline 0,30 & 0,15 & 1.547 & 6.004 & 7.551 & 86 \\
\hline 0,40 & 0,23 & 1.905 & 6.362 & 8.267 & 106 \\
\hline 0,50 & 0,33 & 2.255 & 6.712 & 8.967 & 125 \\
\hline 0,60 & 0,43 & 2.600 & 7.057 & 9.657 & 144 \\
\hline 0,70 & 0,55 & 2.942 & 7.398 & 10.340 & 163 \\
\hline 0,80 & 0,69 & 3.281 & 7.738 & 11.019 & 182 \\
\hline 0,88 & 0,80 & 3.538 & 7.995 & 11.533 & 196 \\
\hline 0,90 & 0,84 & 3.619 & 8.076 & 11.695 & 201 \\
\hline 0,94 & 0,90 & 3.753 & 8.209 & 11.962 & 208 \\
\hline 0,97 & 0,95 & 3.856 & 8.312 & 12.168 & 214 \\
\hline 1,00 & 1,00 & 3.956 & 8.413 & 12.368 & 219 \\
\hline
\end{tabular}
cada uma das situações de fator de perdas.

Tabela 5.14 - Condutor econômico e custos minimizados em função do fator de perdas 
A Figura 5.6 demonstra graficamente que, se fosse utilizado apenas o critério para dimensionamento pela capacidade (100 A), um cabo de bitola de $50 \mathrm{~mm}^{2}$ seria suficiente. Porém, com o aumento das perdas, o condutor que minimiza os custos totais (compostos por custos de perdas e investimentos) poderia alcançar a bitola de $200 \mathrm{~mm}^{2}$, para um fator de carga de 0,90 e fator de perdas de 0,84. A Figura 5.7 apresenta os custos (totais, perdas e investimentos) em função do fator de perdas.

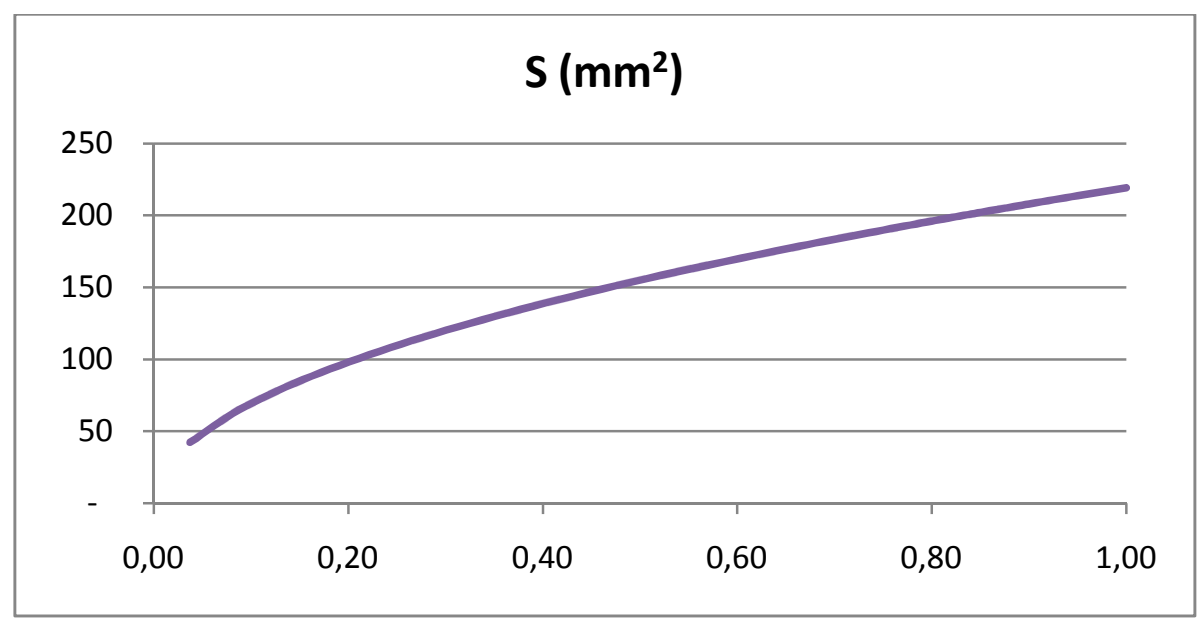

Figura 5.6 - Seção do condutor econômico em função do fator de perdas

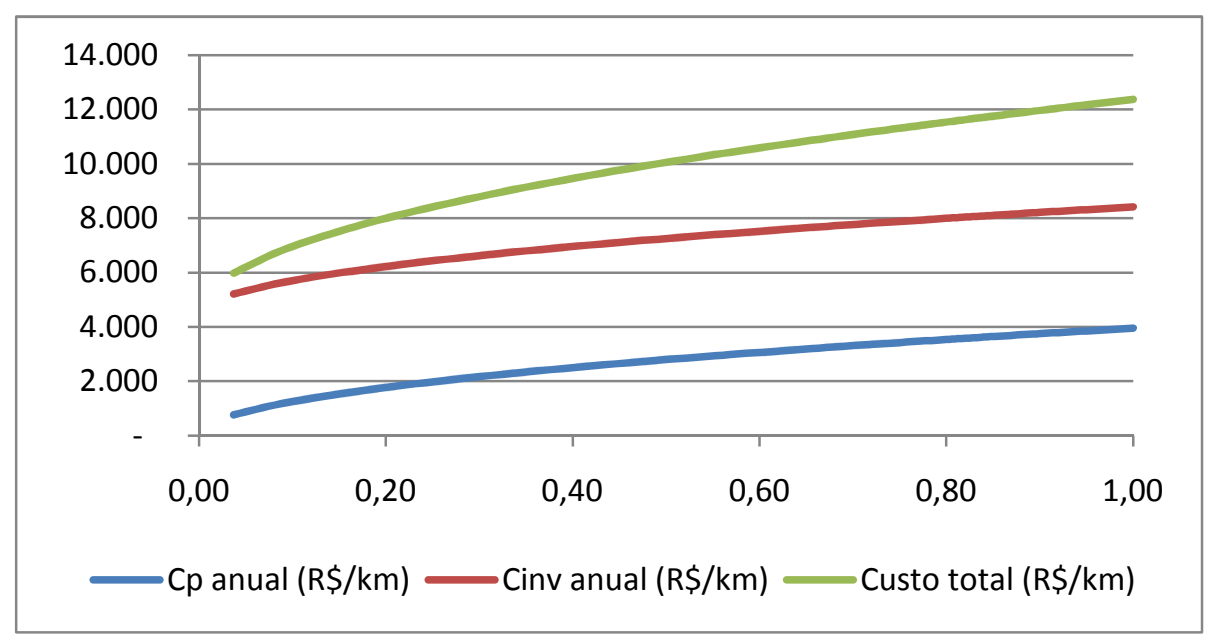

Figura 5.7 - Custo unitários minimizados em função do fator de perdas

Na prática, as distribuidoras planejam a expansão do sistema de distribuição considerando a máxima demanda a ser atendida para determinado perfil de carga que reflete o comportamento do consumidor médio dos consumidores da empresa (fator de carga típico, por exemplo). 
Assim, mantendo-se a carga máxima de 100 A e supondo que na expansão em determinado sistema, o fator de carga e o fator de perdas sejam considerados como constantes; por exemplo, $f c=0,74$ e $f p=0,6$, é possível elaborar outras simulações.

Aplicando-se, então, a equação para esta condição (carga máxima, fatores de perda e de carga constantes) encontra-se o condutor econômico cuja bitola é 170 $\mathrm{mm}^{2}$. Variando-se, então, somente a seção do condutor, é calculada a curva de custos, conforme Tabela 5.15 e Figura 5.8 a seguir.

Tabela 5.15 - Custos unitários em função da seção do condutor

\begin{tabular}{cccc}
\hline $\begin{array}{c}\mathbf{S} \\
\left.\mathbf{( m m}^{2}\right)\end{array}$ & $\begin{array}{c}\text { Cp anual } \\
(\mathbf{R} \mathbf{\$} / \mathbf{k m})\end{array}$ & $\begin{array}{c}\text { Cinv anual } \\
(\mathbf{R} \mathbf{\$} / \mathbf{k m})\end{array}$ & $\begin{array}{c}\text { Custo total } \\
\mathbf{( R \$ / \mathbf { m } )}\end{array}$ \\
\hline 20 & 26.017 & 4.817 & 30.835 \\
40 & 13.009 & 5.178 & 18.187 \\
60 & 8.672 & 5.539 & 14.212 \\
80 & 6.504 & 5.900 & 12.404 \\
100 & 5.203 & 6.261 & 11.465 \\
140 & 3.717 & 6.983 & 10.700 \\
150 & 3.469 & 7.163 & 10.632 \\
160 & 3.252 & 7.344 & 10.596 \\
170 & 3.064 & 7.521 & 10.585 \\
180 & 2.891 & 7.705 & 10.596 \\
190 & 2.739 & 7.885 & 10.624 \\
200 & 2.602 & 8.066 & 10.667 \\
240 & 2.168 & 8.787 & 10.956 \\
260 & 2.001 & 9.148 & 11.150 \\
280 & 1.858 & 9.509 & 11.368 \\
300 & 1.734 & 9.870 & 11.605 \\
320 & 1.626 & 10.231 & 11.857 \\
\hline
\end{tabular}




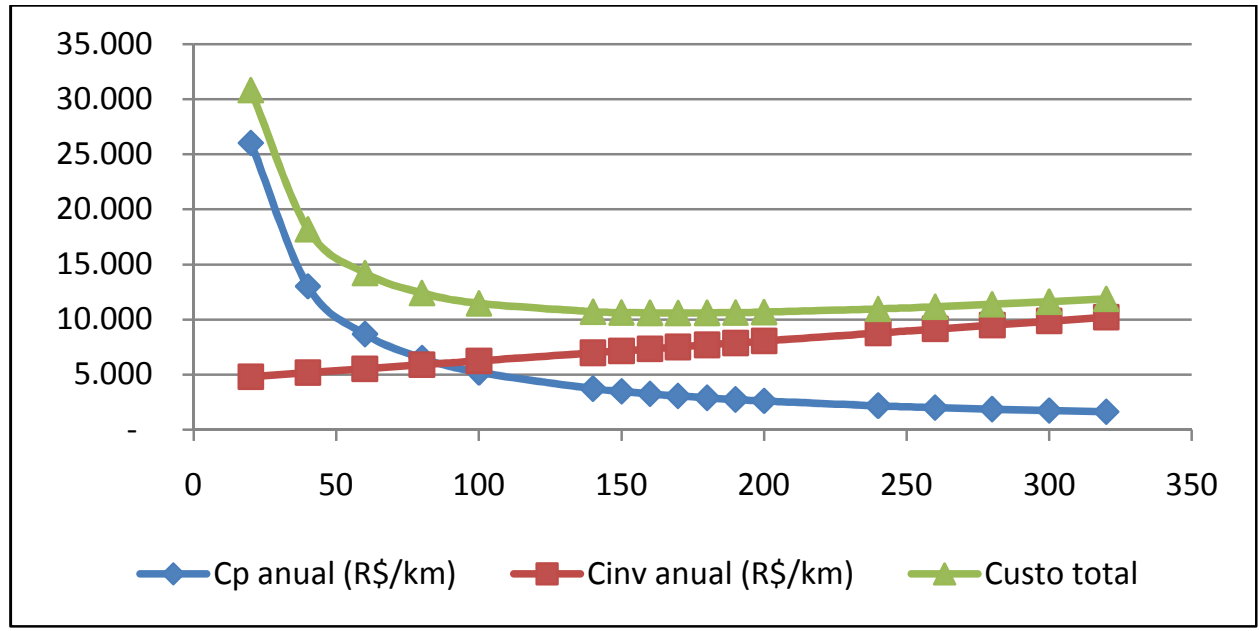

Figura 5.8 - Custos unitários em função da seção do condutor

Pode-se observar, então, que para seções menores há aumento significativo dos custos das perdas enquanto que a variação dos investimentos é linear para todas as bitolas. Porém, a partir de determinada seção de condutor, os custos totais não variam significativamente resultando na indiferença entre aumentar ou não a bitola do cabo.

Uma conclusão possível é que a seção mínima (aproximadamente $100 \mathrm{~mm}^{2}$ ) seria a indicada para ser a utilizada no caso de atendimento à demanda, independentemente das perdas técnicas. Já considerando a necessidade de minimizar o custo das perdas e do investimento, a bitola do condutor econômico seria aproximadamente $170 \mathrm{~mm}^{2}$. A diferença entre esses custos dos investimentos, devido ao dimensionamento de um sistema de distribuição para minimizar as perdas, pode ser explicada pelos fatores de perda dos diferentes perfis de carga do consumidor.

Atualmente, as perdas técnicas são cobradas nas tarifas proporcionalmente ao custo marginal de capacidade. Por isso, entende-se que o critério de alocação horária dos custos deve levar em consideração também as perdas técnicas, uma vez que os custos marginais indiretamente refletem uma escolha do planejador do sistema que contempla o compromisso entre as perdas de energia e o investimento para atender a demanda máxima do sistema.

Por outro lado, os custos das perdas técnicas, mesmo sendo uma componente da tarifa de uso do sistema de distribuição, poderiam ser cobrados em 
função do consumo de energia elétrica do cliente $^{11}$, tal como a parcela da TUSD referente aos encargos setoriais, como CDE e Proinfa. Mesmo nesta situação, seria importante que a metodologia de cálculo considerasse a sinalização de perdas na parcela da tarifa decorrente dos custos de expansão do sistema, como ocorre em Portugal por exemplo.

É importante ressaltar que a influência das perdas no dimensionamento do sistema de distribuição, principalmente em relação às perdas de energia, não está contemplada na metodologia atual. O índice de perdas, que consta da Equação 4.1, busca inserir apenas a necessidade da disponibilização de uma potência maior nos níveis de tensão a montante para o atendimento de uma carga. Em outras palavras, uma carga adicional de $1 \mathrm{~kW}$ no sistema BT precisará que o sistema MT e BT tenham uma capacidade adicional um pouco maior do que apenas a potência demandada.

\subsection{Custo marginal de capacidade}

Após a repartição dos custos segundo as horas de pico das redes-tipo, o método os agrupa formando as tarifas de referência nos postos tarifários de ponta e fora de ponta. Essa agregação corresponde à soma de cada parcela de custo das horas que compõem os postos tarifários.

Por outro lado, Santos (2008) propõe uma nova maneira de representação desses custos para formar os preços de ponta e fora de ponta. Por esse critério, as tarifas são calculadas pela média dos custos das horas que compõem o posto tarifário ao invés da sua soma. Ao mesmo tempo, o autor mantém o critério de somar os custos horários para definir a tarifa média do nível tarifário e conseqüentemente a relatividade entre os níveis de tensão.

Analisando a composição da responsabilidade de potência, observa-se, na Equação 4.1, que a soma dos custos horários de um cliente-tipo corresponderá ao custo marginal de expansão do nível de tensão, se as demandas máximas do

\footnotetext{
${ }^{11}$ Esse é um dos itens de aprimoramento proposto pela ANEEL na Consulta Pública no 056/2009 que trata da proposta de alteração da estrutura tarifária.
} 
cliente-tipo forem coincidentes com as demandas máximas das redes nas quais estava conectado, ou seja, fator $\mathrm{P}_{\mathrm{h}}=1$.

Neste caso, por exemplo, se uma rede-tipo tiver dois horários de pico, o custo unitário de expansão (por kW) será dividido pela metade por conta do critério de eqüiprobabilidade pelo qual o custo unitário é dividido proporcionalmente ao número de horários de ponta da rede-tipo.

Assim, o critério de somar os custos horários está correto em termos de recuperação de custo total. Isto porque, se fosse aplicada a tarifa horária, o montante total a ser arrecadado seria a somatória dos custos horários (por kW) pelas demandas horárias.

Por outro lado, a média proposta por Santos (2008) para formar as tarifas dos postos tem o mérito de mitigar o efeito das diferentes durações dos períodos tarifários: três horas para o período ponta e vinte e uma, para fora de ponta. Em geral, na teoria de precificação de ponta alguns autores adotam períodos com duração idêntica para simplificar a análise do problema, o que pode exigir um tratamento adicional para que as conclusões do caso geral sejam aplicadas em casos que tenham períodos com diferentes durações, como defendido por Williamson (1966).

Embora a metodologia atual permita que seja calculada uma tarifa para cada hora, o aplicativo Tardist, utilizado pela ANEEL, não está configurado para fazer o cálculo adequadamente. Na prática, primeiramente são definidas as horas que formam cada posto tarifário e depois calculadas as tarifas por posto.

Este procedimento pode ser comprovado ao analisar o fator $\mathrm{Ph}$, apresentado no relatório do Tardist. Como visto, esse fator corresponde ao valor percentual (p.u.), em determinada hora, calculado sobre a demanda máxima; porém, o aplicativo utilizado pela ANEEL calcula o valor em p.u. sobre a demanda máxima do posto tarifário.

A Tabela 5.16 apresenta as demandas em p.u. calculadas sobre a demanda máxima e sobre as demandas máximas dos postos tarifários. Observa-se que a demanda máxima do posto tarifário fora de ponta é 49,38 MW (17:00h - 18:00h) 
enquanto que a demanda máxima na ponta é 123,08 (18:00h - 19:00h) que também é a demanda máxima do dia.

Tabela 5.16 - Curva típica e respectivos valores em p.u.

\begin{tabular}{cccc}
\hline Período (h) & MW & $\begin{array}{c}\text { MW / } \\
\text { MWmax } \\
\text { (p.u.) }\end{array}$ & $\begin{array}{c}\text { MW / } \\
\text { MWmaxposto } \\
\text { (p.u.) }\end{array}$ \\
\hline 00:00- 01:00 & 30,45 & 0,247 & 0,617 \\
01:00 - 02:00 & 24,89 & 0,202 & 0,504 \\
02:00 - 03:00 & 23,88 & 0,194 & 0,484 \\
03:00 - 04:00 & 23,51 & 0,191 & 0,476 \\
04:00 - 05:00 & 22,73 & 0,185 & 0,460 \\
05:00 - 06:00 & 25,02 & 0,203 & 0,507 \\
06:00 -07:00 & 26,96 & 0,219 & 0,546 \\
07:00 - 08:00 & 27,01 & 0,219 & 0,547 \\
08:00 -09:00 & 30,05 & 0,244 & 0,609 \\
09:00-10:00 & 25,30 & 0,206 & 0,512 \\
10:00 - 11:00 & 25,13 & 0,204 & 0,509 \\
11:00 - 12:00 & 25,66 & 0,208 & 0,520 \\
12:00 - 13:00 & 28,09 & 0,228 & 0,569 \\
13:00 - 14:00 & 25,68 & 0,209 & 0,520 \\
14:00 - 15:00 & 23,18 & 0,188 & 0,469 \\
15:00 - 16:00 & 31,47 & 0,256 & 0,637 \\
16:00 - 17:00 & 32,72 & 0,266 & 0,663 \\
17:00 - 18:00 & 49,38 & 0,401 & 1,000 \\
18:00 - 19:00 & 123,08 & 1,000 & 1,000 \\
19:00 - 20:00 & 54,16 & 0,440 & 0,440 \\
20:00 - 21:00 & 43,58 & 0,354 & 1,000 \\
21:00 - 22:00 & 39,07 & 0,317 & 0,791 \\
22:00 - 23:00 & 31,41 & 0,255 & 0,636 \\
23:00 - 24:00 & 27,24 & 0,221 & 0,552 \\
\hline
\end{tabular}

No método do DNAEE (1985), este fator não está calculado por posto tarifário, e sim para a demanda máxima da curva de carga. Este critério possibilitaria a soma dos custos horários sem a definição prévia dos postos tarifários.

Porém, após essa agregação, como os custos marginais de capacidade estão referenciados à demanda máxima da curva, é necessária, na visão dos autores do Livro Verde, uma adequação da tarifa do posto tarifário caso a demanda máxima neste período não coincidir com a máxima da curva. O ajuste é, então, realizado pela relação entre a demanda máxima da curva e a demanda máxima do posto tarifário (DNAEE, 1985, p. 287). 
$\mathrm{CMC}_{\mathrm{p}}{ }^{\prime}=\mathrm{CMC}_{\mathrm{p}}{ }^{*}$ demanda máxima / demanda máxima do posto

Onde,

$\mathrm{CMC}_{\mathrm{p}}=$ Custo Marginal de Capacidade do posto tarifário $p$;

$\mathrm{CMC}_{\mathrm{p}}{ }^{\prime}=$ Custo Marginal de Capacidade ajustado do posto tarifário $p$.

Esse critério mantém o montante (em $\mathrm{R} \$$ ) a ser pago pelo cliente-tipo alterando o custo unitário (por kW), no caso da demanda máxima a ser faturada no posto tarifário não corresponder à demanda máxima da curva, para a qual a tarifa foi calculada.

Na prática não há diferenciação entre o procedimento de cálculo do Tardist, que calcula os custos marginais de capacidade já a partir dos fatores $\mathrm{P}_{\mathrm{h}}$ dos postos tarifários, e o critério do Livro Verde que efetua, posteriormente, os ajustes sobre os fatores $\mathrm{P}_{\mathrm{h}}$ independentes de posto tarifário.

Ou seja, as duas etapas do procedimento do DNAEE (cálculo em p.u. da máxima e depois o ajuste com base na demanda do posto tarifário) são equivalentes ao procedimento atual adotado pelo Tardist que já calcula inicialmente os custos em função da demanda do posto tarifário. Porém, o método atual impõe que a definição dos postos tarifários seja realizada antes de se conhecer os custos horários, dificultando a criação posterior de outros postos tarifários distintos dos definidos inicialmente.

De qualquer forma, os custos marginais de capacidade, calculados pela ANEEL, assim como os custos marginais do nível de tensão, calculados por Santos $(2008)^{12}$, têm como função principal definir a relatividade dos custos a serem cobertos pelos consumidores de cada nível tarifário, ou seja, a relatividade vertical.

Quanto à correta aplicação desses custos para a definição da relatividade horizontal ou das tarifas de ponta e fora de ponta, entende-se que a agregação dos custos que formam as tarifas dos postos tarifários deve corresponder à média dos custos horários, porém sem o ajuste promovido atualmente, como será discutido no próximo capítulo.

\footnotetext{
${ }^{12}$ No caso de Santos (2008) também definem a relatividade horizontal.
} 


\subsection{Tarifa de referência}

No modelo anterior as tarifas de referência englobavam toda a cadeia da indústria, desde a geração até a distribuição. Também a alocação dos custos de geração e de transporte (transmissão e distribuição) nas tarifas não estava relacionada de forma direta com as componentes de energia e potência, respectivamente.

No caso de consumidores atendidos em AT, o método estabelecido no Livro Verde, considerava que todo o custo de capacidade (das usinas e do sistema de transporte) era alocado ao preço de potência, pois são clientes com alto fator de carga.

Para os demais consumidores, o método anterior efetuava a repartição do custo marginal de capacidade, que reflete o custo do sistema de transporte, entre preço de potência e de energia, em função do tempo de utilização de cada clientetipo. Ou seja, parte dos custos de demanda de potência era transferida para o preço da energia. Este procedimento, similar ao descrito no item 4.8, que descreve como deveria ser o desenho das modalidades tarifárias, pode ser resumido em quatro passos principais:

1. Os dois custos unitários (por potência e por energia) são transformados em um custo total unitário com a mesma unidade $(\mathrm{R} \$ / \mathrm{kW})$;

2. Os custos totais dos vários clientes-tipo, por posto tarifário, são relacionados com as respectivas horas de utilização em um gráfico (horas na abscissa e custos na ordenada);

3. É construída uma reta passando o mais próximo dos pontos de custos dos clientes-tipo de forma a minimizar os desvios.

4. O ponto que corta a ordenada (custos) corresponde ao preço de potência $(\mathrm{R} \$ / \mathrm{kW})$ e a tangente da curva, ao preço de energia $(\mathrm{R} \$ / \mathrm{kWh})$.

A tarifa de referência era, então, constituída por essas duas parcelas, não estando, porém, o preço por potência relacionado unicamente com os custos de rede e nem os preços por energia apenas com o custo da produção da energia elétrica. 
Há, então, uma diferença significativa no método utilizado atualmente pela ANEEL para a definição das tarifas de referência, pois não há essa transferência de parte dos custos de potência para o preço de energia. Basicamente, hoje os custos de rede estão relacionados com os preços de demanda de potência e os custos de produção de energia com os preços de consumo de energia elétrica.

Alguns agentes entendem que, com a desverticalização das empresas, as tarifas de fornecimento não deveriam ser calculadas de forma integrada. Porém, esse critério anterior, utilizado para o cálculo das tarifas de referência, poderia ser empregado no desenho das modalidades tarifárias horo-sazonais atuais, que são estimadas por um método simplificado de transferência de custos de potência em preços de energia, como será discutido no item 5.8 .

\subsection{Tarifas de aplicação}

$\mathrm{Na}$ passagem dos custos de capacidade para as componentes da TUSD, 0 último ajuste feito pela ANEEL (adequação ao mercado de faturamento) altera a proporção das receitas que seriam arrecadadas por nível, conforme visto no capítulo anterior. A lógica desse procedimento, porém, é manter o desenho das tarifas ajustadas pelo sinal de ponta e fora de ponta. Contudo, a relatividade inicial entre receitas, por nível de tensão, obtidas a partir dos custos marginais de capacidade é alterada.

Em relação aos consumidores BT, a ANEEL calcula uma tarifa, inicialmente, sem distinção de classes. A segregação é feita posteriormente, considerando as relações históricas entre consumidores residenciais (B1), rurais (B2) e comerciais ou industriais (B3), existentes desde a segregação das tarifas em 1995.

De fato, observa-se que há empresas nas quais a tarifa B3 é menor do que a tarifa B1 enquanto que em outras, as tarifas são praticamente iguais, conforme Tabela 5.17 que apresenta as tarifas vigentes em 10/05/2010 para algumas distribuidoras do Brasil. 
Tabela 5.17 - Exemplos de tarifas dos consumidores BT

\begin{tabular}{crrrrr}
\hline & $\begin{array}{c}\text { B1 } \\
\text { (R\$/MWh) }\end{array}$ & $\begin{array}{c}\text { B2 } \\
\text { (R\$/MWh) }\end{array}$ & $\begin{array}{c}\text { B3 } \\
\text { (R\$/MWh) }\end{array}$ & $\begin{array}{c}\text { Relação } \\
\text { B2/B1 }\end{array}$ & $\begin{array}{c}\text { Relação } \\
\text { B3/B1 }\end{array}$ \\
\hline CPFL & 304,51 & 164,49 & 262,41 & $54,0 \%$ & $86,2 \%$ \\
Elektro & 324,15 & 190,91 & 304,57 & $58,9 \%$ & $94,0 \%$ \\
Eletropaulo & 277,22 & 172,54 & 275,28 & $62,2 \%$ & $99,3 \%$ \\
Bandeirante & 296,54 & 184,59 & 294,46 & $62,2 \%$ & $99,3 \%$ \\
Escelsa & 310,03 & 177,98 & 280,38 & $57,4 \%$ & $90,4 \%$ \\
Light & 297,41 & 168,10 & 268,17 & $56,5 \%$ & $90,2 \%$ \\
Cemig & 354,04 & 207,20 & 330,51 & $58,5 \%$ & $93,4 \%$ \\
Copel & 274,08 & 160,65 & 256,33 & $58,6 \%$ & $93,5 \%$ \\
Celpe & 310,17 & 188,59 & 300,90 & $60,8 \%$ & $97,0 \%$ \\
Coelba & 336,74 & 210,69 & 336,10 & $62,6 \%$ & $99,8 \%$ \\
Cosern & 305,69 & 191,70 & 305,81 & $62,7 \%$ & $100,0 \%$ \\
\hline
\end{tabular}

Fonte: ANEEL

Por exemplo, no caso da Cosern, observa-se que essa relação praticamente igual se iniciou em 1995, ocasião em que foi alterado o critério para aplicação dos descontos para consumidores residenciais.

Até 1994, todos os consumidores residenciais pagavam de acordo com uma tarifa escalonada conforme o consumo: de 0 a $30 \mathrm{kWh}$ pagavam um valor; de 31 a $100 \mathrm{kWh}$, outro e assim por diante (FUGIMOTO, 2005). Assim a relação entre a tarifa B3 e a tarifa para consumidor residencial (B1) para a faixa acima de $200 \mathrm{kWh}$ era de 0,84 e para a faixa de 100 a $200 \mathrm{kWh}$ era 1,09 .

A partir de 1995, somente os consumidores classificados como baixa renda continuaram com o benefício da tarifa "escalonada" até o limite regional definido pelo DNAEE. Os demais consumidores residenciais começaram a pagar uma tarifa única independentemente do nível de consumo, calculada de forma ponderada para manter a receita a ser arrecadada. Com isso, as tarifas B3 e B1 "plena" (sem o escalonamento) ficaram praticamente iguais, no caso específico da Cosern.

Essa constatação demonstra que a ANEEL mantém as relações "históricas" existentes entre as tarifas em cada área de concessão. Assim uma nova estrutura tarifária alinhada com os reais custos de atendimento das diversas classes de 
consumidores precisa ser estudada detalhadamente, inclusive quanto aos possíveis impactos dessa alteração.

\subsection{Modalidades tarifárias}

Atualmente a tarifa de demanda de ponta da THS Azul corresponde ao valor calculado da TUSD que, por sua vez, é estimada considerando a média ponderada dos custos marginais de capacidade, como visto.

Já no cálculo da THS Verde, a agência transformava os custos por demanda de potência $(R \$ / k W)$, para o horário de ponta, em custos por energia ( $R \$ / M W h)$, aplicando um fator de carga ponderado dos clientes-tipo.

A partir do inicio deste novo processo de cálculo das modalidades tarifárias, houve a alteração gradual do cruzamento das retas tarifárias (THS Azul e Verde) que ocasionou a migração significativa de consumidores. Aqueles com maior fator de carga passaram a optar pela THS Verde, praticamente restringindo a aplicação da THS Azul somente para uma pequena parcela de consumidores (FUGIMOTO; TAHAN, 2007).

Com essa migração, a ANEEL passou a considerar um fator de carga de 0,6 que estava implícito anteriormente na tarifa.Este critério está inadequado, pois a ANEEL deveria utilizar o procedimento que utiliza os custos dos clientes-tipo em função da sua utilização, como empregado no modelo anterior para cálculo das tarifas de referência.

Dessa forma, o correto seria identificar os custos dos grupos de consumidores de curta e de longa utilização. Com base nesses dois segmentos da curva, determina-se inicialmente a tarifa azul como uma "média ponderada" dos custos dos consumidores de longa utilização e, em seguida, a tarifa verde como aquela que minimiza a diferença entre essa tarifa e os custos de capacidade dos consumidores de curta utilização por meio da curva de custos marginais em função das horas de utilização (ANTUNES, N. P., 2007). 
No caso da tarifa convencional, a ANEEL manteve o procedimento que aloca, na tarifa de demanda, $72 \%$ dos custos de ponta e $100 \%$ dos custos fora de ponta ${ }^{13}$. No início do segundo ciclo de revisão tarifária, o regulador aplicou outro critério para o cálculo da tarifa convencional: os custos fora de ponta foram alocados na tarifa de demanda e os custos de ponta, na tarifa de energia pela aplicação de um fator de carga de $33 \%$.

Na época, por meio de ofício, a ANEEL informou essa alteração possibilitando a alteração do mercado informado pela distribuidora. A possível migração de consumidores, sinalizada pelo regulador, contudo, não ocorreu, pois a tarifa convencional se tornou impraticável.

Após essa constatação, a ANEEL retornou ao critério anterior. Mesmo assim, mantendo o cálculo da tarifa convencional, é importante ressaltar que há migrações de consumidores da THS Verde para a convencional, e não somente para a THS Azul. Essa análise não depende apenas do posto tarifário ponta, como no caso da THS Azul e Verde. Um consumidor com fator de carga alto neste horário, mas com baixo consumo nos demais, optará pela tarifa convencional e não pela THS Verde.

\subsection{Considerações}

Este capítulo procurou analisar os principais aspectos da metodologia para identificar os aprimoramentos e inovações necessários para que seja possível a correta aplicação da metodologia para o cálculo das tarifas de fornecimento.

A sinalização horo-sazonal na tarifa de energia, aplicada por meio de fatores exógenos à metodologia, não está em coerência com o modelo atual do setor elétrico, como também identificado pela ANEEL, recentemente, na Consulta Pública no 11/2010. Identificou-se, com base na análise do PLD, que não há diferenças entre os patamares de carga, considerando o mesmo período de observação. Por outro lado, foi observado a tendência de sinal sazonal, decorrente do modelo de cálculo do custo marginal de operação (CMO) e do PLD.

\footnotetext{
${ }^{13}$ Nessa modalidade há uma única tarifa de demanda que é aplicada sobre o maior valor registrado independentemente do horário.
} 
Por meio da análise de um dos critérios utilizados pelo planejamento das empresas, observou-se que o nível total dos investimentos não pode ser explicado inteiramente pela necessidade de atendimento aos horários de maior carregamento da rede. Dessa forma, a metodologia atual não contempla a lógica utilizada para a minimização dos custos, que inclui as simulações do nível de perdas elétricas e da qualidade exigida pela agência reguladora.

Finalmente, a ANEEL utiliza um fator de carga, definido também exogenamente ao processo, para a definição das modalidades tarifárias, embora seja possível utilizar os custos marginais de capacidade dos clientes-tipo e respectivos fatores de carga, calculados pela metodologia atual, como discutido. 


\section{CAPÍTULO 6 - PROPOSIÇÃO DE METODOLOGIA}

\subsection{Alocação das componentes da receita requerida}

Como explicado no Capítulo 4, a atual metodologia aloca, proporcionalmente aos custos marginais de capacidade, todos os custos da empresa de referência (administrativos, comerciais e operacionais), bem como a remuneração dos ativos, incluindo a quota de reintegração regulatória. Já outros custos são rateados em função ou da energia consumida, ou da potência demandada ou ainda proporcional à receita.

Recentemente, a ANEEL, no âmbito da Consulta Pública n 56/2009, propôs manter este critério de alocação, proporcional ao custo marginal, somente para parte dos custos da empresa de referência, especificamente os custos de operação e manutenção do sistema de distribuição, além da remuneração e quota de reintegração.

Considerando a experiência internacional, a tendência é que os custos relativos ao atendimento comercial, leitura e faturamento sejam rateados pelo número de consumidores de cada classe. Este critério, em relação ao anterior, aumenta os custos para os consumidores BT uma vez que a quantidade de consumidores deste nível de tensão é significativamente maior. Para manter a isonomia, determinado custo da ER, como a área de grandes clientes, poderia ser alocado diretamente aos consumidores AT também na formação da tarifa.

As figuras seguintes apresentam uma estimativa da repartição de custos entre níveis de tensão considerando diferentes critérios de alocação das componentes da Empresa de Referência. 
SIMULAÇAOO DE ALOCAÇÄO DE CUSTOS

\begin{tabular}{|c|c|c|c|c|c|}
\hline CUSTOS & $\mathrm{R} \$$ & Participação & $\begin{array}{c}\text { Alocação de } \\
\text { Custos }\end{array}$ & Alocação de Custos & Opçōes de alocação \\
\hline Administrativos & 63.802 .113 & $24 \%$ & 4 & Marginal & 1 Consumidore \\
\hline Comerciais & 105.338 .720 & $39 \%$ & 4 & Marginal & 2 Energia \\
\hline Distribuiçẫo & 98.185 .796 & $37 \%$ & 4 & Marginal & 3 Demanda \\
\hline TOTAL ER & 267.326 .629 & $100 \%$ & & & 4 Marginal \\
\hline
\end{tabular}
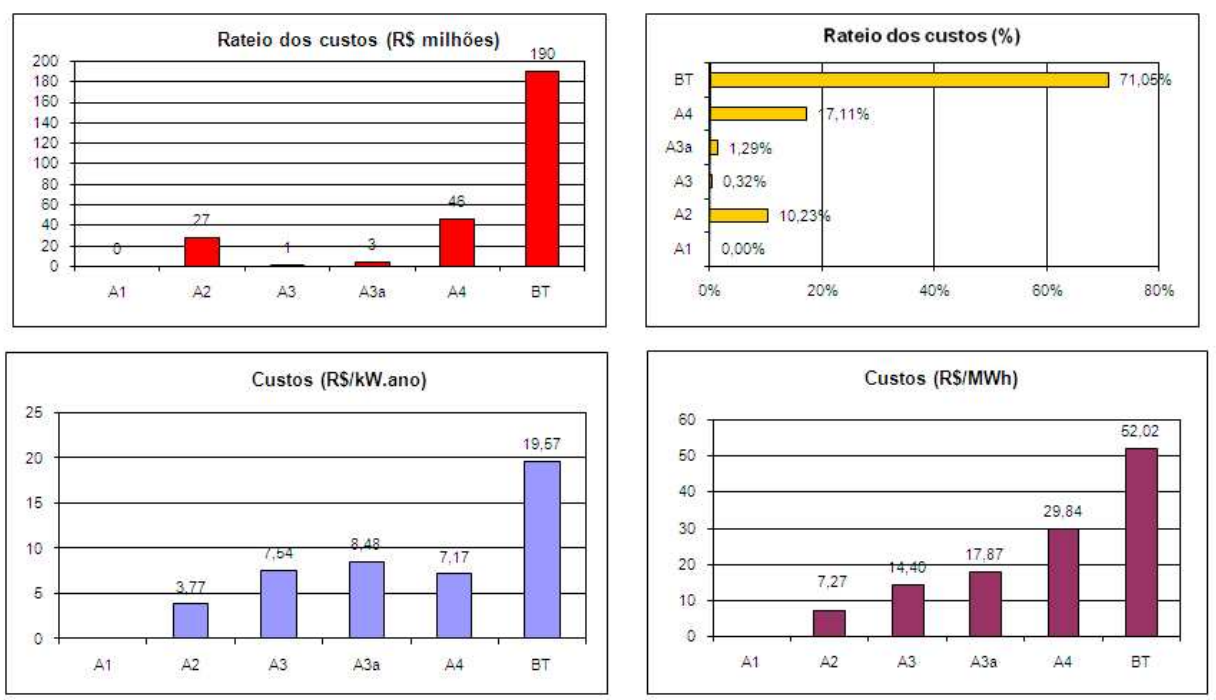

Figura 6.1 - Simulação de alocação ER - situação atual (CMC)

\begin{tabular}{|c|c|c|c|c|c|}
\hline \multirow[b]{2}{*}{ CUSTOS } & \multicolumn{4}{|c|}{ SIMULAÇÄO DE ALOCAÇÄO DE CUSTOS } & \multirow[b]{2}{*}{ Opçôes de alocação } \\
\hline & $\mathrm{R} \$$ & Participação & $\begin{array}{l}\text { Alocação de } \\
\text { Custos }\end{array}$ & Alocação de Custos & \\
\hline Administrativos & 63.802 .113 & $24 \%$ & 4 & Marginal & 1 Consumidores \\
\hline Comerciais & 105.338 .720 & $39 \%$ & 1 & Consumidores & 2 Energia \\
\hline Distribuição & 98.185 .796 & $37 \%$ & 4 & Marginal & 3 Demanda \\
\hline TOTAL ER & 267.326 .629 & $100 \%$ & & & 4 Marginal \\
\hline
\end{tabular}
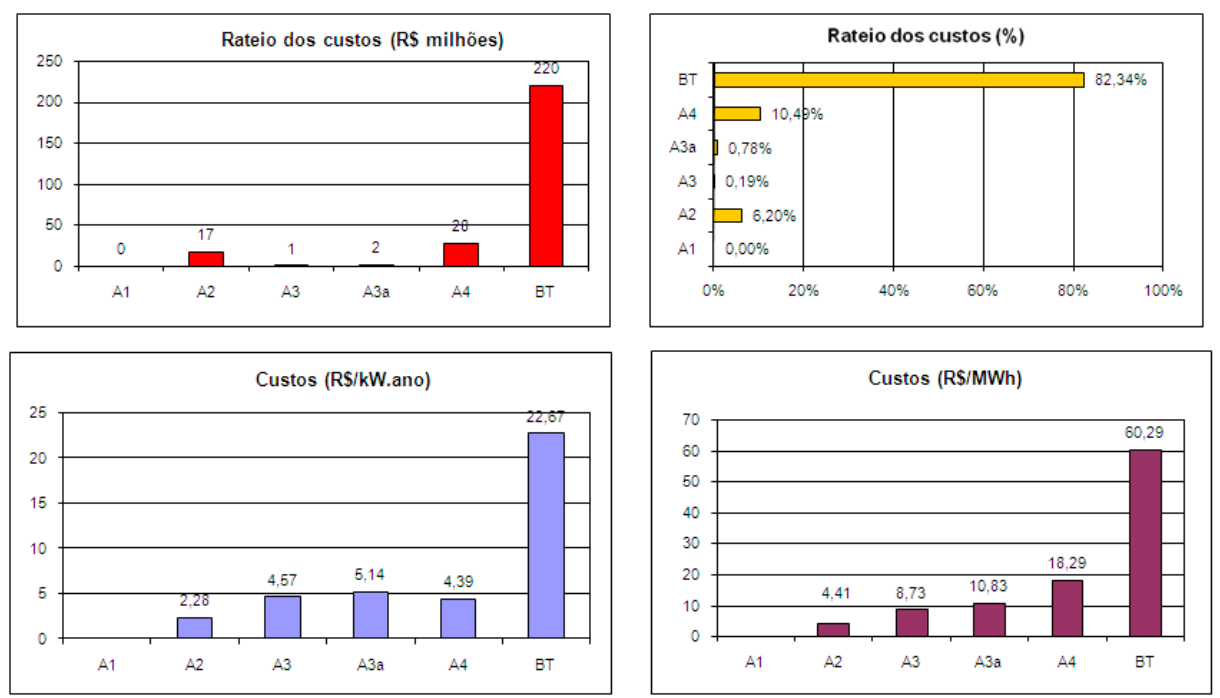

Figura 6.2 - Simulação de alocação ER - custos comerciais por número de clientes 
SIMULAÇÄO DE ALOCAÇÄO DE CUSTOS

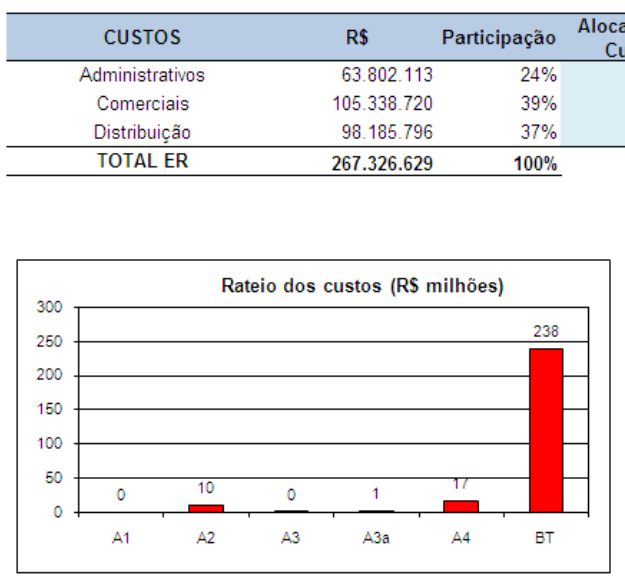

Opções de alocação

1 Consumidores

2 Energia

3 Demanda

4 Marginal
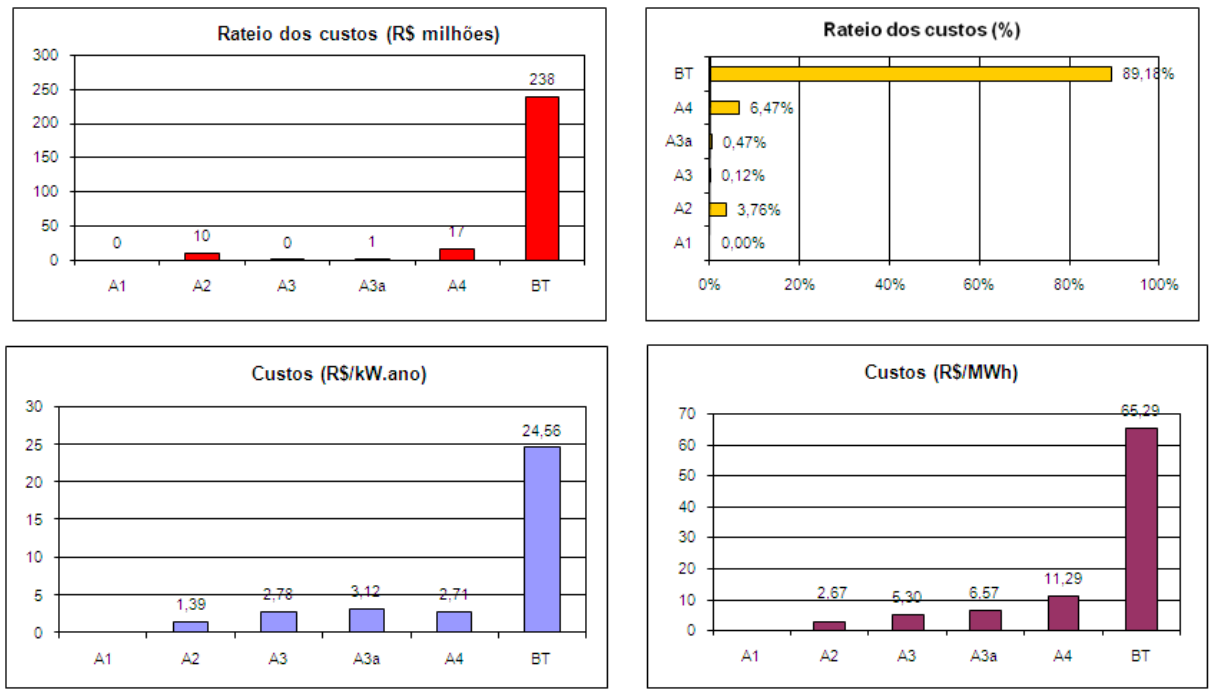

Figura 6.3 - Simulação de alocação ER - custos administrativos e comerciais por número de clientes

Comparando-se a hipótese de alocar os custos administrativos e comerciais em função do número de consumidores com a situação atual, na qual todos os custos são rateados proporcionalmente aos custos marginais de capacidade, observa-se que os custos no nível BT aumentam de $71 \%$ para $89 \%$ do total enquanto que o impacto nas tarifas seria de $26 \%$.

Na situação intermediária em que somente os custos comerciais são alocados proporcionalmente ao número de consumidores, o impacto também é significativo, pois praticamente $100 \%$ desses custos passam a ser de responsabilidade dos consumidores BT, em comparação com os $70 \%$ calculados com base no critério de custo marginal de capacidade.

Propõe-se que os encargos setoriais sejam alocados da mesma forma como são calculados: por energia ou por demanda de potência. Igualmente as perdas de energia, tanto técnica como não técnica, deveriam ser cobradas do consumidor em $\mathrm{R} \$ / \mathrm{kWh}$, sem prejuízo, porém, da sua sinalização nos custos de capacidade como será proposto na tese. 
O Quadro 6.1 apresenta a alocação das componentes das tarifas de fornecimento conforme a proposta da ANEEL na Consulta Pública ํo 56/2009 e discutida nesta tese.

\section{Quadro 6.1 - Critérios para alocação das componentes da receita requerida}

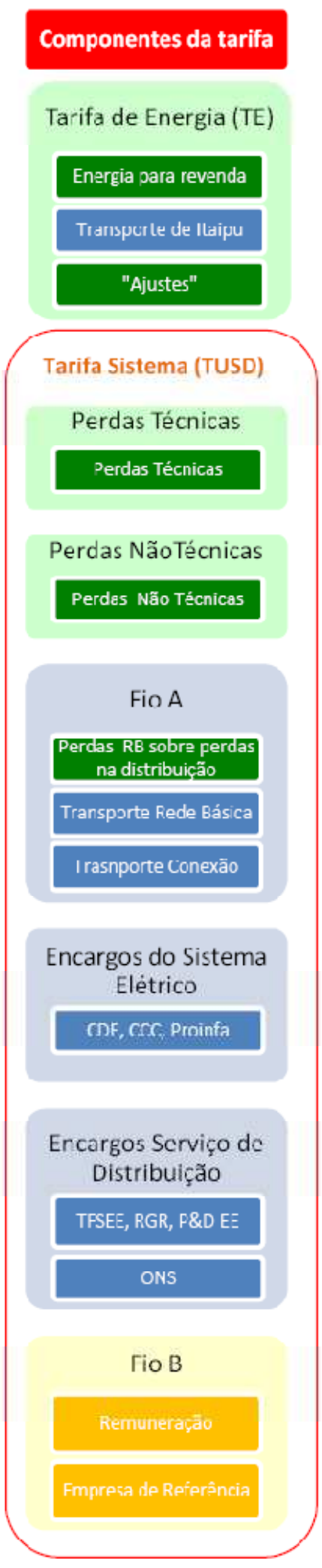

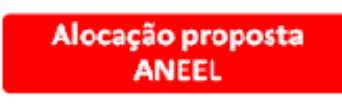

Tarifa de Energia (TE)

Selu Errergia (MWli)

Selo Energia (MWh)

Selo Energla (MWh)

Perdas Técnicas

Mercado (MWh) *Kp

Perdas NäoTécnicas

Proporcional Receita

Fic A

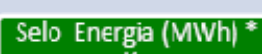

$\mathrm{Kp}$

Mercado $(\mathrm{kW})$ *kp ffcoinc

Mercado (kW)*V.p*fcoinc

Encargos do Sistema Elètrico

Selo Energia (MWh)

Encargos Serviçc de Distribuição

CMC (RGR) e Perecntual

Selc Potência (kW)

Fic B

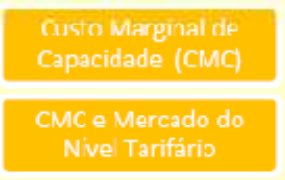

Alocação proposta Tese

Tarifa de Energia (TE)

Selo em tnergıa

Seln em Fnergia

Selo em Energla

Perdas Técnicas

Energia

Perdas NäoTécnicas

Proporcional Receita

Fio $\mathrm{A}$

Encrgia

Selo em Poténcia (ponto)

Selo em Potêrcia

Encargos do Sistema Elétrico

Selo arr Energia

Encargos Serviço de D stribuição

Custo Marginal de Capacidade

Selo em Potência

Fio $\mathrm{B}$

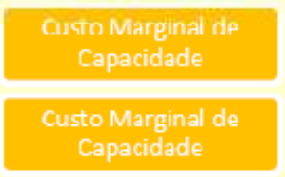




\subsection{Sinalização horo-sazonal da tarifa de energia}

Como visto anteriormente, o custo marginal de geração, que sustentava os sinais horo-sazonais de energia, não é mais calculado da mesma forma. Também não há preços diferenciados, em termos horários ou mensais, nos contratos de longo prazo das distribuidoras.

Por outro lado, a distribuidora repassa, na tarifa horo-sazonal, um sinal econômico para os consumidores cativos que não existe para os consumidores que optam pelo mercado livre. Essa questão poderia se tornar mais grave caso 0 consumidor parcialmente livre pudesse escolher, sem restrições, o horário em que preferisse ficar no mercado regulado ou ir para o mercado livre. Contudo, a Resolução Normativa no 376/2009 corretamente determina que a modulação do consumidor seja compatível com o seu perfil de carga.

Poderia se argumentar que o sinal de ponta na tarifa de energia é necessário para indicar a necessidade de expansão da rede de transporte, em conjunto com o sinal da tarifa de uso do sistema. Se na prática este argumento for verdadeiro, tornase mais evidente ainda a inadequação do cálculo das tarifas de energia. Neste caso, a tarifa de uso do sistema deveria ter sinalização suficiente para indicar os custos relacionados com a expansão do sistema de transmissão e de distribuição em determinados horários.

Observa-se, porém, que uma sinalização inadequada, como no caso da THS Verde, tem causado indevidamente a modulação de consumo no horário de ponta. Isto ocorre não somente por causa dos custos de rede, que neste caso é cobrado sobre o consumo de energia, mas por conta do somatório desses custos de distribuição com o preço da energia, $72 \%$ maior no horário de ponta, que não reflete os custos de aquisição de energia pela distribuidora.

Dessa forma, em relação ao preço do produto energia, considerando que, eventualmente, pode haver pequeno impacto para as empresas em razão da liquidação de curto prazo e do exposto anteriormente, entende-se que a tarifa de energia deve incorporar o sinal sazonal decorrente das características do sistema predominantemente hidrelétrico. Por outro lado, o sinal horário para a tarifa de 
energia não é mais aplicável no atual modelo do setor, conforme exposto nesta tese, a não ser que toda a sistemática de preços de contratação de energia pelas distribuidoras seja alterada.

\subsection{Cálculos dos custos marginais de expansão}

Os custos marginais de expansão por nível de tensão podem ser calculados com base no Plano de Desenvolvimento de Distribuição (PDD). Como visto no Capítulo 5, observa-se, da análise dos dados, que são utilizados todos os tipos de investimentos para o cálculo. Algumas referências, contudo, defendem que somente as obras estritamente necessárias para a expansão do sistema de distribuição devem ser utilizadas para o cálculo do CIMLP.

Entende-se que os custos marginais devem incluir todas as obras, inclusive aquelas necessárias para atender aos requisitos de qualidade e de reforço considerando que a alternativa de expansão é escolhida pelo menor valor presente das opções desde que ela atenda aos critérios técnicos.

Outra justificativa, para utilizar todos os investimentos no cálculo, é a dificuldade de se classificá-los, uma vez que determinadas obras são realizadas tanto para atender a expansão do sistema como para melhorar a qualidade do serviço. Da maneira similar, determinados investimentos em qualidade possibilitam também o aumento da capacidade do sistema de distribuição.

Em relação aos custos de operação e de manutenção associados aos investimentos, entende-se que não estão detalhadamente mensurados no cálculo do CIMLP. Em geral, de acordo com DNAEE (1985), para estimá-los utiliza-se um percentual sobre o investimento realizado ou em função da potência instalada das instalações, sendo mais utilizado o primeiro critério.

Por isso, como detalhado no Capítulo 5, deve-se aplicar esse percentual diretamente ao custo do investimento anualizado, ao invés de somar à taxa de remuneração para compor a taxa de atualização do investimento como é realizado no PDD. 


\subsection{Cálculo horário dos custos marginais conforme sua origem}

Os custos marginais de expansão de cada nível tarifário não são calculados originalmente para diferentes horários ou patamares de carga, isto porque os investimentos em rede são realizados, em geral, para atender a ponta do sistema.

Assim, segundo o DNAEE (1985, p. 124), no caso do custo marginal de geração, o preço no período de ponta deveria ser igual ao custo marginal de capacidade mais o custo marginal de operação na ponta, enquanto que o preço fora de ponta deveria igual somente ao custo marginal de operação neste posto ${ }^{1}$.

Por outro lado, no segmento Interconexão e Transporte Pesado havia uma divisão do custo marginal entre três parcelas: preços de energia fora de ponta e preços de energia na ponta e preços de potência. Assim, nesse segmento os custos eram alocados, de certa maneira, conforme o patamar de carga.

$\mathrm{Na}$ busca de uma metodologia que possa calcular adequadamente tarifas horárias ou por posto tarifário, uma alternativa a ser estudada é a possibilidade de alocar os custos marginais de longo prazo diretamente conforme a sua origem ou função.

Por exemplo, como visto no Capitulo 5, sobre a influência das perdas no dimensionamento do sistema de distribuição, parte dos custos de expansão não estão diretamente relacionados com o horário de ponta. Da mesma forma, investimentos que visam também atender os índices de qualidade exigidos pela agência reguladora não poderiam ser imputados somente ao período de máxima carga.

Assim, no caso das perdas, parte dos investimentos poderia ser alocada não somente no período de ponta do sistema. No caso exemplo apresentado no capitulo anterior, isto corresponderia à diferença entre os custos de investimento na rede com seção de $170 \mathrm{~mm}^{2}$ para os custos da rede de $100 \mathrm{~mm}^{2}$ que representa $\mathrm{R} \$$ $1.260 / \mathrm{km}$.

\footnotetext{
${ }^{1}$ É importante relembrar que, naquela época, o custo marginal de geração de energia era dividido nas componentes de potência e de energia, diferentemente da situação atual, como já comentado anteriormente.
} 
Esse custo adicional, aproximadamente $17 \%$ do total do investimento, poderia ser então atribuído ao critério de minimização de perdas. Pode-se afirmar que, neste caso, a relação entre os custos de ponta, relacionados ao critério de capacidade, e os custos fora de ponta, referentes ao critério de perdas, seria de aproximadamente cinco vezes, correspondendo à relação de $83 \%$ sobre $17 \%$.

Tabela 6.1 - Custos unitários em função da seção do condutor

\begin{tabular}{|c|c|}
\hline$S\left(\mathrm{~mm}^{2}\right)$ & $\begin{array}{l}\text { Custo investimento anual } \\
(\mathbf{R} \$ \mathbf{k m})\end{array}$ \\
\hline 170 & 7.521 \\
\hline 100 & 6.261 \\
\hline Diferença & 1.260 \\
\hline
\end{tabular}

Uma segunda etapa dos estudos para identificar os custos associados aos diferentes períodos de consumo é agregar a influência da qualidade. Para isso, utilizou-se uma rede típica de distribuição no nível de tensão em 13,8 kV que atende uma demanda coincidente de $5 \mathrm{MW}$, composta igualmente por consumidores do nível tarifário A4 e BT.

O alimentador utilizado como exemplo tem um tronco com extensão de $5 \mathrm{~km}$ e condutor 477 MCM e $20 \mathrm{~km}$ de ramais com condutor 4/0 AWG. Também possui chaves seccionadoras e ramal de socorro para, no caso de falha, permitir a transferência de cargas e isolamento de blocos de carga e chaves fusíveis para a proteção de cada ramal, além de bancos de capacitores para atender aos índices de determinados pela agência reguladora.

Os custos dos condutores e do bay de saída do circuito de distribuição são alocados nos horários de ponta e fora de ponta na proporção de 83\% e 17\%, respectivamente, objeto do exemplo anterior. Já os custos referentes à qualidade do serviço e do produto são alocados proporcionalmente a energia que circula no alimentador, conforme demonstrado na Tabela 6.2 a seguir. 
Tabela 6.2 - Custos típicos de rede primária de distribuição

\begin{tabular}{|c|c|c|c|c|c|c|}
\hline \multirow[b]{2}{*}{ Equipamento } & \multirow{2}{*}{$\begin{array}{c}\text { Custo } \\
\text { unitário } \\
\text { (R\$ mil) }\end{array}$} & \multirow[b]{2}{*}{ Qtd } & \multirow{2}{*}{$\begin{array}{c}\text { Total } \\
\text { (R\$ mil) }\end{array}$} & \multicolumn{3}{|c|}{ Alocação dos custos } \\
\hline & & & & $\begin{array}{c}\text { Ponta } \\
\text { (R\$ mil) }\end{array}$ & $\begin{array}{c}\text { Fora Ponta } \\
\text { (R\$ mil) }\end{array}$ & $\begin{array}{l}\text { Energia } \\
\text { ( } \mathbf{R} \$ \mathrm{mil})\end{array}$ \\
\hline Saída de Linha 13,8 kV & 200 & 1 & 200 & 166 & 34 & \\
\hline km tronco (477 MCM) & 80 & 5 & 400 & 332 & 68 & \\
\hline km ramal (4/0 AWG) & 50 & 10 & 500 & 415 & 85 & \\
\hline km socorro (4/0 AWG) & 50 & 1 & 50 & & & 50 \\
\hline Chave seccionadora & 7 & 4 & 28 & & & 28 \\
\hline Banco de capacitores & 15 & 1 & 15 & & & 15 \\
\hline \multirow[t]{2}{*}{ Chave fusível } & 4 & 20 & 80 & & & 80 \\
\hline & & Total & 1.273 & 913 & 187 & 173 \\
\hline
\end{tabular}

Esse critério de alocação indica que, nesse exemplo, aproximadamente $71 \%$ dos custos estariam relacionados propriamente com a ponta da rede, $15 \%$ com o período fora de ponta e os restantes $14 \%$, referentes à qualidade, distribuídos ou proporcionalmente à energia ou igualmente entre as 24 horas. Com base na taxa de remuneração de $10 \%$ a.a. e no período de 25 anos, calcula-se o custo anual e em seguida o custo unitário desse circuito primário, conforme Tabela 6.3.

Tabela 6.3 - Alocação dos custos típicos de rede primária de distribuição

\begin{tabular}{ccccc}
\hline Alocação & $\begin{array}{c}\text { Investimento } \\
\text { (R\$ mil) }\end{array}$ & $\%$ & $\begin{array}{c}\text { Custo anual } \\
\text { (R\$ mil) }\end{array}$ & $\begin{array}{c}\text { Custo unitário } \\
\text { (R\$/kW.ano) }\end{array}$ \\
\hline Ponta & 913 & 71,7 & 100,58 & 20,12 \\
Fora Ponta & 187 & 14,7 & 20,60 & 4,12 \\
Energia & 173 & 13,6 & 19,06 & 3,81 \\
\hline Total & $\mathbf{1 2 7 3}$ & $\mathbf{1 0 0 , 0}$ & $\mathbf{1 4 0 , 2 4}$ & $\mathbf{2 8 , 0 5}$ \\
\hline
\end{tabular}

Para simular os preços horários foi utilizada a curva de carga da rede agregada A2-A4. Nos picos da rede, acima de 90\%, foram alocados os custos de ponta e nos demais horários os custos fora de ponta. Já os custos de qualidade foram alocados considerando o consumo horário. O resultado deste critério de rateio está demonstrado na Figura 6.4 que apresenta os preços horários para a curva agregada resultante do processo de desmodulação de determinados clientes-tipo, implementado no Capítulo 7. 


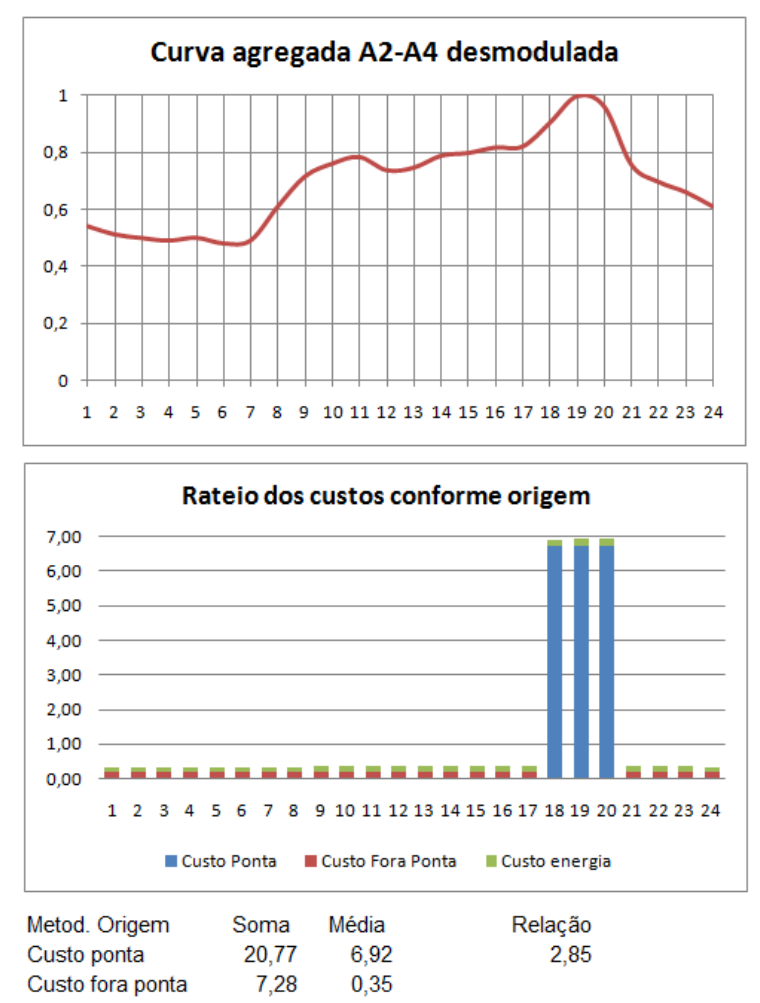

Figura 6.4 - Rateio dos custos da rede primária de distribuição conforme sua origem

Dessa maneira, supondo um período de ponta de 3 horas, os custos no horário de ponta totalizam $\mathrm{R} \$ 20,77 / \mathrm{kW}$ enquanto que no período fora de ponta ${ }^{2}$ somam $R \$ 7,28 / \mathrm{kW}$, representando uma relação de 2,85 .

Essa abordagem é interessante, pois permitiria alocar todos os custos decorrentes do serviço de distribuição diretamente por patamares de carga ou, ainda, por hora. Por outro lado, entende-se que calcular diretamente os custos horários, ou seja, segregar, hora a hora, cada tipo de despesa (operação, perdas, qualidade e expansão) é, em termos de método, no âmbito deste trabalho, uma tarefa complexa. Seria necessário estender a análise, efetuada para as redes primárias de distribuição, para as redes secundárias, os transformadores de subestações, as linhas de subtransmissão e respectivas curvas de carga.

Ainda assim é um método a ser estudado uma vez que estudos similares têm sido desenvolvidos em outros países. Por exemplo, para Ortega et al.(2004), o custo associado à potência corresponderia à rede desenhada unicamente para transportar

\footnotetext{
${ }^{2}$ Os custos nos horários de ponta e fora de ponta incluem o rateio dos custos de qualidade alocados conforme o consumo.
} 
uma capacidade de ponta, enquanto que o custo associado à energia poderia ser calculado pela diferença entre o custo para atender a potência de ponta e o custo da rede completo.

Uma abordagem alternativa, na tentativa de se aproximar deste critério de cálculo horário dos custos marginais conforme sua origem, seria considerar que, no sistema de distribuição, não necessariamente deve-se alocar todos os custos de expansão no horário de ponta e os custos de operação fora da ponta. A maior parte desses custos está realmente relacionada com a ponta do sistema, porém outra parte é resultante do atendimento em horários fora de ponta, como demonstrado a seguir.

\subsection{Metodologia dos custos do cliente: consideração da minimização das perdas}

Um dos pontos importantes é a discussão da adequada sinalização das perdas técnicas na tarifa de uso do sistema. Atualmente, a metodologia incorpora, de forma distinta, dois aspectos das perdas técnicas: as perdas de potência e as perdas de energia.

No cálculo dos custos marginais de capacidade ${ }^{3}$, ou custos marginais do cliente, são consideradas as perdas acumuladas nos vários níveis de tensão que correspondem às denominadas perdas de potência. Com base nos índices de perdas de potência, mais custos são alocados nos níveis de tensão a montante. Em resumo, representa o quanto de potência adicional precisa ser injetada a montante em relação ao ponto de suprimento.

As perdas de energia, que correspondem à energia elétrica adicional comprada pela distribuidora e que se dissipa ao longo do sistema, atualmente constituem uma componente das tarifas de uso, representada por um custo de

\footnotetext{
3 Importante relembrar que o custo marginal de capacidade, ou custos marginais do cliente, corresponde a alocação horária dos custos marginais de expansão aos consumidores levando em consideração o fluxo de potência, os índices de perdas, a demanda do consumidor e a probabilidade de ser atendido pelas redes-tipo.
} 
compra de energia elétrica, e alocada aos consumidores proporcionalmente aos custos marginais de capacidade.

Em tese, a influência das perdas está incorporada nos custos marginais de expansão por nível de tensão, obtidos pelo método de CIMLP, uma vez que os investimentos levam em consideração o critério técnico-econômico de minimização dos custos das obras e das perdas.

Porém, esta influência não está sendo considerada na alocação horária dos custos. Como discutido no Capítulo 5, o critério atual aloca, para o consumidor, os custos marginais somente nos horários em que a rede está mais carregada, porém, não necessariamente o custo da ampliação do sistema decorre apenas desta situação, mas também em razão da necessidade de minimizar os custos das perdas também.

De fato, segundo Ortega et al. (2004), a idéia, implícita em determinados modelos tarifários, de que a expansão do sistema de distribuição depende apenas da potência de ponta, "é um critério simplista que está longe de ser realidade porque ignora outras variáveis determinantes como a energia e a localização geográfica dos consumidores". A energia, por meio da minimização das perdas e do custo da energia não distribuída, é uma variável muito importante e freqüentemente utilizada para estabelecer o nível de investimentos.

Por exemplo, em Portugal, embora a distribuidora não tenha que comprar energia para a cobertura das perdas ${ }^{4}$, a tarifa de uso das redes inclui preços de energia que também correspondem às perdas no sistema de distribuição. $O$ consumidor não paga em dobro pelas perdas porque a receita oriunda desta componente na tarifa da distribuidora não se destina à cobertura de perdas propriamente dita, mas contribui para diminuir o repasse dos custos do serviço de distribuição.

\footnotetext{
${ }^{4}$ Em Portugal, diferentemente do nosso caso, a distribuidora não vende energia elétrica para o consumidor e, portanto não é responsável por cobrir as perdas no sistema de distribuição. A responsabilidade é dos comercializadores que repassam esses custos para seus preços ou para as tarifas, no caso do comercializador de ultimo recurso.
} 
$\mathrm{Na}$ realidade, essas componentes são sinais econômicos que ajudam na cobertura da receita requerida total da distribuidora. De acordo com Oliveira (informação pessoal) ${ }^{5}$ há duas razões para defender os preços de energia na tarifa de redes:

“1. Há vários custos da atividade do distribuidor que não dependem da potência instantânea máxima mas sim do "volume de atividade" da distribuição.

2. Apesar das perdas não serem um custo dos distribuidores, a tarifa pode incluir esse sinal que se soma ao custo das perdas que está na tarifa de energia dos comercializadores. Isto dá, em termos marginais, um sinal de custo econômico das perdas que é o dobro do preço médio (considerando que os preços de energia das tarifas de redes correspondem aos preços médios das perdas) correspondendo à sinalização de que as perdas evoluem quadraticamente com a carga. Nesta situação, é importante referir que não existe um sobrecusto para os consumidores (as perdas não são cobradas em dobro) porque o montante de custos que são recuperados pelas tarifas de redes continua a ser igual aos custos da distribuição (sem as perdas). Apenas a estrutura de preços é que fica com um peso maior nos preços de energia, com a justificação anterior."

Entende-se que a metodologia de alocação horária dos custos deve considerar não somente os horários de maior carregamento, mas também a influência das perdas, uma vez que os custos dos investimentos incorporam os custos das perdas.

Propõe-se o aprimoramento do critério para incorporar a influência das perdas no dimensionamento do sistema de distribuição. A princípio poderia ser incorporada própria curva das redes tipos na alocação horária dos custos e não somente nos picos da rede. A utilização das perdas tenderia a alocar os custos mais uniformemente, como demonstrado na Figura 6.5.

\footnotetext{
${ }^{5}$ Oliveira P. Perdas. Mensagem recebida por sergio.fugimoto@edpbr.com.br em 20 jul. 2009.
} 

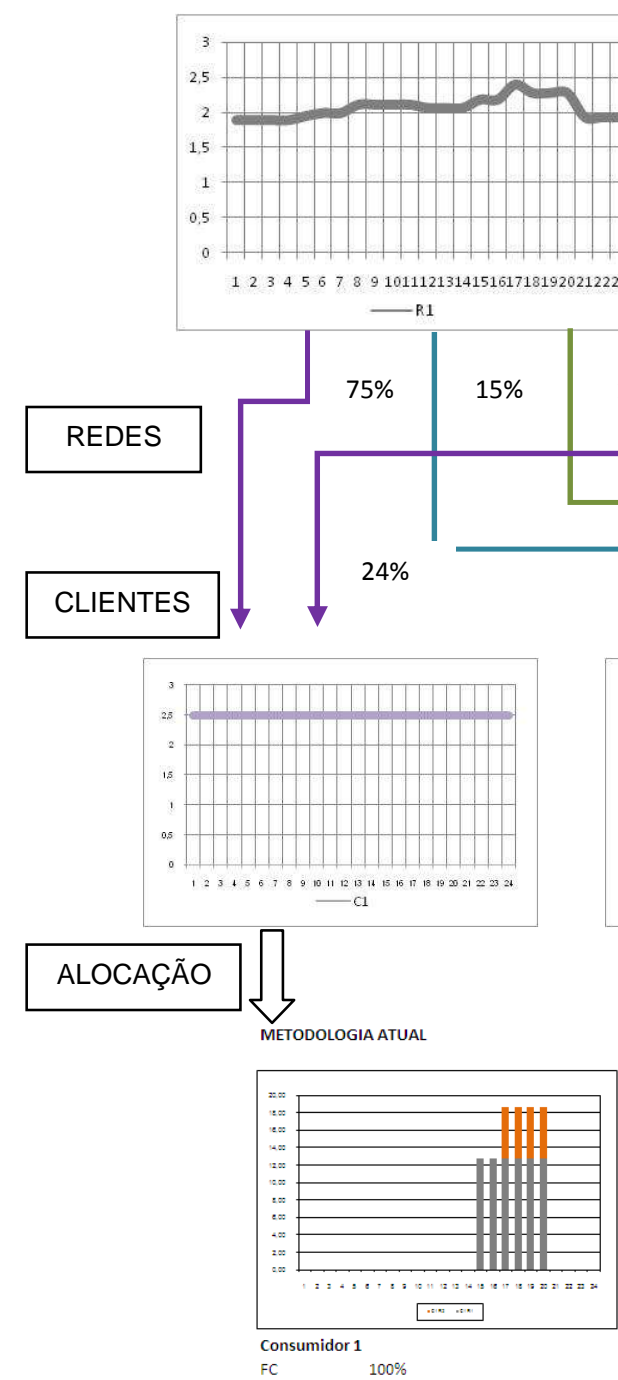

FC $\quad 100 \%$

Fperdas $\quad 100 \%$

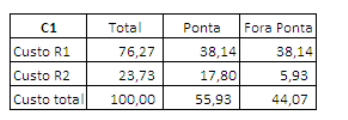

METODOLOGIA PERDAS (proporcional)
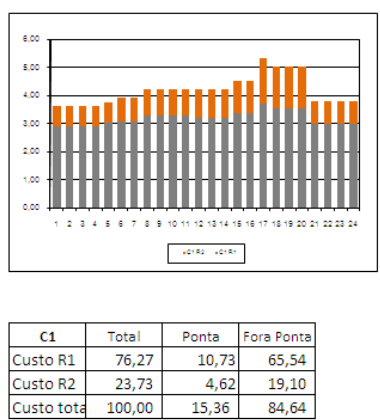
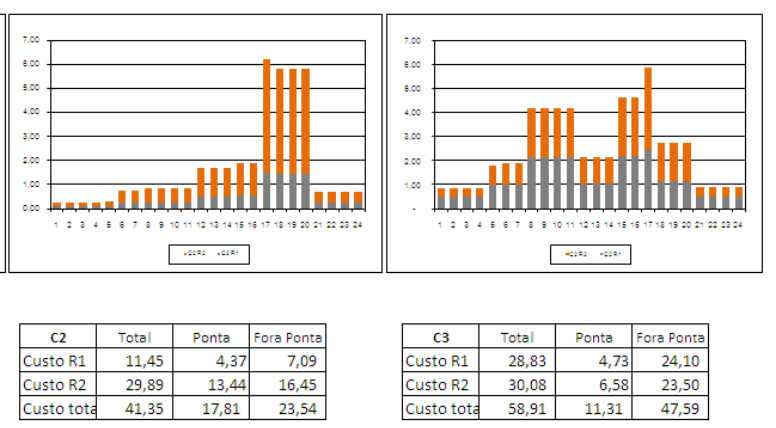

Figura 6.5 - Alocação de custos nas pontas versus alocação conforme perfil da rede 
A Figura 6.5 demonstra que o restante das curvas não coincidente com 0 horário de maior carregamento das redes não é utilizado pela metodologia atual. Observa-se também a influência do fator de coincidência que é menor que um somente para os horários 18,19 e 20 do cliente tipo 3 , resultando em custo menor para este consumidor.

Contudo, esse critério não está totalmente adequado uma vez que considera que o custo total dos investimentos seria decorrente de acréscimo de carga em qualquer período, não levando em consideração o rateio de custos identificados no item anterior que discutiu os cálculos horários dos custos marginais conforme sua origem.

A abordagem anterior considerava a diferença entre os custos da rede mínima necessária para atender apenas o critério de capacidade e os custos da rede utilizada pela distribuidora que atende também o critério de minimização de perdas técnicas.

Uma forma de buscar inserir essa discussão na metodologia atual seria aprimorar a alocação horária para que considere a influência dos custos das perdas não somente nos horários de pico, mas também em outros momentos.

Essa questão pode ser resolvida, alterando-se na metodologia atual os momentos em que os fatores de contribuição são considerados para a alocação de custos. Em vez de aplicar o atual critério de utilização das pontas das redes-tipo (acima de 90\%) poderia ser adotado um percentual menor que alocasse os custos em horários em que a rede estivesse um pouco menos carregada.

O percentual adequado poderá ser estimado a partir da discussão sobre três fundamentos teóricos desta proposta: o fator de contribuição exposto por Santos (2008), a classificação das redes de distribuição em função da sua utilização e o critério utilizado para o planejamento do sistema de distribuição.

Em relação ao primeiro assunto, Santos (2008) demonstra que o custo de fornecimento formulado por Balasko (1975) pode ser transposto para o modelo atual do setor elétrico. Inicialmente, no estudo do autor francês, para os períodos em que não se exigia a máxima potência do sistema, o custo de fornecimento ao cliente era 
constituído somente pelos custos médios de geração, isto porque, por definição, a probabilidade de falha era zero. Já para os períodos de máxima demanda, somavam-se, aos custos médios de geração, também os custos de déficit com a sua probabilidade de ocorrência.

$$
\sum_{t \in T_{i}} x_{t}^{j} * \mu_{t}=\bar{\mu}_{m} * \sum_{t \in T_{i}} x_{t}^{j}+\left(D_{t}-\bar{\mu}_{m}\right) * \sum_{t \in T_{i}} P_{t}^{m} * x_{t}^{j}
$$

Onde,

$\mu_{t},=$ custo de fornecimento ao consumidor $j$ no instante $t$,

$\bar{\mu}_{m}=$ custo médio de geração do tipo $m$ no instante $t$;

$P_{t}^{m}=$ probabilidade de ocorrer uma geração do tipo $m$ no instante t;

$D_{t}=$ custo marginal de déficit em $t$;

$x_{t}^{j}=$ contribuição do consumidor $j$ à carga do sistema em $t$;

$T_{i}=$ período tarifário

O custo de fornecimento pode ser explicado por uma função teórica que é proporcional ao consumo e variável com o fator de carga, conforme equacionamentos a seguir.

Inicialmente, multiplicando-se e dividindo-se a Equação 6.1 pela demanda máxima do consumidor $\hat{x}_{t}^{j}$, obtém-se a seguinte equação:

$$
\sum_{t \in T_{i}} x_{t}^{j} * \mu_{t}=\hat{x}_{t}^{j} *\left(\frac{\bar{\mu}_{m} * \sum_{t \in T_{i}} x_{t}^{j}}{\hat{x}_{t}^{j}}+\frac{\left(D_{t}-\bar{\mu}_{m}\right) * \sum_{t \in T_{i}} P_{t}^{m_{*}} x_{t}^{j}}{\hat{x}_{t}^{j}}\right)
$$

Agrupando-se convenientemente a Equação 6.2, obtém-se:

$$
\begin{gathered}
\sum_{t \in T_{i}} x_{t}^{j} * \mu_{t}=\hat{x}_{t}^{j} *\left[\bar{\mu}_{m} * g\left(\theta_{T_{i}}^{j}\right)+\delta_{T_{i}} * f\left(\theta_{T_{i}}^{j}\right)\right] \\
g\left(\theta_{T_{i}}^{j}\right)=\frac{\sum_{t \in T_{i}} x_{t}^{j}}{\hat{x}_{t}^{j}} \\
\delta_{T_{i}}=\left(D_{t}-\bar{\mu}_{m}\right) * \sum_{t \in T_{i}} P_{t}^{m}
\end{gathered}
$$




$$
f\left(\theta_{T_{i}}^{j}\right)=\frac{\sum_{t \in T_{i}} P_{t}^{m} * x_{t}^{j}}{\hat{x}_{t}^{j} \sum_{t \in T_{i}} P_{t}^{m}}
$$

Onde,

$\hat{x}_{t}^{j}=$ demanda máxima do consumidor $j$ em $T_{i}$;

$g\left(\theta_{T_{i}}^{j}\right)=$ horas de utilização do consumidor $\mathrm{j}$, fator de carga multiplicado pelo período;

$\delta_{T_{i}}=$ custo de desenvolvimento do $\mathrm{kW}$ garantido pelo sistema em $T_{i}$;

$f\left(\theta_{T_{i}}^{j}\right)=$ fator de contribuição do consumidor $j$ ao custo de desenvolvimento $\delta_{T_{i}}$.

As formulações estabelecidas por Balasko foram desenvolvidas para um ambiente verticalizado, devendo ser transpostas para o atual ambiente. Neste caso, Santos (2008) propõe que o custo médio de geração seja considerado zero e que o custo marginal de déficit seja substituído pelo custo marginal de expansão do nível tarifário.

$$
\begin{gathered}
\sum_{t \in T_{i}} x_{t}^{j} * \mu_{t}=\hat{x}_{t}^{j} * \delta_{T_{i}} * f\left(\theta_{T_{i}}^{j}\right) \\
\delta_{T_{i}}=C I M L P * \sum_{t \in T_{i}} P_{t}^{m}
\end{gathered}
$$

Onde,

$\delta_{T_{i}}=$ custo de desenvolvimento do $\mathrm{kW}$ garantido pelo sistema em $T_{i}$;

$C I M L P=$ aproximação do custo marginal de expansão do nível;

$P_{t}^{m}=$ probabilidade da carga ser atendida pela rede-tipo.

A Equação 6.7 mede o fator de contribuição do consumidor ao custo de desenvolvimento do $\mathrm{kW}$ garantido no intervalo. Essa contribuição pode ser explicada pelo fator de carga da unidade consumidora e pela probabilidade de ocorrência de déficit que, no caso do ambiente atual, corresponde à probabilidade de a carga $j$ estar sendo atendida pela rede $i\left(\pi_{\mathrm{ji}}\right)$ no horário de demanda máxima deste sistema, de acordo com Santos (2008). 
Em resumo, as formulações elaboradas por Balasko, adaptadas por Santos (2008) para o ambiente institucional atual, correspondem à equação utilizada pela metodologia atual para o cálculo do custo marginal de capacidade dos clientes (CMC).

Assim, o fator de contribuição $f\left(\theta_{T_{i}}^{j}\right)$ corresponde, na metodologia atual, a combinação dos fatores $\pi_{\mathrm{ji}}$ e do fator $P_{j}(h)$ que considera, para o consumidor $j$, a demanda no horário $h$ em relação à demanda máxima $\left(\frac{x_{t}^{j}}{x_{t}^{j}}\right)$, calculados para as horas de pontas das redes.

É importante, então, considerar também a influência do percentual que define a ocorrência das pontas de rede. Como os custos são alocados nesses horários, um percentual menor representará uma maior quantidade de pontas de rede. Nesse caso, mantendo-se fixo os fatores $\pi_{\mathrm{ji}}$ e $P_{j}(h)$, os custos horários diminuirão. Embora o valor da soma dos custos horários seja mantido, o surgimento de custos em horários diferentes tende a diminuir o custo no posto tarifário ponta. O contrário, um percentual maior, diminuirá a ocorrência das pontas de rede aumentando os custos horários e, conseqüentemente, o custo no posto tarifário ponta.

Outra análise, considerando o perfil de carga do consumidor, é que a diminuição do percentual que define a ocorrência de pontas, aumenta os custos para um consumidor com um perfil de consumo mais constante ou com fator de carga alto. Isto porque nas horas de ponta, ou de maior carregamento, por exemplo, acima de $95 \%$ da demanda máxima, possivelmente mesmo consumidores com fator de carga baixo contribuem para a formação dessa ponta.

Por outro lado, considerando um percentual, por exemplo, de 70\% para definir as horas em que serão alocados os custos, possivelmente um consumidor com fator de carga alto contribuiria mais do que um consumidor com fator de carga baixo nessas horas incluídas com a diminuição do percentual.

Assim, a proposição da alteração do percentual considerado na metodologia, não corresponde somente a uma diminuição do nível a partir do qual deve ser considerado como ponta, mas uma mudança no paradigma de que os custos devem 
ser alocados somente no momento de máxima demanda. O percentual passa, então, a ser tratado, na metodologia proposta, como o carregamento da rede a partir do qual os custos devem ser alocados.

A discussão anterior direciona as reflexões para o segundo tópico da fundamentação teórica. As redes podem ser classificadas em Coletivas, Semicoletivas ou Individualizadas, conforme a quantidade de clientes que as utilizam, segundo DNAEE (1979). Esta categorização poderia ser utilizada para a alocação dos custos de capacidade em termos de potência ou energia, como proposto pelo referido estudo.

De fato, Santos (2010) apresenta estudos sobre a influência da alteração do percentual de carregamento, concluindo que nas Redes Individualizadas, os clientes contribuem integralmente para o máximo carregamento da rede, ou seja, fator igual a 1,0; enquanto que, nas Redes Coletivas, a contribuição dos consumidores, por causa da diversidade, está relacionada com a potência média, ou seja, fator 0,5, aproximadamente; e, por fim, nas Redes Semi-coletivas, o fator de contribuição estaria na faixa entre 0,5 e 1,0 .

De acordo com DNAEE (1979), M. Boiteux e Stasi ${ }^{6}$ mostraram que se, por um lado, o desenvolvimento de uma obra de transporte de energia elétrica está intimamente ligado a potência máxima demandada, por outro lado, o acréscimo de custos ocasionado pelo cliente marginal, devido à característica aleatória da demanda, poderia estar mais relacionado com a potência média na ponta, ou seja, com a energia no período.

Assim, não parece ser adequada a alocação de custos de capacidade somente em termos de potência. Contudo, sabe-se, que potência e energia são produtos ligados tanto sob o ponto de vista da produção como do consumo. Segundo DNAEE (1979), os custos de desenvolvimento poderiam ser então alocados em termos de potência no caso de Rede Individualizada, enquanto na Rede Coletiva seriam em termos de potência média. Já para a Rede Semi-coletivas, parte dos custos de capacidade alocados em termos de potência e a restante seria, então, repartida sobre os custos de energia.

\footnotetext{
6 "Sur la détermination des prix de revient dans un système interconnecté" (UNIPEDE, Rome, 1952)
} 
Em Portugal, como descrito no Capítulo 2, é adotado um critério semelhante, no qual os preços de potência contratada estão associados com os trechos próximos do consumidor (Redes Individualizadas segundo referência DNAEE, 1979) enquanto que os preços de potência média, em horas de ponta, procuram transmitir os custos dos trechos mais centrais do sistema de distribuição (Redes Coletivas).

Dessa forma, ao alterar o percentual de carregamento a partir do qual os custos são alocados, a metodologia proposta nesta tese está permitindo a distribuição mais adequada para os consumidores, em sintonia com a discussão sobre a formação dos custos de distribuição.

Foram calculados os custos marginais de capacidade total e nos postos horários para os consumidores A4 variando-se os fatores de carregamento desde 0,5 até 0,9 (metodologia atual), de modo similar ao discutido por Santos (2010). A Tabela 6.2 apresenta os resultados da simulação e a Figura 6.6 demonstra graficamente a variação obtida nos custos em função da alteração do fator de carregamento.

Tabela 6.2 - Custos marginais de capacidade em função do carregamento

\begin{tabular}{|c|c|c|c|c|c|c|}
\hline \multirow{2}{*}{ Curvas clientes-tipo } & \multirow{2}{*}{$\begin{array}{c}\text { Fator de } \\
\text { Carga }\end{array}$} & \multicolumn{5}{|c|}{ Custos (R\$/kW. ano) } \\
\hline & & $\begin{array}{c}\text { Fator } \\
0,5\end{array}$ & $\begin{array}{c}\text { Fator } \\
0,6\end{array}$ & $\begin{array}{c}\text { Fator } \\
0,75\end{array}$ & $\begin{array}{c}\text { Fator } \\
0,80\end{array}$ & $\begin{array}{c}\text { Fator } \\
0,9\end{array}$ \\
\hline 06 - Clientes A4 -1 & 0,93 & 85,12 & 85,66 & 86,25 & 86,72 & 89,92 \\
\hline 06 - Clientes A4 -2 & 0,88 & 68,61 & 68,50 & 66,40 & 66,14 & 68,44 \\
\hline 06 - Clientes A4 -3 & 0,79 & 74,08 & 76,60 & 79,68 & 80,86 & 85,00 \\
\hline 06 - Clientes A4 -4 & 0,59 & 60,22 & 64,93 & 73,58 & 74,61 & 81,65 \\
\hline 06 - Clientes A4 -5 & 0,46 & 38,95 & 43,17 & 53,63 & 51,95 & 58,70 \\
\hline 06 - Clientes A4 -6 & 0,50 & 53,68 & 59,26 & 65,91 & 64,03 & 74,60 \\
\hline 06 - Clientes A4 -7 & 0,72 & 72,40 & 75,84 & 81,05 & 80,98 & 86,16 \\
\hline 06 - Clientes A4 -8 & 0,52 & 45,65 & 49,28 & 60,89 & 64,42 & 76,13 \\
\hline 06 - Clientes A4 -9 & 0,67 & 45,65 & 49,28 & 60,89 & 64,42 & 76,13 \\
\hline 06 - Clientes A4 -10 & 0,82 & 78,91 & 80,54 & 84,66 & 85,80 & 89,48 \\
\hline 06 - Clientes A4 -11 & 0,58 & 65,39 & 69,95 & 78,34 & 78,84 & 85,94 \\
\hline 06 - Clientes A4 -12 & 0,82 & 64,07 & 64,43 & 66,64 & 67,26 & 70,85 \\
\hline Agregada 06 - Clientes A4 & 0,72 & 67,68 & 70,85 & 76,48 & 76,49 & 84,57 \\
\hline
\end{tabular}




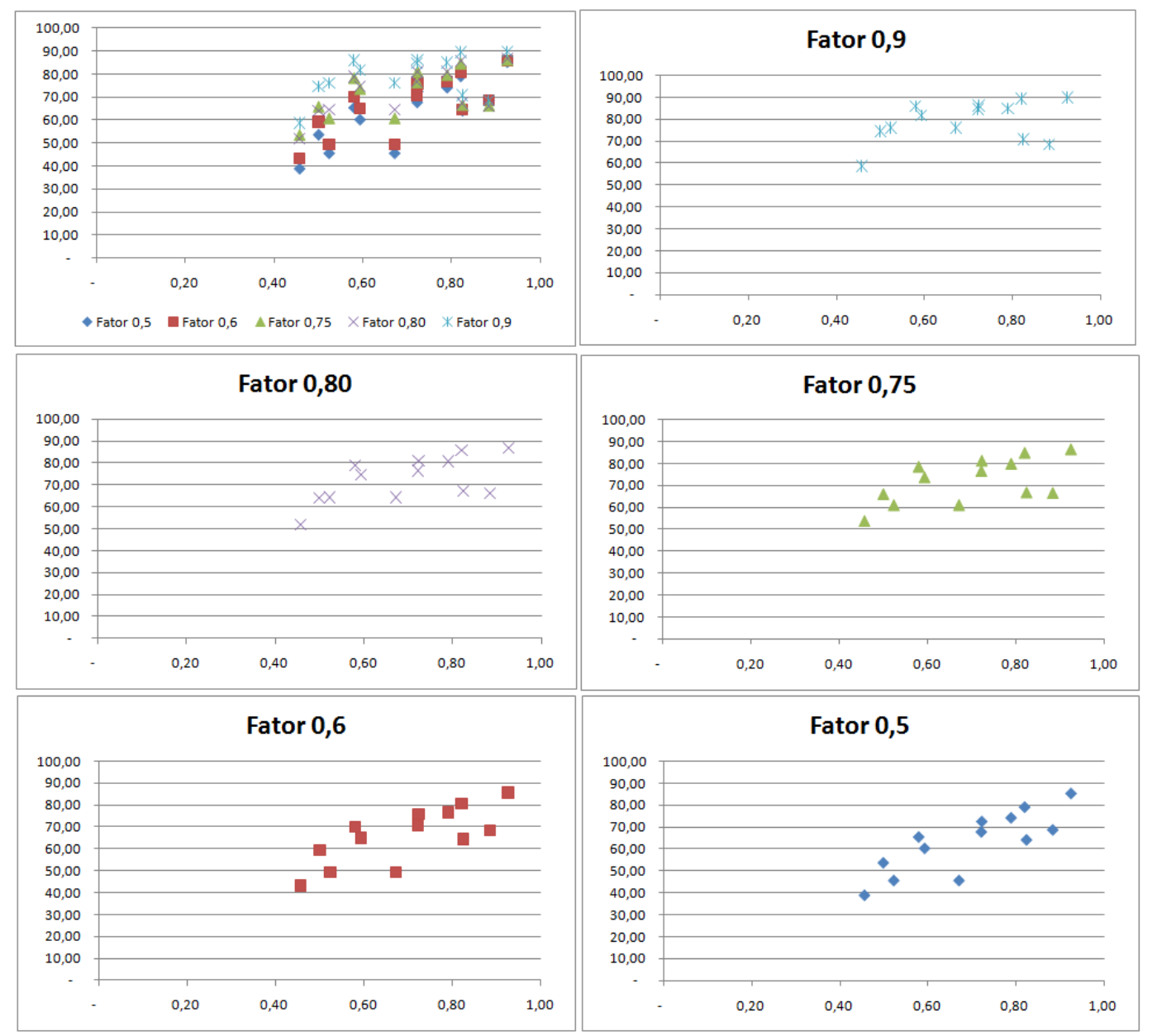

Figura 6.6 - Custos marginais de capacidade (R\$/kW.ano) - clientes A4

Observa-se que para um fator de 0,5 a relação entre os custos e o fator de carga dos clientes aproxima-se de uma relação linear, como já discutido por Santos (2010). Por outro lado, para um fator de 0,9 os custos não variam tanto com o fator de carga indicando que a alocação de custos não estaria adequada para uma rede de distribuição caracterizada como semi-coletiva.

A percepção de que os custos podem variar também com o fator de carga do consumidor é uma das características positivas da atual metodologia que não vem sendo aplicada corretamente. Portanto, a alteração do fator de carregamento como proposto na metodologia possibilita a modelagem das modalidades tarifárias, como será discutido nos próximos tópicos. 
Em relação ao terceiro item da fundamentação, em geral, o planejamento técnico da expansão do sistema de distribuição utiliza módulos para subestações e estruturas de redes que foram padronizados considerando os critérios técnicos de atendimento, inclusive minimização de perdas.

Por exemplo, a Tabela 6.3 apresenta os carregamentos máximos dos alimentadores em função da bitola do condutor enquanto que a Tabela 6.4 apresenta os cabos utilizados por uma distribuidora de São Paulo para alimentadores em área urbana e os respectivos carregamentos previstos.

Tabela 6.3 - Carregamentos máximos por condutor

\begin{tabular}{ccc}
\hline \multicolumn{3}{c}{ Carregamentos Máximos } \\
Bitola & I máx. (50ㄷ) (A) & MVA para 13,8 kV \\
\hline 2 AWG & 138 & 3,3 \\
1/0 AWG & 184 & 4,4 \\
4/0 AWG & 293 & 7,0 \\
336 MCM & 395 & 9,4 \\
477 MCM & 485 & 11,6 \\
\hline
\end{tabular}

Fonte: Cipoli (1993)

Tabela 6.4 - Carregamentos padronizados dos alimentadores urbanos

\begin{tabular}{ccccc}
\hline \multicolumn{2}{c}{ Cabo ASC } & \multicolumn{2}{c}{ Carregamento (MVA) } & \multirow{2}{*}{ Observação } \\
Bitola & Seção $\left(\mathbf{m m}^{2}\right)$ & Inicial & Previsto 50 ano & \\
\hline 4/0 AWG & 107 & 2,5 & 3,0 a 3,5 & para extensões já existentes \\
336 MCM & 170 & 2,5 & 4,1 a 5,8 & para extensões já existentes \\
477 MCM & 241 & 2,5 & 4,1 a 5,9 & \\
\hline
\end{tabular}

Fonte: Cipoli (1993)

Observa-se que em função da flexibilidade operativa e do nível de perdas, a distribuidora utiliza cabos com bitolas maiores daquelas que seriam empregadas caso fosse utilizado somente o critério de capacidade. De fato, conforme Cipoli (1993), em relação às perdas, "a bibliografia mostra que a carga econômica para determinada bitola é a que vai de um quarto a um terço de sua corrente", como já demonstrado no Capítulo 5. 
Dessa forma, no dimensionamento dos padrões construtivos da distribuidora já estão incorporados determinados fatores de carga e de perdas típicos. No exemplo do Capitulo 5, empregou-se o fator de perda de 0,60 para o alimentador de distribuição, que corresponde aproximadamente a um fator de carga de 0,74, considerado padrão para o dimensionamento dos circuitos primários de distribuição.

O fator de carregamento proposto para alocação dos custos também é uma aproximação do fator de carga para um perfil de curva de rede mais linear, o que ocorre em sistemas de distribuição ${ }^{7}$. Assim, sob a ótica de incremento marginal da demanda, a proposição de um fator de carregamento acima de 0,80 também tende a alocar os custos em horários que atende o critério de dimensionamento do sistema de distribuição. Ao contrário, a alocação em horários com menor carregamento não seria adequada uma vez que o sistema já está originalmente dimensionado para o atendimento desses horários, considerando um carregamento típico utilizado no planejamento.

\footnotetext{
${ }^{7}$ Evidentemente que determinadas curvas de rede pode ter um fator de carga muito baixo, porém com pontas em determinados instantes, não sendo neste caso possível considerar que o fator de carregamento seria uma boa aproximação do fator de carga.
} 

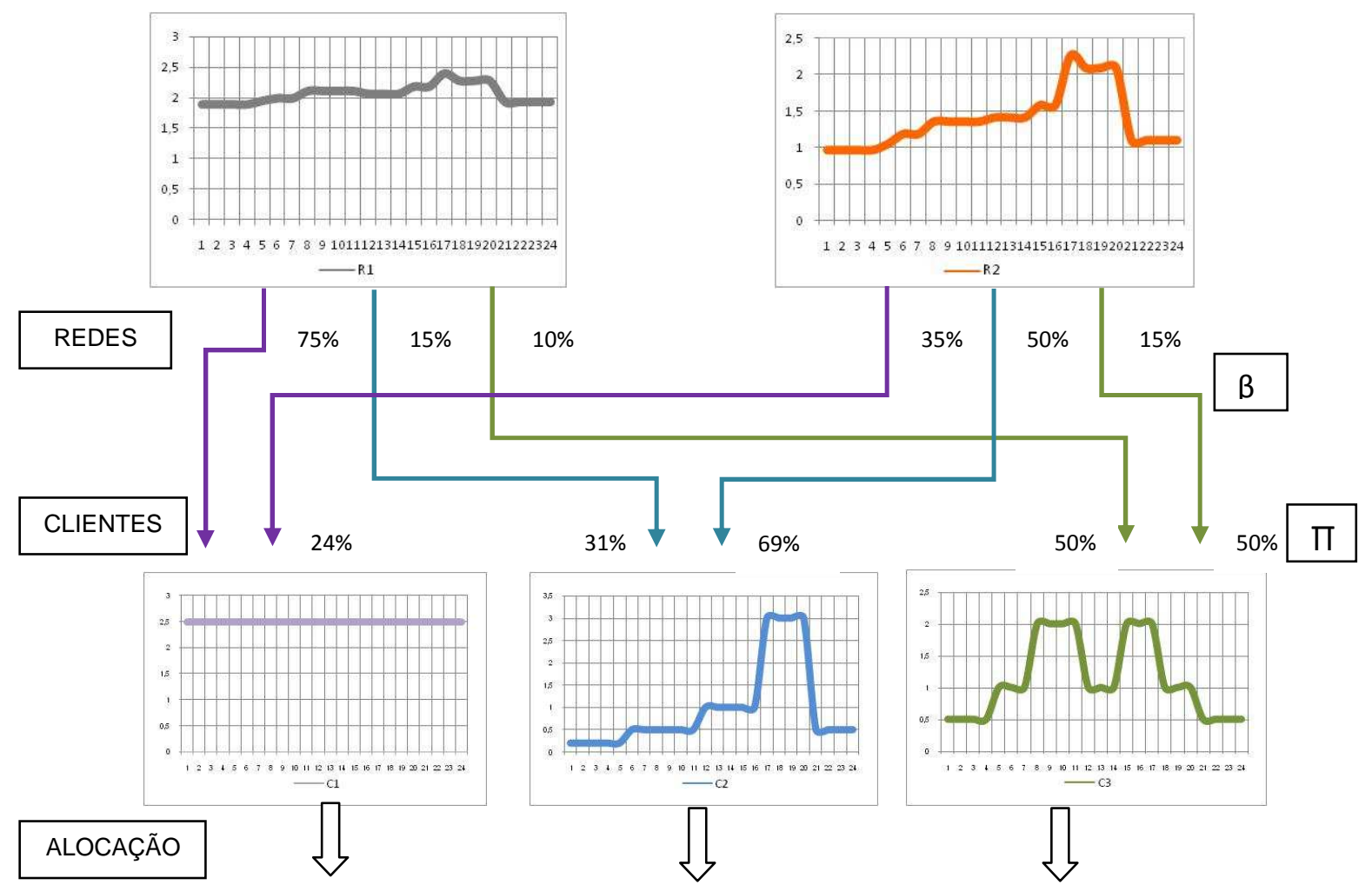

METODOLOGIA ATUAL
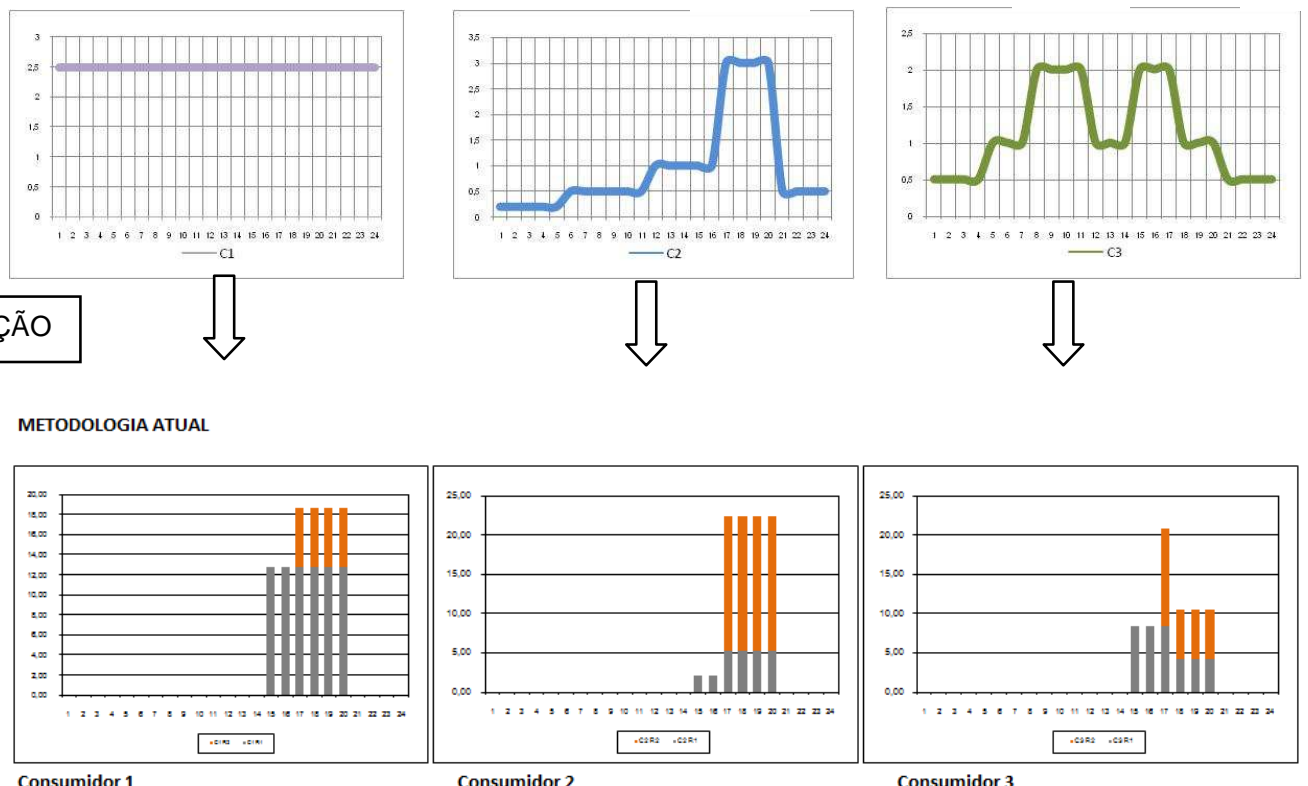

FC

Fperdas $\quad 100 \%$

\begin{tabular}{|l|r|r|r|}
\hline \multicolumn{1}{|c|}{ C1 } & \multicolumn{1}{|c|}{ Total } & \multicolumn{1}{c|}{ Ponta } & Fora Ponta \\
\hline Custo R1 & 76,27 & 38,14 & 38,14 \\
\hline Custo R2 & 23,73 & 17,80 & 5,93 \\
\hline Custo total & 100,00 & 55,93 & 44,07 \\
\hline
\end{tabular}
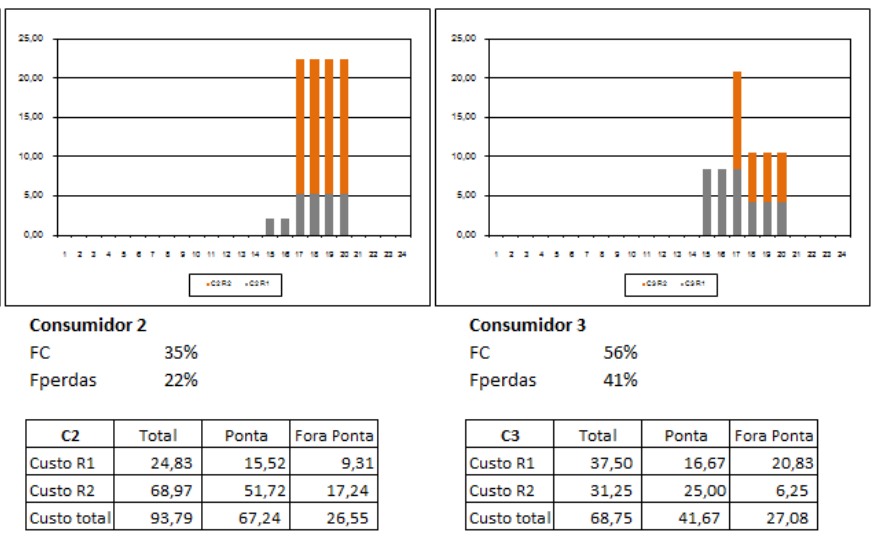

$\begin{array}{ll}\text { FC } & 56 \% \\ \text { Fperdas } & 41 \%\end{array}$

METODOLOGIA PERDAS (alteração percentual)

$80 \%$

\begin{tabular}{|l|r|r|r|}
\hline \multicolumn{1}{|c|}{ C3 } & \multicolumn{1}{|c|}{ Total } & \multicolumn{1}{c|}{ Ponta } & Fora Ponta \\
\hline Custo R1 & 37,50 & 16,67 & 20,83 \\
\hline Custo R2 & 31,25 & 25,00 & 6,25 \\
\hline Custo total & 68,75 & 41,67 & 27,08 \\
\hline
\end{tabular}
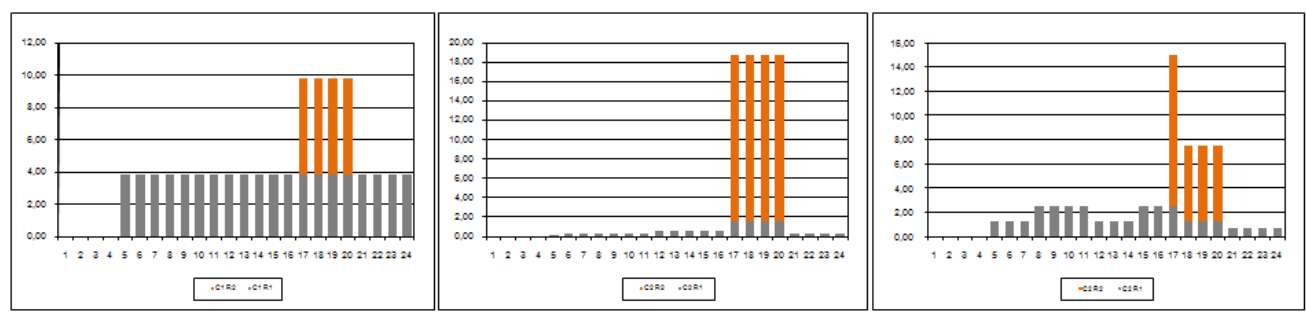

\begin{tabular}{|l|r|r|r|}
\hline \multicolumn{1}{|c|}{ C1 } & \multicolumn{1}{|c|}{ Total } & \multicolumn{1}{c|}{ Ponta } & Fora Ponta \\
\hline Custo R1 & 76,27 & 11,44 & 64,83 \\
\hline Custo R2 & 23,73 & 17,80 & 5,93 \\
\hline Custo tota & 100,00 & 29,24 & 70,76 \\
\hline
\end{tabular}

\begin{tabular}{|l|r|r|r|}
\hline \multicolumn{1}{|c|}{ C2 } & \multicolumn{1}{|c|}{ Total } & Ponta & Fora Ponta \\
\hline Custo R1 & 12,54 & 4,66 & 7,88 \\
\hline Custo R2 & 68,97 & 51,72 & 17,24 \\
\hline Custo tota & 81,50 & 56,38 & 25,12 \\
\hline
\end{tabular}

\begin{tabular}{|l|r|r|r|}
\hline \multicolumn{1}{|c|}{ C3 } & \multicolumn{1}{c|}{ Total } & \multicolumn{1}{|c|}{ Ponta } & Fora Ponta \\
\hline Custo R1 & 31,25 & 5,00 & 26,25 \\
\hline Custo R2 & 31,25 & 25,00 & 6,25 \\
\hline Custo tota & 62,50 & 30,00 & 32,50 \\
\hline
\end{tabular}

Figura 6.7 - Alocação de custos conforme critério de $80 \%$ do perfil da curva de rede 
Em conclusão, considerando que i) as formulações de Balasko indicam que o custo do sistema está relacionado com o fator de contribuição dos clientes nas redes; ii) os tipos de redes (coletivas, semi-coletivas ou individualizadas) estão relacionados com a participação dos clientes nas redes, sendo que a maior parte do sistema de distribuição é constituído por redes semi-coletivas; iii) as redes padronizadas incorporam no seu dimensionamento um fator de carga típico; propõese que os custos sejam alocados em horários em que a rede estiver com carregamento acima de $80 \%$ em relação à demanda máxima da rede-tipo.

\subsection{Comparação entre a alocação horária conforme a origem dos custos e a metodologia proposta}

Antes de comparar a alocação dos custos horários conforme a sua origem, detalhado no item 6.4 , com a abordagem proposta no item anterior, é importante ressaltar a influência da quantidade de pontas da rede no método de cálculo atual.

Isto porque os custos totais de ponta e fora de ponta estão diretamente relacionados ao número de horas que formam cada posto tarifário. Como o período fora de ponta é sete vezes o período de ponta, a relação entre os custos horários nos dois postos aumenta na mesma proporção

Supondo que há apenas uma curva de rede-tipo e uma curva de cliente-tipo os custos são divididos igualmente entre a quantidade de picos (acima de $90 \%$ da máxima, por exemplo) da curva de rede.

Por sua vez, esses picos podem coincidir ou não com o posto tarifário ponta da distribuidora. Caso todos os picos da rede estejam concentrados neste posto, o custo marginal será alocado somente no horário de ponta; da mesma forma, será totalmente alocado no horário fora de ponta no caso inverso.

Observa-se então que, neste caso de existência de somente um cliente-tipo, a quantidade de picos da rede e a sua ocorrência no horário de ponta definirá a relação entre os custos alocados nos postos tarifários. 
Depois dessas considerações, é possível continuar as comparações do critério de alocação em função da origem dos seus custos apresentadas na Figura $6.4 \mathrm{com}$ a metodologia atual e a proposta de aprimoramento. Como visto, a metodologia atual alocará os custos totais, independentemente da sua finalidade, somente nos momentos de pico da rede considerados atualmente como igual ou acima de $90 \%$ da máxima demanda. Como, coincidentemente, todos os picos da rede se encontram no período do posto tarifário ponta, todo o custo ( $R \$ 26,90 / \mathrm{kW})$ é alocado na ponta.

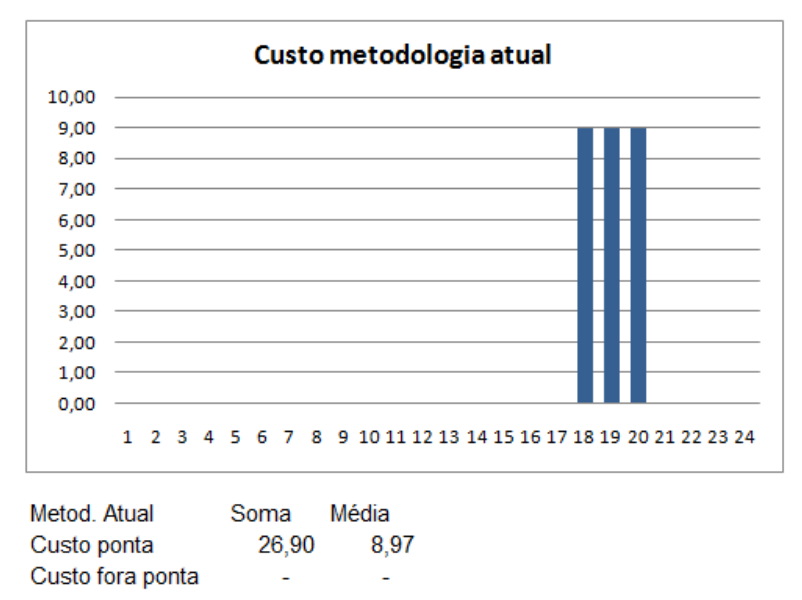

Figura 6.8 - Custos horários no método atual (ponta 90\%) - rede primária exemplo

Se fosse alterado o critério de pontas da rede para valores iguais ou acima de $95 \%$, o efeito prático, nesse caso, seria nulo, uma vez que os custos totais continuariam sendo alocados em duas horas que compõem o posto tarifário ponta, aumentando-se os custos horários para $R \$ 13,45 / \mathrm{kW}$, porém permanecendo os valores totais e médios, como pode ser visto na Figura 6.12 .

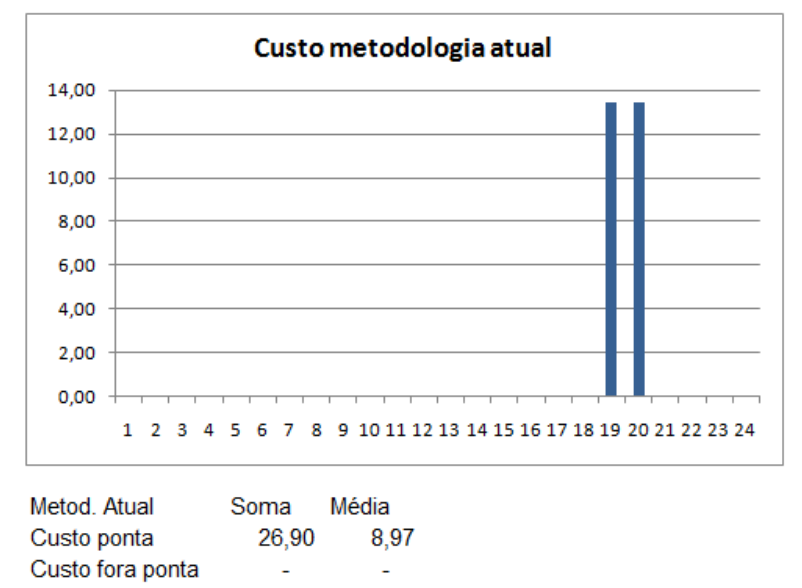

Figura 6.9 - Custos horários no método atual (ponta 95\%) - rede primária exemplo 
A metodologia apresentada nesta tese propõe, dentre outros aprimoramentos, a alocação dos custos marginais de longo prazo nos momentos (ou horas) em que a curva de carga da rede suplanta o valor de 0,80 da demanda máxima. Aparentemente, trata-se de alterar o critério de ponta, porém, como já explicado, busca-se alocar os custos de expansão não associados diretamente com os picos da rede. Por isso, aplica-se a metodologia proposta na mesma curva de carga da rede-tipo, para que se possa aferir a fundamentação teórica discutida anteriormente.

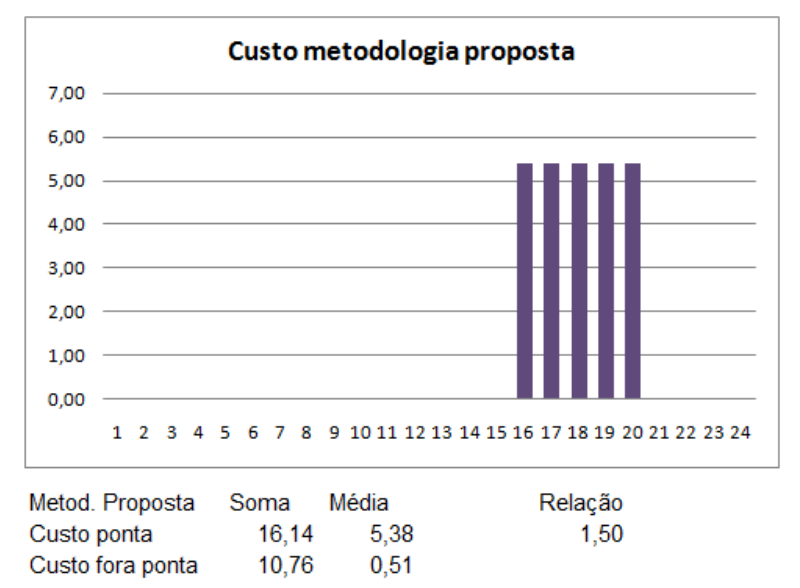

Figura 6.10 -Metodologia proposta - rede primária exemplo

Comparando-se os valores das figuras anteriores observa-se que o critério proposto aloca custos em horários fora do posto tarifário ponta e de forma mais uniforme do que a metodologia atual. Evidentemente a alocação dependerá do perfil da curva de carga. Assim, se o critério proposto, fator de contribuição de $80 \%$ aplicado em determinada curva de rede-tipo, definir três picos de rede localizados no posto tarifário ponta e dois no posto fora de ponta, a relação entre os custos será de 1,5 , como visto.

Um valor acima provocaria a diminuição das pontas, aumentando a relação de custos entre ponta e fora de ponta, se a hora que deixasse de ser considerada fosse no horário fora de ponta e vice-versa. Um valor abaixo em redes com fator de carga alto, aumentaria o número de picos e conseqüentemente de horários em que se aloca o custo, diminuindo de maneira significativa a relação entre ponta e fora de ponta. Por isso, entende-se que as simulações anteriores demonstram a fundamentação teórica da alteração do critério de alocação em função de determinado carregamento da rede. 


\subsection{Agregação dos custos horários e definição de postos tarifários}

Conforme análise apresentada no capítulo anterior, a agregação dos custos horários que formam a tarifa do posto tarifário não deveria sofrer o ajuste defendido no método de cálculo atual que efetua a ponderação pela demanda máxima de cada período.

Isto porque, embora os custos estejam referenciados à demanda máxima, entende-se que a lógica do custo marginal, ou seja, do custo para atender um incremento de potência em cada hora deva prevalecer.

Dessa forma, a tarifa do posto tarifário deveria, em vez de buscar a manutenção das mesmas receitas nos postos tarifários ${ }^{8}$, manter a relatividade original, encontrada nos custos horários, que tem implícito o custo marginal para atender a demanda, pois considera o fator de contribuição do cliente naquele horário.

Além disso, como proposto por Santos (2008), entende-se que é possível definir novos postos horários a partir da análise dos custos horários calculados pela metodologia atual e da sua agregação como proposto anteriormente. Dessa forma, pode-se definir a quantidade de postos tarifários com base nos períodos nos quais os níveis de custos sejam semelhantes,

Seguindo a mesma lógica de sinalização do custo marginal, utilizada para defender a utilização dos custos horários sem o ajuste pela demanda máxima do posto, entende-se que as tarifas de referência dos postos tarifários deveriam corresponder à média dos custos horários originais em vez da simples somatória como aplicada pelo método atual.

Como o método de cálculo possibilita identificar as tarifas horárias, a passagem dos custos horários para formar a tarifa de referência do posto tarifário

\footnotetext{
${ }^{8}$ É importante relembrar que o ajuste tem a premissa de que a receita a ser recuperada, calculada a partir da aplicação do custo horário sobre a demanda máxima, deveria permanecer constante independentemente da demanda do posto tarifário. Assim, para efeitos de faturamento, se essa demanda do posto tarifário não corresponder à máxima de demanda do cliente, a tarifa no posto tarifário deveria ser ajustada para manter a mesma receita.
} 
deve considerar o número de horas que compõem o período e os custos horários. Assim, a aplicação das tarifas horárias originais é considerada para formar a relatividade vertical de custos (entre níveis de tensão) enquanto que a relatividade da média dos custos horários dos postos tarifários é mantida para formar as tarifas de referência dos postos tarifários.

Esse critério pode ser fundamentado pela abordagem de Williamson (1966) que ressalta a necessidade de tratamento diferenciado para períodos com diferentes quantidade de horas. Entende-se assim que o critério proposto possibilita que a sinalização de custos horários não seja perdida em meio aos diferentes períodos dos postos tarifários.

Ambos os procedimentos serão aplicados no Capítulo 7, sendo denominados de nova agregação dos custos horários e definição de novos postos tarifários, respectivamente.

\subsection{Relações entre as tarifas de ponta e fora de ponta}

Como analisado no capitulo anterior, as relações entre os horários de ponta e fora de ponta também estão refletindo o ambiente institucional anterior, pois embora sejam calculados os custos em cada posto tarifário, a ANEEL utiliza os fatores exógenos empregados no passado.

A manutenção dessas relações poderia ser parcialmente justificada pelo fato de que os custos no horário de ponta refletem a influência da própria tarifa horosazonal à qual o cliente está exposto.

Contudo, entende-se que é possível utilizar as tarifas calculadas para os diversos horários considerando o novo método que propõe a alteração do fator de contribuição para considerar a alocação horária mais aderente aos critérios de planejamento da expansão das redes e a agregação média de custos horários para formar a sinalização de postos tarifários.

Em adição, Santos (2008) propõe a utilização das elasticidades para estimar a curva de carga do cliente considerando novas tarifas realimentando o processo de 
cálculo até atingir a convergência das tarifas e do mercado de fornecimento. Já Antunes, N. P. (2007) expõe um método no qual a curvas dos clientes são desmoduladas com base em uma tarifa única para todo o período. Utilizando as mesmas probabilidades de associação $\left(\pi_{\mathrm{ji}}\right)$ calculadas pelo método, são então remontadas curvas de redes a partir das novas curvas de carga dos clientes. Com base nesta nova configuração são calculados os custos horários dos clientes.

As propostas dos autores estão corretas, podendo-se utilizar ambas em conjunto visando à precificação correta dos custos nos postos horários e a convergência das tarifas em razão do comportamento do cliente. Uma abordagem interessante seria considerar a curva resultante do processo de desmodulação e compará-la como a curva ideal que se deseja para o sistema da distribuidora. Em tese, os preços poderiam e deveriam induzir o conjunto dos consumidores a tornar a curva do sistema de distribuição mais plana. A nova proposta de cálculo poderia então ser aplicada sobre uma dessas abordagens para efeito de estudo de caso.

A definição das tarifas de ponta e fora de ponta (ou mesmo um terceiro posto tarifário "vazio") deve estar embasada nos resultados horários do custo marginal de capacidade e na otimização das redes que alimentam os consumidores. Para isso, propõe-se alteração do método atual que define ex-ante os postos tarifários, mantendo a demanda máxima da curva do cliente-tipo, como base para calcular o fator de contribuição, ao invés da máxima de cada posto tarifário.

Além de impedir o cálculo ex-post dos postos tarifários, este procedimento atual distorce o sinal vertical (entre postos) uma vez que busca apenas manter a relatividade entre as receitas que seriam recuperadas em cada posto. Entende-se que o procedimento correto é manter as relatividades entre as tarifas de referência em cada posto tarifário.

De modo similar a Santos (2008), propõe-se utilizar os custos marginais de capacidade para definir a relação vertical entre os níveis de tensão ${ }^{9}$. A relação horizontal será definida com base na média ajustada das tarifas horárias, que

\footnotetext{
${ }^{9}$ A proposta de Santos (2008) para as tarifas por posto tarifário considera a média das tarifas horárias, diferentemente da apresentada nesta tese que considera a soma das tarifas horárias calculadas, porém sobre a demanda máxima da curva do cliente-tipo.
} 
compõem cada posto tarifário, calculadas sobre a mesma base, que é a demanda máxima do cliente-tipo.

\subsection{Aprimoramentos da construção das modalidades tarifárias}

No caso da construção das modalidades tarifárias azul, verde e convencional, a agência reguladora, como já visto, calcula essas tarifas a partir do custo marginal de capacidade que corresponde ao valor médio dos custos dos clientes-tipo, não levando em consideração toda a curva de custos estimada na metodologia (custos marginais de capacidade dos clientes tipo em função das horas de utilização).

Assim, as tarifas de demanda da THS Azul correspondem exatamente ao valor da TUSD enquanto que a THS Verde no horário de ponta, cobrada em termos de energia, é decorrente da transformação da tarifa azul, cobrada em termos de demanda, por meio da aplicação de um fator de carga definido externamente ao processo de cálculo. Já, no caso da tarifa convencional, a ANEEL aloca, na tarifa de demanda, $72 \%$ dos custos de ponta e $100 \%$ dos custos fora de ponta.

Assim, uma das proposições de aprimoramento da tese é a correção do cálculo das atuais modalidades tarifárias existentes THS Azul e Verde, além da tarifa convencional. O método adequado seria identificar os custos dos grupos de consumidores de curta e de longa utilização. Com base nesses dois segmentos da curva, determina-se inicialmente a tarifa azul como uma "média ponderada" dos custos dos consumidores de longa utilização e, em seguida, a tarifa verde como aquela que minimiza a diferença entre essa tarifa e os custos de capacidade dos consumidores de curta utilização (ANTUNES, 2007). A tarifa convencional também deve ser calculada com base nos dados das tipologias. 


\subsection{Considerações}

Neste capítulo, cerne da tese, foram propostos aprimoramentos e inovações necessários de maneira a atualizar a metodologia para ambiente institucional existente.

Entende-se que a alocação dos componentes da tarifa deve ser a mais adequada possível o que implica que deveriam estar alinhadas com a lógica de origem dos seus custos.

A proposta da ANEEL apresentada no Quadro 6.1 seria uma boa aproximação de que como deveriam ser os custos e em conseqüência uma tarifa de referência. Isto porque a alocação de custos que não estão relacionados diretamente com a energia consumida ou potência demandada, como o dos custos comerciais, pode acarretar a não recuperação da receita, caso o consumidor altere o seu perfil de consumo. Por outro lado, observa-se que todos os custos comerciais seriam alocados nos clientes BT, o que poderia provocar o aumento significativo de preços. De todo modo, as tarifas a serem aplicadas, que diferem das tarifas de referência, devem também reconhecer algumas restrições, como a capacidade de pagamento e a substituição da energia elétrica, sendo, no entanto, imprescindível o conhecimento do custo real que o cliente está incorrendo, para que sejam efetuados ajustes se necessários.

Uma das principais inovações é a mudança do paradigma de que os custos de expansão estão integralmente alocados no horário de ponta do sistema, por meio da alteração do fator de contribuição que passa a definir o nível a partir do qual os custos são alocados e não mais o percentual que identifica as pontas da rede de distribuição. Ressalta-se que essa abordagem alternativa se originou da tentativa de se aproximar do critério de cálculos horários dos custos marginais conforme sua origem, discutido inicialmente.

Também é importante destacar, dentre outros aprimoramentos, a nova forma de agregação de custos horários que não considera o ajuste defendido no Livro Verde e aplicado atualmente, bem como a possibilidade de definir postos tarifários 
distintos a partir dos custos horários, que embora sejam calculados pela metodologia atual, não são aplicados para essa finalidade.

Finalmente, outro destaque da proposta é o cálculo ex-post das tarifas de referência dos postos tarifários bem como a sua formação, considerando a aplicação dos custos horários originais para compor a relatividade vertical e a manutenção da relatividade dos custos horários médios dos postos, 


\section{CAPÍTULO 7 - APLICAÇÕES DA PROPOSTA}

Como visto, as principais inovações na metodologia proposta estão relacionadas com a alocação horária dos custos marginais, em especial a alteração do fator de contribuição e da forma de agregação dos custos nos postos tarifários.

Assim, na primeira seção são implantadas essas alterações separadamente para que os resultados possam ser comparados com os valores originalmente calculados pela metodologia atual e, em seguida, com a formulação proposta agregando as duas alterações.

As próximas duas seções tratam de estudos da aplicação de um processo de desmodulação, no qual são alterados os perfis de determinados clientes-tipo que podem estar influenciados pela diferença das tarifas nos postos tarifários, e do processo de remontagem das curvas de redes-tipo. Com base nesses novos dados, são recalculados os novos custos marginais de capacidade sem a possível influência dos postos tarifários atuais.

Finalmente, em relação às tarifas de aplicação, são discutidas as modificações necessárias para se calcular adequadamente as tarifas para consumidores BT, bem como, são desenhadas as tarifas horo-sazonais considerando a metodologia proposta.

\subsection{Implementação da proposta de metodologia}

\subsubsection{Novos fatores de contribuição}

Com base curvas de redes-tipo e de clientes-tipo resultantes da campanha de medidas e da caracterização da carga da Escelsa referentes ao processo de revisão tarifária de 2010, foram calculados, pela agência reguladora, os custos marginais de capacidade e todas as suas componentes, como as probabilidades de associação.

As Figura 7.1 e 7.2 apresentam as curvas dos clientes-tipo agregadas por nível de tensão e por tipo, caso dos consumidores BT, que foram utilizadas no cálculo dos custos marginais de capacidade. 


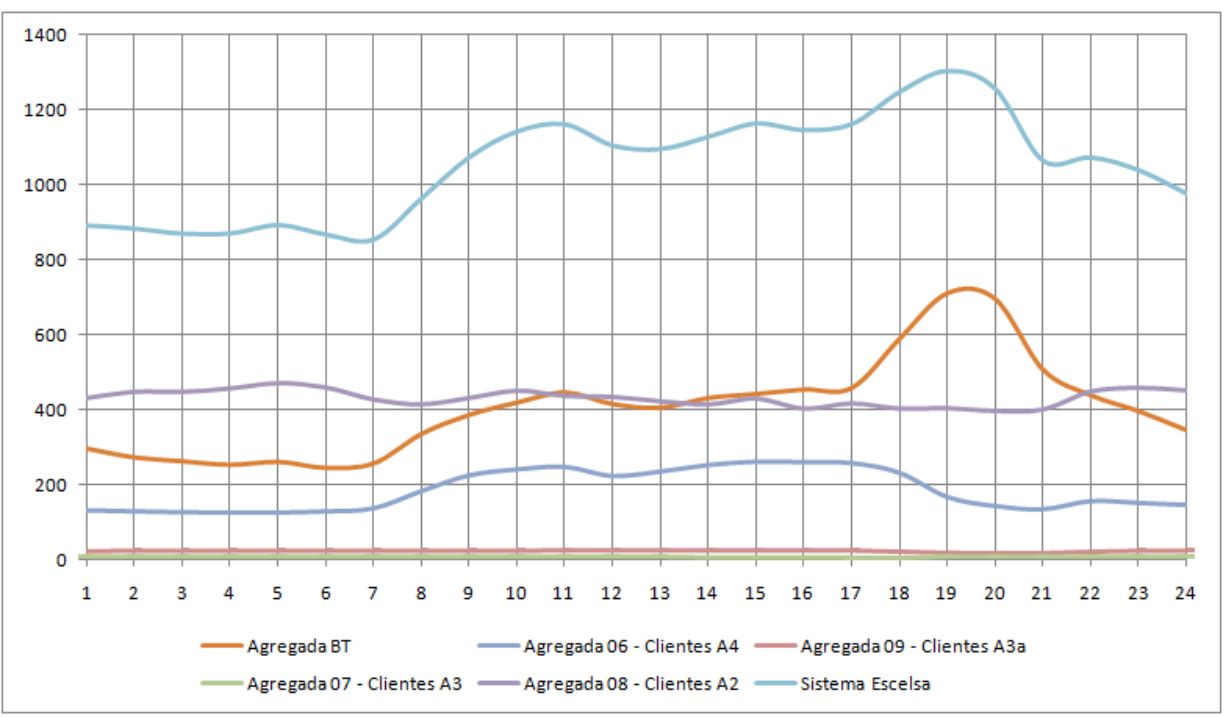

Figura 7.1 - Curvas agregadas por nível de tensão

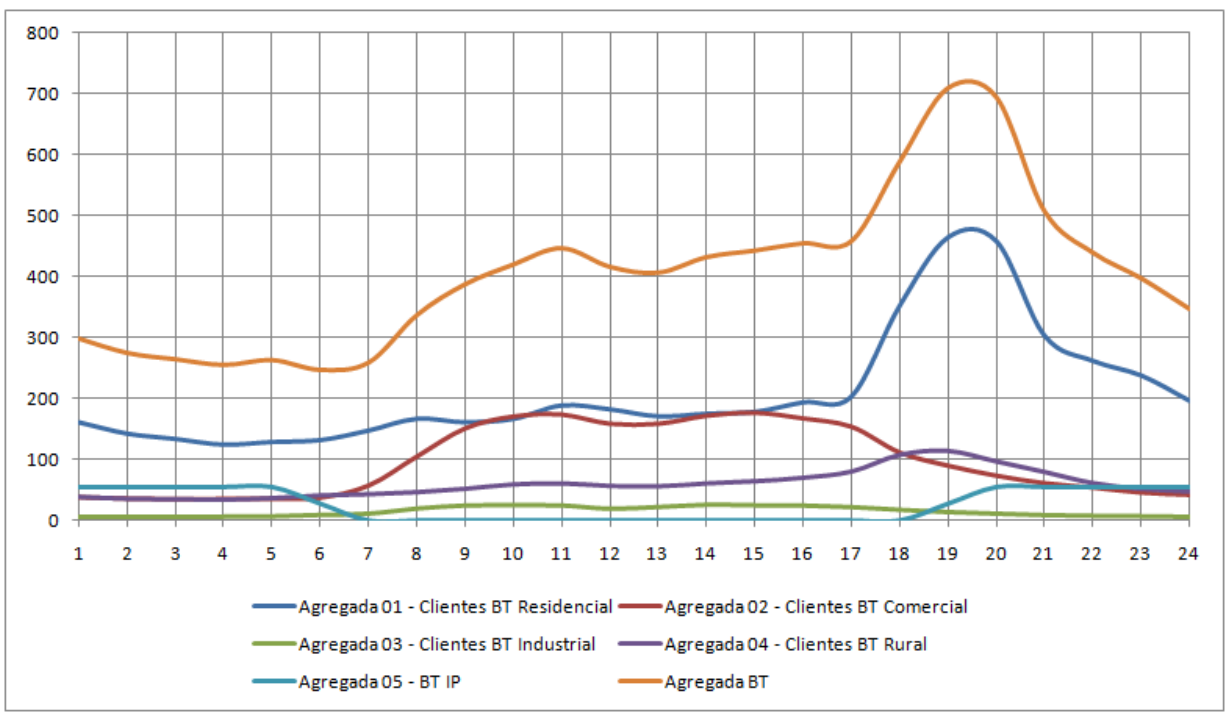

Figura 7.2 - Curvas agregadas BT por tipo de consumidor

A Tabela 7.1 apresenta os custos marginais de capacidade calculados pelo método atualmente utilizado pela agência reguladora que será utilizada como base para comparação das proposições apresentadas no Capítulo 6. 
Tabela 7.1 - Custos por posto tarifário - metodologia atual

\begin{tabular}{cccccccc}
\hline \multirow{2}{*}{ Tipos de consumidores } & \multicolumn{2}{c}{$\begin{array}{c}\text { CMC } \\
\text { (R\$/kW) }\end{array}$} & \multicolumn{2}{c}{ Dem. Máxima (MW) } & \multirow{2}{*}{$\begin{array}{c}\text { Receita } \\
\text { (R\$ x mil) }\end{array}$} & Part. \\
\cline { 2 - 5 } & $\mathbf{P}$ & $\mathbf{F P}$ & $\mathbf{P}$ & $\mathbf{F P}$ & & \\
\hline Média - Clientes A2 & 2,26 & 24,67 & 402,70 & 472,04 & & $12.556,298$ & $10,6 \%$ \\
Média - Clientes A3 & 13,53 & 40,25 & 7,01 & 7,31 & 388,838 & $0,3 \%$ \\
Média - Clientes A3a & 13,00 & 53,13 & 16,64 & 25,55 & $1.573,961$ & $1,3 \%$ \\
Média - Clientes A4 & 17,89 & 66,32 & 167,90 & 260,35 & $20.271,432$ & $17,1 \%$ \\
Média Baixa Tensão & 52,70 & 79,09 & 709,58 & 588,67 & $83.947,734$ & $70,7 \%$ \\
\hline Média - BT Residencial & 54,32 & 55,77 & 464,68 & 352,59 & $44.908,361$ & $37,8 \%$ \\
Média - BT Rural & 44,25 & 70,10 & 114,45 & 107,95 & $12.631,803$ & $10,6 \%$ \\
Média - BT Comercial & 40,49 & 87,89 & 89,78 & 176,49 & $19.145,736$ & $16,1 \%$ \\
Média - BT Industrial & 27,05 & 90,47 & 13,33 & 24,32 & $2.560,716$ & $2,2 \%$ \\
Média - BT IP & 56,49 & 29,47 & 54,69 & 54,69 & $4.701,110$ & $4,0 \%$ \\
\hline
\end{tabular}

Implementou-se, nesta seção, os cálculos para alteração dos fatores de contribuição, considerando que os custos sejam alocados em horários em que a rede estiver com carregamento acima de $80 \%$ em relação à demanda máxima da rede-tipo. A Tabela 7.2 apresenta os resultados dessa proposição.

\section{Tabela 7.2 - Custos por posto - metodologia fator de contribuição}

\begin{tabular}{cccccccc}
\hline \multirow{2}{*}{ Tipos de consumidores } & \multicolumn{2}{c}{$\mathbf{C M C}$} & \multicolumn{2}{c}{ Dem. Máxima (MW) } & \multicolumn{2}{c}{$\begin{array}{c}\text { Receita } \\
\text { (R\$ x mil) }\end{array}$} & Part. \\
\cline { 2 - 5 } & $\mathbf{P}$ & $\mathbf{F P}$ & $\mathbf{P}$ & $\mathbf{F P}$ & & \\
\hline Média - Clientes A2 & 3,80 & 23,65 & 402,70 & 472,04 & $12.696,543$ & $11,3 \%$ \\
Média - Clientes A3 & 11,13 & 42,88 & 7,01 & 7,31 & 391,229 & $0,3 \%$ \\
Média - Clientes A3a & 10,95 & 54,58 & 16,64 & 25,55 & $1.576,892$ & $1,4 \%$ \\
Média - Clientes A4 & 15,06 & 63,34 & 167,90 & 260,35 & $19.018,347$ & $17,0 \%$ \\
Média Baixa Tensão & 40,02 & 84,98 & 709,58 & 588,67 & $78.425,102$ & $70,0 \%$ \\
\hline Média - BT Residencial & 40,93 & 62,96 & 464,68 & 352,59 & $41.218,978$ & $36,8 \%$ \\
Média - BT Rural & 34,94 & 68,82 & 114,45 & 107,95 & $11.427,779$ & $10,2 \%$ \\
Média - BT Comercial & 31,91 & 88,81 & 89,78 & 176,49 & $8.537,908$ & $16,5 \%$ \\
Média - BT Industrial & 22,83 & 89,94 & 13,33 & 24,32 & & $2.491,555$ & $2,2 \%$ \\
Média - BT IP & 40,41 & 46,42 & 54,69 & 54,69 & $4.748,882$ & $4,2 \%$ \\
\hline
\end{tabular}

Os valores dos custos marginais de capacidade (CMC) por posto tarifário apresentados na Tabela 7.2 não podem ser interpretados ainda como os valores que devem ser aplicados, uma vez que as inovações referentes ao tratamento dos períodos de ponta e fora de ponta serão implantadas no próximo item. Ou seja, 
embora os custos horários já estejam aprimorados, a agregação nos postos tarifários, neste caso, considera ainda a metodologia atual.

Por isso, é importante analisar a distribuição dos custos decorrentes desse aprimoramento. Para apresentar visualmente a diferença entre os critérios da alocação dos custos horários utilizados atualmente e o proposto nesta tese, são apresentadas nas Figuras 7.3 e 7.4 o resultado das aplicações para o Cliente A4, correspondente a agregação de todos os clientes-tipo deste nível.

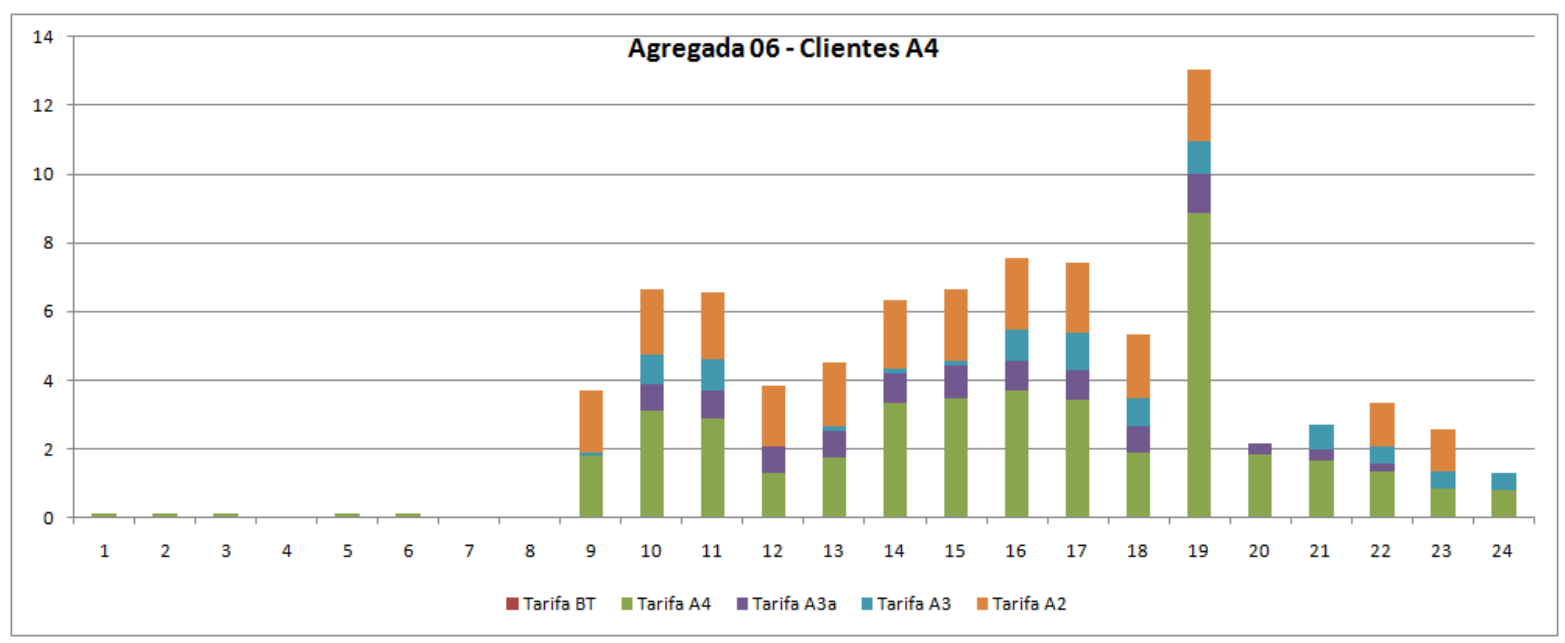

Figura 7.3 - Custos horários do Cliente A4 - metodologia atual

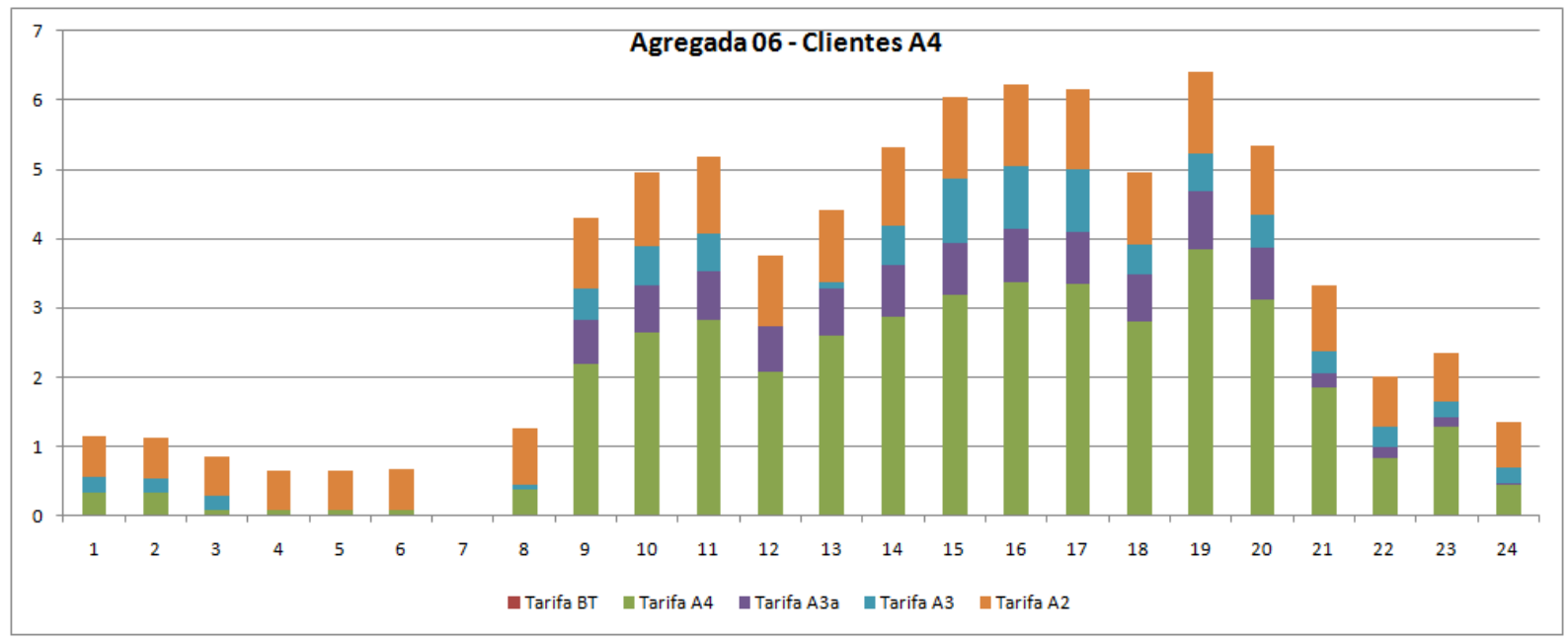

Figura 7.4 - Custos horários do Cliente A4 - critério fator contribuição

Observa-se que a implementação do fator de contribuição resulta uma distribuição de custos mais uniforme em praticamente em todo o período do dia, uma vez que os horários com menor carregamento passam a ser considerados nesse novo critério. 
Embora tenha sido apresentado o exemplo para a curva agregada dos clientes A4, foram elaboradas simulações que demonstram a diferença entre os critérios para a alocação dos custos horários para todas as curvas de clientes-tipo.

\subsubsection{Nova agregação dos custos em postos tarifários}

Para a implementação deste critério, as curvas dos clientes-tipo devem ser calculadas em p.u. da demanda máxima, não sendo necessário promover o ajuste proposto por Dnaee (1985). Além disso, para formar as tarifas de referência dos postos tarifários na ponta e fora de ponta é considerado o procedimento proposto no Capítulo 6: a receita total é formada a partir da aplicação dos custos horários originais e a proporcionalização das tarifas mantém a sinalização dos custos horários médios originais dos postos tarifários.

A Tabela 7.3 apresenta os custos marginais de capacidade calculados conforme proposta de agregação de custos horários, sendo que a Tabela 7.4 demonstra a diferença dos custos entre os dois critérios (Tabela 7.3 versus Tabela 7.1).

Tabela 7.3 - Custos por posto - nova agregação dos custos horários

\begin{tabular}{|c|c|c|c|c|c|c|}
\hline \multirow{2}{*}{ Tipos de consumidores } & \multicolumn{2}{|c|}{$\mathrm{CMC}(\mathrm{R} \$ \mathbf{k W})$} & \multicolumn{2}{|c|}{ Dem. Máxima (MW) } & \multirow{2}{*}{$\begin{array}{l}\text { Receita } \\
\text { (R\$ x mil) }\end{array}$} & \multirow{2}{*}{ Part. } \\
\hline & $\mathbf{P}$ & FP & $\mathbf{P}$ & FP & & \\
\hline Média - Clientes A2 & 9,83 & 17,93 & 402,70 & 472,04 & $12.422,42$ & $11,3 \%$ \\
\hline Média - Clientes A3 & 37,58 & 16,66 & 7,01 & 7,31 & 384,93 & $0,3 \%$ \\
\hline Média - Clientes A3a & 37,88 & 33,98 & 16,64 & 25,55 & $1.498,51$ & $1,4 \%$ \\
\hline Média - Clientes A4 & 50,32 & 41,31 & 167,90 & 260,35 & $19.204,56$ & $17,4 \%$ \\
\hline Média Baixa Tensão & 92,79 & 18,66 & 709,58 & 588,67 & $76.825,86$ & $69,6 \%$ \\
\hline Média - BT Residencial & 79,70 & 8,87 & 464,68 & 352,59 & $40.164,61$ & $36,4 \%$ \\
\hline Média - BT Rural & 88,75 & 18,94 & 114,45 & 107,95 & $12.202,37$ & $11,1 \%$ \\
\hline Média - BT Comercial & 87,96 & 53,62 & 89,78 & 176,49 & $17.359,98$ & $15,7 \%$ \\
\hline Média - BT Industrial & 69,45 & 60,52 & 13,33 & 24,32 & $2.397,79$ & $2,2 \%$ \\
\hline Média - BT IP & 79,99 & 5,96 & 54,69 & 54,69 & $4.701,11$ & $4,3 \%$ \\
\hline
\end{tabular}




\section{Tabela 7.4 - Diferenças entre os custos: atual e nova agregação}

\begin{tabular}{ccc}
\hline Tipos de consumidores & CMC (diferença) \\
& P & FP \\
\hline Média - Clientes A2 & $334 \%$ & $-27 \%$ \\
Média - Clientes A3 & $178 \%$ & $-59 \%$ \\
Média - Clientes A3a & $191 \%$ & $-36 \%$ \\
Média - Clientes A4 & $181 \%$ & $-38 \%$ \\
Média Baixa Tensão & $76 \%$ & $-76 \%$ \\
\hline Média - Clientes BT Residencial & $47 \%$ & $-84 \%$ \\
Média - Clientes BT Rural & $101 \%$ & $-73 \%$ \\
Média - Clientes BT Comercial & $117 \%$ & $-39 \%$ \\
Média - Clientes BT Industrial & $157 \%$ & $-33 \%$ \\
Média - BT IP & $42 \%$ & $-80 \%$ \\
\hline
\end{tabular}

A Figura 7.5 apresenta visualmente a alocação de custos considerando a proposta de agregação dos custos horários. Os custos horários médios dos postos tarifários são representados pelas linhas pontilhadas: em vermelho para os custos na ponta e em azul para os custos fora de ponta ${ }^{1}$. Comparando-a com a Figura 7.3, que mostra a metodologia atual, percebe-se que o critério proposto, neste caso do cliente A4, diminui os custos horários no posto tarifário ponta.

Isto ocorre porque os preços unitários são calculados sobre a demanda máxima do posto tarifário, no caso da metodologia atual, e sobre a demanda máxima da rede, no caso do método proposto.

\footnotetext{
${ }^{1}$ Esses valores correspondem aos custos horários médios originais ainda sem o ajuste necessário para manter a receita total do nível calculada pelo somatório da aplicação dos custos horários.
} 


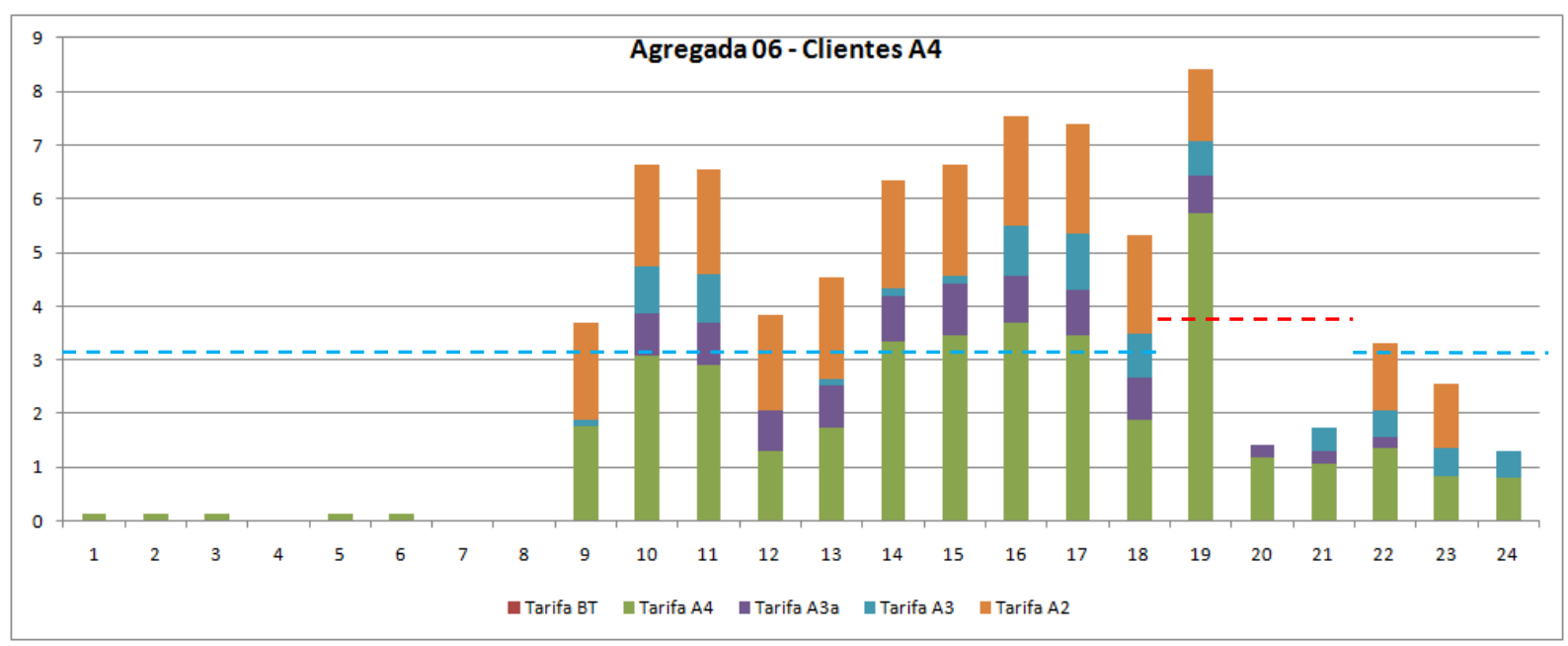

Figura 7.5 - Custos horários do Cliente A4 - critério agregação dos custos

\subsubsection{Implementação da nova metodologia}

As simulações nas seções anteriores foram necessárias para estudar isoladamente as implementações dos critérios. Nesta seção, foram incorporados, nos cálculos, os dois critérios simultaneamente. Dessa forma, as Tabelas 7.5 e 7.6 apresentam os resultados e as comparações com o método atual enquanto que a Figura 7.6 apresenta graficamente os resultados da metodologia proposta no Capítulo 6.

Tabela 7.5 - Custos por posto - nova metodologia

\begin{tabular}{cccccccc}
\hline \multirow{2}{*}{ Tipos de consumidores } & \multicolumn{2}{c}{$\mathbf{C M C}(\mathbf{R} \mathbf{\text { kW }})$} & \multicolumn{2}{c}{ Dem. Máxima (MW) } & \multicolumn{2}{c}{$\begin{array}{c}\text { Receita } \\
\text { (R\$ x mil) }\end{array}$} & Part. \\
\cline { 2 - 5 } & $\mathbf{P}$ & $\mathbf{F P}$ & $\mathbf{P}$ & $\mathbf{F P}$ & & \\
\hline Média - Clientes A2 & 13,94 & 14,52 & 402,70 & 472,04 & $12.471,605$ & $12,0 \%$ \\
Média - Clientes A3 & 34,64 & 19,89 & 7,01 & 7,31 & 388,016 & $0,4 \%$ \\
Média - Clientes A3a & 33,94 & 37,12 & 16,64 & 25,55 & $1.513,343$ & $1,5 \%$ \\
Média - Clientes A4 & 44,15 & 41,13 & 167,90 & 260,35 & $18.120,378$ & $17,5 \%$ \\
Média Baixa Tensão & 81,11 & 23,02 & 709,58 & 588,67 & $71.103,696$ & $68,6 \%$ \\
\hline Média - BT Residencial & 68,51 & 11,42 & 464,68 & 352,59 & $35.863,935$ & $34,6 \%$ \\
Média - BT Rural & 76,91 & 20,41 & 114,45 & 107,95 & $11.006,171$ & $10,6 \%$ \\
Média - BT Comercial & 75,22 & 58,80 & 89,78 & 176,49 & $17.130,635$ & $16,5 \%$ \\
Média - BT Industrial & 61,46 & 63,10 & 13,33 & 24,32 & $2.354,073$ & $2,3 \%$ \\
Média - BT IP & 74,59 & 12,24 & 54,69 & 54,69 & $4.748,882$ & $4,6 \%$ \\
\hline
\end{tabular}


Tabela 7.6 - Diferenças entre os custos: atual e nova metodologia

\begin{tabular}{ccc}
\hline Tipos de consumidores & \multicolumn{3}{c}{ CMC (diferença) } \\
& P & FP \\
\hline Média - Clientes A2 & $516 \%$ & $-41 \%$ \\
Média - Clientes A3 & $156 \%$ & $-51 \%$ \\
Média - Clientes A3a & $161 \%$ & $-30 \%$ \\
Média - Clientes A4 & $147 \%$ & $-38 \%$ \\
Média Baixa Tensão & $54 \%$ & $-71 \%$ \\
\hline Média - Clientes BT Residencial & $26 \%$ & $-80 \%$ \\
Média - Clientes BT Rural & $74 \%$ & $-71 \%$ \\
Média - Clientes BT Comercial & $86 \%$ & $-33 \%$ \\
Média - Clientes BT Industrial & $127 \%$ & $-30 \%$ \\
Média - BT IP & $32 \%$ & $-58 \%$ \\
\hline
\end{tabular}

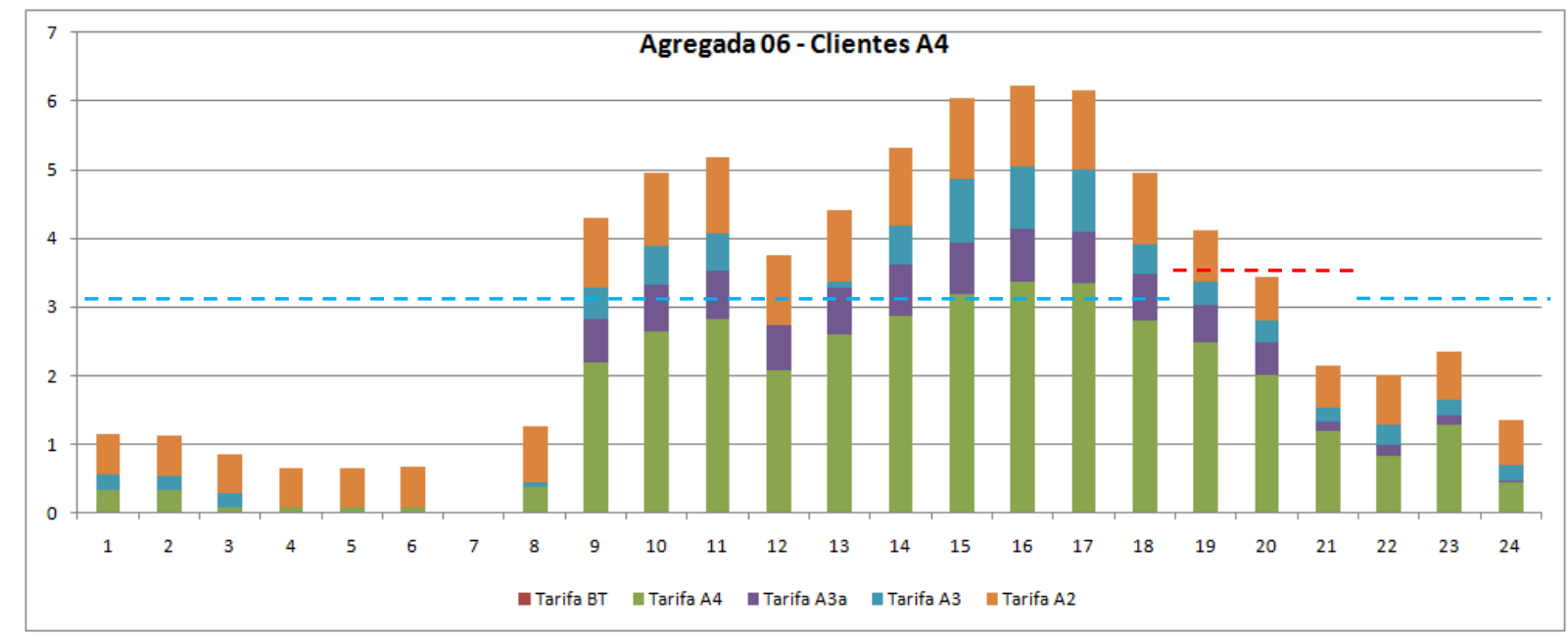

Figura 7.6 - Custos horários do Cliente A4 - critério agregação dos custos

O resultado da implementação conjunta dos dois critérios é a alocação mais uniforme dos custos considerando a influência dos critérios técnico-econômico para dimensionamento do sistema de distribuição e a agregação pela média dos custos unitários calculados pela demanda máxima da rede e não do posto tarifário.

\subsection{Estudo de caso da realimentação da metodologia}

Como discutido, propõe-se um estudo de caso que considera a desmodulação de determinadas curvas de clientes-tipo, a formação de novas curvas de redes-tipo a partir das probabilidades de associação e das curvas desmoduladas 
e, finalmente, o recálculo dos custos marginais de capacidade mantendo-se a metodologia atual e também com as alterações propostas.

\subsubsection{Desmodulação das curvas dos clientes-tipo}

Para a aplicação do estudo, assumiu-se que determinados tipos de consumidores poderiam alterar o seu comportamento considerando alterações nas atuais das relações de custos entre os postos horários, como no caso de não haver diferenças de tarifas nos postos tarifários.

Para os dados da campanha de medidas da revisão tarifária da Escelsa em 2010, foram identificadas cinco curvas de clientes-tipo A4, uma A3a e duas curvas A2 que poderiam passar pelo processo de desmodulação, considerando a análise do consumo. Não foram escolhidas as curvas dos consumidores BT porque não há sinal de preço na ponta para esses consumidores. Já os consumidores $A 3$, conforme os dados obtidos na campanha de medidas, originalmente não possuem modulação no horário de pico, ou seja, não alteram seu perfil de consumo em função do preço, neste caso.

A Figura 7.7 apresenta o perfil original e a desmodulação assumida para a aplicação do caso. 

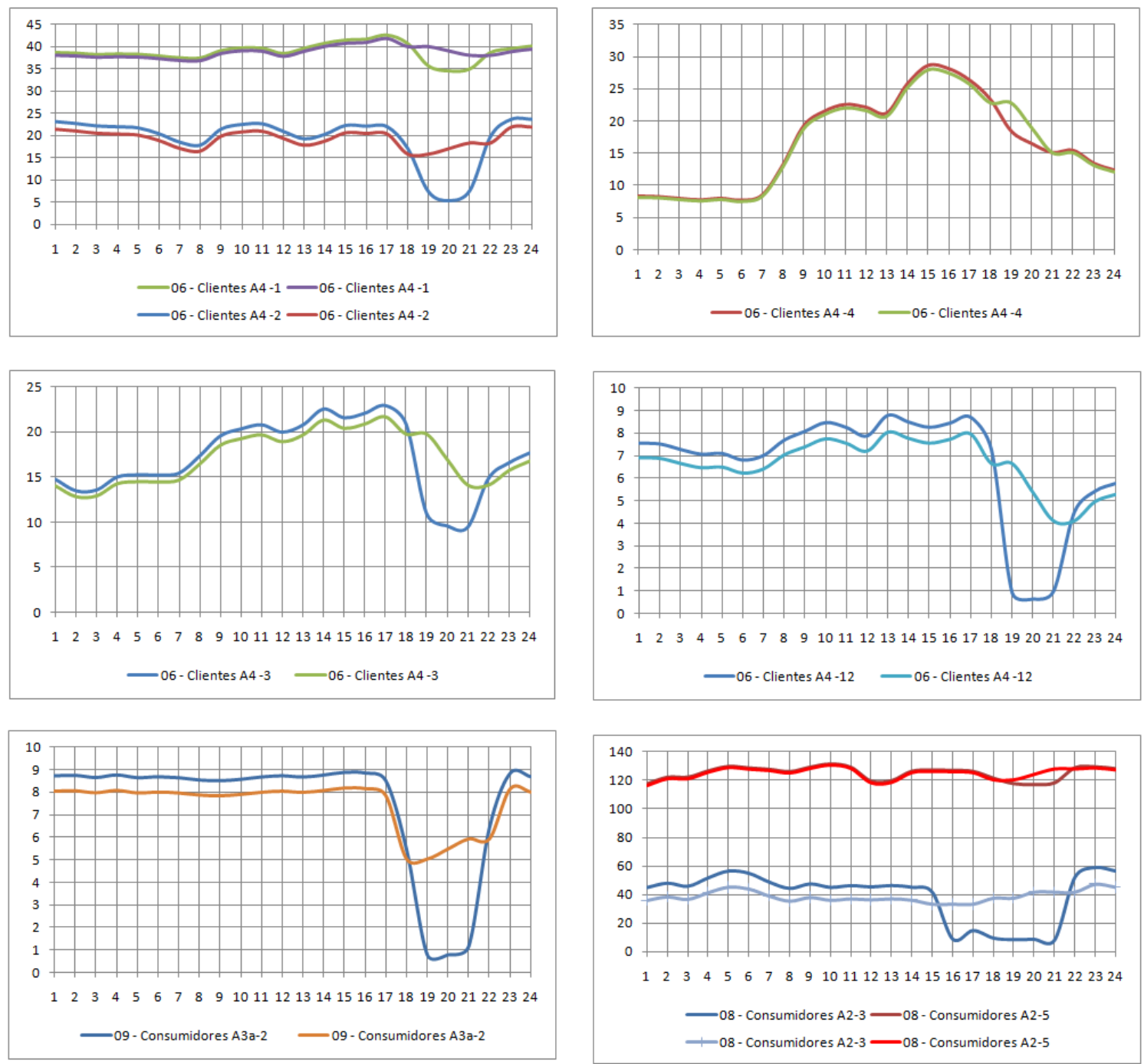

Figura 7.7 - Desmodulação dos clientes-tipo

\subsubsection{Remontagem das curvas das redes-tipo}

Utilizando-se as probabilidades de associação, oriundas do processo de otimização, é possível estimar as novas curvas de redes-tipo a partir das curvas de clientes-tipo desmoduladas. Ou seja, mantendo-se as mesmas relações existentes entre as curvas típicas, remontam-se as curvas de redes-tipo.

Esse processo de remontagem é necessário porque a metodologia efetua a alocação nas horas mais carregadas das redes-tipo. A Figura 7.8 apresenta as comparações das curvas de redes-tipo das transformações A2/A4 originais e as redesenhadas levando em consideração as curvas alteradas dos clientes-tipo. 

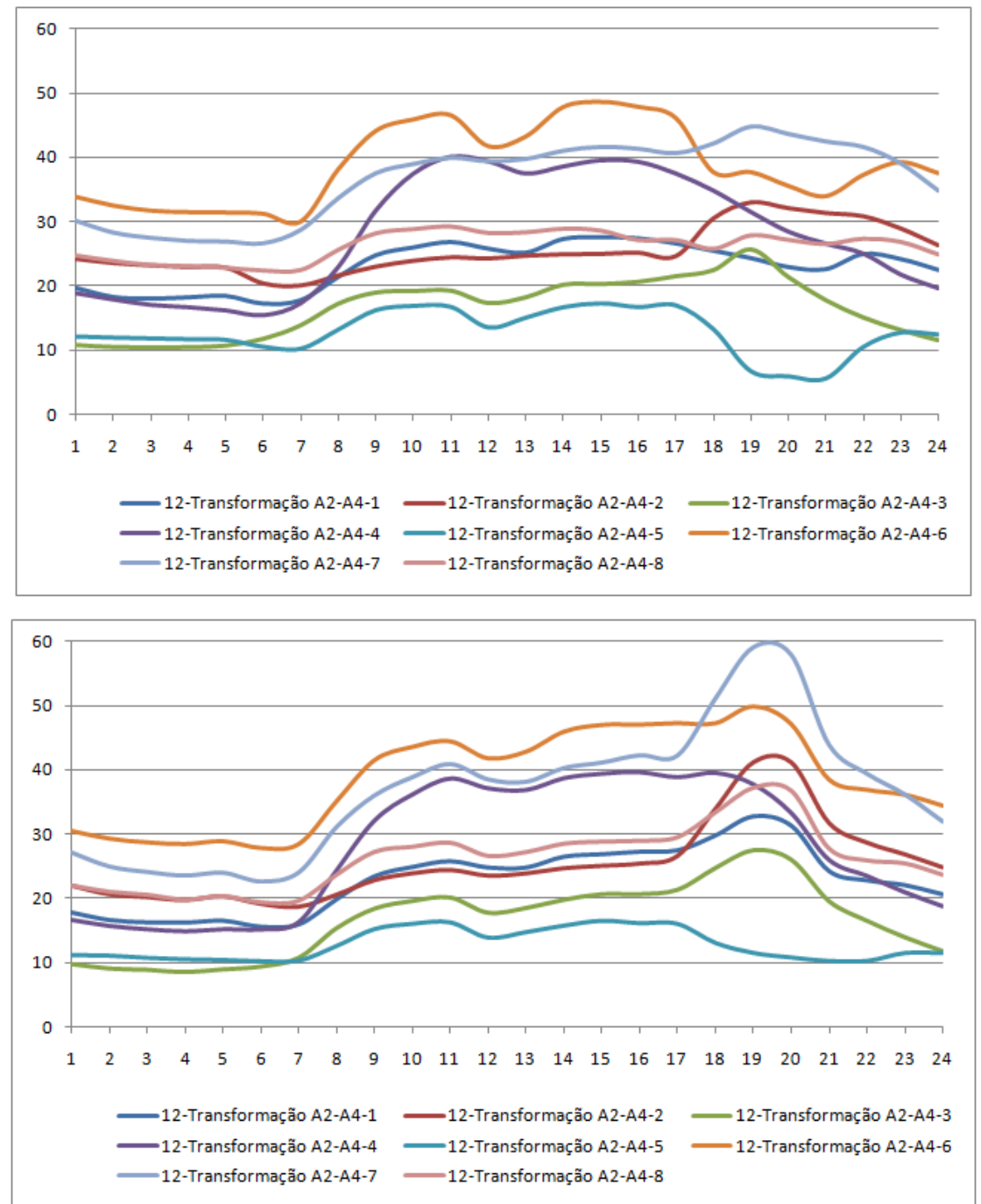

Figura 7.8 - Redes-tipo A2-A4 originais e formadas a partir das curvas desmoduladas dos clientes-tipo

Além das transformações A2-A4 detalhadas anteriormente, é importante demonstrar o efeito do processo de desmodulação nos demais níveis de tensão. Dessa forma, a Figura 7.9 compara as curvas de redes-tipo agregadas, sendo as originais destacadas à esquerda e as redesenhadas à direita. 

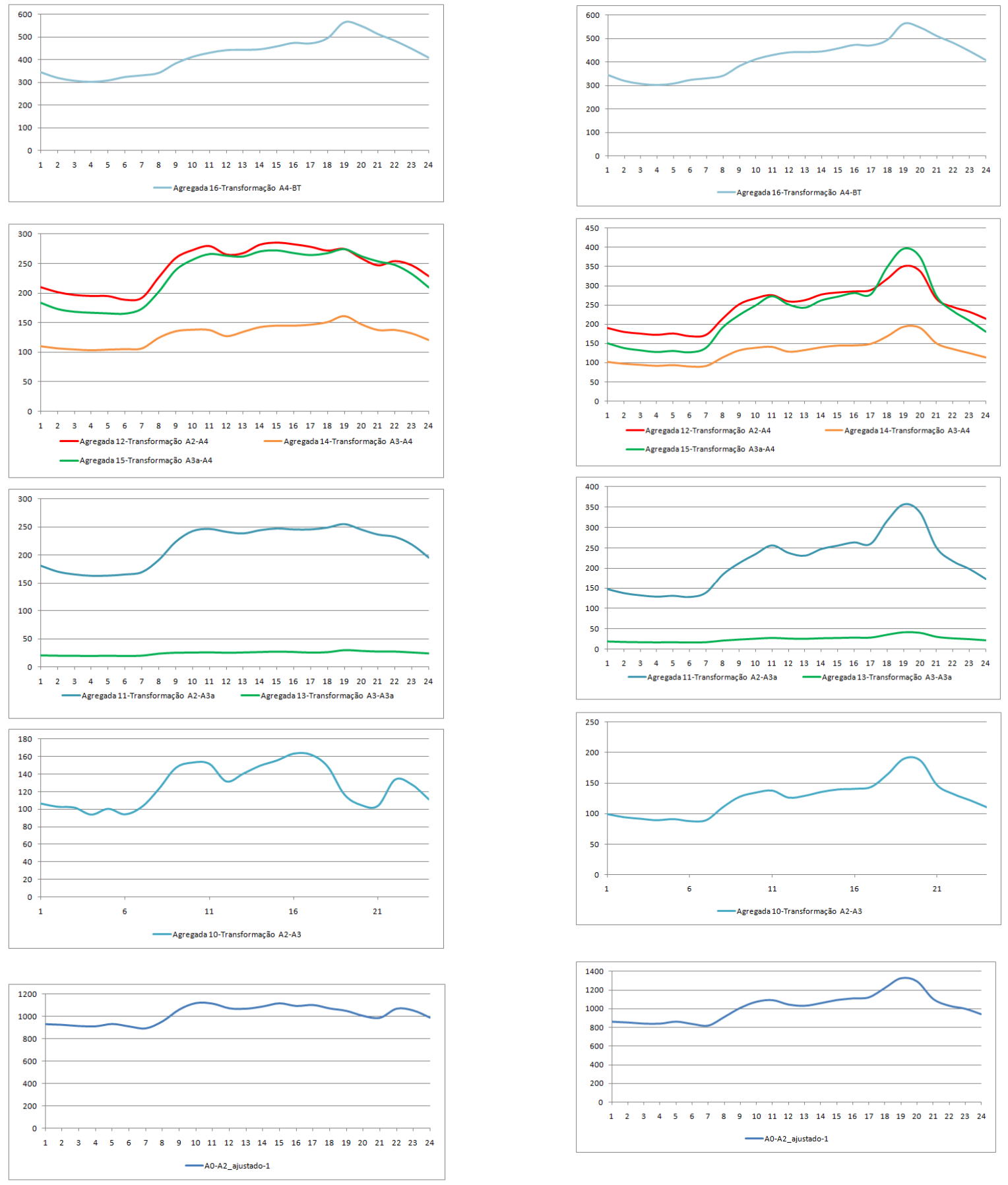

Curvas originais

Curvas modificadas

Figura 7.9 - Efeito das alterações dos perfis dos consumidores nas redes-tipo

\subsubsection{Estudo da aplicação das curvas desmoduladas no método atual}

Com as novas curvas de redes e de clientes recalculadas, é aplicada a metodologia atual utilizada pela ANEEL, com o objetivo de estudar isoladamente os efeitos da desmodulação das curvas dos clientes-tipo. 
As Tabelas 7.7 e 7.8 apresentam os resultados e as comparações com 0 método atual enquanto que a Figura 7.10 apresenta graficamente os resultados da metodologia proposta.

Tabela 7.7 - Custos por posto - metodologia atual sobre curvas alteradas

\begin{tabular}{cccccccc}
\hline \multirow{2}{*}{ Tipos de consumidores } & \multicolumn{2}{c}{$\mathbf{C M C}(\mathbf{R} \mathbf{\text { kW }})$} & \multicolumn{2}{c}{ Dem. Máxima (MW) } & \multicolumn{2}{c}{$\begin{array}{c}\text { Receita } \\
\text { (R\$ x mil) }\end{array}$} & Part. \\
\cline { 2 - 5 } & $\mathbf{P}$ & $\mathbf{F P}$ & $\mathbf{P}$ & $\mathbf{F P}$ & & \\
\hline Média - Clientes A2 & 19,28 & 9,15 & 443,33 & 460,15 & $12.755,843$ & $9,7 \%$ \\
Média - Clientes A3 & 50,40 & 5,48 & 7,01 & 7,31 & 393,109 & $0,3 \%$ \\
Média - Clientes A3a & 57,13 & 7,75 & 20,88 & 24,88 & $1.385,744$ & $1,1 \%$ \\
Média - Clientes A4 & 56,53 & 28,04 & 199,92 & 255,72 & $18.472,545$ & $14,0 \%$ \\
Média Baixa Tensão & 101,22 & 45,56 & 709,58 & 588,67 & $98.644,664$ & $74,9 \%$ \\
\hline Média - BT Residencial & 103,27 & 33,19 & 464,68 & 352,59 & $59.691,319$ & $45,3 \%$ \\
Média - BT Rural & 89,58 & 45,83 & 114,45 & 107,95 & $15.199,874$ & $11,5 \%$ \\
Média - BT Comercial & 85,08 & 46,45 & 89,78 & 176,49 & $15.837,239$ & $12,0 \%$ \\
Média - BT Industrial & 71,71 & 50,80 & 13,33 & 24,32 & $2.191,480$ & $1,7 \%$ \\
Média - BT IP & 91,23 & 13,45 & 54,69 & 54,69 & $5.724,752$ & $4,3 \%$ \\
\hline
\end{tabular}

Tabela 7.8 - Diferenças entre os custos da metodologia atual: curvas originais e alteradas

\begin{tabular}{ccc}
\hline Tipos de consumidores & \multicolumn{3}{c}{ CMC (diferença) } \\
& P & FP \\
\hline Média - Clientes A2 & $752 \%$ & $-63 \%$ \\
Média - Clientes A3 & $272 \%$ & $-86 \%$ \\
Média - Clientes A3a & $340 \%$ & $-85 \%$ \\
Média - Clientes A4 & $216 \%$ & $-58 \%$ \\
Média Baixa Tensão & $92 \%$ & $-42 \%$ \\
\hline Média - Clientes BT Residencial & $90 \%$ & $-40 \%$ \\
Média - Clientes BT Rural & $102 \%$ & $-35 \%$ \\
Média - Clientes BT Comercial & $110 \%$ & $-47 \%$ \\
Média - Clientes BT Industrial & $165 \%$ & $-44 \%$ \\
Média - BT IP & $62 \%$ & $-54 \%$ \\
\hline
\end{tabular}

Observa-se que houve um aumento nas tarifas de ponta, demonstrando a influência da alteração das curvas dos clientes-tipo e das redes-tipo. De fato, da análise das curvas de redes-tipo formadas a partir das curvas de clientes-tipo desmoduladas, observa-se que houve uma diminuição da quantidade média de picos (demandas acima de $90 \%$ ) que passou de 5,7 no caso anterior para 3,6. Essa 
situação concentra os custos em determinados períodos, diminuindo a sua dispersão, como pode ser observado na Figura 7.10.

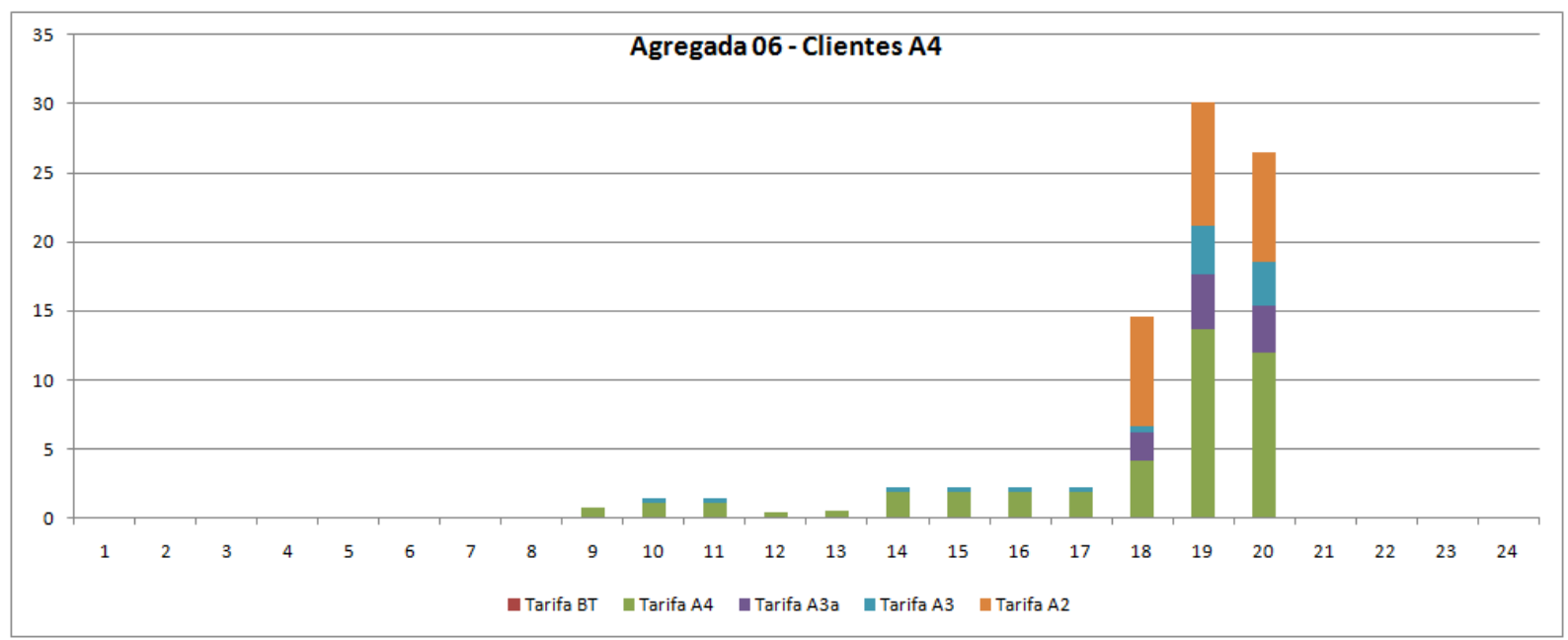

Figura 7.10 - Custos horários do Cliente A4 - metodologia atual sobre curvas alteradas

É importante relembrar que os custos horários são agregados considerando a demanda máxima de cada posto tarifário na metodologia atual. Dessa forma, sendo a tarifa uma relação entre custos e demanda do posto, o preço unitário, considerando as curvas desmoduladas, teria tendência de diminuir para 0 consumidor A4 agregado que, neste caso, possui demanda máxima fora do horário de ponta. Esta é a razão pela qual se defende nesta tese que sejam considerados os preços sempre em função da demanda máxima da curva, independentemente do posto tarifário, como já explicado. 


\subsection{Estudo da aplicação da proposta sobre as curvas desmoduladas}

\subsubsection{Nova forma de agregação aplicada sobre curvas desmoduladas}

A comparação realizada no item anterior não demonstra efeito total da desmodulação, pois a metodologia atual realiza ajustes nos custos dos postos tarifários não coincidentes com a demanda máxima, como citado anteriormente. Por isso, a metodologia proposta parcial, com a alteração somente da agregação média dos custos, será aplicada sobre as curvas desmoduladas. Os resultados serão comparados com as simulações do item 7.2 que corresponde ao mesmo critério aplicado sobre as curvas originais.

A Tabela 7.9 apresenta os resultados e a Tabela 7.10, as comparações da metodologia proposta de alteração da forma de agregação, curvas alteradas e curvas originais (Tabela 7.9 versus Tabela 7.3 ).

Tabela 7.9 - Custos por posto - nova agregação dos custos horários sobre curvas alteradas

\begin{tabular}{cccccccc}
\hline \multirow{2}{*}{ Tipos de consumidores } & \multicolumn{2}{c}{$\mathbf{C M C}(\mathbf{R} \mathbf{\text { kW }})$} & \multicolumn{2}{c}{ Dem. Máxima (MW) } & \multicolumn{2}{c}{$\begin{array}{c}\text { Receita } \\
\text { (R\$ x mil) }\end{array}$} & Part. \\
\cline { 2 - 5 } & $\mathbf{P}$ & $\mathbf{F P}$ & $\mathbf{P}$ & $\mathbf{F P}$ & & \\
\hline Média - Clientes A2 & 26,16 & 1,84 & 443,33 & 460,15 & $12.443,366$ & $10,3 \%$ \\
Média - Clientes A3 & 53,14 & 0,86 & 7,01 & 7,31 & 378,558 & $0,3 \%$ \\
Média - Clientes A3a & 55,64 & 1,28 & 20,88 & 24,88 & $1.193,928$ & $1,0 \%$ \\
Média - Clientes A4 & 71,75 & 6,50 & 199,92 & 255,72 & $16.006,395$ & $13,2 \%$ \\
Média Baixa Tensão & 122,61 & 7,40 & 709,58 & 588,67 & $91.356,180$ & $75,3 \%$ \\
\hline Média - BT Residencial & 119,23 & 4,15 & 464,68 & 352,59 & $56.868,399$ & $46,9 \%$ \\
Média - BT Rural & 122,40 & 8,44 & 114,45 & 107,95 & $14.919,122$ & $12,3 \%$ \\
Média - BT Comercial & 103,43 & 15,86 & 89,78 & 176,49 & $12.084,332$ & $10,0 \%$ \\
Média - BT Industrial & 98,73 & 18,22 & 13,33 & 24,32 & $1.759,576$ & $1,4 \%$ \\
Média - BT IP & 102,51 & 2,16 & 54,69 & 54,69 & $5.724,752$ & $4,7 \%$ \\
\hline
\end{tabular}

Observa-se que os custos calculados sobre as curvas alteradas são maiores do que os custos calculados sobre as curvas originais, aplicando-se o mesmo critério de agregação de custos, demonstrando agora o efeito integral da aplicação das curvas desmoduladas sobre processo de desmodulação. 
Tabela 7.10 - Diferenças entre os custos da nova agregação: curvas alteradas e originais

\begin{tabular}{ccc}
\hline Tipos de consumidores & \multicolumn{2}{c}{ CMC (diferença) } \\
& P & FP \\
\hline Média - Clientes A2 & $166 \%$ & $-90 \%$ \\
Média - Clientes A3 & $41 \%$ & $-95 \%$ \\
Média - Clientes A3a & $47 \%$ & $-96 \%$ \\
Média - Clientes A4 & $43 \%$ & $-84 \%$ \\
Média Baixa Tensão & $32 \%$ & $-60 \%$ \\
\hline Média - Clientes BT Residencial & $50 \%$ & $-53 \%$ \\
Média - Clientes BT Rural & $38 \%$ & $-55 \%$ \\
Média - Clientes BT Comercial & $18 \%$ & $-70 \%$ \\
Média - Clientes BT Industrial & $42 \%$ & $-70 \%$ \\
Média - BT IP & $28 \%$ & $-64 \%$ \\
\hline
\end{tabular}

A Figura 7.10 apresenta graficamente os resultados do critério proposto de agregação aplicado sobre as curvas desmoduladas que devem ser comparados com os resultados demonstrados na Figura 7.5. Observa-se também a influência significativa da desmodulação nos preços de ponta decorrente da concentração dos custos em menores quantidades de picos.

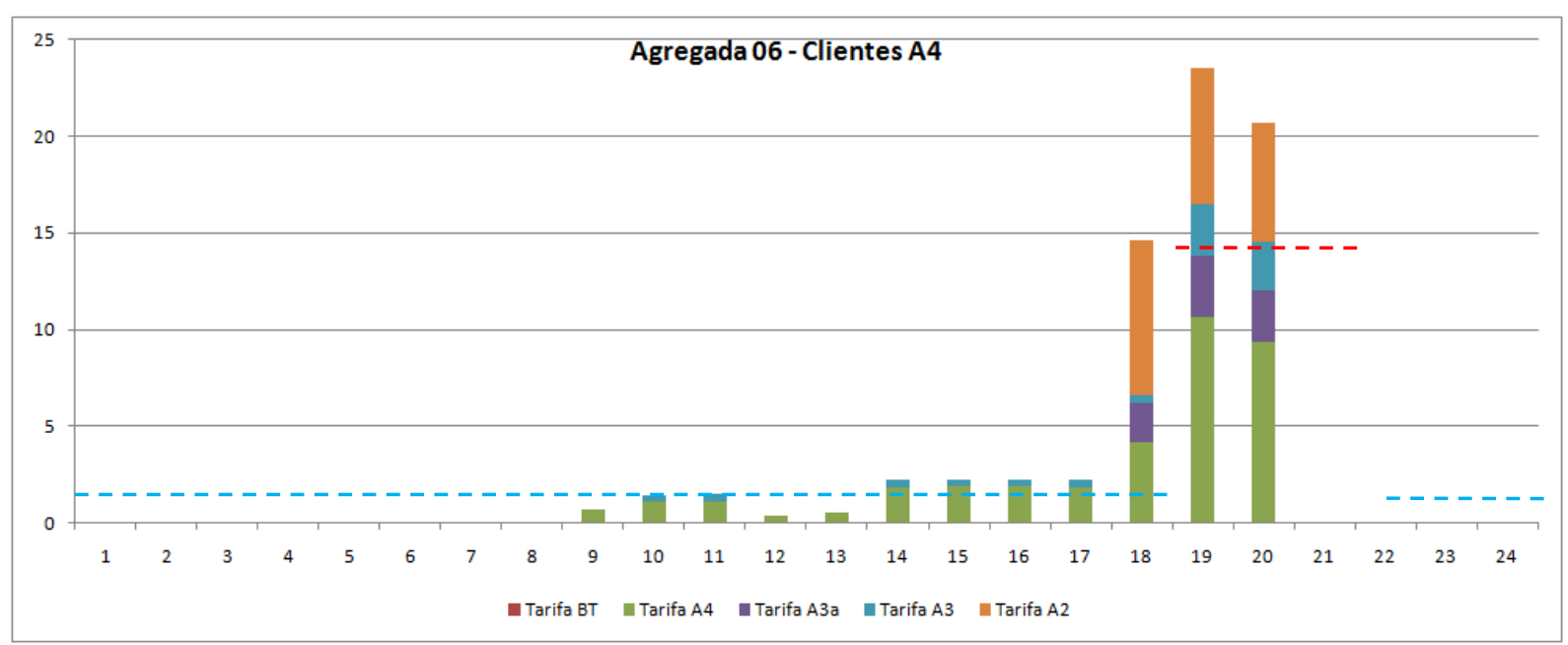

Figura 7.10 - Custos horários do Cliente A4 - critério agregação dos custos sobre curvas alteradas 


\subsubsection{Metodologia proposta sobre curvas desmoduladas}

Finalmente, a última simulação dessa série, é a aplicação da metodologia proposta, que incorpora as duas proposições de alteração do fator de contribuição e da forma de agregação de custos nos postos, sobre as curvas alteradas pelo processo de desmodulação.

A Tabela 7.11 apresenta os custos por posto tarifário calculado sobre as curvas alteradas enquanto que a Tabela 7.12 compara esses custos com aqueles calculados pela metodologia atual com as curvas originais (Tabela 7.11 versus Tabela 7.1). Observa-se, nessa análise, o aumento de dos custos no horário de ponta resultado da desmodulação das curvas.

Tabela 7.11 - Custos por posto - nova metodologia sobre curvas alteradas

\begin{tabular}{|c|c|c|c|c|c|c|}
\hline \multirow{2}{*}{ Tipos de consumidores } & \multicolumn{2}{|c|}{$\mathrm{CMC}(\mathrm{R} \$ \mathrm{~kW})$} & \multicolumn{2}{|c|}{ Dem. Máxima (MW) } & \multirow{2}{*}{$\begin{array}{c}\text { Receita } \\
\text { (R\$ x mil) }\end{array}$} & \multirow{2}{*}{ Part. } \\
\hline & $\mathbf{P}$ & FP & $\mathbf{P}$ & FP & & \\
\hline Média - Clientes A2 & 21,96 & 6,15 & 443,33 & 460,15 & $12.567,124$ & $11,0 \%$ \\
\hline Média - Clientes A3 & 47,14 & 4,83 & 7,01 & 7,31 & 365,514 & $0,3 \%$ \\
\hline Média - Clientes A3a & 54,66 & 7,58 & 20,88 & 24,88 & $1.330,126$ & $1,2 \%$ \\
\hline Média - Clientes A4 & 68,32 & 16,98 & 199,92 & 255,72 & $18.001,504$ & $15,8 \%$ \\
\hline Média Baixa Tensão & 103,16 & 14,75 & 709,58 & 588,67 & $81.883,741$ & $71,7 \%$ \\
\hline Média - BT Residencial & 93,23 & 8,17 & 464,68 & 352,59 & $46.204,653$ & $40,5 \%$ \\
\hline Média - BT Rural & 102,56 & 14,16 & 114,45 & 107,95 & $13.265,622$ & $11,6 \%$ \\
\hline Média - BT Comercial & 101,42 & 37,13 & 89,78 & 176,49 & $15.658,119$ & $13,7 \%$ \\
\hline Média - BT Industrial & 92,92 & 38,94 & 13,33 & 24,32 & $2.185,794$ & $1,9 \%$ \\
\hline Média - BT IP & 79,37 & 4,18 & 54,69 & 54,69 & $4.569,554$ & $4,0 \%$ \\
\hline
\end{tabular}

Tabela 7.12 - Diferenças entre os custos: atual e nova metodologia

\begin{tabular}{crl}
\hline Tipos de consumidores & \multicolumn{2}{c}{ CMC (diferença) } \\
& P & FP \\
\hline Média - Clientes A2 & $870 \%$ & $-75 \%$ \\
Média - Clientes A3 & $248 \%$ & $-88 \%$ \\
Média - Clientes A3a & $321 \%$ & $-86 \%$ \\
Média - Clientes A4 & $282 \%$ & $-74 \%$ \\
Média Baixa Tensão & $96 \%$ & $-81 \%$ \\
\hline Média - Clientes BT Residencial & $72 \%$ & $-85 \%$ \\
Média - Clientes BT Rural & $132 \%$ & $-80 \%$ \\
Média - Clientes BT Comercial & $150 \%$ & $-58 \%$ \\
Média - Clientes BT Industrial & $243 \%$ & $-57 \%$ \\
Média - BT IP & $41 \%$ & $-86 \%$ \\
\hline
\end{tabular}




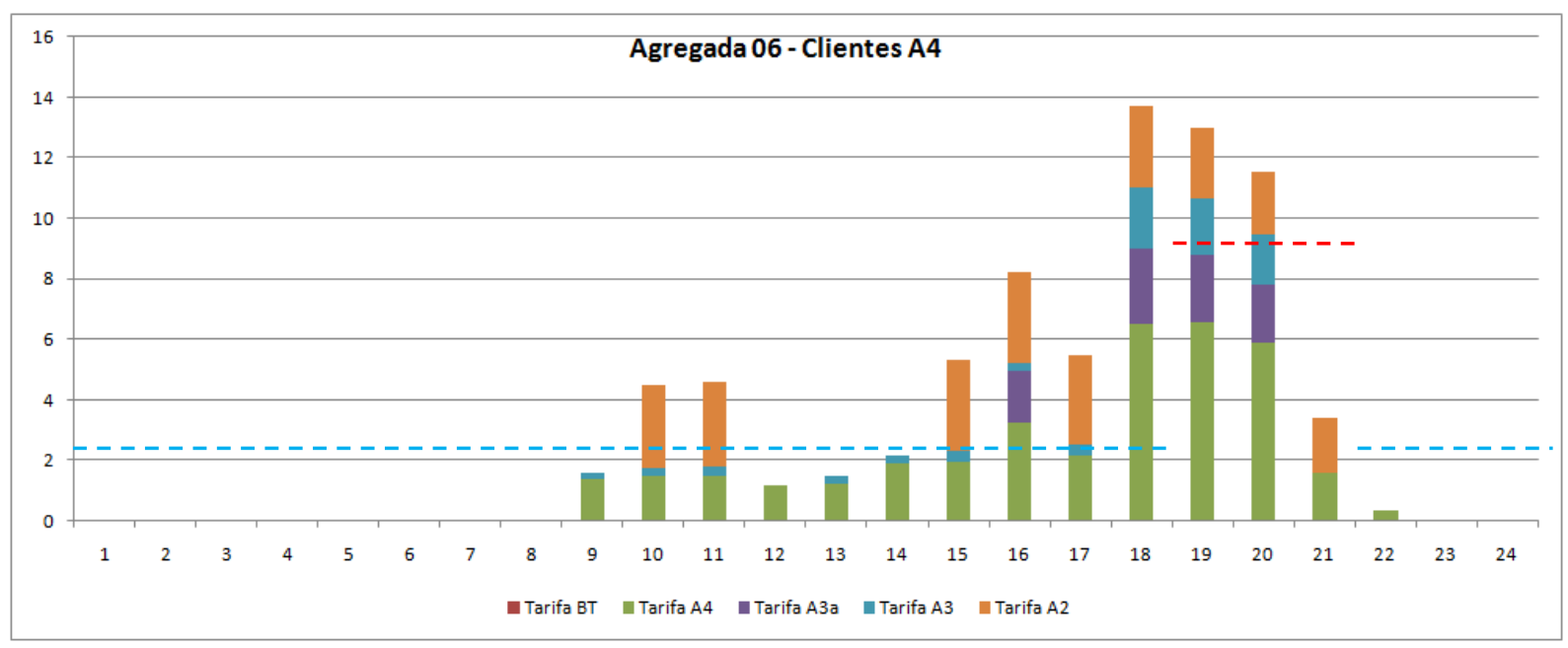

Figura 7.11 - Custos horários do Cliente A4 - critério agregação dos custos

\subsection{Implementação dos postos tarifários}

Como a metodologia proposta efetua os cálculos horários independentemente do posto tarifário pré-existente, é possível visualizar os patamares de custos eventualmente existentes e, a partir desta identificação, propor postos tarifários diferenciados dos atuais.

Para efeito de comparação com as próximas simulações é apresentada a curva de custos horários do Cliente A4 (curva agregada dos clientes-tipo A4) em conjunto com curva dos custos horários médios considerando somente os dois postos tarifários atuais, conforme Figura 7.12.

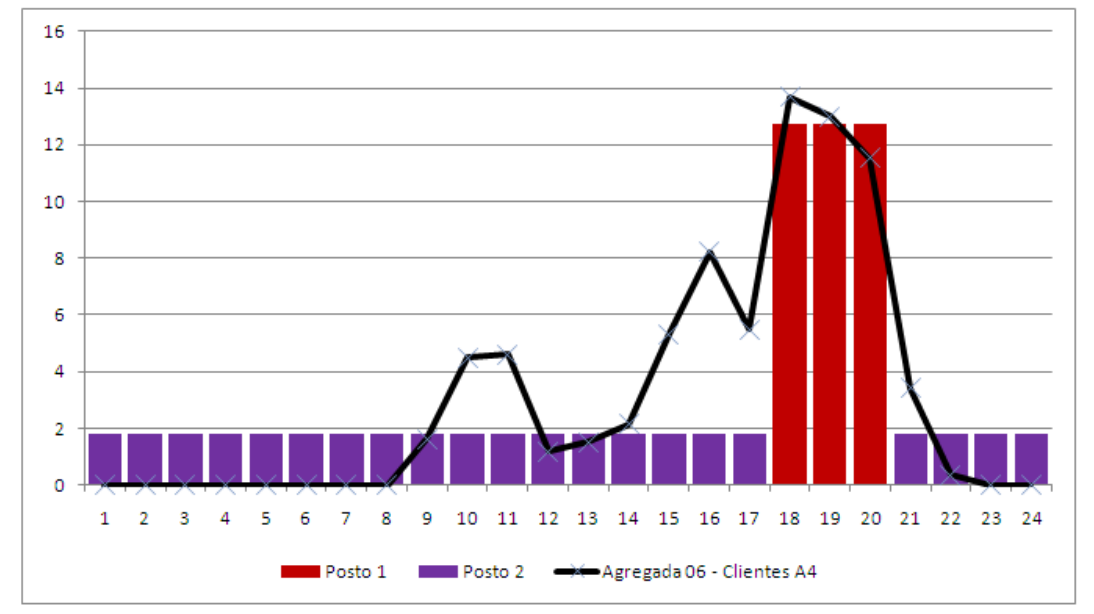

Figura 7.12 - Curva de custos horários (2 postos) - Cliente A4 
Neste caso, os custos por período e os custos horários médios são apresentados na Tabela 7.13.

Tabela 7.13 - Custos por posto tarifário (2 postos) - Cliente A4

\begin{tabular}{lcccc}
\hline Postos Tarifários & $\begin{array}{c}\text { Soma } \\
\text { (R\$/kW.ano) }\end{array}$ & Horas & $\begin{array}{c}\text { Média* } \\
\text { (R\$/kW.ano) }\end{array}$ & $\begin{array}{c}\text { Média ajustada } \\
\text { (R\$/kW.ano) }\end{array}$ \\
\hline Custo total & $\mathbf{7 6 , 4 9}$ & $\mathbf{2 4}$ & $\mathbf{3 , 1 9}$ & \\
Custo posto 1 & 38,21 & 3 & 12,74 & 66,93 \\
Custo posto 2 & 34,27 & 21 & 1,82 & 9,56 \\
\hline
\end{tabular}

*Média sem ajuste

Como exemplo, aplicou-se a metodologia para os consumidores atendidos no nível A4 que são representados por 12 curvas de clientes-tipo além da curva agregada dos consumidores. A Figura 7.13 apresenta a curva de custos horários calculados para a curva agregada dos consumidores A4.

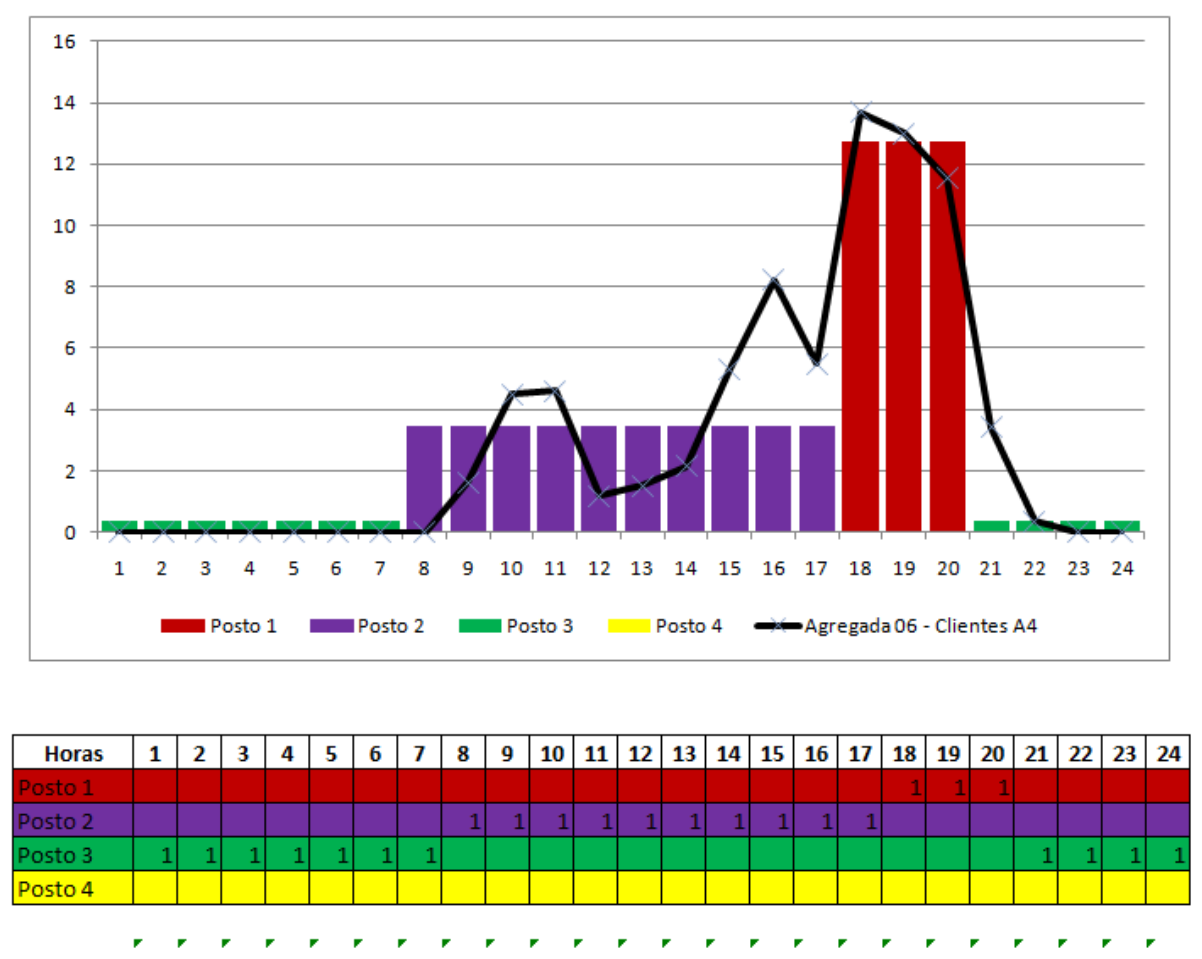

Figura 7.13 - Curva de custos horários (3 postos) - Cliente A4

Analisando-se os custos pode-se identificar, por exemplo, três patamares de custos: o primeiro, das 18 às 20 horas; o segundo, das 8 às 17 horas; e o terceiro, o restante das horas, ou seja, das 21 às 7 horas. Neste caso, na Figura 7.13 é 
possível visualizar os períodos escolhidos e os custos horários em cada posto tarifário.

A Tabela 7.14 apresenta os custos por posto tarifário calculados a partir dos custos horários da curva agregada: soma-se os custos que compõem o posto tarifário escolhido e divide-se pelo número de horas.

Tabela 7.14 - Custos por posto tarifário (3 postos) - Cliente A4

\begin{tabular}{lcccc}
\hline Postos Tarifários & $\begin{array}{c}\text { Soma } \\
\text { (R\$/kW.ano) }\end{array}$ & Horas & $\begin{array}{c}\text { Média* } \\
\text { (R\$/kW.ano) }\end{array}$ & $\begin{array}{c}\text { Média ajustada } \\
\text { (R\$/kW.ano) }\end{array}$ \\
\hline Custo total & $\mathbf{7 6 , 4 9}$ & $\mathbf{2 4}$ & $\mathbf{3 , 1 9}$ & \\
Custo posto 1 & 38,21 & 3 & 12,74 & 58,95 \\
Custo posto 2 & 34,51 & 10 & 3,45 & 15,96 \\
Custo posto 3 & 3,77 & 11 & 0,34 & 1,57 \\
\hline
\end{tabular}

*Média sem ajuste

Definido o critério para o cálculo dos custos por posto tarifário, é possível aumentar o número de patamares até o limite de vinte e quatro, que corresponderá à aplicação de uma tarifa horária. Contudo, as recomendações encontradas na literatura indicam que uma quantidade excessiva de postos tarifários prejudica a percepção de custos pelo consumidor. A título de exemplo, é adicionado mais um posto tarifário na simulação anterior, conforme apresentado na Figura 7.14.
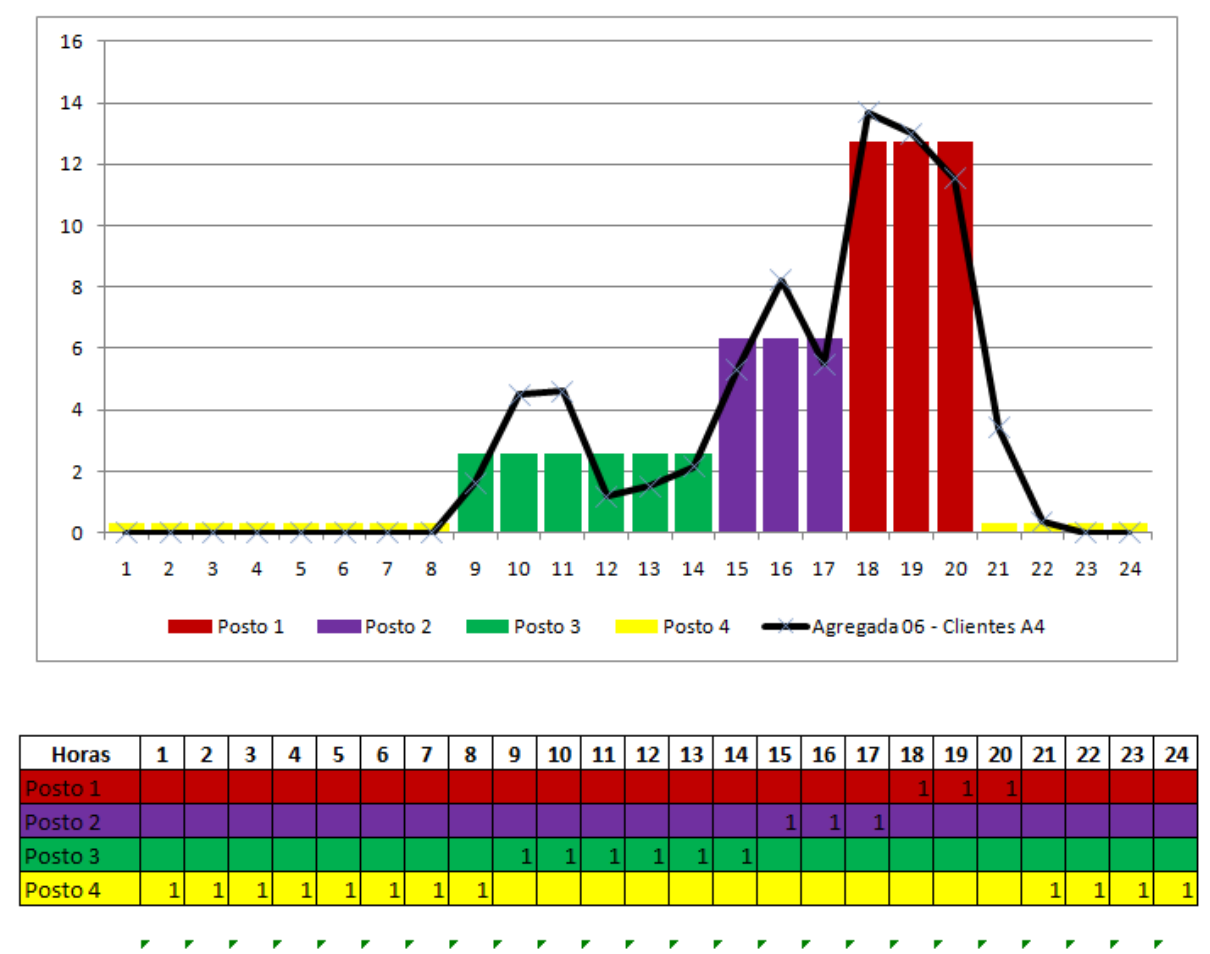

Figura 7.14 - Curva de custos horários (4 postos) - Cliente A4 
O acréscimo de um quarto posto tarifário torna a relação de preços entre os patamares mais próximo dos custos horários originais da curva agregada, conforme pode ser observado na figura anterior e na Tabela 7.15.

Tabela 7.15 - Custos por posto tarifário (4 postos) - Cliente A4

\begin{tabular}{lcccc}
\hline Postos Tarifários & $\begin{array}{c}\text { Soma } \\
\text { (R\$/kW.ano) }\end{array}$ & Horas & $\begin{array}{c}\text { Média* }^{*} \\
(\mathbf{R} \mathbf{k W . a n o})\end{array}$ & $\begin{array}{c}\text { Média ajustada } \\
\text { (R\$/kW.ano) }\end{array}$ \\
\hline Custo total & $\mathbf{7 6 , 4 9}$ & $\mathbf{2 4}$ & $\mathbf{3 , 1 9}$ & \\
Custo posto 1 & 38,21 & 3 & 12,74 & 44,36 \\
Custo posto 2 & 18,99 & 3 & 6,33 & 22,04 \\
Custo posto 3 & 15,52 & 6 & 2,59 & 9,02 \\
Custo posto 4 & 3,77 & 12 & 0,31 & 1,08 \\
\hline
\end{tabular}

*Média sem ajuste

Embora tenha sido apresentado o exemplo para a curva agregada dos clientes A4, foi aplicada também essa metodologia nas demais curvas dos clientestipo do nível A4.

\subsection{Implementação das modalidades tarifárias}

Como proposto no Capítulo 6, a THS Verde e Azul, no caso de consumidores atendidos em MT, A3a e A4, deve ser calculadas a partir dos custos marginais de capacidade de cada cliente-tipo em função do seu fator de carga.

A Figura 7.15 demonstra esquematicamente o procedimento de cálculo envolvido na definição das THS Verde e Azul. A partir dos custos marginais dos clientes-tipo no posto tarifário ponta e dos respectivos fatores de carga, é possível identificar, basicamente, dois grupos de consumidores e definir, para cada um deles, a tarifa mais adequada. 


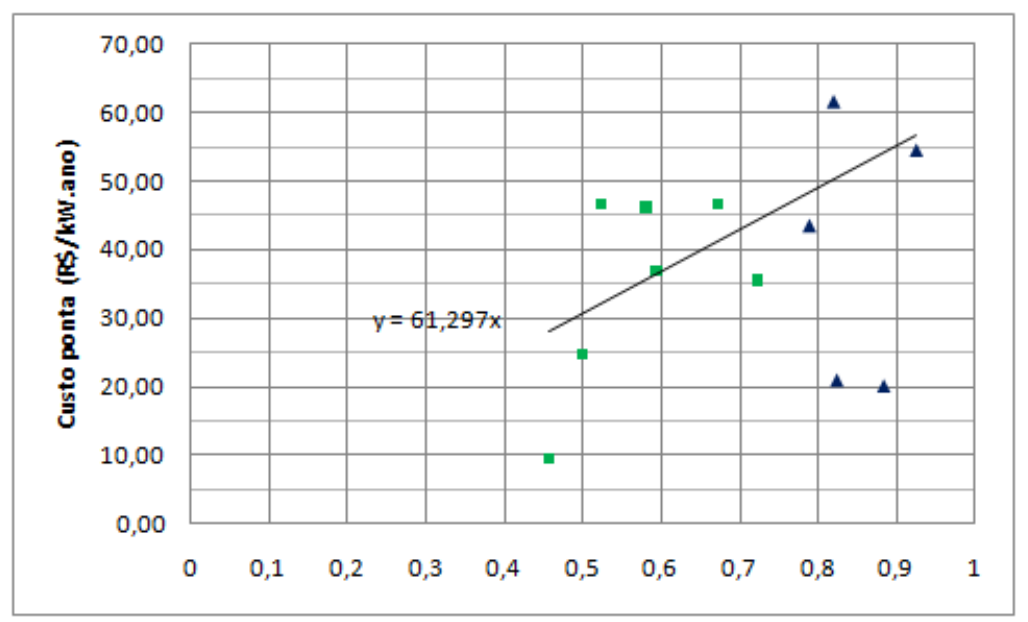

Figura 7.15 - Cálculo das tarifas horo-sazonais verde e azul - Cientes A4

No exemplo anterior, o custo marginal de ponta para consumidores com fator de carga maior do que 0,70 seria acima de $R \$ 50,00 / \mathrm{kW}$.ano enquanto que para os demais consumidores o custo seria de aproximadamente $R \$ 62,30 / \mathrm{MWh}$ obtido da inclinação da curva de linha de tendência dos custos dos clientes com menor fator de carga. Como visto na Tabela 7.13, o custo no posto ponta para o agregado dos clientes $\mathrm{A} 4$, que corresponde ao custo médio ponderado, é $\mathrm{R} \$ 38,21 / \mathrm{kW}$.ano.

No caso da tarifa convencional, uma alternativa seria identificar os consumidores que poderiam ser beneficiados por esse tipo de tarifa, e a partir dos seus custos marginais de capacidade em função do fator de carga também definir os preços de demanda de potência e de energia, como demonstrado na Figura 7.16.

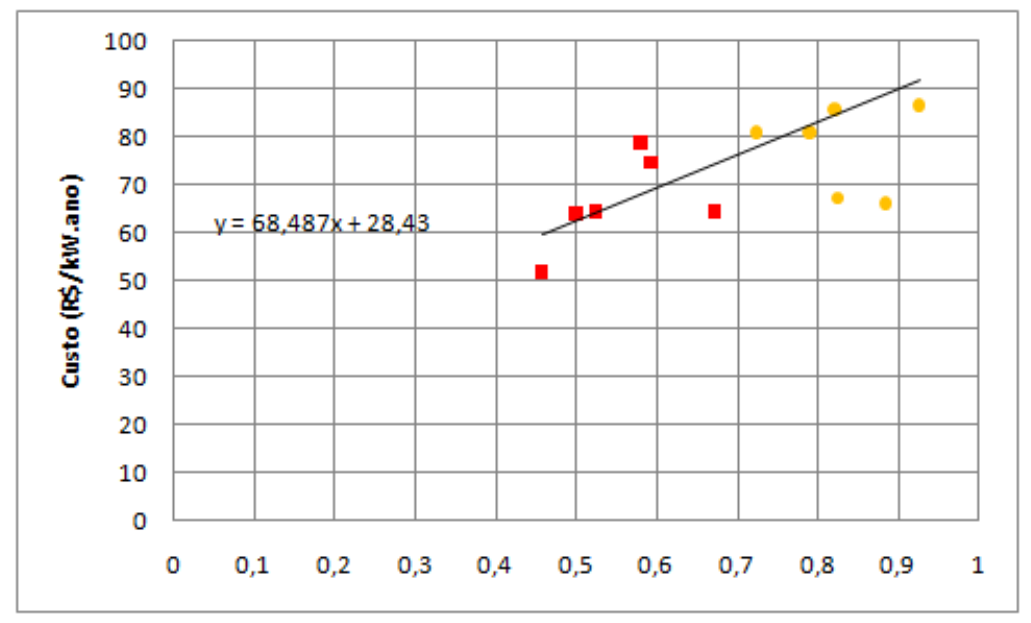

Figura 7.16 - Cálculo da tarifa convencional - Cientes A4 
Neste exemplo, também a partir dos consumidores com fator de carga mais baixo, estimou-se uma linha de regressão que permite obter os preços de demanda de potência como $R \$ 28,43 / \mathrm{kW}$.ano e um preço de energia de $\mathrm{R} \$ 68,49 / \mathrm{MWh}$.

A titulo de comparação, caso fossem utilizados os custos de todos os consumidores, os valores resultantes seriam de $R \$ 44,32 / \mathrm{kW}$.ano e de $R \$$ 40,65/MWh, como pode ser observado na Figura 7.17, frente a um custo médio de $\mathrm{R} \$ 76,49 / \mathrm{kW}$.ano que pode ser verificado na Tabela 7.13 .

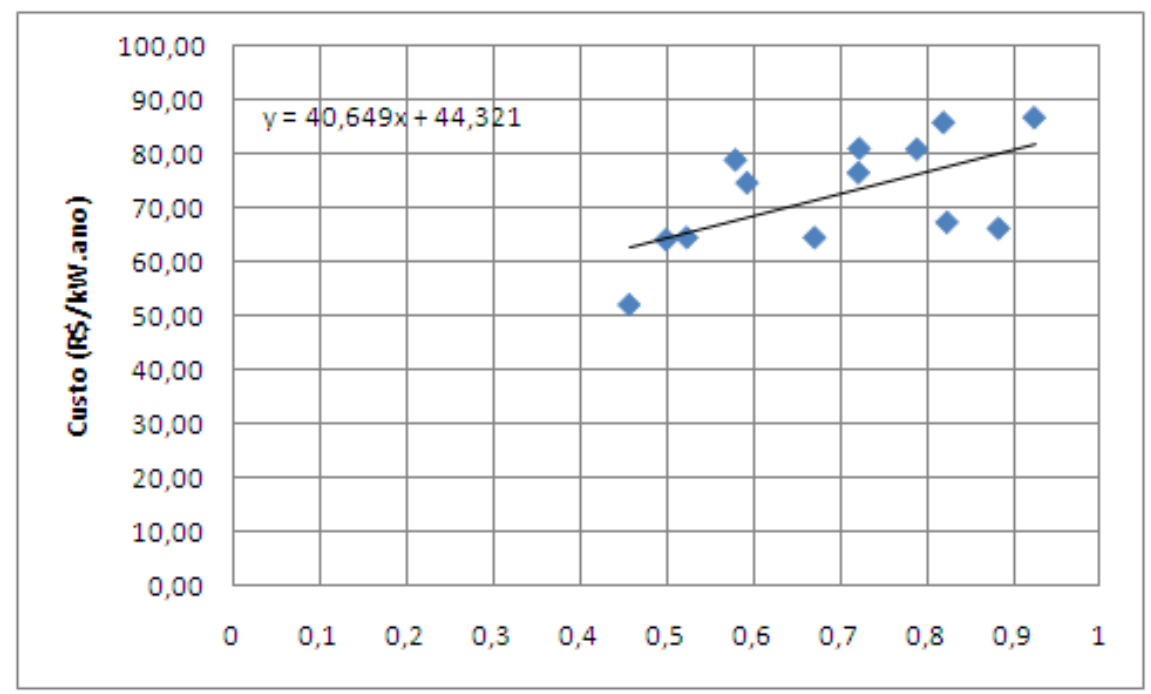

Figura 7.17 - Custos marginais de capacidade - Cientes A4

\subsection{Considerações}

Observa-se que a implementação da proposta do fator de contribuição em comparação com a metodologia atual, diminui os custos de ponta por causa da dispersão maior de custos entre as horas do dias. Da mesma forma, a proposta de agregação sem ajuste dos custos horários diminui os custos no posto tarifário em que a demanda do período não coincide com a máxima demanda. Por outro lado, a agregação média dos custos horários para formar a tarifa de referência dos postos tarifários mantém a sinalização da média dos custos entre postos tarifários considerando o efeito do tamanho do período de ponta e fora ponta, três e vinte e uma horas, respectivamente. 
Evidentemente, como a proposta de alteração da metodologia engloba esses aspectos, o impacto da sua implantação corresponderá aos efeitos somados dos casos anteriores.

No caso do caso de estudo com as curvas desmoduladas, as alterações das curvas dos clientes-tipo também afetam as curvas das redes-tipo resultando um aumento da demanda no posto tarifário ponta da empresa, como pode ser observado na Figura 7.8.

Aplicando-se $\mathrm{o}$ atual critério sobre as novas curvas e comparando os resultados com os valores atuais, observa-se o aumento dos custos de ponta, como demonstrados nas Tabelas 7.7 e 7.8, demonstrando o efeito das curvas desmoduladas na metodologia de cálculo.

Porém, como o método atual incorpora um ajuste nos custos dos postos tarifários, o efeito total da alteração das curvas decorrentes do processo de desmodulação somente pode ser observado comparando os resultados da aplicação da proposta de agregação média de custos sem o ajuste pela demanda máxima do posto. Assim, as Tabelas 7.9 e 7.10 apresentam o real impacto do processo de desmodulação no cálculo das tarifas.

A implementação do critério proposto nesta tese sobre as curvas desmoduladas, apresentado na Tabela 7.11, demonstra o resultado dos aprimoramentos na metodologia. Como visto, na Tabelas 7.12, o resultado das simulações indica o aumento de custo no posto tarifário ponta, em sintonia com o discutido teoricamente. Ressalta-se que esses valores dos postos tarifários correspondem à média dos custos horários, sendo necessário lembrar que estes se tornaram significativamente maiores no horário de ponta, em razão da sua duração corresponder a apenas 3 horas.

Finalmente a implementação dos postos tarifários, similar ao proposto por Santos (2008), demonstra, nas Tabelas 7.13 a 7.15, a repartição dos custos totais nos vários postos tarifários simulados, destacando os custos horários de cada período além do custo do posto tarifário, propriamente dito. 
O exemplo de simulação das tarifas horo-sazonais, com base na curva dos custos dos clientes-tipo e não com o fator de carga exógeno ao processo, necessita de aprimoramentos uma vez que a agregação das curvas dos clientes-tipo não foi realizada, no processo de caracterização da carga, tendo em vista a opção do consumidor pelas tarifas horo-sazonais azul ou verde ou pela tarifa convencional.

De todo modo, tanto a possibilidade de definir novos postos tarifários como 0 desenho de novas modalidades tarifárias demonstram a utilidade dos custos marginais dos clientes-tipo calculados pela metodologia, afastando a crítica comum do compromisso entre a complexidade da metodologia e a relativamente pequena aplicação. 


\section{CAPÍTULO 8 - CONCLUSÕES}

As atuais tarifas de energia elétrica foram desenhadas em 1985 com base nos estudos da EDF, que indicavam a necessidade da adequada sinalização dos custos de fornecimento por meio das tarifas horo-sazonais.

Embora as tarifas fossem constituídas por duas componentes, não necessariamente a tarifa cobrada em termos de energia estava relacionada somente aos custos de geração, pois parte dos custos de transmissão eram alocados nessa parcela. Da mesma forma, na componente cobrada em termos de demanda de potência, existiam os custos dos investimentos na capacidade de geração, além dos custos dos sistemas de distribuição e de transmissão.

Em razão do mecanismo de equalização, as tarifas de fornecimento também refletiam a ponderação dos preços regionais de energia elétrica, inclusive nos sinais horo-sazonais. Todos esses fatores sofreram a influência, no passado, de toda a cadeia industrial de energia elétrica, condição que não está mais aderente ao atual ambiente institucional. Contudo, nas atuais tarifas são empregados ainda sinais exógenos ao processo, que foram calculados no antigo ambiente, como os custos marginais de expansão, os sinais horo-sazonais e a própria construção das modalidades tarifárias.

Os estudos desenvolvidos nesta tese abrangeram, então, a análise comparativa da metodologia visando alcançar o entendimento do mecanismo de cálculo das tarifas e identificar a origem de fatores, hoje exógenos ao processo, porém empregados na metodologia atual.

Pontos importantes deste trabalho foram sistematizar um conhecimento que está disperso em várias referências bibliografias, identificar o grau de aplicação da metodologia e analisar os aspectos que precisam ser aprimorados.

A tese defendida neste trabalho busca provar, então, que a metodologia atual, embora desenhada na época em que o setor elétrico era verticalizado, pode ser adaptada segundo os aprimoramentos e inovações propostas e, assim, aplicada ao ambiente atual no qual as empresas e as tarifas estão segregadas. Ressalta-se que 
a tarifação é um assunto complexo, o que abre espaço para futuros estudos que aprimorem análise iniciada neste trabalho. Dessa forma, são destacados neste capítulo os principais assuntos discutidos na tese bem como os temas que podem ser objetos de pesquisas futuras.

\subsection{Principais pontos da discussão}

O custo marginal de expansão por nível de tensão, uma das entradas do método de alocação horária, pode ser calculado atualmente pelo método CIMLP com base nos investimentos informados no PDD. Isto porque, a partir da implantação do Prodist, a distribuidora é obrigada, anualmente, a enviar o seu plano de obras para a ANEEL, incluindo análise dos investimentos realizados. Além disso, como os investimentos são considerados no cálculo do Fator $X$, a ANEEL irá fiscalizar o cumprimento dos montantes de investimentos informados por ocasião da revisão tarifária.

Dessa forma, o CIMLP, com base nos dados do PDD, se torna um método mais confiável para estimar os custos marginais de expansão. Contudo, como discutido anteriormente, deve se atentar para a qualidade das informações, em especial ao acréscimo de carga por nível de tensão e à estimativa adequada das obras do sistema de distribuição.

De todo modo, é importante relembrar que o objetivo central deste estudo não era abordar profundamente o cálculo do custo incremental de longo prazo, mas propor aprimoramentos e inovações no procedimento de alocação horária desses custos.

Como visto, o custo marginal de expansão não é calculado por patamar de carga, sendo a metodologia responsável pela alocação horária desses custos. Contudo, de maneira semelhante ao método utilizado para estimar o custo do sistema de transmissão de interesse restrito à geração, elaborou-se um critério para obter diretamente os custos marginais, por patamar ou por hora, a partir da identificação da origem do investimento; ou seja, para qual finalidade determinada obra, ou parte da sua capacidade, era necessária. 
Procurou-se, então, relacionar os investimentos com o atendimento à ponta do sistema, com a minimização das perdas elétricas e com a qualidade exigida pelo regulador. Obteve-se, para um alimentador de distribuição típico, montantes de investimentos que estão distribuídos da seguinte forma: aproximadamente $71 \%$ referentes à ponta, 15\% para os demais períodos, e 14\% relativos à qualidade que podem ser alocados proporcionalmente à energia. Estudos semelhantes conduzidos por Lusvarghi (2010) encontraram percentuais semelhantes, como 18\% relativos aos investimentos para a qualidade quando buscava o modelo de tarifa otimizada.

A complexidade de se obter os custos incorridos inviabilizou, no âmbito deste estudo, a aplicação direta desse método de cálculo horário dos custos marginais conforme sua origem. Contudo, as simulações foram importantes para comprovar, como detalhado anteriormente, que os custos de expansão não devem ser alocados somente no horário de maior carregamento do sistema, sendo necessário aprimorar a metodologia atual.

Assim, um dos aspectos centrais deste trabalho é a alteração do paradigma da alocação dos custos de expansão somente no horário de ponta do sistema. Essa abordagem tradicional, ou americana, do problema da precificação de ponta, tem como essência a idéia de que os custos de capacidade dependeriam exclusivamente da máxima demanda do período, sendo irrelevante aquilo que ocorreria quando a demanda não fosse máxima.

Por outro lado, o custo nos horários de ponta do sistema depende não somente da natureza da carga, mas também de variações da capacidade disponível por causa do tipo de usina que atende o período. De maneira similar à abordagem britânica de precificação de ponta entende-se que parte dos custos de expansão também deve ser alocada nos demais horários.

Da mesma forma, pode ocorrer que determinadas restrições para o atendimento estariam mais relacionadas com a temperatura dos equipamentos de distribuição do que com o horário de máxima carga, ou conforme as características do sistema de distribuição, em sintonia com a abordagem francesa da precificação de ponta. 
Com base nessas idéias, que envolveram discussões sobre as formulações de Balasko apresentadas por Santos (2008), o dimensionamento e os tipos de redes existentes no sistema de distribuição, concluiu-se que os custos devem ser alocados em horários distintos da máxima demanda.

Assim, a alocação dos custos em horários em que a rede estiver com carregamento acima de $80 \%$ em relação à demanda máxima seria uma aproximação adequada da distribuição de custos em comparação com a teoria de precificação de ponta e com a estimativa de custos por patamar de uma rede de distribuição típica.

Em relação à aplicação da nova metodologia, entende-se que o comportamento de determinados consumidores poderia estar influenciado pela relação de tarifas entre os postos tarifários. Foi realizado um estudo de caso com a aplicação da metodologia proposta também em curvas estimadas sem o possível efeito da modulação. Após outro processo, denominado no trabalho como remontagem das curvas de rede, foi aplicada novamente a metodologia de cálculo e identificado a influência da desmodulação nos custos dos postos tarifários.

Observou-se também, na implantação da definição ex-post dos postos tarifários, que os custos marginais de capacidade por posto tarifário devem ser analisados considerando a duração do período do posto tarifário. De fato, essa questão é importante e, às vezes, esquecida ao tratar da precificação da ponta e fora de ponta, como no método proposto por Steiner, abordagem americana, que simplifica o problema ao considerar que a duração dos períodos é idêntica.

No nosso caso, como a tarifa de referência do posto tarifário corresponderá a agregação média dos custos horários. Assim, a duração do posto tarifário influi uma vez que, atualmente, o período fora de ponta possui vinte e uma horas enquanto que o período de ponta, somente três horas.

Embora a metodologia exija que sejam levantados os dados de diversos estratos e faixas de consumo que possibilitem o cálculo dos custos marginais de capacidade para os clientes-tipo, somente um custo por nível de tensão é utilizado, ao final do processo. Isso nos leva a questionar a necessidade do detalhamento cuidadoso da amostragem e dos cálculos de custos de capacidade para os clientestipo, se não são completamente utilizados. 
Contudo, o fato da não utilização plena do potencial da metodologia não significa que esta deva ser abandonada. Em tese, diferentes clientes-tipo teriam diferentes tarifas ao contrário de uma tarifa única por nível de tensão, o que possibilitaria a definição adequada das modalidades tarifárias e, também, dos custos dos diferentes tipos de consumidores atendidos em BT. Assim, entende-se que a proposta de utilizar os custos dos clientes-tipo e respectivos fatores de carga para 0 desenho da tarifa horo-sazonal é mais adequada do que o método atual.

Igualmente, poderiam ser calculados custos diferentes para os clientes BT residenciais, comerciais e industriais, ou ainda rurais. No caso dos consumidores localizados na área urbana, a diferença de custos seria definida, basicamente, por conta dos diferentes perfis de consumo dos consumidores residenciais, comerciais e industriais. No segundo caso, a diferenciação dos custos entre rurais e demais consumidores não seria definida somente em função das curvas de carga, mas sim considerando os custos marginais nas áreas urbanas e rurais decorrentes de diferentes padrões de atendimento e densidades de cargas.

Essa situação indica um aprimoramento do processo de cálculo que poderia ser estudado posteriormente: a consideração de regiões dentro de uma mesma área de concessão. Não necessariamente seriam regiões eletricamente continuas, mas poderiam ser regiões com características semelhantes, como urbana, rural, industrial.

Por outro lado, é importante observar que a estrutura de mercado da distribuidora poderá indicar se o esforço para se calcular corretamente as tarifas por região atingirá a eficiência esperada, traduzida pela otimização dos investimentos.

Finalmente, a proposição desta tese busca identificar o custo tecnicamente adequado que o consumidor acarreta para a distribuidora ao utilizar o serviço de distribuição. Não necessariamente a estrutura de tarifas aplicada corresponderá à estrutura de custos identificados pela metodologia, pois outros fatores como a capacidade de pagamento do cliente e a contestação de mercado, seja por outros energéticos seja pelo sistema de transmissão, devem ser incorporados na definição das tarifas finais. 
Porém, a estrutura de custos tecnicamente corretos, calculados pela metodologia, será a base para a elaboração dessas tarifas, podendo com isso identificar a necessidade ou não de subsídios incorporados à aplicação da política tarifária.

\subsection{Considerações e estudos futuros}

As análises e proposições feitas nos Capítulos 5 e 6 demonstraram a complexidade do tema e sua multidisciplinaridade, merecendo que essa problemática seja abordada em novos estudos de caráter aprofundado.

Como temas para futuras pesquisas podem ser nomeados: a investigação do processo de otimização que identifica a probabilidade de associação, o método de cálculo horário dos custos marginais conforme sua origem e a resposta do consumidor aos sinais de preço da energia elétrica.

Como discutido, a partir de uma estimativa de cálculo horário dos custos marginais conforme sua origem foi adotada uma abordagem alternativa. Contudo, estudos futuros poderiam estender a análise efetuada nesta tese objetivando identificar diretamente os custos horários, ou seja, segregar, hora a hora, cada tipo de despesa (operação, perdas, qualidade e expansão), levando em consideração os tipos de redes, coletivas, semi-coletivas e individuais, que formam o sistema de distribuição.

Embora o serviço de transporte seja o foco principal da distribuidora, a comercialização de energia elétrica para o seu mercado cativo continua existindo, sendo necessário tratar as tarifas de forma global, pois o cliente não consegue diferenciar, na prática, os custos associados ao serviço de distribuição e à aquisição da mercadoria energia.

Enquanto a demanda por eletricidade dentre as varias classes de consumidores tem sido objeto de diversos estudos, a resposta do consumidor frente a diferentes preços horários e sazonais, incluindo os efeitos da substituição ou complementaridade, necessita de pesquisas complementares por causa do risco da ocorrência de mudanças da demanda no horário de ponta (shifting peak). 
Do ponto de vista de racionalidade econômica estrita, todos os consumidores mudariam seus equipamentos para o horário fora de ponta, resultando na invalidação da suposição de período de ponta fixo. Por outro lado, alterações constantes nos sinais de preços e uma tabela complexa de preços de energia, de uso do sistema e de conexão podem dificultar a resposta do consumidor. Entendese, assim, que uma vez definidos os custos tecnicamente corretos, sob o ponto de vista da oferta, há um grande espaço para estudos futuros abrangendo a resposta do consumidor aos preços da energia elétrica, que é um fator decisivo para o sucesso da aplicação da estrutura tarifária. 


\section{REFERÊNCIAS BIBLIOGRÁFICAS}

AGÊNCIA NACIONAL DE ENERGIA ELÉTRICA (ANEEL). Proposta de Tarifas de Uso (Resolução no 286/99): Nota de Esclarecimento. Brasília: 2000.

- Metodologia do Cálculo das Tarifas de Uso dos Sistemas de Distribuição: Revisão das Tarifas Publicadas na Resolução ANEEL ํo 286/99 (nota técnica proposta AP no 03/01). 44 p. Brasília: 2001.

Nota Técnica no 050/2007-SRD/ANEEL. Cálculo das Tarifas de Referência

- TR para revisão das Tarifas de Uso dos Sistemas de Distribuição - TUSD da Espírito Santo Centrais Elétricas S.A. - ESCELSA. 11 p. Brasília: 2007.

. Por dentro da conta de luz: informação de utilidade pública. 4. ed. Brasília: ANEEL, 2008. 32 p.

Nota Técnica no 271/2009-SRE-SRD/ANEEL. Proposta de Alteração Metodológica da Estrutura Tarifária Aplicada ao Setor de Distribuição de Energia Elétrica no Brasil - 1aㅡ parte. 39 p. Brasília: 2009a.

. Plano de Desenvolvimento da Distribuição (PDD): Manual de Utilização - Revisão 4 - 15/12/2009. Brasília: 2009b.

. Resolução Normativa no 395/2009. Aprova a 1ạ Revisão dos Procedimentos de Distribuição de Energia Elétrica no Sistema Elétrico Nacional PRODIST, e dá outras providências. Brasília: ANEEL, 2009c.

. Nota Técnica no 219/2010-SRE-SRD/ANEEL. Proposta de Alteração da Metodologia de Definição da Estrutura Tarifária Aplicada ao Setor de Distribuição de Energia Elétrica no Brasil - 2ª parte. Temas III e IV. 49 p. Brasília: 2010.

AMENDOLA, A. G. Metodologias de cálculo de custos marginais. Apresentado no Curso de custos marginais e tarifação de energia elétrica (CCMT) - Universidade Mackenzie, 2007, São Paulo. Trabalho não publicado.

ANTUNES, A. U. Análise Crítica e Proposições Metodológicas para Avaliação dos Custos Marginais de Expansão de Redes de Distribuição de Energia 
Elétrica. 208 p. Tese (Doutorado) - Escola Politécnica da Universidade de São Paulo. São Paulo, 2004.

ANTUNES, N. P. Estrutura de Tarifas. Apresentado no Curso de tarifas no novo modelo do setor elétrico, 2007, Serra do Cipó, MG. Trabalho não publicado.

ARAÚJO, J. L. R. H. Modelos de formação de preços na regulação de monopólios. Revista Econômica, Vol. 3, №. 1, p. 35-66, jun. 2001.

AYALA, G. et al. An electrical tariffs structure based on cost allocation: a cooperative game theory approach. In: IAEE (International Association of Energy Economics) International ConferenceRio de Janeiro, 2010.

BALASKO, Y. Optimal forms of Electricity Tariffs. EDF Conference on Electricity Tariffs, Madri 1975. International Union of Producers and Distributors of Electrical Energy.

BITU, R. S.; BORN, P. H. Tarifas de Energia: Aspectos Conceituais e Metodológicos. 1. ed. São Paulo: MM Editora Ltda,1993. 173 p.

BOITEUX, M. Peak-Load Pricing. The Journal of Business, Vol. 33, №. 2, p. 157179, Apr. 1960. The University of Chicago Press.

CIPOLI, J. A. Engenharia de Distribuição. Rio de Janeiro: Qualitymark, 1993. 340p.

CREW, M; KLEINDORFER, P. Marshall and Turvey on Peak-Load our Joint Product Pricing. The Journal of Political Economy, Vol. 79, № 6, p. 1369-1377, Nov. - Dec. 1971. The University of Chicago Press.

DAIMON ENGENHARIA E SISTEMAS (DAIMON). Sistema de Análise e Caracterização da Carga e da Estrutura Tarifária: Especificação Técnica. 31 p. São Paulo, 2007.

DEPARTAMENTO NACIONAL DE ÁGUAS E ENERGIA ELÉTRICA (DNAEE). Estudo do sistema tarifário brasileiro de energia elétrica com base nos custos marginais. Brasília: Dnaee/Eletrobrás 1979. 
. Nova Tarifa de Energia Elétrica, Metodologia e Aplicação. Brasília: Dnaee, 1985. 444 p.

. Estrutura Tarifária de Referência para Energia Elétrica. Brasília: Dnaee/Eletrobrás, 1981.5 vol.

DRÈZE, J. H. Some Postwar Contributions of French Economists to Theory and Public Policy: With Special Emphasis on Problems of Resource Allocation. The American Economic Review, Vol. 54, №. 4, Part 2, Supplement, Surveys of Foreign Postwar Developments in Economic Thought), p. 2-64, Jun., 1964. American Economic Association Stable.

EMPRESA DE PESQUISA ENERGÉTICA (EPE). Resenha Mensal do Mercado de Energia Elétrica. Brasília. Disponível em: < http://www.epe.gov.br>. Acesso em: 03 jul. 2010.

ENTIDADE REGULADORA DOS SERVIÇOS ENERGÉTICOS. Estrutura Tarifária do Sector Eléctrico em 2010. Lisboa, Portugal. Disponível em: <http://www. erse.pt/>. Acesso em: 03 jun. 2010.

FUGIMOTO, S. K. ; TAHAN, C. M. V. As distorções na tarifa de fornecimento de energia elétrica e o processo de realinhamento tarifário. In: $V$ CONGRESSO BRASILEIRO DE REGULAÇÃO DE SERVIÇOS PÚBLICOS, 2007, Olinda. V Congresso Brasileiro de Regulação de Serviços Públicos, 2007.

Análise do cálculo da TUSD e da construção das modalidades tarifárias. In: SEMINÁRIO NACIONAL DE DISTRIBUIÇÃO DE ENERGIA ELÉTRICA, 2008, Recifie. Seminário Nacional de Distribuição de Energia Elétrica, 2008.

FUGIMOTO, S. K. A Universalização do Serviço de Energia Elétrica: Acesso e Uso Contínuo. 2005. 264 f. Dissertação (Mestrado em Engenharia) - Escola Politécnica, Universidade de São Paulo, São Paulo, 2005.

GILBERT, R. J., editor. Regulatory Choices: A Perspective on Developments in Energy. Berkeley: University of California Press, 1991. 
JOSKOW, P. L. Contribution to the Theory of Marginal Cost Pricing. The Bell Journal of Economics, Vol. 7, №. 1 (Spring 1976) pp. 197-206. The RAND Corporation

HENG, H. Y., LI, F. R., WANG, X. F. Chaging for network security based on longrun incremental cost pricing. IEEE Transactions on Power Systems, Vol. 24, №. 4, p. 1686-1693. 2009.

HIRSHELIFER, J. Peak Loads and Efficient Pricing Comment. The Quartely Journal of Economics, Vol. 72, №. 3, p. 451-462, Aug. 1958. The MIT Press.

HOURHAKKER, H. S. Electricity Tariffs in Theory and Practice. The Economic Journal, March 1951.

LI, F. et al. Network benefits from introducing an economic methodology for distribution charging. 2005. Disponível em: <http://www.ofgem.gov.uk/>. Acesso em: 19 mar. 2007.

LI, F. L. et al. Framework for assessing the economic efficiencies of long-run network pricing models. IEEE Transactions on Power Systems, Vol. 24, №. 4, p. 1641-1648, 2009.

LI, F.; TOLLEY, D. L. Long-run incremental cost pricing based on un-used capacity. IEEE Transactions on Power Systems, Vol. 22, N ‥ 4, p. 1683-1689. 2007.

LUSVARGHI, S. A. S. Impactos Econômicos da Descontinuidade do Serviço Elétrico Utilizando um Modelo de Mercado. 113 p. Dissertação (Mestrado) Universidade Federal de Itajubá, Itajubá (MG), 2010.

MINISTÉRIO DE MINAS E ENERGIA (MME). Programa de Revisão Tarifaria PRT. Brasília: MME/Dnaee, 1994.

- Metodologia de cálculo da garantia física das usinas. Brasília: MME/EPE, 2008.

MOREIRA, J. N. M. Custos e preços como estratégia gerencial em uma empresa de saneamento. Dissertação (Mestrado) - Universidade Federal de Santa Catarina, Florianópolis, 1998. 
NODA, C. S. Implantação da tarifa de uso do sistema de distribuição: A experiência brasileira. 2005. 112 p. Dissertação (Mestrado em Energia) Programa Interunidades de Pós-graduação em Energia, Universidade de São Paulo, São Paulo, 2005.

OPERADOR NACIONAL DO SISTEMA (ONS). Dados Técnicos do SIN. Rio de Janeiro. Disponível em: < http://www. ons.org.br>. Acesso em: 16 mar. 2010.

ORTEGA, M. P. et al. Tarifas de Redes de Distribuición: Un Problema Resuelto? Escuela Tecnica Superior de Inginieri, Universidad Pontificia Comillas, Madri, 2004. Disponível em: < http://www.iit.upcomillas.es/docs/IIT-04-026A.pdf>. Acesso em: 17 mar. 2009.

PESSANHA, J. F. M. et al. Methodology andApplication for Computation of Supply Marginal Cost andConsumer Tariff of Distribution System. In: America Power \& Gas, 2001, Rio de Janeiro.

PIRES, J. C. L.; PICCININI, M. S. Modelo de regulação tarifária do setor elétrico. Revista do BNDES, Rio de Janeiro, Junho de 1998.

SANTOS, P. E. S. et al. Metodologia do Cálculo das Tarifas de Uso dos Sistemas de Distribuição. In: Congresso Brasileiro de Regulação dos Serviços Públicos, 2001, São Paulo.

SANTOS, P. E. S. Tarifas de Energia: estrutura tarifária. 1. ed. Rio de Janeiro: Interciência Editora, 2010. 139 p.

. Tarifa de distribuição para unidades consumidoras e micro-geradores considerando a elasticidade-preço das cargas. 2008. 163 p. Tese (Doutorado) Universidade Federal de Itajubá, Itajubá (MG), 2008.

Proposta de Aprimoramento dos Procedimentos de Cálculo das Tarifas de Uso dos sistemas de Distribuição. In: Seminário Nacional de Distribuição de Energia Elétrica, 18., 2008, Olinda.

STEINER, P. O. Peak Loads and Efficient Pricing. The Quartely Journal of Economics, Vol. 71, №. 4, p. 585-610, Nov. 1957. The MIT Press. 
TURVEY, R. Peak-Load Pricing. The Journal of Political Economy, Vol. 76, №. 1, p. 101-113, Jan. - Feb. 1968. The University of Chicago Press.

TURVEY, R. Marginal Cost. The Economic Journal, Vol. 79, №. 3141, p. 282-299, Jun. 1969. Blackwell Publishing for the Royal Economic Society.

VISCUSI, W. K.; VERNON, J. M.; HARRINGTON, J. E. Economics of regulation and antitrust. Lexington: D. C. Heath and Company, 1992.

WENDERS, J. T. Peak-Load Pricing in the Electric Utility Industry. The Bell Journal of Economics, Vol. 7, №. 1, p. 232-241, Spring 1976. The RAND Corporation.

WILLIAMSON, O. E. Peak-Load Pricing and Optimal Capacity under Indivisibility Constraints. The American Economic Review, Vol. 56, №. 4, Part 1, p. 810-827, Sept. 1966. American Economic Association.

WILLIAMSON, O. E. Peak-Load Pricing: Some Further Remarks. The Bell Journal of Economics and Management Science, Vol. 5, №. 1, p. 223-228, Spring 1974. The RAND Corporation. 


\section{Apêndice - Representação matemática - LRIC Pricing}

A metodologia Long-Run Incremental Cost (LRIC) Pricing foi desenvolvida pela Universidade de Bath em conjunto com a Western Power Distribution (WPD) no âmbito das discussões, promovidas pelo regulador, sobre a necessidade de aprimoramentos na metodologia de cálculo das tarifas no Reino Unido.

A proposta apresenta, no início dos cálculos, similaridades com o método Investment Cost-Related Pricing (ICRP), utilizado no sistema de transmissão pela National Grid Company, que leva em consideração as alterações no fluxo de potência em razão da injeção de um incremento em cada nó da rede.

Porém, ao contrário do método ICRP, que pressupõe que o sistema está perfeitamente ajustado para a carga existente e que as expansões ocorrem linearmente sem gerar excesso de capacidade, a metodologia LRIC Pricing inova ao considerar o momento em que haverá necessidade de investimentos decorrentes da entrada de um incremento de carga ou de geração em determinado nó do sistema.

Assim, a capacidade não utilizada de um componente do sistema elétrico influi na identificação do tempo necessário para que o investimento no reforço da rede seja realizado. Considerando o valor do dinheiro no tempo, conclui-se que a necessidade de antecipação de investimentos aumentará o valor presente de um eventual custo. Ao contrário, se for possível adiar investimentos, o valor presente diminuirá, mantida constante a taxa de retorno do investimento.

As etapas de cálculo da metodologia, adaptado das referências Li, F. R. et al. (2005) e Heng, H. Y., Li, F. R., Wang, X. F. (2009), são as seguintes: 
1. Tempo inicial em que o investimento em reforços será necessário, dada uma taxa de crescimento ( $r)$.

Se um circuito $\ell$ tiver uma capacidade $C_{\ell}$ e um nível de carregamento $D_{\ell}$, será necessário um reforço quando o carregamento atingir a capacidade do elemento, supondo uma taxa de crescimento $r$, conforme Equação 1.

$$
C_{l}=D_{l} *(1+r)^{n_{l}}
$$

Adaptando a formulação anterior, é possível calcular o número de anos $\mathrm{n}_{\ell}$ necessários para que o investimento em reforços seja realizado, como exposto na Equação 2.

$$
n_{l}=\frac{\log C_{l}-\log D_{l}}{\log (1+r)}
$$

Na proposta original (LI, TOLLEY; 2007) é considerado um fator de segurança igual a 2, de forma semelhante ao adotado no sistema de transmissão no Reino Unido. Isto implica que a distribuição de energia vai exigir o dobro das instalações para o caso de falta em qualquer circuito, de modo a manter o critério de segurança. Em resumo, neste caso pressupõe-se que o investimento será necessário quando o carregamento atingir $50 \%$ da capacidade do circuito.

Adicionalmente, um aprimoramento dessa abordagem considera o fluxo de potência adicional em cada componente do sistema no caso de contingência de N-1 elementos, incorporando a lógica do planejamento do sistema (HENG, LI, WANG; 2009).

2. Valor presente do investimento futuro, dada uma taxa de retorno (d)

$$
P V_{l}=\frac{\text { Asset }_{l}}{(1+d)^{n_{l}}}
$$


3. Custo incremental unitário do circuito $\ell$

$$
U_{l}=\frac{P V_{l}}{C_{l}}=\frac{\text { Asset }_{l}}{C_{l^{*}}(1+d)^{n_{l}}}
$$

4. Tempo para o investimento em reforços após a entrada de $1 \mathrm{MW}$ no sistema

Se a injeção de $1 \mathrm{MW}$ no sistema resultar uma alteração $\Delta P_{l}$ no fluxo de carga no circuito $\ell$, o novo tempo em que serão necessário os investimentos será calculadom por:

$$
n_{l, \text { new }}=\frac{\log C_{l}-\log \left(D_{l}+\Delta P_{l}\right)}{\log (1+r)}
$$

5. Variação no valor presente dos investimentos para atender a injeção de $1 \mathrm{MW}$ no sistema

$$
\Delta P V_{l}=P V_{l, \text { new }}-P V_{l}=\frac{\text { Asset }_{l}}{(1+d)^{n_{l}, \text { new }}}-\frac{\text { Asset }_{l}}{(1+d)^{n_{l}}}
$$

6. Variação no custo incremental unitário do circuito $\ell$ para atender a injeção de 1 MW no sistema

$$
\Delta U_{l}=U_{l, \text { new }}-U_{l}=\frac{\text { Asset }_{l}}{C_{l}} *\left(\frac{1}{(1+d)^{n_{l, \text { new }}}}-\frac{1}{(1+d)^{n_{l}}}\right)
$$

7. Custo incremental de longo prazo

$$
L R I C_{N}=\frac{\sum_{l} \Delta U_{l}}{\Delta P_{l N}}
$$

Onde:

$\Delta \mathrm{u}_{\ell}=$ é a variação dos custos unitários resultante da injeção de $1 \mathrm{MW} ;$

$\Delta \mathrm{P}_{\hat{\mathbb{N}}}=$ é a injeção de potência no nó $\mathrm{N}$, assumida, neste texto, como $1 \mathrm{MW}$ 